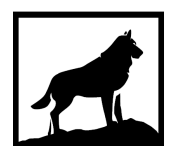

Michigan

Technological

1 8 8 5 University
Michigan Technological University

Digital Commons @ Michigan Tech

2018

\title{
ANALYSIS OF INJECTION PARAMETERS INFLUENCING GASOLINE DIRECT INJECTION COMPRESSION IGNITION (GDICI) ENGINE OPERATION IN LTC USING NAPHTHA
}

Devyani Patil

Michigan Technological University, devyanip@mtu.edu

Copyright 2018 Devyani Patil

Recommended Citation

Patil, Devyani, "ANALYSIS OF INJECTION PARAMETERS INFLUENCING GASOLINE DIRECT INJECTION COMPRESSION IGNITION (GDICI) ENGINE OPERATION IN LTC USING NAPHTHA", Open Access Master's Thesis, Michigan Technological University, 2018.

https://doi.org/10.37099/mtu.dc.etdr/744

Follow this and additional works at: https://digitalcommons.mtu.edu/etdr

Part of the Heat Transfer, Combustion Commons 
ANALYSIS OF INJECTION PARAMETERS INFLUENCING GASOLINE DIRECT INJECTION COMPRESSION IGNITION (GDICI) ENGINE OPERATION IN LTC USING NAPHTHA

\title{
By
}

Devyani Patil

\begin{abstract}
A THESIS
Submitted in partial fulfillment of the requirements for the degree of MASTER OF SCIENCE

In Mechanical Engineering
\end{abstract}

MICHIGAN TECHNOLOGICAL UNIVERSITY

2018

(C) 2018 Devyani B. Patil 
This thesis has been approved in partial fulfillment of the requirements for the Degree of MASTER OF SCIENCE in Mechanical Engineering.

Department of Mechanical Engineering-Engineering Mechanics

Thesis Advisor: $\quad$ Dr. Youngchul Ra

Committee Member: $\quad$ Dr. Sajjad Bigham

Committee Member: Dr. Stanislaw Szwaja

Department Chair: Dr. William W. Predebon 


\section{Table of Contents}

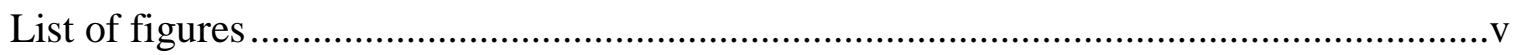

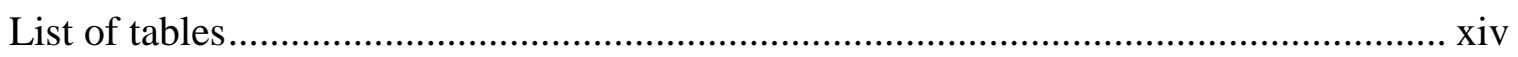

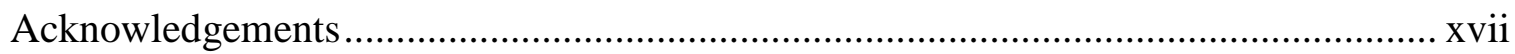

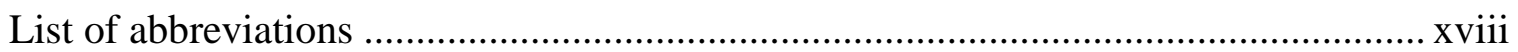

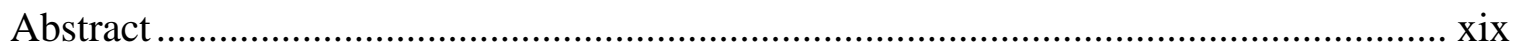

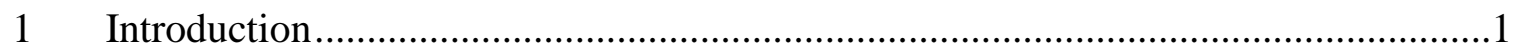

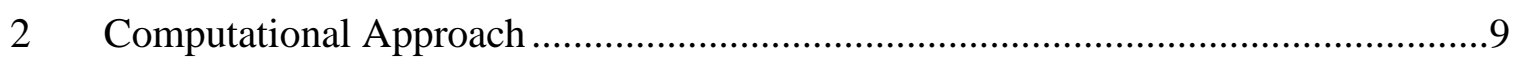

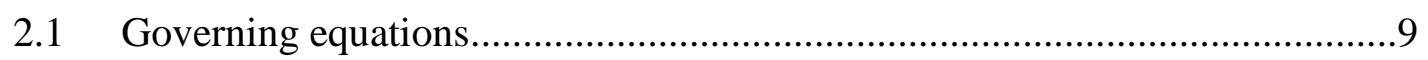

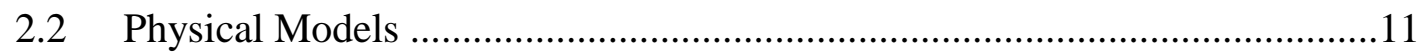

2.2.1 Drop Breakup ............................................................................ 11

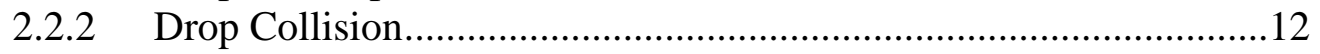

2.2.3 Drop Distortion/Deformation........................................................13

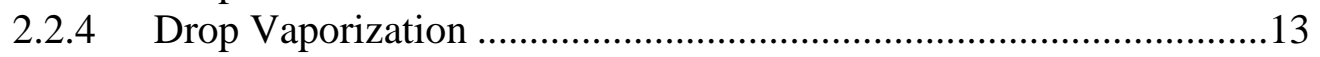

2.2.5 Wall Interaction ..........................................................................

2.2.6 Turbulence Model ....................................................................

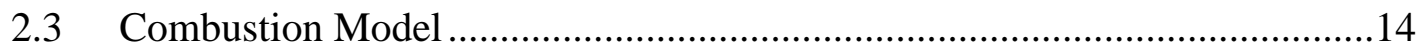

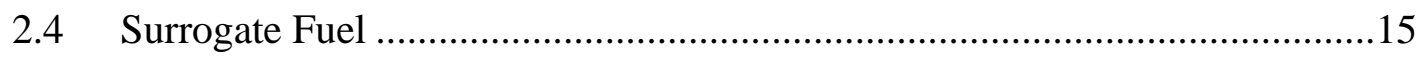

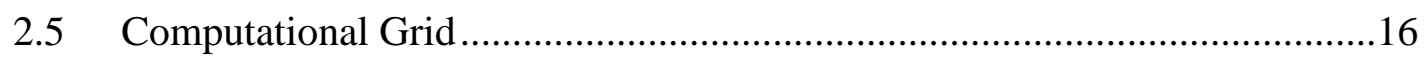

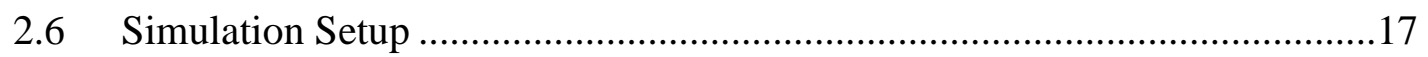

2.7 General Code Structure ………………………....................................18

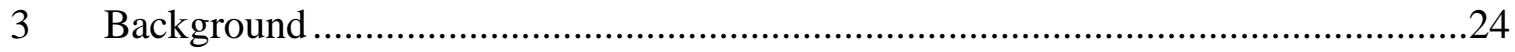

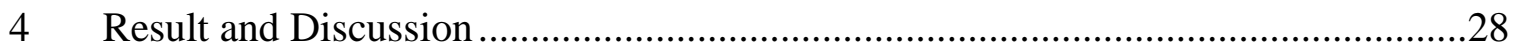

4.1 Baseline Operating Condition ............................................................28

4.2 Change in charge temperature at IVC ........................................................60

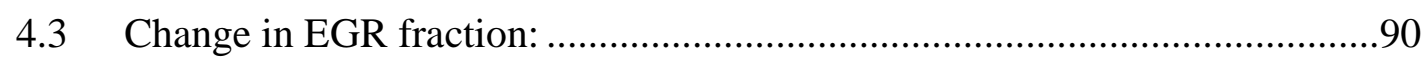

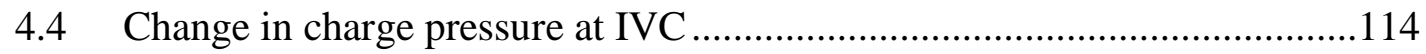

4.4.1 Injection Pressure Variation............................................................141 


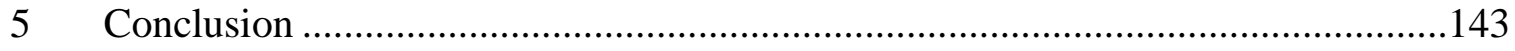

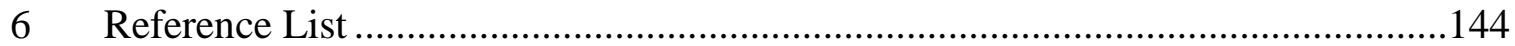




\section{List of figures}

Figure 1-1. Different combustion mode [5] .............................................................

Figure 1-2. Dependency of stable combustion on Air-fuel ratio and Intake Temperature [27].

Figure 1-3. Crude oil refinement [46] .....................................................................

Figure 2-1. Modified hybrid KH-RT break up model ......................................................12

Figure 2-2. Surrogate Fuel Composite..........................................................................15

Figure 2-3 . a) Complete 3-D computational grid b) vertical cross section view of

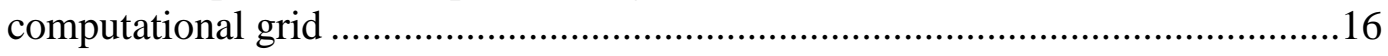

Figure 2-4. General KIVA code structure [47] ............................................................23

Figure 4-1. Comparison of predicted combustion efficiency at various injection timings

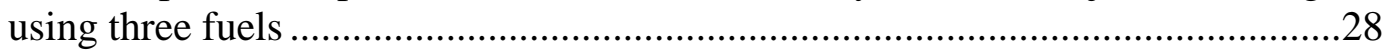

Figure 4-2. Comparison of predicted ignition delay at various injection timings using

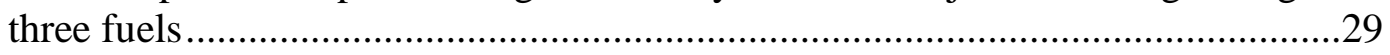

Figure 4-3. Comparison of predicted thermal efficiency at various injection timings using

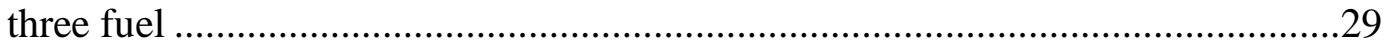

Figure 4-4. Comparison of predicted PRR at various injection timings for three fuels ....31

Figure 4-5. Comparison of predicted NOx at various injection timings for three fuels ....31

Figure 4-6. Comparison of predicted $\mathrm{CO}$ at various injection timings for three fuels .......32

Figure 4-7. Comparison of predicted UHC at various injection timings for three fuels ...33

Figure 4-8. Comparison of predicted pressure and HRR at -25 deg ATDC injection timing

Figure 4-9. Comparison of predicted average temperature at -25 deg ATDC injection

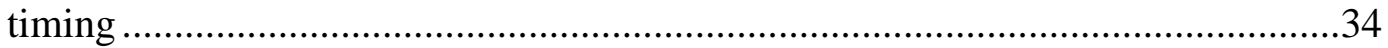

Figure 4-10. Comparison of predicted vaporization rate at -25 deg ATDC injection timing

Figure 4-11. Predicted equivalence ratio distribution at -25 deg ATDC injection timing a) heavy naphtha at -6 deg ATDC b) PRF50 at -3 deg ATDC and c) light naphtha at 3 deg ATDC 
Figure 4-12. Comparison of predicted pressure and HRR at -45 deg ATDC injection timing

Figure 4-13. Comparison of predicted a) average Temperature b) peak temperature at -45 $\operatorname{deg}$ ATDC injection timing .38

Figure 4-14. Comparison of predicted vaporization trend at $-45 \mathrm{deg}$ ATDC injection timing

Figure 4-15. Predicted equivalence ratio at -45 deg ATDC injection timing a) heavy Naphtha ta -6 deg ATDC b) PRF50 at -6 deg ATDC c) Light Naphtha at 8 deg ATDC.

Figure 4-16. Predicted fuel distribution in-cylinder combustion chamber at a) $-40 \mathrm{deg}$ ATDC b) $-20 \operatorname{deg}$ ATDC and c) $-10 \operatorname{deg}$ ATDC

Figure 4-17. Comparison of predicted pressure and HRR for similar ignition delay using three fuels

Figure 4-18. Predicted equivalence ratio distribution a) Heavy Naphtha at -6 deg ATDC

b) PRF50 at -6 deg ATDC and c) Light Naphtha at 4 deg ATDC.

Figure 4-19. Comparison of predicted vaporization trend for similar ignition delay .44

Figure 4-20. Comparison of predicted pressure and HRR for $-15 \mathrm{deg}$ ATDC and $-45 \mathrm{deg}$ ATDC injection timings .45

Figure 4-21. Comparison of predicted a) Average Temperature and b) Peak Temperature for -15 deg ATDc and -45 deg ATDC injection timings

Figure 4-22. Comparison of predicted vaporization rate for $-15 \mathrm{deg}$ ATDC and $-45 \mathrm{deg}$ ATDC injection timing

Figure 4-23. Predicted equivalence ratio distribution a) -15 deg ATDC Injection Timing at TDC b) $-45 \mathrm{deg}$ ATDC injection timing at $-6 \mathrm{deg}$ ATDC

Figure 4-24. Comparison of predicted pressure and HRR for three fuels at -25 deg ATDC injection timing and 600 Bar injection pressure

Figure 4-25. Comparison of predicted average temperature for three fuels at $-25 \mathrm{deg}$ ATDC injection timing and 600 Bar injection pressure

Figure 4-26. Comparison of predicted vaporization rate for three fuels at -25 deg ATDC and 600 Bar injection pressure.

Figure 4-27. Predicted equivalence ratio distribution for a) Heavy Naphtha at -5 deg ATDC b) PRF50 at -6 deg ATDC and c) Light Naphtha at -5 deg ATDC .52 
Figure 4-28. Comparison of predicted pressure and HRR for three fuels at -40 deg ATDC injection timing and 200 bar injection pressure ....................................................54

Figure 4-29. Comparison of predicted average temperature for three fuels at -40 deg ATDC injection timing and $200 \mathrm{Bar}$ injection pressure.

Figure 4-30. Predicted equivalence ratio distribution for a) Heavy Naphtha at -8 deg ATDC b) PRF50 at -8 deg ATDC and c) Light Naphtha at 2 deg ATDC.

Figure 4-31. Comparison of predicted vaporization rate for three fuels at -40 deg ATDC

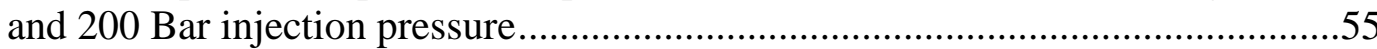

Figure 4-32. Comparison of predicted pressure and HRR at 300 Bar and 500 Bar injection pressure

Figure 4-33. Predicted equivalence ratio distribution a) 300 Bar injection pressure at -3 $\operatorname{deg}$ ATDC b) 500 Bar injection pressure at $-5 \operatorname{deg}$ ATDC.

Figure 4-34. Comparison of predicted vaporization trend at 300 Bar and 500 Bar injection

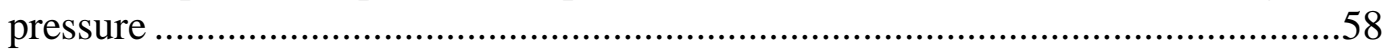

Figure 4-35. Comparison of predicted effect on combustion efficiency due to variation in charge temperature at IVC for various injection timings.......................................61

Figure 4-36. Comparison of predicted effect on ignition delay due to variation in charge temperature at IVC for various injection timings

Figure 4-37. Comparison of predicted effect on PRR due to variation in charge temperature at IVC for various injection timing.....

Figure 4-38. Comparison of predicted effect on $\mathrm{CO}$ at EVO due to variation in charge temperature at IVC for various injection timings

Figure 4-39. Comparison of predicted effect on $\mathrm{UHC}$ at EVO due to variation in charge temperature at IVC for various injection timings

Figure 4-40. Comparison of predicted effect on NOx at EVO due to variation in charge temperature at IVC for various injection timings.....

Figure 4-41. Comparison of predicted pressure and HRR at injection timing -45 deg ATDC for charge temperatures $371.49 \mathrm{~K}$ and $386.49 \mathrm{~K}$

Figure 4-42. Comparison of predicted fuel vaporization rate at injection timing -45 deg ATDC for charge temperatures $371.49 \mathrm{~K}$ and $386.49 \mathrm{~K}$ 
Figure 4-43. Predicted equivalence ratio distribution at injection timing - 45 deg ATDC for a) charge temperatures $386.49 \mathrm{Kat}-2 \mathrm{deg}$ ATDC b) $371.49 \mathrm{~K}$ at $8 \mathrm{deg}$ ATDC

Figure 4-44. Comparison of predicted combustion efficiencies for charge temperature $386.49 \mathrm{~K}$ at various injection timings using three fuels.

Figure 4-45. Comparison of predicted ignition delay for charge temperature $386.49 \mathrm{~K}$ at various injection timings using three fuels .73

Figure 4-46. Comparison of predicted thermal efficiencies for charge temperature 386.49 $\mathrm{K}$ at various injection timings using three fuels. .73

Figure 4-47. Comparison of predicted pressure rise rates for charge temperature $386.49 \mathrm{~K}$ at various injection timings using three fuels .74

Figure 4-48. Comparison of predicted NOx for charge temperature $386.49 \mathrm{~K}$ at various injection timings using three fuels

Figure 4-49. Comparison of predicted UHC for charge temperature $386.49 \mathrm{~K}$ at various injection timings using three fuels

Figure 4-50. Comparison of predicted CO for charge temperature $386.49 \mathrm{~K}$ at various injection timings using three fuels

Figure 4-51. Comparison of predicted pressure and HRR at charge temperature $386.49 \mathrm{~K}$ at IVC with -15 deg ATDC injection timing using three fuels .77

Figure 4-52. Comparison of predicted vaporization rate at charge temperature $386.49 \mathrm{~K}$ at IVC with -15 deg ATDC injection timing using three fuels

Figure 4-53. Comparison of predicted average temperature at charge temperature 386.49

$\mathrm{K}$ at IVC with $-15 \mathrm{deg}$ ATDC injection timing using three fuels

Figure 4-54. Predicted equivalence ratio distribution at charge temperature $386.49 \mathrm{~K}$ at IVC with -15 deg ATDC injection timing for a) Heavy Naphtha at TDC b) Light Naphtha at $6 \mathrm{deg}$ ATDC c) PRF50 at $1 \mathrm{deg}$ ATDC.

Figure 4-55. Comparison of predicted pressure and HRR at charge temperature $386.49 \mathrm{~K}$ at IVC with $-25 \mathrm{deg}$ ATDC injection timing using three fuels

Figure 4-56. Comparison of predicted vaporization rate at charge temperature $386.49 \mathrm{~K}$ at IVC with -25 deg ATDC.

Figure 4-57. Comparison of predicted average temperature at charge temperature 386.49

$\mathrm{K}$ at IVC with $-25 \mathrm{deg}$ ATDC injection timing using three fuels. .81 
Figure 4-58. Predicted equivalence ratio distribution at charge temperature $386.49 \mathrm{~K}$ at IVC with -25 deg ATDC injection timing for a) Heavy Naphtha at -6 deg ATDC

b) Light Naphtha at $1 \mathrm{deg}$ ATDC c) PRF50 at $1 \mathrm{deg}$ ATDC.

Figure 4-59. Comparison of predicted pressure and HRR at charge temperature $386.49 \mathrm{~K}$ at IVC with $-40 \mathrm{deg}$ ATDC injection timing using three fuels .84

Figure 4-60. Comparison of predicted vaporization rate at charge temperature $386.49 \mathrm{~K}$ at IVC with -40 deg ATDC injection timing using three fuels .84

Figure 4-61. Comparison of predicted average temperature at charge temperature 386.49 $\mathrm{K}$ at IVC with $-40 \mathrm{deg}$ ATDC injection timing using three fuels.

Figure 4-62. Predicted equivalence ration distribution at charge temperature $386.49 \mathrm{~K}$ at IVC with -40 deg ATDC injection timing for a) Heavy Naphtha at -2 deg ATDC

b) Light Naphtha at $2 \operatorname{deg}$ ATDC c) PRF50 at -9 deg ATDC .86

Figure 4-63. Comparison of predicted effect on combustion efficiency due to variation in EGR fraction for various injection timings. .91

Figure 4-64. Comparison of predicted effect on ignition delay due to variation in EGR fraction for various injection timings.

Figure 4-65. Comparison of predicted effect on thermal efficiency due to variation in EGR fraction for various injection timings.

Figure 4-66. Comparison of predicted effect on pressure rise rate due to variation in EGR fraction for various injection timings.

Figure 4-67. Comparison of predicted effect on NOX at EVO due to variation in EGR fraction for various injection timings.

Figure 4-68. Comparison of predicted effect on $\mathrm{CO}$ at EVO due to variation in EGR fraction for various injection timings

Figure 4-69. Comparison of predicted effect on UHC at EVO due to variation in EGR fraction for various injection timings.

Figure 4-70. Comparison of predicted pressure and HRR at injection timing -40 deg ATDC for EGR Fraction $37 \%$ and $45 \%$

Figure 4-71. Comparison of predicted average temperature at injection timing -40 deg ATDC for EGR Fraction $37 \%$ and $45 \%$

Figure 4-72. Comparison of predicted vaporization trend at injection timing -40 deg ATDC for EGR Fraction $37 \%$ and $45 \%$ 
Figure 4-73. Predicted equivalence ratio distribution at injection timing - 40 deg ATDC for EGR Fraction a) $37 \%$ at $2 \mathrm{deg}$ ATDC and b) $45 \%$ at $7 \mathrm{deg}$ ATDC. 100

Figure 4-74. Comparison of predicted combustion efficiencies for $45 \%$ EGR fraction cases at various injection timings using three fuels.....

Figure 4-75. Comparison of predicted ignition delay for $45 \%$ EGR fraction cases at various injection timings using three fuels

Figure 4-76. Comparison of predicted thermal efficiencies for $45 \%$ EGR fraction cases at various injection timings using three fuels

Figure 4-77. Comparison of predicted pressure rise rate for $45 \%$ EGR fraction cases at various injection timings using three fuels

Figure 4-78. Comparison of predicted NOx for $45 \%$ EGR fraction cases at various injection timings using three fuels

Figure 4-79. Comparison of predicted CO for $45 \%$ EGR fraction cases at various injection timings using three fuels.....

Figure 4-80. Comparison of predicted UHC for $45 \%$ EGR fraction cases at various injection timings using three fuels.....

Figure 4-81. Comparison of predicted pressure and HRR for $45 \%$ EGR fraction with -35 deg ATDC injection timing using three fuels

Figure 4-82. Comparison of predicted average temperature for $45 \%$ EGR fraction with 35 deg ATDC injection timing using three fuels .106

Figure 4-83. Comparison of predicted vaporization trend for $45 \%$ EGR fraction with -35 deg ATDC injection timing using three fuels

Figure 4-84. Predicted equivalence ratio distribution with $45 \%$ EGR naphtha fraction and -35 deg ATDC injection timing for a) Heavy Naphtha at -7 deg ATDC $b$ ) Light Naphtha at 5 deg ATDC c) PRF50 at -7 deg ATDC.

Figure 4-85. Comparison of predicted pressure and HRR at injection timing -40 deg ATDC EGR Fraction $17 \%$ and $37 \%$.

Figure 4-86. Comparison of average temperature at injection timing -40 deg ATDC for EGR Fraction $17 \%$ and $37 \%$

Figure 4-87. Comparison of predicted vaporization trend at injection timing -40 deg ATDC for EGR Fraction 17\% and 37\% 
Figure 4-88. Predicted equivalence ratio distribution at injection timing -40 deg ATDC for EGR Fraction a) 37\% at $2 \operatorname{deg}$ ATDC and b) $17 \%$ at -7 deg ATDC... 110

Figure 4-89. Comparison of predicted effect on combustion efficiency due to variation in charge pressure at IVC for various injection timings

Figure 4-90. Comparison of predicted effect on ignition delay due to variation in charge pressure at IVC for various injection timings .....................................................116

Figure 4-91. Comparison of predicted effect on thermal efficiency due to variation in charge pressure at IVC for various injection timings

Figure 4-92. Comparison of predicted effect on pressure rise rate due to variation in charge pressure at IVC for various injection timings

Figure 4-93. Comparison of predicted effect on NOx due to variation in charge pressure at IVC for various injection timings

Figure 4-94. Comparison of predicted effect on $\mathrm{CO}$ due to variation in charge pressure at IVC for various injection timings

Figure 4-95. Predicted effect on UHC due to variation in charge pressure at IVC for various injection timings

Figure 4-96. Comparison of predicted pressure and HRR for injection timing -15 deg ATDC for charge pressure 1.41 Bar and 2.41 Bar..

Figure 4-97. Comparison of predicted average temperature for injection timing -15 deg ATDC for charge pressure 1.41 Bar and 2.41 Bar.

Figure 4-98. Comparison of predicted vaporization trend for injection timing -15 deg ATDC for charge pressure 1.41 Bar and 2.41 Bar.

Figure 4-99. Predicted equivalence ratio distribution for injection timing -15 deg ATDC for charge pressure a) $1.41 \mathrm{Bar}$ at TDC and b) $2.41 \mathrm{Bar}$ at $-4 \operatorname{deg}$ ATDC

Figure 4-100. Comparison of predicted pressure and HRR for injection timing -45 deg ATDC for charge pressure 1.41 Bar and 2.41 Bar.

Figure 4-101. Comparison of predicted average temperature for injection timing -45 deg ATDC for charge pressure 1.41 Bar and 2.41 Bar.

Figure 4-102. Comparison of predicted vaporization trend for injection timing -45 deg ATDC for charge pressure 1.41 Bar and 2.41 Bar 
Figure 4-103. Predicted equivalence ratio distribution for injection timing -45 deg ATDC for charge pressure a) $1.41 \mathrm{Bar}$ at $-6 \mathrm{deg}$ ATCD and b) $2.41 \mathrm{Bar}$ at $-13 \mathrm{deg}$ ATDC

Figure 4-104. Comparison of predicted pressure and HRR for injection timing -45 deg ATDC for charge pressure 1.41 Bar and 2.41 Bar.

Figure 4-105. Comparison of predicted average temperature for injection timing $-45 \mathrm{deg}$ ATDC for charge pressure 1.41 Bar and 2.41 Bar....

Figure 4-106. Comparison of predicted vaporization trend for injection timing $-45 \mathrm{deg}$ ATDC for charge pressure 1.41 Bar and 2.41 Bar..... 130

Figure 4-107. Predicted equivalence ratio distribution for injection timing -45 deg ATDC for charge pressure a) 1.41 Bar at $8 \mathrm{deg}$ ATDC and b) $2.41 \mathrm{Bar}$ at $-6 \mathrm{deg}$ ATDC

Figure 4-108. Comparison of combustion efficiencies for charge pressure 2.41 Bar at various injection timings using three fuels

Figure 4-109. Comparison of ignition delay for charge pressure 2.41 Bar at various injection timings using three fuels

Figure 4-110. Comparison of thermal efficiencies for charge pressure 2.41 Bar at various injection timings using three fuels

Figure 4-111. Comparison of pressure rise rates for charge pressure 2.41 Bar at various injection timings using three fuels

Figure 4-112. Comparison of NOx for charge pressure 2.41 Bar at various injection timings using three fuels

Figure 4-113. Comparison of for charge pressure 2.41 Bar at various injection timings using three fuels

Figure 4-114. Comparison of predicted pressure and HRR at charge pressure 2.41 Bar at IVC with -25 deg ATDC injection timing using three fuels

Figure 4-115. Comparison of predicted average temperature at charge pressure 2.41 Bar at IVC with $-25 \mathrm{deg}$ ATDC injection timing using three fuels

Figure 4-116. Comparison of predicted vaporization trend at charge pressure 2.41 Bar at IVC with -25 deg ATDC injection timing using three fuels

Figure 4-117. Comparison of predicted equivalence ratio distribution at charge pressure 2.41 Bar at IVC with -25 deg ATDC injection timing for a) Heavy Naphtha at -12 $\operatorname{deg}$ ATDC b) $-6 \operatorname{deg}$ ATDC c) $-11 \operatorname{deg}$ ATDC 136 
Figure 4-118. Comparison of predicted pressure and HRR at charge pressure 2.41 Bar at IVC with -40 deg ATDC injection timing using three fuels..............................138

Figure 4-119. Comparison of predicted average temperature at charge pressure 2.41 Bar at IVC with -40 deg ATDC injection timing using three fuels ...........................138

Figure 4-120. Predicted equivalence ratio distribution at charge pressure 2.41 Bar at IVC with -40 deg ATDC injection timing for a) Heavy Naphtha at -14 deg ATDC b) Light Naphtha at -7 deg ATDC c) PRF50 at -13 deg ATDC

Figure 4-121. Comparison of predicted vaporization rate at charge pressure 2.41 Bar at IVC with -40 deg ATDC injection timing using three fuels..............................140 


\section{List of tables}

Table 2-1. Engine and Injection System Specification and baseline operating condition.17

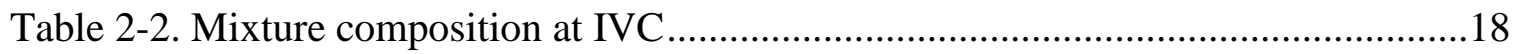

Table 4-1. Maximum combustion efficiency and corresponding injection timing for three

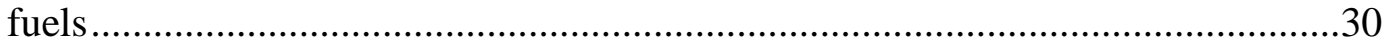

Table 4-2. Predicted combustion characterstics at -25 deg ATDC injection timing .........33

Table 4-3. Predicted combustion characteristics at -45 deg injection timing ...................37

Table 4-4. Predicted combustion characteristics for same ignition delay using three fuels

Table 4-5. Predicted combustion characteristics for injection timing -15 deg ATDC and44

Table 4-6. Optimum combustion cases for three fuels at 400 Bar. .48

Table 4-7. Maximum combustion efficiency and respective injection timing for various injection pressure

Table 4-8. Predicted combustion characteristics for three fuels at $-25 \mathrm{deg}$ ATCD injection timing and 600 Bar injection pressure

Table 4-9. Predicted combustion characteristics for three fuels at -40 deg ATDC and 200 Bar injection pressure

Table 4-10. Predicted combustion characteristics for 300 Bar and 500 Bar injection pressure

Table 4-11. Predicted optimum combustion cases for three fuels with various injection pressure

Table 4-12. Predicted combustion characteristics at injection timing -45 deg ATDC for different charge temperatures at IVC.

Table 4-13. Predicted combustion characteristics at -15 deg ATDC injection timing using three fuels

Table 4-14 Predicted combustion characteristics at -25 deg ATDC injection timing using three fuels

Table 4-15. Predicted combustion characteristics at -40 deg ATDC injection timing using three fuels .83 
Table 4-16. Maximum Combustion Efficiency for heavy naphtha .86

Table 4-17. Maximum Combustion Efficiency for light naphtha..................................87

Table 4-18. Maximum Combustion Efficiency for PRF50 87

Table 4-19. Maximum combustion efficiency and injection timing for injection pressure

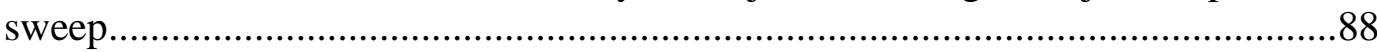

Table 4-20. Optimum case condition for each fuel at injection pressure sweep .89

Table 4-21. Predicted Combustion Characteristics at injection timing -40 deg ATDC for

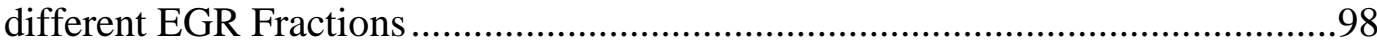

Table 4-22 predicted combustion characteristics at -35 deg ATDC injection timing using three fuels

Table 4-23. Predicted combustion characteristics at -40 deg ATDC injection timing using three fuels 108

Table 4-24. Maximum Combustion Efficiency for heavy naphtha .111

Table 4-25. Maximum Combustion Efficiency for light naphtha. 111

Table 4-26. Maximum Combustion Efficiency for PRF50

Table 4-27. Maximum combustion efficiency and injection timing for injection pressure sweep.

Table 4-28. Optimum case condition for each fuel at injection pressure sweep

Table 4-29. Predicted combustion characteristics at injection timing -15 deg ATDC for different charge pressure at IVC

Table 4-30. Predicted combustion characteristics at injection timing -45 deg ATDC for different charge pressure at IVC

Table 4-31. Predicted combustion characteristics at injection timing -45 deg ATDC for different charge pressure at IVC

Table 4-32. Predicted combustion characteristics at -25 deg ATDC injection timing using three fuels

Table 4-33. Predicted combustion characteristics at -45 deg ATDC injection timing using three fuels

Table 4-34. Maximum Combustion Efficiency for heavy naphtha 140 
Table 4-35. Maximum Combustion Efficiency for light naphtha.................................140

Table 4-36. Maximum Combustion Efficiency for PRF50 .........................................141

Table 4-37. Maximum combustion efficiency and injection timing for injection pressure

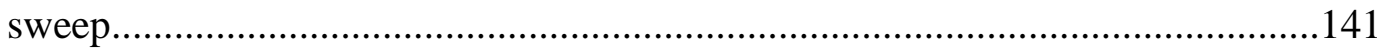

Table 4-38. Optimum case condition for each fuel at injection pressure sweep .............142 


\section{Acknowledgements}

Foremost, I would like to express my special thanks of gratitude to my advisor Professor Dr. Ra for his continuous support and guidance throughout my Master's course. It is my honor to be his student.

Secondly, I would like to thank my thesis defense committee: Dr. Sajjad Bighma and Dr, Stanislaw Szwaja for their patience and insightful comments.

I am also grateful to the Department of Mechanical Engineering and Engineering Mechanics at Michigan Technological University for giving me an opportunity to receive higher studies in the field of IC engines. As an international student and first time studying away from home, I will never forget help and support Michigan Tech gave me.

I thank all my colleague and friends at Michigan Tech for their help and encouragement.

Lastly, and most importantly I would like to thank my parents for their endless support, love, and encouragement, without whom I would never have enjoyed so many opportunities. 


\section{List of abbreviations}

\begin{tabular}{|c|c|}
\hline IC Engine & Internal Combustion Engine \\
\hline LTC & Low Temperature Combustion \\
\hline DI & Direct Injection \\
\hline GDICI & Gasoline Direct Injection Compression Ignition \\
\hline GDI & Gasoline Direct Injection \\
\hline $\mathrm{HCCI}$ & Homogeneous Charge Compression Ignition \\
\hline PCCI & Premixed Charge Compression Ignition \\
\hline ATDC & After Top Dead Centre \\
\hline TDC & Top Dead Centre \\
\hline $\mathrm{BDC}$ & Bottom Dead Centre \\
\hline CAD & Crank Angle Degree \\
\hline IVC & Intake Valve Close \\
\hline EVO & Exhaust Valve Open \\
\hline CI & Compression Ignition \\
\hline SI & Spark Ignition \\
\hline EGR & Exhaust Gas Recirculation \\
\hline NOx & Nitric Oxide \\
\hline PRR & Pressure Rise Rates \\
\hline $\mathrm{UHC}$ & Unburned Hydro-Carbons \\
\hline $\mathrm{CO}$ & Carbon Monoxide \\
\hline $\mathrm{CN}$ & Cetane Number \\
\hline $\mathrm{CR}$ & Compression Ratio \\
\hline
\end{tabular}




\section{Abstract}

A multi-dimensional CFD study using MTU-KIVA-Geq-CHEMKIN code has been carried out for direct injection compression ignition engine combustion fueled with heavy naphtha, light naphtha, and PRF50 in low-temperature combustion (LTC) regime. At constant fueling, combustion characteristics are investigated as a function of injection timing and injection pressure. Further, operating limits of fuel confined by combustion efficiency, noise level (Maximum Pressure rise rate) and emissions at exhaust valve opening (EVO) are evaluated using parametric variation of initial gas temperature, exhaust gas recirculation fraction, boost pressure. Research conducted focuses on ability of fuel to get good combustion which is combustion efficiency $>/=90 \%$, Pressure rise rate $</=10$ bar/deg and NOx at EVO $</=5 \mathrm{~g} / \mathrm{Kg}$-f. It is confirmed that all three fuels display lowtemperature combustion at baseline operating condition. For light naphtha due to its low cetane index, injection timings near TDC are advantageous whereas high cetane index fuel does give high efficiency with low-pressure rise rate and low emissions at EVO for injection timing early in the compression stroke. Increasing charge temperature advances injection timing operating range whereas increasing boost and EGR fraction have opposite effect. Numerical investigation helped to understand effects of air-fuel distribution on combustion characteristics and ways to manipulate it although further work is deemed necessary to understand operating of all three fuels under different load conditions. 


\section{Introduction}

Advantages such as low production cost, proven durability, and compactness make IC engines an attractive option for different applications ranging from small passenger cars to large-scale automobiles such as trains, ships, and heavy-duty trucks. New promising technologies like hybridization of an automobile and electric car are possible successors to internal combustion engines. However, these technologies are too expensive and still in development to totally replace IC engines. As a result, an IC engine remains to be the dominant source of energy production in an automobile industry. According to a report published by Word's AutoWorld, approximately 1.015 billion motor vehicles were used all around the world in the year 2010, whereas this number is expected to reach 2 billion motor vehicles by 2020 [1]. Around 72.11 million vehicles were produced in the world in the year 2016 [2]. In 2016, out of total energy consumed in the United States, automobiles used $29 \%$ of the energy. In the same year, around $92 \%$ of the energy used by US transportation sector was provided by petroleum products mainly gasoline and diesel. [3]. Such vast use of fuel leads to the production of a large amount of emissions. Emissions produced by IC engine are a global concern as it creates risk for the environment as well as human health. Emission products such as oxides of nitrogen $\left(\mathrm{NO}, \mathrm{N}_{2} \mathrm{O}, \mathrm{NO}_{2}\right)$, particulate matter (PM), carbon monoxide (CO), carbon dioxide $\left(\mathrm{CO}_{2}\right)$ and oxides of Sulphur become more and more important issue due to continuing and increasing use of an IC engine. In the United States, Environment Protection Agency (EPA) sets standards for emissions and these restrictions are continuously increasing to curb the pollution and its effects on the environment. There are also growing concerns about depleting fuel sources. In order to save fuel as much as possible, it is important to enhance the fuel efficiency and thereby reducing fuel consumption. Tightened performance and environmental requirements are challenging engineers for an application of new and advanced engineering along with extensive modification in the existing technologies.

Spark ignition (SI) and compression ignition (CI) are the two conventional engine technologies with established use in automobile industries. SI engines mainly operated with gasoline as a fuel; are characterized by spark-assisted ignition followed by flame propagation through homogeneous air-fuel mixture. Fuel properties and spark phasing controls flame propagation. Stoichiometric and premixed mixture results in low production of PM and NOx. However, a compression ratio of SI engine is relatively low to avoid knocking. On the other hand, conventional CI engines operate with diffusion-controlled spray combustion of diesel fuel with higher compression ratios. The physical properties of diesel enable to robustly control injection timing to initiate auto-ignition over a wide range of pressure, temperature and equivalence ratio. Diesel CI engines have thermodynamically advantages over SI engines due to a lean mixture, high compression ratio and being able to run unthrottled.

One main disadvantage regarding diesel engine is NOx and PM formation. Lean mixtures near high temperature flames cause NOx formation. Whereas, particulate matter (PM) or soot is formed due to existence of local fuel rich reaction zones in the combustion chamber. For diesel engine, high level of exhaust gas recirculation (EGR) can reduce the burned gas 
temperature but it will also reduce the oxygen content available for soot oxidation. Advanced engine combustion technologies aim to mix fuel and air sufficiently before ignition to reduce the formation of soot at first place.

One of the combustion methodology used to achieve stringent emission standards without affecting efficiency is low-temperature combustion (LTC). Low-temperature combustion can be achieved by diluting the fuel/air mixture with either excessive air or exhaust gas recirculation. In addition, ignition delay increases with leaner mixtures (via early fuel injection) or higher EGR ratio. Longer ignition delay allows longer time for mixing of fuel and air to make more uniform mixtures, which helps reduce soot and NOx formation simultaneously. However, extremely dilute mixture either can result in higher $\mathrm{HC}$ and $\mathrm{CO}$ emissions or may misfire [4]. Different LTC techniques such as HCCI, PCI, and PPCI etc. have been being studied as potential to replace conventional engines.

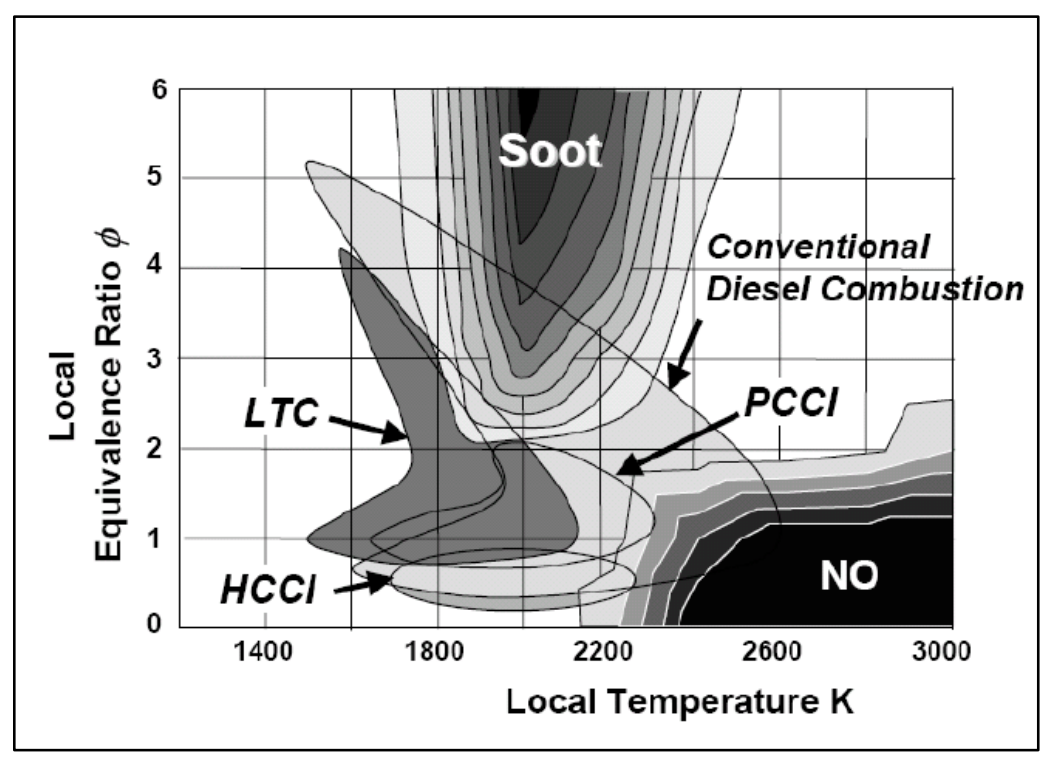

Figure 1-1. Different combustion mode [5]

Figure 1.1 helps to understand advantages of LTC technique over diesel engine. Conventional diesel engine passes through the large soot and NOx islands where as LTC mode escapes those regions because of low local temperatures and leaner mixtures inside the cylinder. In order to use LTC for high load operation, use of increased EGR level is helpful for maintaining low burned gas temperatures at the expense increased formation of $\mathrm{CO}$ and UHC and combustion noise. Many researches have been conducted to apply LTC regime to high engine load operation by using injection strategy variation [6-7].

A milestone in the history of CI engine was put by Onishi in '79 [8]. Using a two-stroke engine he developed the concept of "Active Thermo-Atmosphere Combustion", a fairly homogeneous mixture is compressed until autoignition which takes place simultaneously all over the combustion volume. Because of the homogeneity and relatively fast combustion, the process was highly efficient with low NOx and soot production. As a 
pioneering work, Najt et al [9] proved that an internal combustion engine can be operated in HCCI mode through the proper use of temperature and hydrocarbon species concentration. Homogeneous Charge Compression Ignition (HCCI) mode can be achieved by using a carburetor or intake port fuel injector to provide a pre-mixture of fuel and air before being introduced to the combustion chamber, or by injecting fuel directly into the combustion chamber during the intake process or very early in the compression stroke [1013]. Homogeneous mixtures in an HCCI engine auto-ignite at multiple points throughout cylinder volume [14-15], when a sufficiently high cylinder temperature is attained during the compression stroke without apparent flame front. When the auto-ignition occurs, the combustion takes place nearly instantaneously throughout the cylinder. Typically, the bulk gas temperatures of dilute charge mixtures at the time of ignition are around 800-1000 K. As a result of low-temperature combustion there is a dramatic reduction in NOx emissions and PM emissions are reduced due to well-mixed condition. In addition, like diesel engine, wide-open throttle reduces throttling losses, resulting in improved thermal efficiency [16$18]$.

The application of HCCI combustion suffers from several practical problems. First, because the mixture combusts almost instantaneously, the heat release is very rapid. If the auto-ignition occurs too far Before Top Dead Center (BTDC), this rapid heat release results in very high cylinder pressure rise rates, and high peak cylinder pressures. In addition, this rapid heat release tends to expose the in-cylinder nitrogen and oxygen to prolonged high temperatures, which can lead to high NO formation rates. Second, early injection can result in spray impingement on combustion chamber wall surfaces, since the spray penetration is increased at the low gas densities in the chamber early in the compression stroke. However, perhaps the biggest challenge with HCCI combustion is control. Because the heat release occurs so rapidly after auto-ignition, control of the timing of the auto-ignition event is very important for emissions and appropriate combustion phasing. Even small, cycle-to-cycle variations in cylinder and temperatures can have drastic impacts on the auto ignition timing. This makes emissions control, and Overall engine control, difficult. HCCI engines also have a major problem with stable cold starting. One enabler suggested is to manage EGR dilution [19-20]. Epping et al [21] summarized research conducted about the different method used to control combustion timing. Many experimental and simulation work showed that the ignition timing of HCCI engine is controlled by low temperature (< $950 \mathrm{~K}$ ) oxidation kinetics, but the energy release process is controlled by high temperature (>1000 K) hydrocarbon oxidation kinetics. Thring [22] conducted experiments with EGR ratios $13-33 \%$ and high fuel injection temperatures $\left(>370^{\circ} \mathrm{C}\right)$ to achieve smooth and stable HCCI operation. In the research, it was shown that HCCI engines produce similar fuel economy to diesel engines. HCCI engine is being used in the practical application as dualmode combustion systems. In such systems, HCCI is used for idle and low to mid load conditions where stable HCCI operation is possible. For cold starting or heavy loads, the system is switched to conventional SI/ CI combustion [21-23]. Fuel flexibility is also considered as an advantage of HCCI engine. HCCI engine can be operated on a wide range of fuel [24-25]. Singh et al [26] experimentally conducted combustion, performance and emission analysis of HCCI engine using market diesel as a fuel. They achieved successful HCCI combustion with low volatile diesel using external mixture preparation technique 
called diesel vaporizer. However low reactivity and higher volatility of gasoline make a better candidate for HCCI engines. Figure 1-2 shows the distribution of combustion regions for gasoline HCCI engine operation with respect to air-fuel ration and intake temperature.

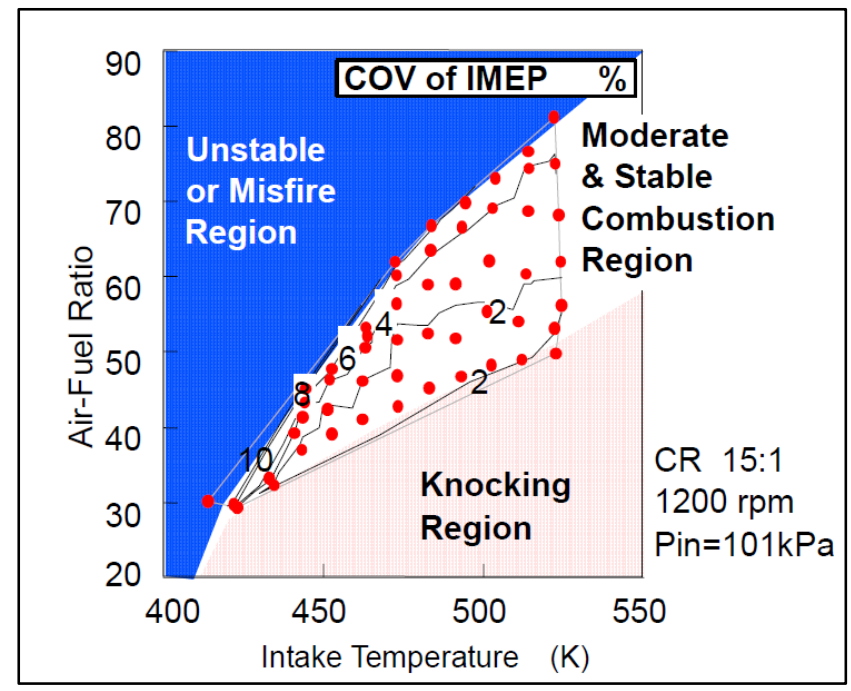

Figure 1-2. Dependency of stable combustion on Air-fuel ratio and Intake Temperature [27]

Three combustion zones are observed. For low intake temperatures and high air-fuel ratios, chances of misfire/ unstable operation are higher since the high temperature is required for auto-ignition of lean gasoline/air mixtures. However, at high intake temperatures and low air-fuel ratios promote knocking. The stable combustion region shrinks as the engine load increases.

Another LTC strategy to overcome the problems of HCCI is Partially Premixed Compression Ignition (PPC/PPCI) [28-29]. In PPCI, fuel is injected early in the compression stroke to form stratified charge mixtures that give short ignition delay in comparison to $\mathrm{HCCI}$ engines but long ignition delay compared to conventional diesel engines. As compared to the conventional diesel engine, a PPCI engine can have better fuel economy and meet stringent emissions requirements. PPCI operation mode is however restricted by steep pressure rise rates [30]. Due to its low burned gas temperatures the PPCI can also cause the disadvantages such as excessive emissions of UHC and $\mathrm{CO}$ at low loads. Auto-ignition propensity is one of the crucial properties of fuel to affect the performance of PPCI engines. It depends upon fuel's chemical structure as well thermal conditions and composition of a charge mixture. Cetane number $(\mathrm{CN})$ and research octane number $(\mathrm{RON})$ are widely used to express auto-ignition characteristics of a fuel. Higher $\mathrm{CN}$ indicates higher tendency to auto-ignite and higher RON indicates stronger tendency to resist to autoignite. Conventional diesel has $\mathrm{CN}$ greater than 40 whereas gasoline's $\mathrm{CN}$ is approximately less than 30 [30]. In PPCI combustion mode using diesel, high CN of diesel leads to early combustion of fuel/air mixtures before they become homogeneous. Use of EGR in a charge mixture helps to lengthen its ignition delay, which enables to maintain high engine 
efficiency while reducing NOx. Nevertheless, diesel PPCI engines will need aftertreatment system to meet the tightened restriction in a wide operation range. Low volatility and high reactivity of diesel are factors to limit wide use of diesel PPCI.

Gasoline-like fuels can achieve better premixing due to longer ignition delay (pertaining to its higher resistance to auto-ignition) and higher volatility resulting into low NOx while maintaining combustion efficiency. Employing an advanced common rail injection system with a wide range of injection pressure, gasoline can be injected multiple times in the intake and compression strokes to control mixture stratification at various engine speeds and loads. Taking the advantage of higher volatility and diffusivity of gasoline, gasoline can be combusted in PPCI mode, which is called as Gasoline Direct Injection Compression Ignition(GDICI). Kalghatgi et al. in their pioneering work [31] suggested that, to get low NOx and smoke, combustion should occur at low temperatures and heat release should be delayed till fuel and air are sufficiently mixed. They conducted experiments with the range of fuel from diesel to gasoline with injection near the top dead center and high level of exhaust gas content in the charge mixture to achieve low temperature combustion. They concluded that gasoline-like fuels, which gives low NOx compared to that of diesel, are appropriate to achieve low-temperature PPCI combustion mode.

Each fuel presented combination of advantages and shortcomings for PPCI combustion mode. Highly volatile gasoline enables port fuel injection but low cetane number makes it difficult to auto ignite at low loads. Conversely, diesel with higher cetane number can undergo autoignition however control combustion provides challenges. Hence combination of diesel and high levels of EGR are used for appropriate combustion phasing. A lot of effort has been made in both experimental and computational research to find out optimal fuel and operating conditions to enhance the performance of PPCI mode. Kalghatgi et al. [32] compared single cylinder diesel engine operations fueled with diesel and gasoline under constant engine speed, boosted pressure and high EGR ratio for different fueling rates and injection strategies. They showed that use of gasoline always gives low emission values for the same engine load. Hanson et al. [33] studied the partially premixed combustion using a heavy-duty diesel engine with commercially available gasoline of an octane number 91. They concluded that use of gasoline in HD diesel engine results in low engine-out emissions while maintaining or even reducing indicated specific fuel consumption. Shen et al. [35] tested the effects of EGR ratio and boost pressure on the performance and emissions of a partially premixed combustion engine using three fuels; gasoline, diesel, and ethanol. They stated that increase in EGR ratio/ boost pressure reduces emissions with corresponding improvements in combustion efficiency and gross indicated efficiency, particularly at relatively low oxygen concentration for diesel and gasoline PPC. On the contrary, for ethanol PPC, less EGR was beneficial for reducing pressure rise rate due to low reactivity of ethanol. Manente el al. [36] discussed the effect of fuel properties on the performance and emissions of a PPC engine using fuels within the range of gasoline boiling points. EGR, boost pressure and advanced injection strategies were used to conduct load sweep at a constant speed and constant compression ratio. They could get high gross efficiencies while maintaining NOx and PM at low values for all the fuels tested. However, high-pressure rise rates were observed for fuels with high octane numbers. Koci et al. [37] 
investigated multiple injection strategies using ultra-low sulfur diesel in the LTC regime to understand the performance and emission benefits of multiple injection. In their experiments and 3-D simulations, they presented optimized operation maps for a range of injection timing and split ratio to produce high efficiency and low emissions. Opat et al. [29] conducted a parametric study with injection timing sweep in a highly dilute environment to understand the UHC/CO generation mechanism in LTC at part load. They also explored the effects of operating parameters such as rail pressure, swirl ratio and inlet temperature on $\mathrm{HC} / \mathrm{CO}$ formation using 3-D CFD simulations. Marriott et al. [38] applied gasoline direct injection to a heavy-duty diesel engine to study effects of fuel injection parameters on combustion phasing in premixed compression ignition combustion. Fuel stratification in the cylinder was effective for producing optimal combustion phasing over a range of intake air temperatures, engine loads, and engine speed conditions. In-cylinder fuel stratification was also found to lead to faster heat generation rate and shorter combustion duration, making such an operating range limited by knocking. Costa et al. [39] has discussed optimization analysis to maximize the energy efficiency of GDI engine under lean operating conditions using 3-d CFD engine simulations. They carried out a parametric study for injection pressure, injection timing and spark advance to find optimized indicated mean effective pressure with a low value of $\mathrm{CO}$ for a single injection. They also employed double injections and found similar optimized IMEP to that of the single injection case, but with reduced NO. Yoshizawa et al. [16] presents a new autoignition combustion model to study combustion phasing in GCI engines. They also presented parametric study to analyze effects of air-fuel distribution and temperature on combustion characteristics. They concluded that air-fuel distribution within chamber highly affects combustion parameters. They even proposed two step autoignition theory to avoid knocking achieved by gaining fuel rich zone at the center for heavy load gasoline engine. Ra et al. [30] investigated gasoline direct injection compression ignition (GDICI) engine in LTC regime with double-pulse fuel injection. The operating range of GDICI engine with respect to injection timing, EGR ratio and split ratio was identified with constraints of combustion efficiency $(>85 \%)$, pressure rise rate $(<7 \mathrm{bar} / \mathrm{deg})$ and NOx emission $(<1 \mathrm{~g} / \mathrm{kg}-\mathrm{f})$. They also conducted a parametric study for initial temperature, injection pressure and boost pressure which confirmed that GDICI engines can achieve about $0.1 \mathrm{~g} / \mathrm{Kg}$-f NOx and PM emission with gross ISFC about $180 \mathrm{~g} / \mathrm{kW}$-hr. Shibata et al. [40] conducted an experiment with a supercharged single cylinder diesel PPCI engine with the high-pressure common rail fuel injection system to determine methods to reduce engine noise. They also determined that maximum pressure rise rate is the governing parameter related with engine noise whereas combustion duration and maximum rise in heat release rate are respectively the second and third important cause of the engine noise. They showed that EGR and supercharging are the methods to achieve high load and low noise engine operation. Rose et al. [41] presented a work in which GCI combustion was achieved using market European gasoline in compression ignition engine operated at high to relatively low loads by using adequate compression ratio, advanced injection strategies such as double or triple injection and variable valve actuation for internal EGR. 


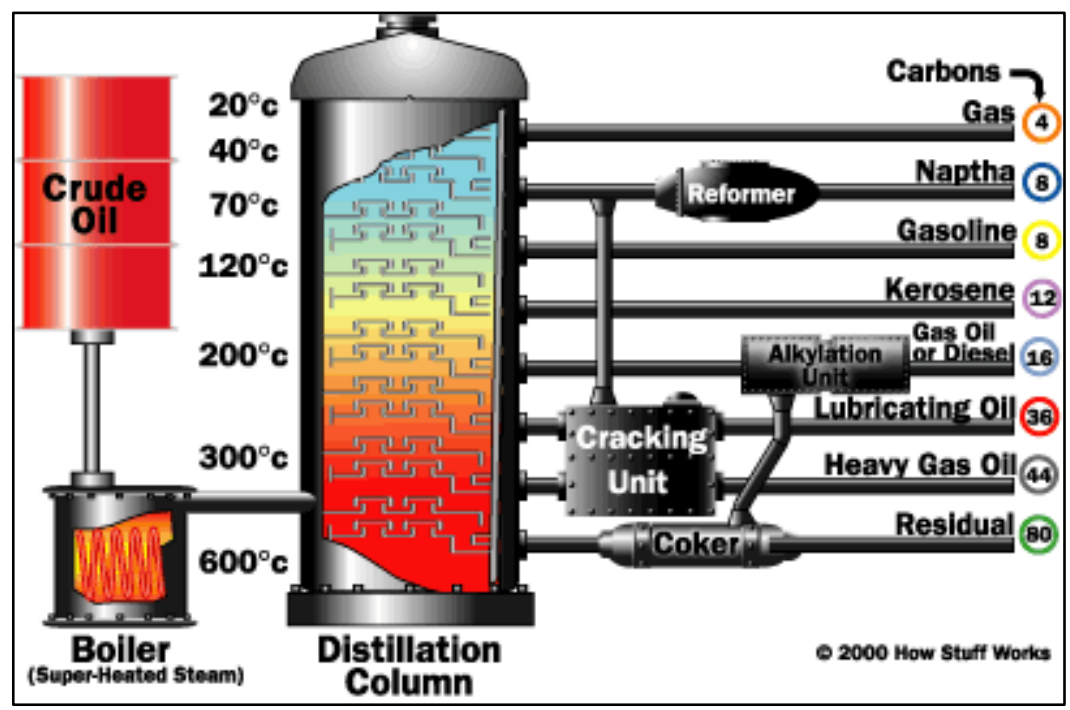

Figure 1-3. Crude oil refinement [46]

To achieve significant growth in fuel economy along with a reduction in emissions, selection of suitable fuel is also an important step. In spite of growth in the alternative options to the petroleum, even by the year 2040, 90\% transport energy is expected to come from petroleum. This demand is expected to be skewed heavily towards heavier fuels like diesel and jet fuel as compared to the gasoline. Demand proportion for diesel plus jet fuel to gasoline is expected to increase to 2.4 to 3.8 [42]. In order to manage future energy demand and supply, we should make full use of petroleum product range. Hence the development of an engine working with fuels other than conventional diesel such as poorquality gasoline such as naphtha, CNG (compressed natural gas) is important. Naphtha represents a range of light petroleum distillates and it is feedstock for market gasoline. Naphtha is composed of C5 to C11 hydrocarbons and it is at the slightly lighter location as compared to the diesel on distillation curve. As compared to the market gasoline, naphtha has low research octane number and has higher lower heating and energy density value. Naphtha is also more advantageous over gasoline because it is significantly less processed as compared to the market gasoline. Percentage of energy used from well to pump is approximately equal to $22 \%$ for gasoline whereas it is just $13 \%$ for naphtha. Another advantage for naphtha is regarding the well to pump greenhouse gas emission. For gasoline well to pump greenhouse gas emission is approximately equal to $18 \mathrm{~g} / \mathrm{MJ}$ of fuel energy whereas the same value for naphtha is $12 \mathrm{~g} / \mathrm{MJ}$ of fuel energy. Heavy and light naphtha are two fractions of Naphtha. Light naphtha contains complex hydrocarbons with 5 to 11 carbon atoms. Light naphtha has boiling point between 30 to $90^{\circ} \mathrm{C}$. Whereas, heavy naphtha has hydrocarbon molecules with 7 to 11 carbon atoms and a boiling point between 90 to $200{ }^{\circ} \mathrm{C}$. Heavy naphtha has higher reactivity (higher cetane number) and lower volatility (higher boiling point) as compared to light naphtha. Because of known benefits such as higher reactivity, high heating value, and energy density, lower $\mathrm{CO}_{2}$ emissions and refinement costs as compared to gasoline, naphtha can be an efficient fuel for the PPCI mode of combustion. Leermakers et al. [43] conducted an engine testing with commercially available naphtha blends in the partially premixed combustion mode to check the 
sensitivity of fuel to injection strategies, dilution levels, and emission performance. Their results showed that engine operation with some naphtha blends meets legislated emission levels while maintaining the gross indicated efficiency of 50\%. Change et al. [44] conducted a study with an aim to investigate the operation of existing modern diesel engine with low cetane fuels like naphtha. They showed that using narrow-cut naphtha with a derived cetane (DCN) number of 38 can be used to run an engine at all relevant speed and load conditions, while meeting or exceeding the efficiency and emissions requirements. Violet et al. [45] carried out 6-cylinder GCI engine experiments with test conditions similar to urban driving cycle using light and heavy naphtha as a fuel for three different compression ratios. They proved that combination of higher compression ratio and fuels like naphtha (with higher cetane number than gasoline) offers better fuel consumption in comparison to base SI engine rather than relying only on higher cetane number fuels. Akihama et al. [34] conducted an experimental and computational study to understand the performance of low octane gasoline under high load operating conditions. Their results showed that naphtha fuels at low and medium loads promise low emission values whereas at high loads with split injection strategies showed high NOx and PM values.

Because of current technology trend, the demand for diesel in the global market is increasing leaving the surplus amount of light gasoline-based fuel for the future. Development of new efficient engine operation mode within the stricter emission standard using light gasoline-based fuel is becoming the need of the time. 


\section{Computational Approach}

In order to depict in-cylinder dynamics of an advanced internal combustion engine, it is important to simulate highly complex and closely coupled physical and chemical process. MTU-KIVA-Geq-CHEMKIN code, an in-house version of KIVA code [47] coupled with Chemkin library [48] and SpeedChem model is being used for analysis of transient threedimensional dynamics of evaporating fuel sprays interacting with multicomponent gases undergoing mixing, ignition, chemical reactions, and heat transfer. Transient, threedimensional, multiphase, multicomponent KIVA code has been developed by Los Alamos National Laboratory. It was first released for public use in 1985. Since then KIVA codes with much more improvements have been released. In house MTU KIVA code has added and modified many sub-models, is being used and validated in the field of engine combustion simulation research. Code uses structured block mesh and discretized special variables using finite volume method. It uses implicit method for time advancement. Code solve unsteady equations using spatial finite difference mesh which further subdivided computational domain number of the hexahedral cell. This finite-difference mesh is used to confine boundaries and can move as combustion geometry changes. Operational range for KIVA codes ranges from low speeds to supersonic speed for both laminar and turbulent flows. KIVA allows a user to solve turbulent and chemical reactions for an unlimited number of species. Finite time increments (called as cycles or time steps) are used so that the transient solution can march in time. Values of dependent variables are calculated at each cycle using input and results of the previous cycle. Computational efficiency improvements, numerical accuracy improvements, new or improved physical sub-models, and improvements in ease-of-use and versatility, are some of the advantages of MTUKIVA-Geq-CHEMKIN over its predecessor.

\subsection{Governing equations}

The CFD code employed solves an equation for fluid flow i.e both gaseous and liquid phase. Dynamics of fluid flow is governed by conservation of mass, momentum, and energy. Equations describing turbulence and transport of passive scalars and species are also present. All the continuity equations and turbulent equations are solved for gaseous phase. Liquid phase in a combustion chamber is represented by a mostly liquid spray. The behavior of a liquid drop is resolved by a different set of modeled partial differential equations. Change in the concentration of a species in the cell volume because of a chemical reaction is modeled by rate equation which includes both Arrhenius form of kinetic reaction along with equilibrium reaction. In order to solve all these equations, boundary conditions need to describe. Inflow and outflow boundary conditions can be expressed by velocity or pressure. A velocity of the flow at mesh boundaries can be defined as either no-slip, free slip or law-of wall condition. Adiabatic, fixed temperature, temperature function are the wall temperature boundary options. Governing equations are solved for all the species included in the chemical mechanism.

Conservation of mass for a specific species can be given as follows: 
$\frac{\partial \rho_{m}}{\partial t}+\nabla \cdot\left(\rho_{m} u\right)=\nabla \cdot\left[\rho D \nabla\left(\frac{\rho_{m}}{\rho}\right)\right]+\rho_{m}^{\cdot c}+\rho^{\cdot s} \delta_{m}$

Here, $\rho m$ is a density of species $m$ where $\rho$ is total fluid density. Flow velocity is represented by $u$. D is single diffusivity coefficient from Fick's law of diffusion. $\rho c$ and $\rho \mathrm{m}$ are the two terms representing the source of species from the chemical reaction and from spray respectively. $\delta$ is a Dirac delta function and species 1 is the species of which spray is composed of.

Conservation of momentum for a fluid mixture is given as follows:

$\frac{\partial(\rho u)}{\partial t}+\nabla \cdot(\rho u u)=-\frac{1}{\alpha^{2}} \nabla p-A_{o} \nabla(2 / 3 \rho k)+\nabla \cdot \sigma+F^{s}+\rho g$

Here $\mathrm{P}$ is the total fluid pressure. $\mathrm{A}_{\mathrm{o}}$ is zero is flow is laminar, it is equal to 1 if turbulent flow is considered. $\sigma$ is a Newtonian stress tensor and it is given by,

$\sigma=\mu\left[\nabla u+(\nabla u)^{T}\right]+\lambda \nabla \cdot \mathrm{u} \mathrm{I}$

$\mu$ and $\lambda$ are the dynamic and kinematic viscosity respectively. T represents transpose.

Conservation of an internal energy is given as follows,

$\frac{\partial(\rho I)}{\partial t}+\nabla \cdot(\rho u I)=-p \nabla \cdot u+\left(1-A_{o}\right) \sigma: \nabla u-\nabla \cdot J+A_{o} \rho \varepsilon+Q^{\cdot c}+Q^{\cdot s}$

I is the specific internal energy. $Q^{c}$ and $Q^{s}$ are two source term representing heat release from chemical reaction and spray interaction. Heat flux vector $J$ is the sum of heat conduction and enthalpy diffusion and equation for $\mathbf{J}$ is as follows:

$J=-K \nabla T-\rho D \sum_{m} h_{m} \nabla\left(\rho_{m} / \rho\right)$

$\mathrm{T}$ is temperature. $\mathrm{K}$ and $\mathrm{D}$ are conduction and diffusion coefficient. $\mathrm{h}_{\mathrm{m}}$ is an enthalpy of a species $\mathrm{m}$.

In order to model turbulent flow within the combustion chamber RNG k- $\varepsilon$ model is used. Two additional transport equations for turbulent kinetic energy $\mathrm{k}$ and dissipation rate $\varepsilon$ are solved. These two equations are given here,

$$
\frac{\partial \rho k}{\partial t}+\nabla \cdot(\rho u k)=-\frac{2}{3} \rho k \nabla \cdot u+\sigma: \nabla u+\nabla \cdot\left[\frac{\mu}{P r_{k}} \nabla k\right]-\rho \varepsilon+W^{\cdot s}
$$




$$
\begin{aligned}
& \frac{\partial \rho \varepsilon}{\partial t}+\nabla \cdot(\rho u \varepsilon)=-\left(\frac{2}{3} c_{\varepsilon_{1}}-c_{\varepsilon_{3}}\right) \rho \varepsilon \nabla \cdot u+\nabla \cdot\left[\left(\frac{\mu}{P r_{\varepsilon}}\right) \nabla \varepsilon\right]+\frac{\varepsilon}{k}\left[c_{\varepsilon_{1}} \sigma: \nabla u-c_{\varepsilon_{2}} \rho \varepsilon+\right. \\
& \left.c_{S} W^{\cdot s}\right]
\end{aligned}
$$

Turbulence model is discussed in depth by Han et al [55]

\subsection{Physical Models}

Evaluating spray behavior and its interaction with gases inside the combustion chamber is extremely complicated. Spray characteristics are greatly important as it affects mixture formation and thereby affecting combustion. Distribution of spray droplets size, their temperature and velocities etc, these are some important parameters required to calculate mass, momentum and energy exchange between gas and spray. As waber number is greater than unity in most of the fuel sprays, mathematical simulation for drop oscillation, distortion, collision, coalescences and break up has to be included.

\subsubsection{Drop Breakup}

Injector properties and user inputs are used to calculate effective injection velocity, the size of fuel blob (a sphere with diameter equal to effective nozzle diameter) getting injected into the chamber. Modified Kelvin Helmholtz and Rayleigh Taylor (KH-RT) model presented by Beale and Reitz [49] is used to simulate drop break up. This model combines both effects, Kelvin-Helmholtz waves driven by aerodynamic forces and Rayleigh-Taylor instabilities due to acceleration, to model drop breakup ejected into the gas flow. Both these models based on wave growth on the droplet surface and attributes drop breakup to fastest growing instability based on the local conditions. Injected fuel blobs are tracked by the Lagrangian method and break up of each blob within the dense liquid core region is prominently due to sudden acceleration and it is modeled by exclusively $\mathrm{KH}$ model. Modification made by Beale and Reitz allows the RT accelerative instabilities to affect all the drops outside the intact liquid core of jet as opposed to previous models in which RT models are employed along with $\mathrm{KH}$ model only for drop breakup occurring after the breakup length and beyond the liquid region. Beale and Reitz also included Rosin-Rammler distribution to predict size of children drop size after parcel breakup due to RT instability. Overall modifications made in hybrid KH-RT model by researcher improves temperature dependence of the liquid penetration and significantly increases accuracy of capturing liquid penetration at low ambient densities. 


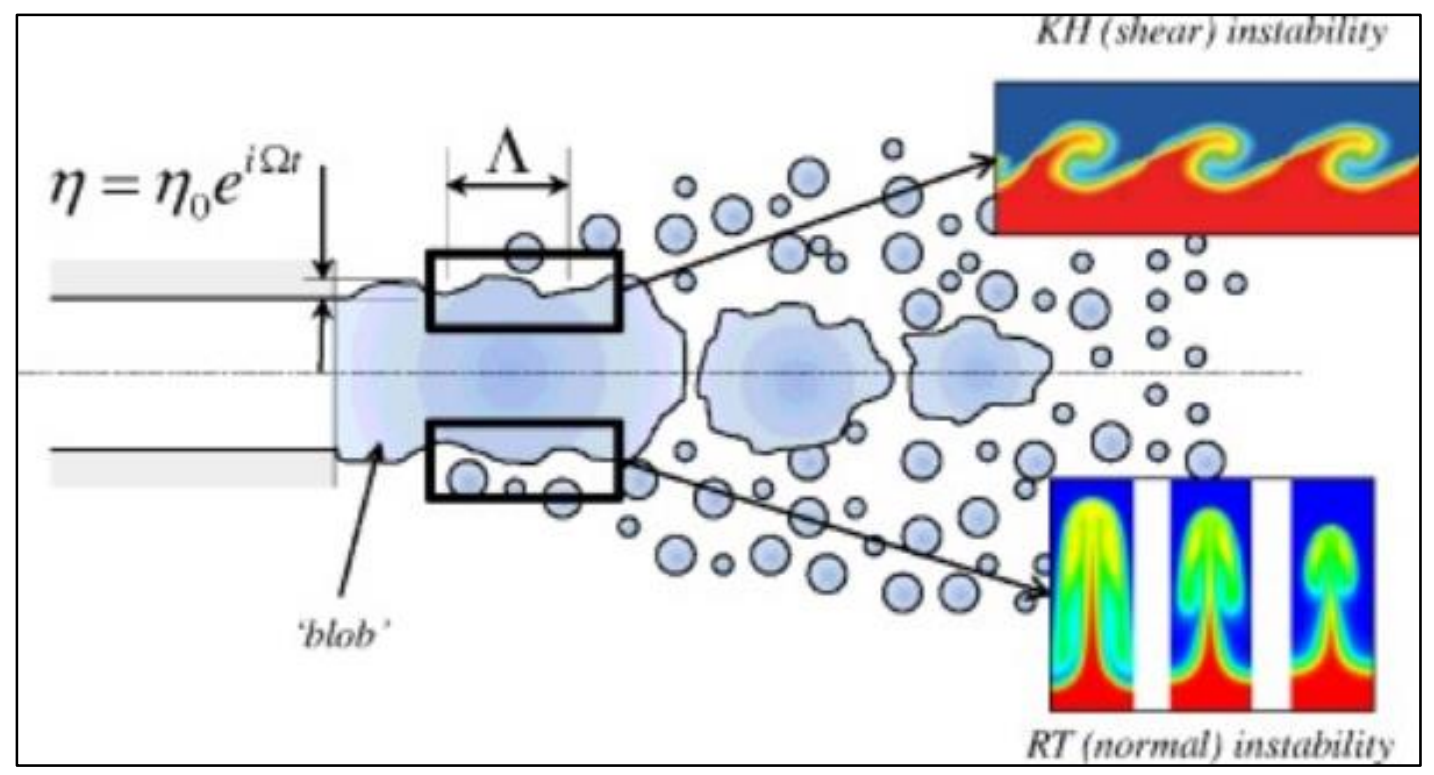

Figure 2-1. Modified hybrid KH-RT break up model

Figure 2.1 gives basic representation of implementation of modified hybrid KH-RT break up model.

\subsubsection{Drop Collision}

Instead of trying to represent the complete drop distribution properties occurring due to a collision, droplet collision is represented by sampling procedure consistent with stochastic particle method. Here, collision frequency between drops associated with one particle A and drop associated with all other particle is calculated. This collision frequency will be used to calculate the probable number of drops of particle A undergoing a collision with all other particle drops. Numbers of drops of a particle for which collision is taking place are then subtracted from a total number of drops and one/more number of particles produced due to the collision are created. The disadvantage of this method is that a large number of particles; more than the capacity of a computer; are being quickly created. Another way to handle the collision is that to use Collison frequency to calculate probability $\mathrm{P}$ of collision between drops of particle A to all other particle drops. All the drops associated with particle A will behave in the same manner. Then all the drops of particle A will collide and the probability of the event is P. As a result, no new particle has to be created. MTU-KIVA-Geq-CHEMKIN code implements radius-of influence (ROI) collision model developed by Munnannur and Reitz [51]. This study employs use of radius of influence to calculate probability of collision for each parcel in the cell. This strategy helps to reduce time-step and mesh dependency in spray calculations. 


\subsubsection{Drop Distortion/Deformation}

Variation of drop drag causes momentum change between a drop and ambient gases which in turn changes drop-gas relative velocity. Due to this change, drop breakup and coalescence processes also gets affected. Hence calculation of drag becomes critical in order to analyze spray behavior. In order to calculate drag on fuel drop, droplet used to be treated as a rigid sphere. However, experimental research conducted for drop trajectories and size measurements using high magnification photographs has proved that a liquid drop with sufficiently high Weber number gets distorted from its spherical shape as it interacts with gases. Liu, Mather, and Reitz [52] proposed a modified drag model in which drag coefficient changes dynamically with the flow conditions during droplet lifetime. Value of a drag coefficient lies between a lower limit (drag coefficient for a rigid sphere) to an upper limit (drag coefficient for a disk). The developer of this drag model has modeled distortion of a rigid sphere using forced, damped harmonic oscillator model (Taylor's analogy between drop and spring system) where the surface tension acts as a restoring force whereas viscosity provides damping term.

Modified equation for drag coefficient is given below:

$C_{d}=C_{d, \text { sphere }}[1.0+2.632 y]$

$\mathrm{y}$ is a drop distortion and it varies between 0 (rigid sphere) to 1 (disk).

\subsubsection{Drop Vaporization}

Unsteady vaporization model developed by $\mathrm{Ra}$ [53] deals with the evaporation of multicomponent fuel using discrete multi-component approach (DMC), that is tracking each fuel component individually regardless of a direction of motion during vaporization process. Ambient temperature and pressure conditions present in the cylinder under which fuel vaporization takes place varies widely. As a result of which fuel can go under either normal evaporation or evaporation by flash boiling. Flash boiling occurs when fuel is injected at fuel temperatures higher than its saturation temperature at corresponding ambient pressure. Hence, superheated fuel undergoes sudden vaporization by boiling. Light components in the multicomponent fuel are most susceptible to flash boiling because of high volatility. The current improved model accommodates both modes of vaporization (normal and flash boiling) along with smooth transition between two modes. Instead of assuming droplet surface temperature is equal to the droplet interior temperature, the current vaporization model calculates the drop surface temperature from the drop interior and ambient gas temperatures. Amount of net heat required for vaporization is determined after considering hear transfer from droplet interiors to surface as well as heat flowing from surrounding gas to the drop surface. The density change of the droplets as a function of time was also considered. The model determines the amount of fuel to be treated as vapor when the drop surface temperature reaches the critical temperature for vaporization even though the drop interior temperature has not. 


\subsubsection{Wall Interaction}

A numerical model describing dynamics and vaporization of liquid wall film within the complex geometry had developed by O'Rourke and Amsden [54]. This model is used in the current simulation. According to the developed model, impinging spray (through mass, tangential momentum and energy addition), wall (through the no-slip boundary condition and heat transfer) and gas flow near the wall (through tangential stresses and heat and mass transfer in the gas boundary layers above the films) are major influencing factors for the dynamics of film. As wall film is sufficiently thin, film flow is assumed laminar and inertia forces are neglected. The model accurately predicts transport in the boundary layers above the vaporizing films along with unsteady heating of a wall film. This model also successfully captures wall film behavior near sharp corners using inertia separation criterion.

\subsubsection{Turbulence Model}

Modified RNG $\kappa-\varepsilon$ model by Han [55] is used to predict turbulence within in cylinder flows. Han et al modified basic RNG $\kappa-\varepsilon$ turbulence model developed by Yakhot and Orszag [56,57] to accommodate variable density flows in internal combustion engine. Current turbulence model used show better prediction of combustion parameters due to additional consideration for flow compressibility.

\subsection{Combustion Model}

Fuels used in Internal combustion engine are complex compounds consisting wide variety of hydrocarbon. Representing combustion properties of real fuel is beyond the computation capacities due to complex composition. For the ease of simulation, physical (volatility, density, viscosity, lower heating value etc.) and chemical (chemical composition, hydrogen to carbon ratio, ignition delay etc.) properties of multi-component fuels are imitated by set of surrogate hydrocarbons. For example, n-heptane for diesel and iso-octane for gasoline respectively are widely accepted representations. Group Chemistry Representation (GCR) $[64,65]$ is used to capture chemical kinetics. A skeletal reaction mechanism for primary reference fuel (PRF) oxidation with 49 species and 167 reactions is used as a surrogate for PRF50 fuel. Whereas a blend of 254 species and 1115 reactions is used to model both the naphtha fuels.

NOx formation mechanism includes four species ( $\mathrm{N}, \mathrm{NO}, \mathrm{N}_{2} \mathrm{O}$ and $\mathrm{NO}_{2}$ ) and consists of 14-reaction. This mechanism is derived from detailed GRI mechanism [58] and added to current mechanism. A phenomenological model [59] derived from Hiroyasu soot model [60] is used to predict soot formation. Soot oxidation calculation are conducted using Nagle-Stricklend-Constable (NSC) model [61]. Current model presents soot results well in agreement with experimental observations under higher ambient gas density, temperature or increased nozzle diameter. 
Validating predictions of all the models is not the scope of this study, however all these sub models are employed and validated in many previous research works $[29,30,62]$.

\subsection{Surrogate Fuel}

Composition of surrogate fuel representing PRF50, Heavy naphtha and light naphtha is shown below in Fig 2-2.

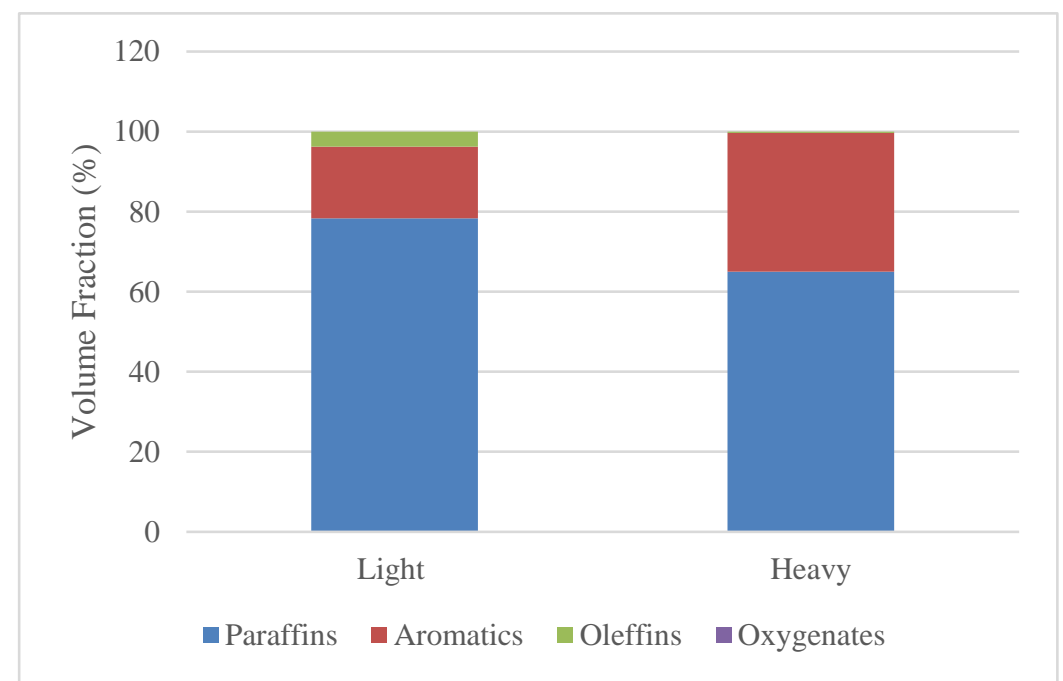

Figure 2-2. Surrogate Fuel Composite 


\subsection{Computational Grid}

A three-dimensional computational grid employed consists of a pent roof engine with a bowl in the piston (see Figure $2.3 \mathrm{a}$ ). The average cell dimensions are $0.5 \mathrm{~mm}$ to $7 \mathrm{~mm}$ in vertical direction and $2.5 \mathrm{~mm}$ average in horizontal direction. This computational grid was developed using ICEM CFD software [63]. Blocking feature provided by ANSYS ICEM CFD is used to create structured hex-mesh. First outer geometry is captured by threedimensional blocks after which minor geometry is depicted by deleting, splitting and/or merging blocks. The volume of these blocks is filled with hexahedral cells. Grid generated in the ICEM CFD is then converted into KIVA $3 \mathrm{~V}$ format.

a)

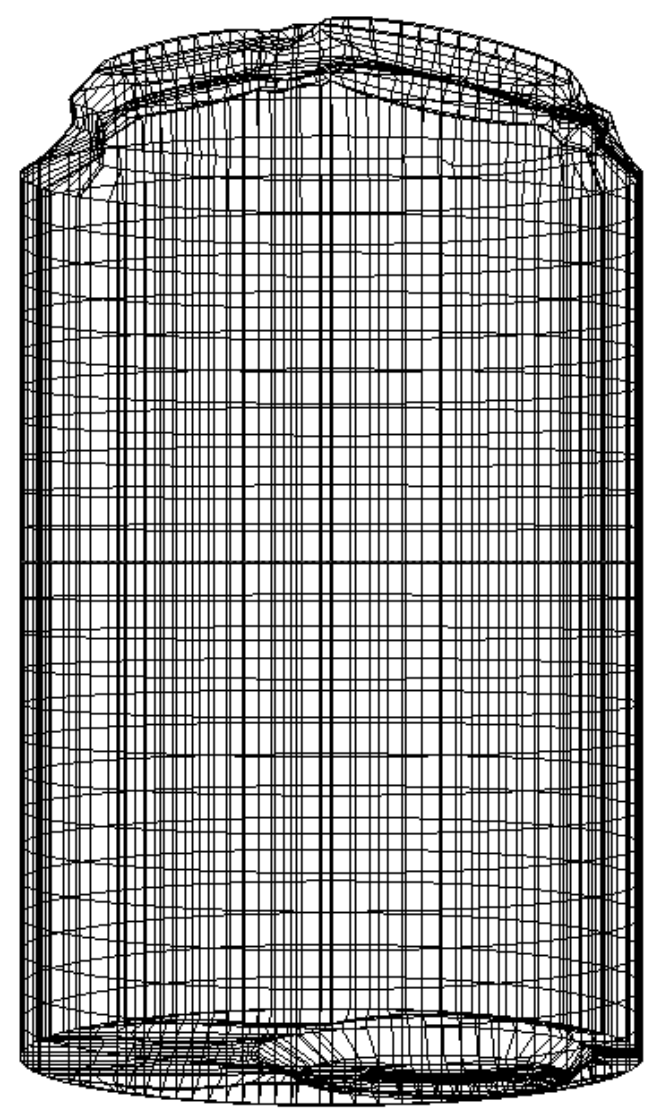

b)

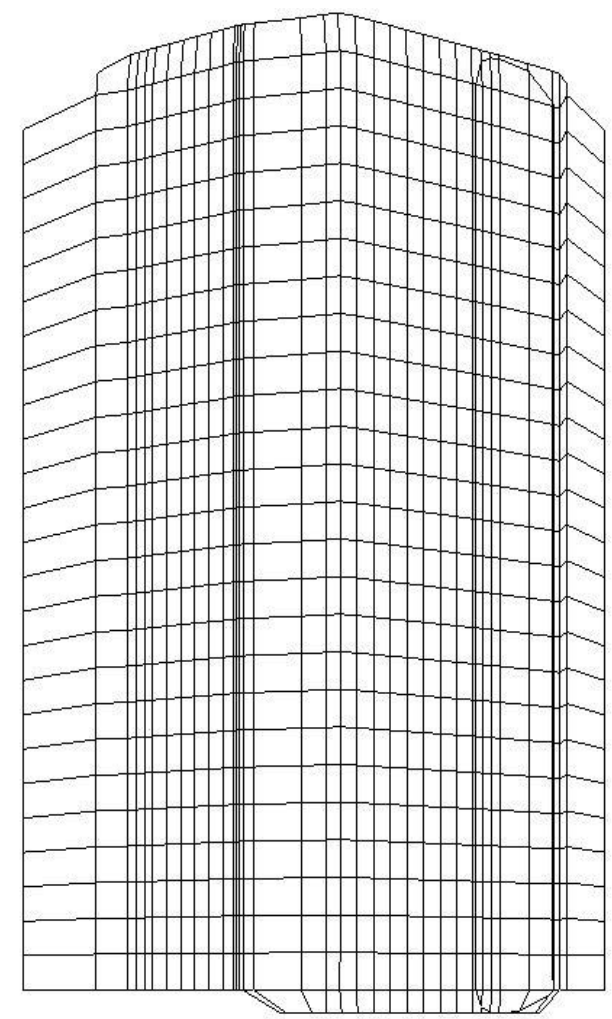

Figure 2-3 . a) Complete 3-D computational grid b) vertical cross section view of computational grid 


\subsection{Simulation Setup}

Combustion in a 4-valve pent roof engine with a compression ratio of 16 is simulated using MTU-KIVA code. Initial and boundary conditions for the baseline case were obtained from the experiment conducted with PRF50 fuel. Table 1 gives the engine and injector specification along with the baseline operating conditions.

Table 2-1. Engine and Injection System Specification and baseline operating condition

\begin{tabular}{|c|c|}
\hline \multicolumn{2}{|c|}{ Engine } \\
\hline Type & 4 valve Pent roof engine \\
\hline Bore x Stroke $(\mathrm{mm})$ & $81 \times 135$ \\
\hline Connecting rod length $(\mathrm{mm})$ & 145 \\
\hline Compression ratio & $16: 1$ \\
\hline \multicolumn{2}{|c|}{ Valve timings } \\
\hline IVC (deg ATDC) & -150 \\
\hline EVO (deg ATDC) & 126 \\
\hline \multicolumn{2}{|c|}{ Temperature } \\
\hline Wall (K) & 453 \\
\hline Head $(\mathrm{K})$ & 520 \\
\hline Piston(K) & 540 \\
\hline \multicolumn{2}{|c|}{ Injector } \\
\hline No. of holes & 6 \\
\hline Included angle (deg) & 156 \\
\hline Nozzle hole diameter $(\mathrm{mm})$ & 0.134 \\
\hline Injection timing (deg ATDC) & -50 to -15 \\
\hline Injection pressure (Bar) & 200 to 900 \\
\hline Injection Amount (mg) & 19.96 \\
\hline \multicolumn{2}{|c|}{ Baseline Operating Condition } \\
\hline Speed (rpm) & 2000 \\
\hline IVC Temperature (K) & 371.497 \\
\hline IVC Pressure (Bar) & 1.412 \\
\hline$\% \mathrm{O}_{2}$ at IVC & 15 \\
\hline Fuel & Heavy naphtha, Light naphtha \\
\hline Computational angle (deg ATDC & IVC-EVO \\
\hline
\end{tabular}

For this study, computational grid of a single cylinder with bore $81 \mathrm{~mm}$ and stroke $135 \mathrm{~mm}$ is used. Temperatures of head, piston and cylinder walls were maintained at 520, 540, and $453 \mathrm{~K}$, respectively, which were determined to match the measured motoring pressure profile with the experimental initial conditions. The simulations were conducted from IVC (-150 deg ATDC) to EVO (126 deg ATDC). A 6-hole injector with 156 deg included spray angle is simulated for the present study. Top-hat injection profile is used for all the test cases. Variation in injection pressure was simulated by varying injection duration. As the injection duration changes in the simulation, it manipulates the velocity of fuel jet entering 
into the cylinder such that the pressure difference and fuel velocity satisfy the Bernoulli's equation. The number of fuel parcels injected was set to 3000. Injection timings are varied between -50 and -15 deg ATDC. Whereas injection pressure sweep is carried between 200 and 900 Bar. Table 1 also gives baseline operating parameters studied. For constant fueling viz $19.96 \mathrm{mg} /$ stroke, engine speed is also kept constant equal to $2000 \mathrm{rpm}$. As simulation starts at IVC, initial mixture properties are described at IVC. Charge temperature and pressure at IVC are set to be $371.49 \mathrm{~K}$ and $1.412 \mathrm{bar}$, respectively, for all test cases. The gas temperature and pressure at IVC were little higher as compared to those at the intake port. This is because of heat transfer from the wall and slight compression from BDC to IVC. For baseline cases, the amount of EGR was fixed to 37\%. EGR composition was obtained from the exhaust gas composition of the experimental data. Table 2-2 gives the composition of the mixture at IVC.

Table 2-2. Mixture composition at IVC

\begin{tabular}{|c|c|}
\hline Component & Percentage composition (\%) \\
\hline Unburned Hydrocarbons $(\mathrm{UHC})$ & 0.0012 \\
\hline Oxygen $\left(\mathrm{O}_{2}\right)$ & 15.3221 \\
\hline Nitrogen $\left(\mathrm{N}_{2}\right)$ & 75.5911 \\
\hline Carbon dioxide $\left(\mathrm{CO}_{2}\right)$ & 3.7862 \\
\hline Water vapor $\left(\mathrm{H}_{2} \mathrm{O}\right)$ & 5.2743 \\
\hline Carbon Monoxide $(\mathrm{CO})$ & 0.0226 \\
\hline Oxides of Nitrogen $(\mathrm{NOx})$ & 0.0025 \\
\hline
\end{tabular}

$\mathrm{UHC}$ and $\mathrm{NOx}$ in the mixture were assigned to $\mathrm{n}$-heptane and $\mathrm{NO}_{2}$, respectively.

\subsection{General Code Structure}

Following Figure 2-4 gives the flow chart for KIVA program used. This computer program consists of number of subroutines to simulate all the physical and chemical process involve in a combustion chamber of an IC engine. 


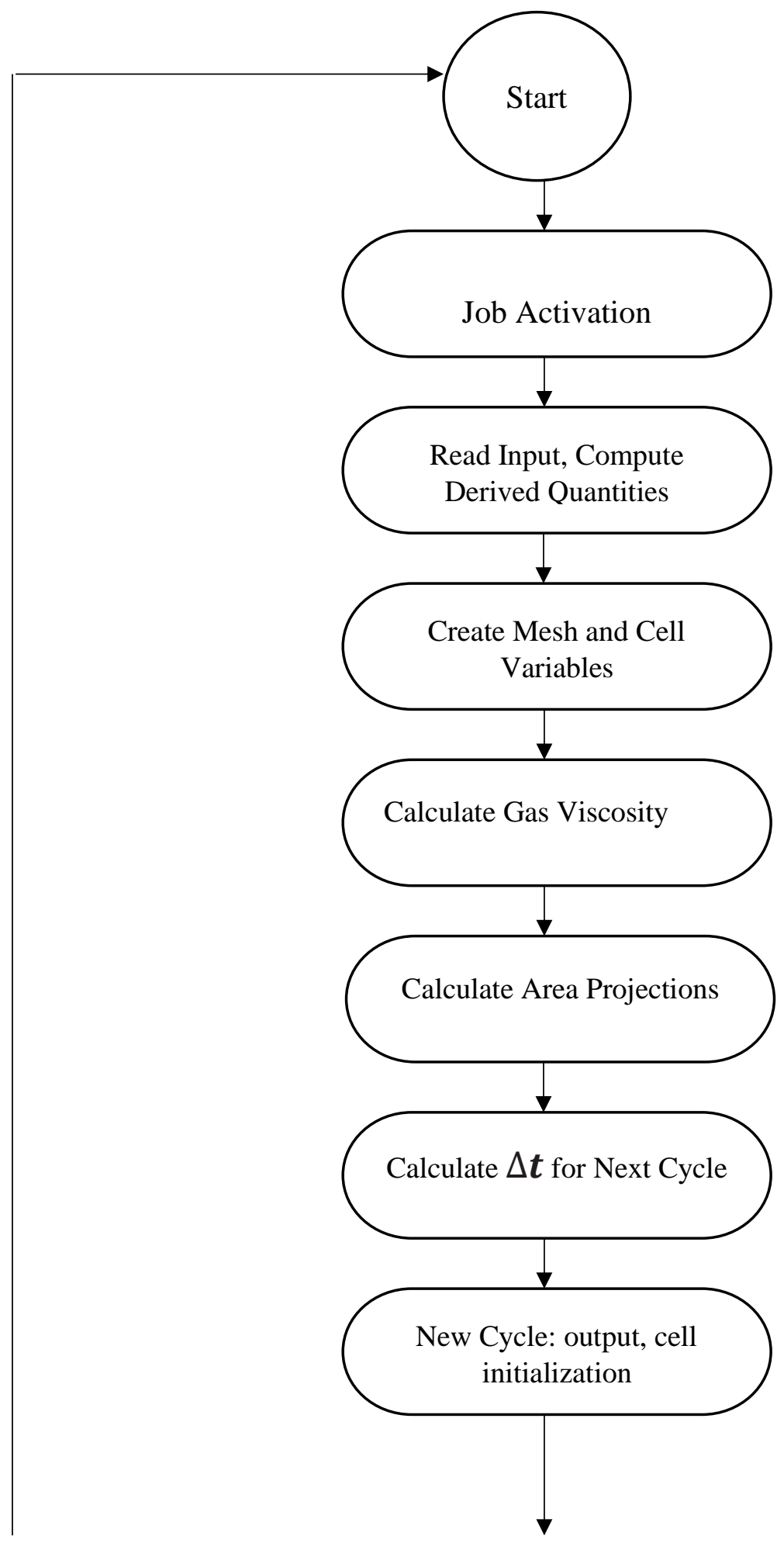




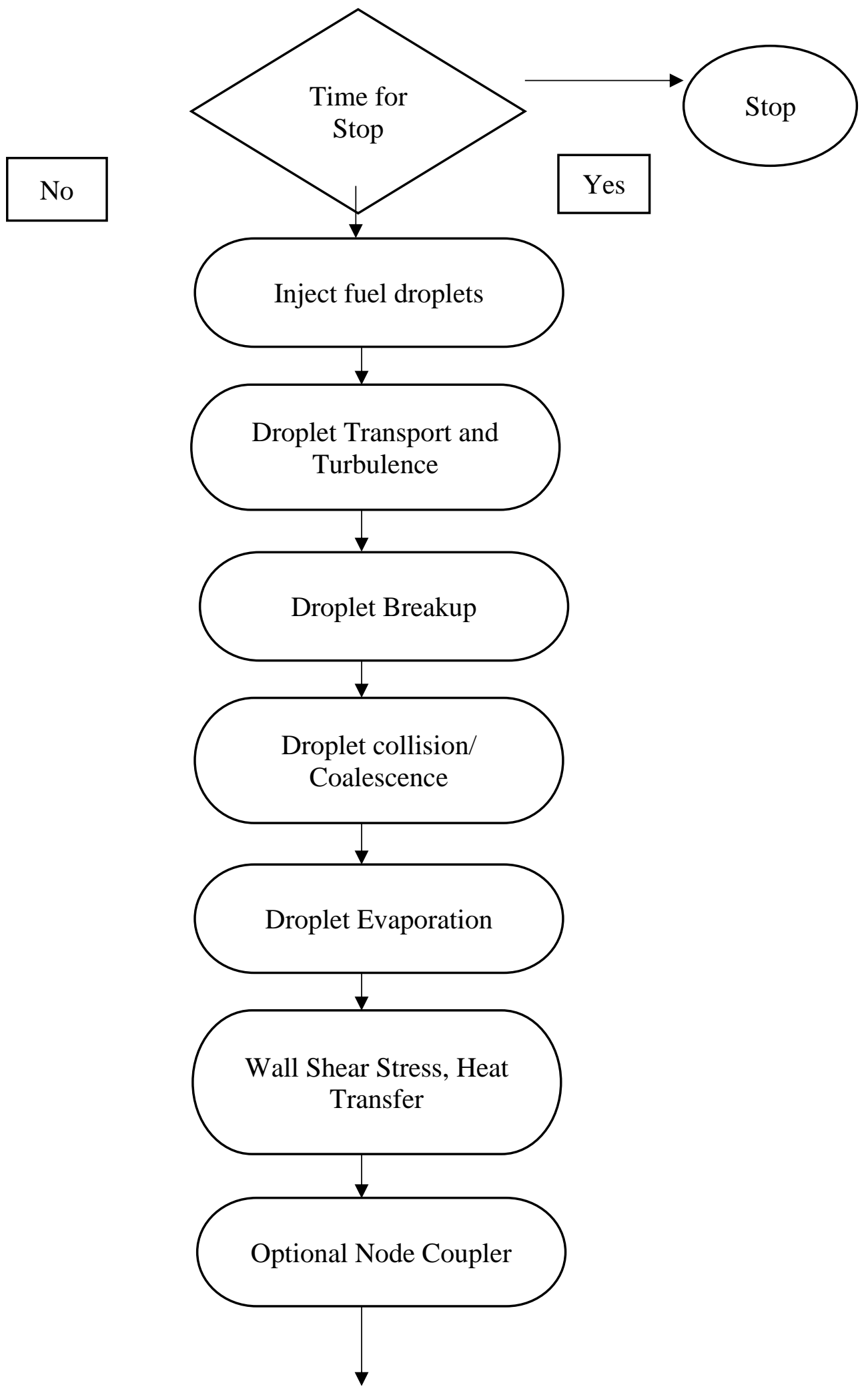




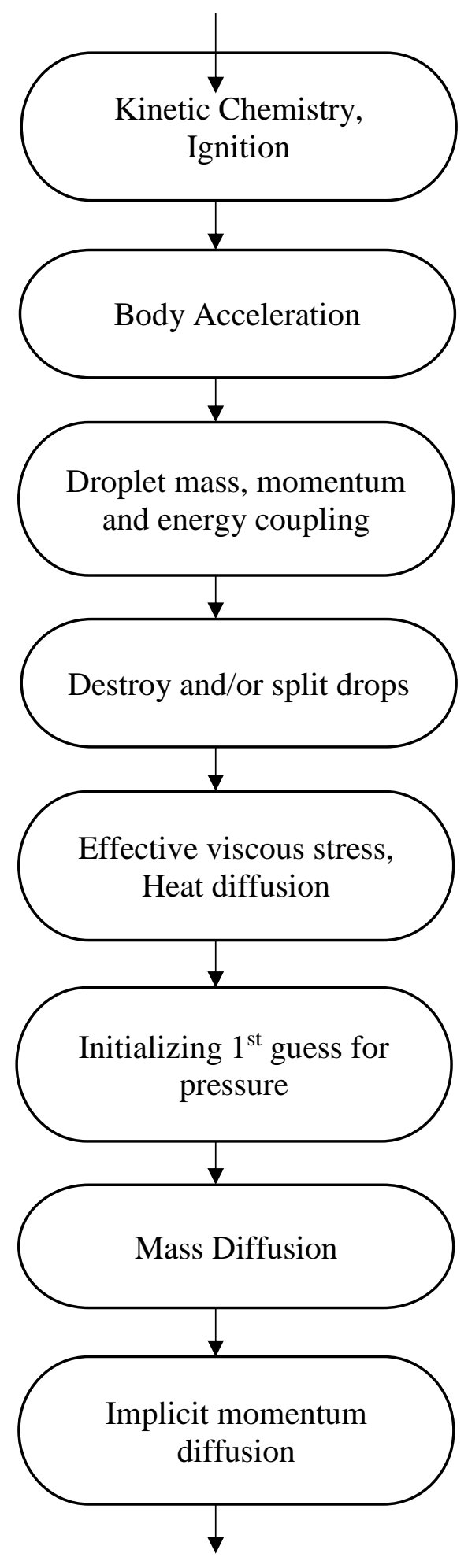




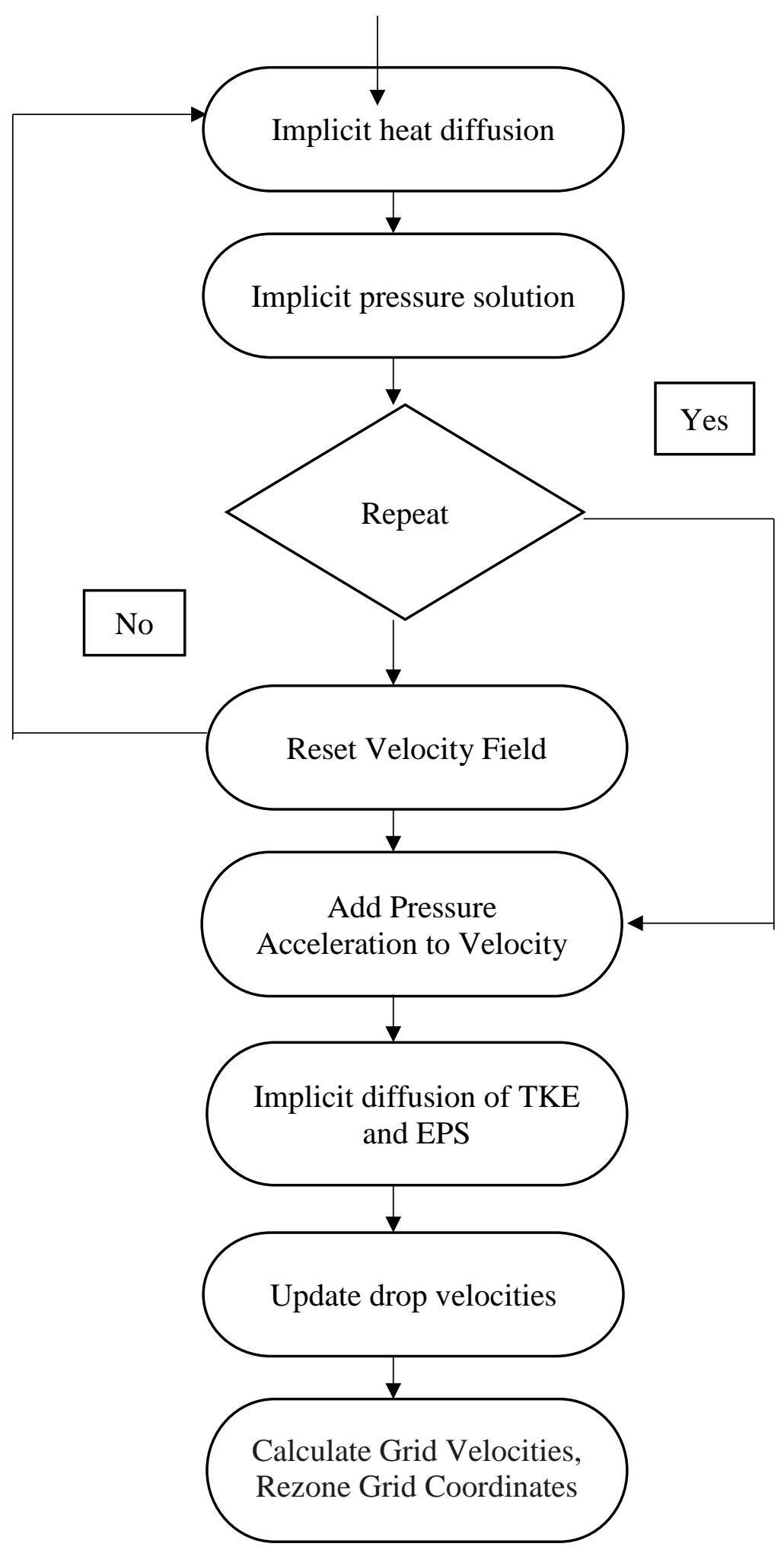




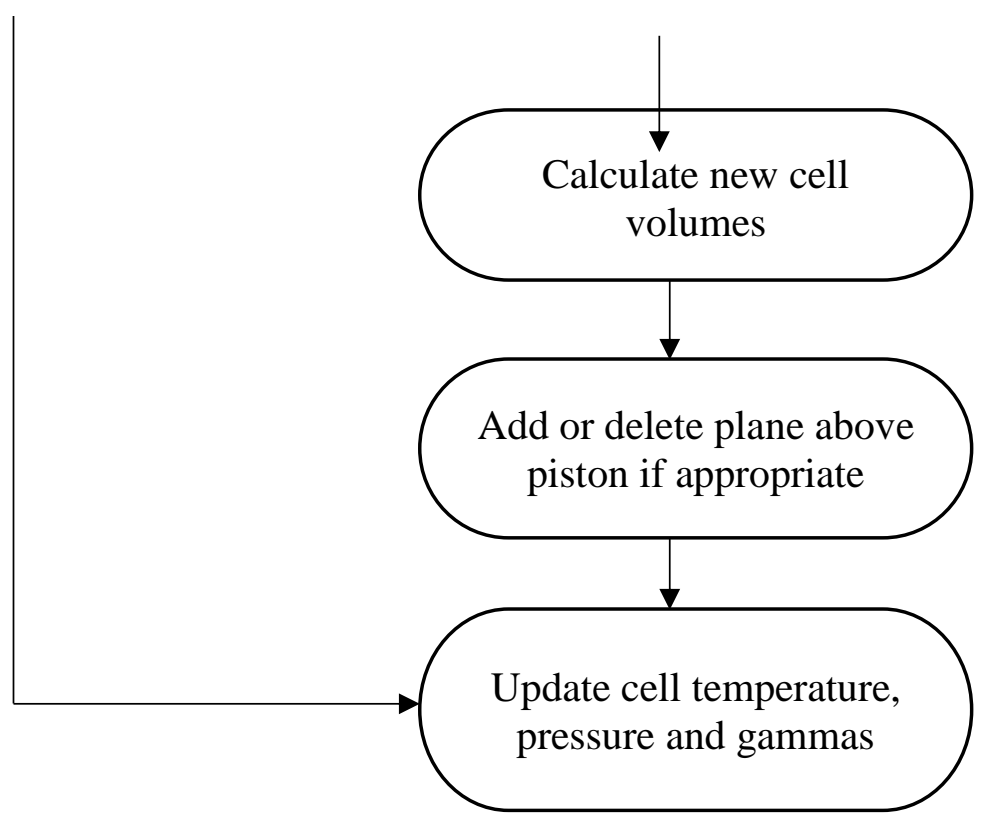

Figure 2-4. General KIVA code structure [47] 


\section{Background}

Auto-ignition is a fuel oxidation process that leads to rapid energy release without being initiated by any external ignition source. A temperature at which spontaneous ignition occurs is called auto-ignition temperature. Chemical reactions involved in hydrocarbon oxidation can be categorized broadly as chain initiation, chain propagation/branching, and chain termination reaction. Formation of radicals from a stable reactant is chain initialization reaction. Chain branching reactions are the reactions in which two or more reactive radicals are produced from each radical consumption. Chain termination reactions result in stable products consuming radicals.

In kinetically-controlled combustion, as a temperature of fuel-air mixture increases, chain branching reactions accelerates since a rate of reactions is exponentially dependent on the temperature. As a rate of chain branching reaction increases, a number of radicles being produce increases as well. When rate with which radicles are produced becomes sufficiently high, the reaction rate becomes extremely fast, rapidly releasing heat energy. The reaction rate and subsequently, heat release rate of auto-ignition is heavily dependent on the temperature, pressure and equivalence ratio of the fuel-air mixture. Excessive heat release rates in burning of premixture charge in an engine result in high a pressure rise rate that damages the engine.

One way to avoid steep pressure rise rates while controlling the timing of auto-ignition in LTC engines is to use fuel and/or thermal stratification. Mixture stratification is basically creating local zones with equivalence ratio gradient inside the combustion chamber that allow gradual ignition of mixtures. Thermal stratification, which results from wall heat transfer and flow convection in the cylinder [66], helps to achieve higher efficiency with lower PRR. However, manipulating thermal distribution inside the cylinder is difficult. On the other hand, mixture stratification can be achieved and controlled relatively easy, and thus is getting more attention. Fuel distribution inside the chamber is highly dependent on ignition delay which is the time between the start of fuel injection and the start of the combustion. The start of combustion is typically obtained as CA10, the crank angle at which 10 percent of injected fuel is burned. The longer the ignition delay, the more time for fuel to mix with air leading to more uniform mixture.

Auto-ignition delay is a result of various complex chemical, physical and energetic processes that take place during the auto-ignition process. The ignition delays represent the chemistry; the pressure and the heat release represent the power, work, energy and heat involved. The physical events that causes ignition delay involves atomization, vaporization and the mixing of fuel with air. Parameters controlling these processes are engine design, operating conditions, fuel characteristics etc. Atomization is controlled by injection pressure, injector nozzle design (Spray angle, number of holes and diameter), and viscosity of fuel and cylinder pressure. Ambient pressure, temperature, volatility of fuel along with fuel droplet size and distribution affects vaporization heavily. Mixing of an air-fuel is dependent on the arrangement of spray, spray cone angle and penetration length, air flow etc. Chemical part of ignition delay is governed by pre-combustion reactions. Pre- 
combustion reactions are affected by the composition of the fuel, charge temperature and pressure conditions and the physical process of atomization, vaporization, and mixing. In summary, the physical and chemical process leading towards combustion are directly affected by mixture temperature and pressure, equivalence ratio and fuel properties. These process in turn control ignition delay.

Kokjohn et al [97] conducted a constant volume ignition delay calculation illustrating the effect of equivalence ratio and Primary Reference Fuel (PRF) number on ignition delay at constant operating conditions. The change in the combustion characteristics with change in mixture stratification can be explained by the influence of equivalence ratio and fuel reactivity on ignition delay.

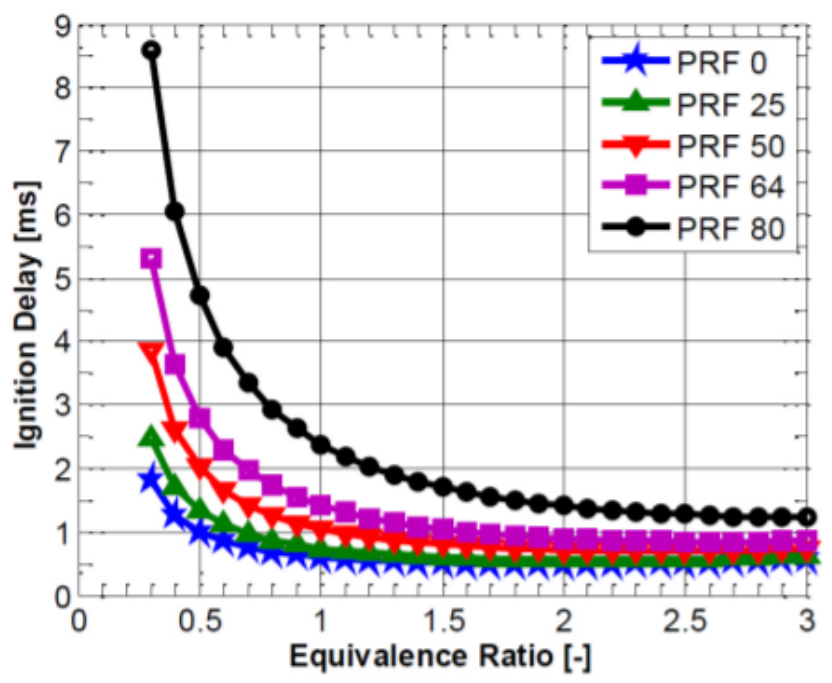

Figure 3.1. Effect of equivalence ratio and reactivity of a fuel on ignition delay in constant volume chamber at constant operating conditions. [97]

From the Figure 3.1 above, we can conclude that for higher equivalence ratio, ignition delay increases with decreasing equivalence ratio for all the fuels with different reactivity. For higher equivalence ratio, ignition delay exhibit much weaker dependence on fuel reactivity and equivalence ratio, nevertheless leaner regions, shows a strong dependence on both. Lower reactive fuel has considerably higher ignition delay for same equivalence ratio than higher reactive fuels.

Sjoberg et al [68] showed that combustion tended to progress from regions of higher equivalence ration to regions of lower equivalence ration. In a combustion chamber for a particular fuel, shortest ignition delay is corresponding to the area of highest equivalence ratio. Temperature increases as rapid heat releases in the auto-ignition pockets. These auto ignition pockets then grow and merge into surrounding reaction zones. As ideal stratification helps to avoid over rich or over lean regions, it helps to increase the combustion efficiency. Not all the fuels inside the combustion chamber undergo auto ignition simultaneously giving lower the maximum pressure rise rates and bulk gas 
temperature. The ideal mixture, therefore, would be stratified in such a way that the minimum local in-cylinder $\phi$ is within flammability limit so combustion can reach completion, and the maximum local $\phi$ in-cylinder is lower to refrain formation of hightemperature pockets so to avoid NOx. In literature several stratification techniques are examined: different GDI injectors, increased swirl, and changes in injection pressure, to determine which parameters are effective for improving the combustion efficiency while maintaining NOX emissions.

When fuel is injected at the early stage of the compression stroke, sufficient time is available for the vaporized fuel to mix the ambient air before reaching the auto-ignition temperature. This increased mixing time, in turn, tends to make the fuel-air mixtures leaner and more uniform, resulting in longer ignition delays. With excessive mixing of fuel and air, the ignition delay tends to become too long to complete the ignition process within available residence time before the charge mixtures are quenched during the expansion stroke. Furthermore, there will also be some pockets of very lean mixtures which are beyond the ignitability limit, resulting into high unburned hydrocarbons and thereby lowered combustion efficiency. On the contrary, when fuel is injected at the late stage of the compression stroke, i.e., near TDC, the compression temperature of the gases is high enough to drive the ignition of the charge mixtures in a short time, hence the injected fuel tends to burn at rich conditions under highly stratified conditions. Reactions under oxygendeficient conditions can lead to incomplete combustion, lowering combustion efficiency. There exist optimal injection timings that enable to achieve high combustion efficiency and they are strongly dependent on the fuel's properties in a given engine.

The spray is known to significantly affect the fuel distribution and thereby combustion and emission processes in GDI engine. During combustion, a spray is simply the introduction of liquid into a gaseous environment through a nozzle such that the liquid, through its interaction with the surrounding gas and by its instability, fuel spray breaks-up into droplets then vaporizes and mixes with ambient air. By optimizing spray characteristics, the engine out emissions from the engine which are mainly NOx and PM can be minimized. Investigations into diesel sprays characteristics have concentrated on the effect of the spray characteristic on engine performance such as the spray tip penetration, break-up length and droplet size and velocity distributions. The injection pressure has a significant effect on spray liquid penetration. The spray tip penetration gets longer as the injection pressure increases. This result is related to both higher quantity and higher velocity of the droplets at higher injection pressures. Proportional to injection pressure, the spray penetrates faster at higher injection pressures. Paper showed that higher injection pressure stimulated the air-fuel mixing process with more effective air entrainment [70]. This effect can be explained by analyzing the diameter of the droplets. The diameter of droplets decreases as injection pressure increases. The smaller droplets from, the higher injection pressure make the spray wider and rounder, and because of little momentum, the spray composed with the small droplets bents and mixes with air by intake flow more smoothly. As a result, it can be said that the higher injection pressure confers a benefit for the spray quality concerning smaller droplets and homogeneous mixture. [70] 
Inlet charge temperature is one of the critical parameters to control and improve autoignition. The rise in the inlet charge temperature is not only used to improve fuel vaporization but also to accelerate the overall kinetics. Thermal energy is directly related to the motion at a molecular level. At higher temperature, molecules move faster and the probability that two molecules will collide is higher. Higher the number of a collision, higher the chances of rearrangement of molecular structure. Overall improvement in the rate of reaction can be explained mathematically with the help of the Arrhenius equation of kinetics

$K=A * \exp ^{\left(-E_{a} / R * T\right)}$

Here $\mathrm{K}$ is a rate coefficient, and $\mathrm{A}$ is a preexponential constant, $\mathrm{E}_{\mathrm{a}}$ is the activation energy, $\mathrm{R}$ is the universal gas constant, and $\mathrm{T}$ is the temperature in Kelvin. Apparently as per the equation rate coefficient is a function of $-\left(\mathrm{E}_{\mathrm{a}} / \mathrm{RT}\right)$. The hence larger magnitude of $\mathrm{K}$ (faster reaction) can be achieved by lower activation energy and higher temperature.

Ignition delay is affected by the physical process such as atomization and vaporization and pre-combustion chemical reactions. Because of more efficient vaporization and accelerated chemical reactions, increase in the charge temperature lowers the ignition delay. Thus, high inlet air temperature can be said to advance the start of combustion. Reduced ignition delay/earlier beginning of combustion can undoubtedly be useful for more advanced injection timing to avoid over mixing. Apart from reduced ignition delay, there are other advantaged of increased charge temperature as well. Higher charge temperature promotes the fuel in a lean region to undergo combustion. And it also helps in the completion of delayed reactions such as conversion of $\mathrm{CO}$ to $\mathrm{CO}_{2}$ thereby increasing combustion efficiency. On the other hand, higher ambient temperature nurtures spontaneous combustion of fuel in the rich region instead of sequential combustion leading to an increase in the peak cylinder temperature thereby increasing NOx formation and giving higher PRR. Exhaust Gas Recirculation (EGR) is one of the well-known and effective methods to reduce engine-out NOx. In this process percentage of exhaust gases are recycled using a control valve from the exhaust to intake system. Recycled exhaust gases dilute the unburned mixture thus increasing heat capacity overall. Higher heat capacity prevents an increase in the absolute temperature reached after heat release during combustion. Lower the temperature, lower the NOx formation. Hence NOx amount varies inversely with EGR fraction. However, there is an adverse effect of a high percentage of EGR. Rate coefficient mathematically explained by Arrhenius equation of kinetics strongly depends upon ambient temperature. Reduction in temperature reduces the value of $\mathrm{K}$ (see equation 3-1) and therefore slows down all combustion reactions. In other words, residence time is higher for greater EGR fraction. Extremely reduced temperatures then cause lowered hydrocarbon burnup increasing UHC in the exhaust. All these adverse effects limit the EGR fraction to be used. Crossing the limits for EGR fraction can cause partial combustion or even misfire. In this study, the composition of EGR is kept constant. It is the composition of exhaust gas for the baseline condition. The fraction of EGR is raised to lower NOx at the exhaust valve opening. It is also interesting to see how fuels with different reactivity react to different EGR percentage. 


\section{Result and Discussion}

\subsection{Baseline Operating Condition}

In the baseline case conditions, efforts were made to achieve idea fuel stratification for all three fuels by manipulating ignition delay. Let's discuss the injection timing sweep results for three fuels. Figure 4-1 shown below compares combustion efficiency for all three fuels.

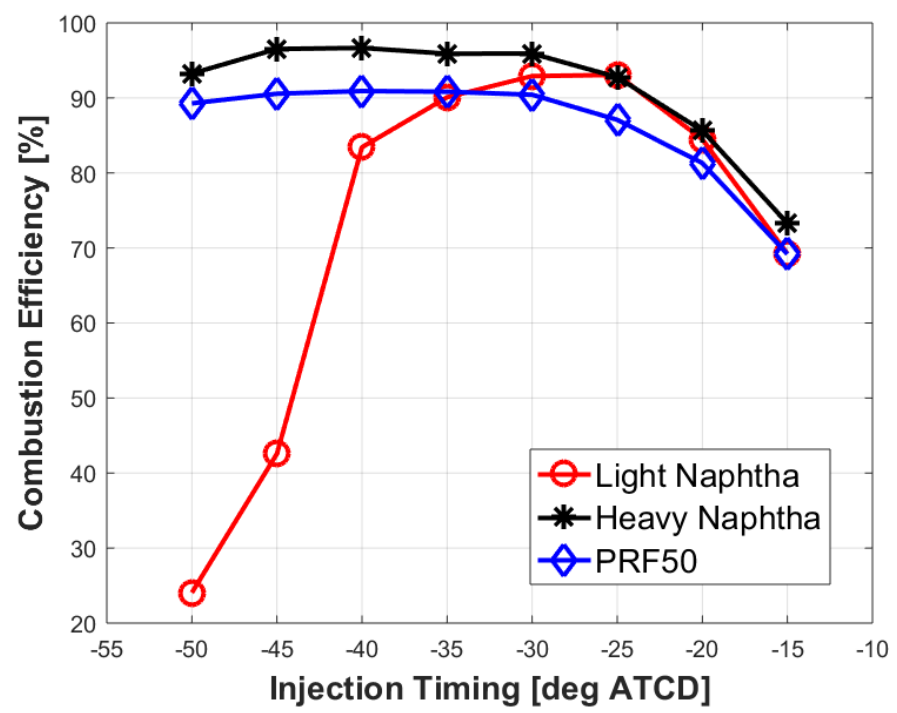

Figure 4-1. Comparison of predicted combustion efficiency at various injection timings using three fuels

Heavy naphtha and PRF50 show a similar trend for change in combustion efficiency for this injection timing sweep. Combustion efficiency first increases as injection timing advances from TDC, it then remains constant. For more advanced injection timings, combustion efficiency for heavy naphtha and PRF50 also shows a decreasing trend. For light naphtha combustion efficiency first increases and then starts to drop immediately. For increasing combustion efficiency trend, the rate with which combustion efficiency is increasing is highest for light naphtha. Between injection timings (-15 to -35 deg ATDC) all three fuels have comparable combustion efficiency. Whereas for injections earlier than -40 deg atdc in the compression stroke, light naphtha gives very low combustion efficiency. Heavy naphtha has the highest combustion efficiencies for all injection timing sweep at 400 Bar injection pressure.

As pointed out above, the dropping tend of combustion efficiency for late injections is due to lack of mixing time, while it is attributed to over-mixing for early injections. However, it is seen that the efficiency drop with advance of injection timing starts at different injection timings for the three fuels. For light naphtha, the case with injection timing of $35 \mathrm{deg}$ ATDC already shows a significant drop of combustion efficiency, whereas for heavy naphtha and PRF50 it occurs with SOI=-50 deg ATDC. As mentioned earlier, 
ignition delay has a major effect on the mixture preparation inside the chamber and hence combustion efficiency trends can be better explained with the help of ignition delay values.

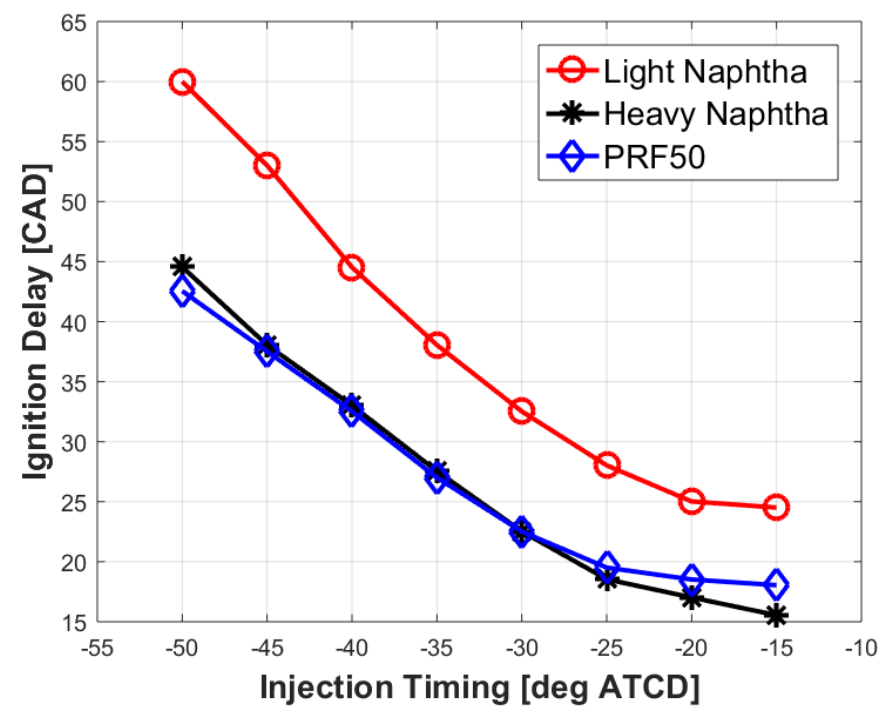

Figure 4-2. Comparison of predicted ignition delay at various injection timings using three fuels

Figure4-2 shown above gives the ignition delay for different injection timing all the fuels. Ignition delay increases for all the fuels as injection timings are advanced. Evidently, light naphtha has longest ignition delay for all injection timings. Heavy naphtha and PRF50 has very similar values over the entire injection timing sweep.

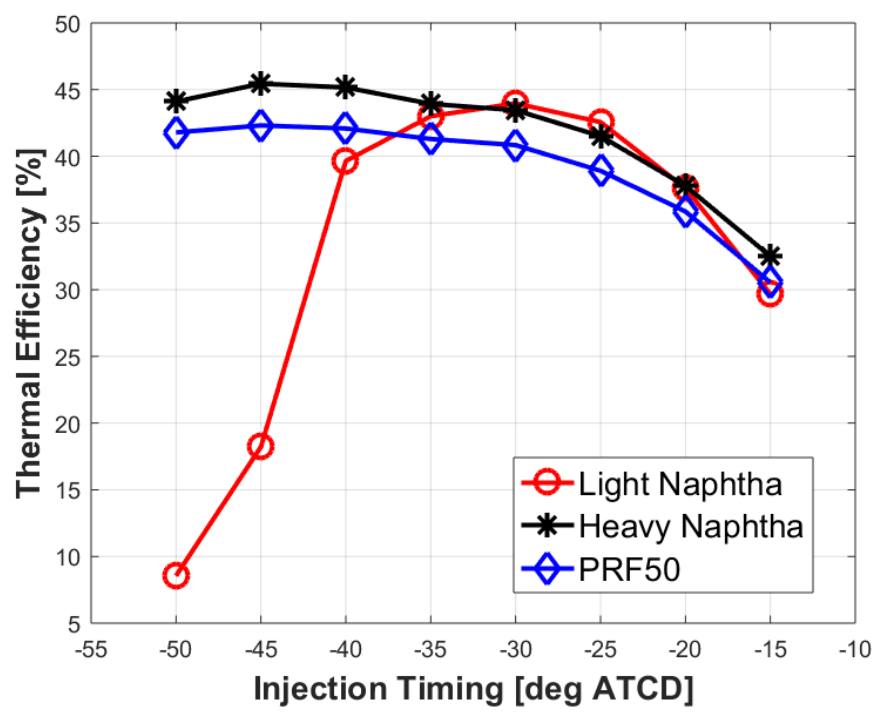

Figure 4-3. Comparison of predicted thermal efficiency at various injection timings using three fuel 
Increasing ignition delay with advancing injection timings from TDC is expected as fuel is injected into colder ambient gases. Longer ignition delay shown by light naphtha can be explained can be explained as the fuel properties effects. Light naphtha has the lowest reactivity (cetane number) among three fuels however heavy naphtha and PRF50 shows similar reactivity. Because of lower reactivity (or less propensity to auto-ignite), light naphtha has longer ignition delay for given injection timing.

Thermal efficiency depends upon multiple factors, for example, the cumulative amount of heat released (e,g., CA50), heat losses to the cylinder, ports and valve walls. Figure 4-3 compares thermal efficiency for all three fuels over the injection timing sweep.

For later injection timings (-15 to $-30 \mathrm{deg}$ ATDC), light naphtha shows the highest rate for increasing thermal efficiency. As injection timings further advances thermal efficiency drops rapidly in light naphtha case similar to the combustion efficiency (see Figure 4-1). Heavy naphtha always maintains higher thermal efficiency with respect to PRF50 pertaining to its higher cetane number. Table 4-1 shows the maximum thermal efficiency and injection timing at which it is obtained

Table 4-1. Maximum combustion efficiency and corresponding injection timing for three fuels

\begin{tabular}{|c|c|c|}
\hline Fuel & Maximum Thermal Efficiency & Injection Timing \\
\hline Light Naphtha & 43.96944 & $\operatorname{deg}$ ATDC \\
\hline Heavy Naphtha & 45.44343 & -30 \\
\hline PRF50 & 42.31255 & -45 \\
\hline
\end{tabular}

As expected light naphtha has maximum thermal efficiency at later injection timing as compared to those of heavy naphtha and PRF50. Heavy naphtha is predicted to have higher thermal efficiency which is consistent with the trend of combustion efficiency see in Figure 4-1.

LTGC/HCCI combustion engine operation is often limited by maximum pressure rise rate (PPR) since acoustic oscillations in the cylinder gases induced by high pressure rise rates can result in audible engine knock. If this phenomenon is not controlled, it can result in unacceptable noise levels and potentially, engine damage. The acceptable knock limit for LTGC engines is often defined in terms of a maximum allowable PRR in bar/ ${ }^{\circ} \mathrm{CA}$.

Figure 4-4 indicates maximum pressure rise rates for injection timing sweep. Maximum pressure rise rate was obtained by averaging three highest sequential values measured with a 0.5 deg crank angle interval. 


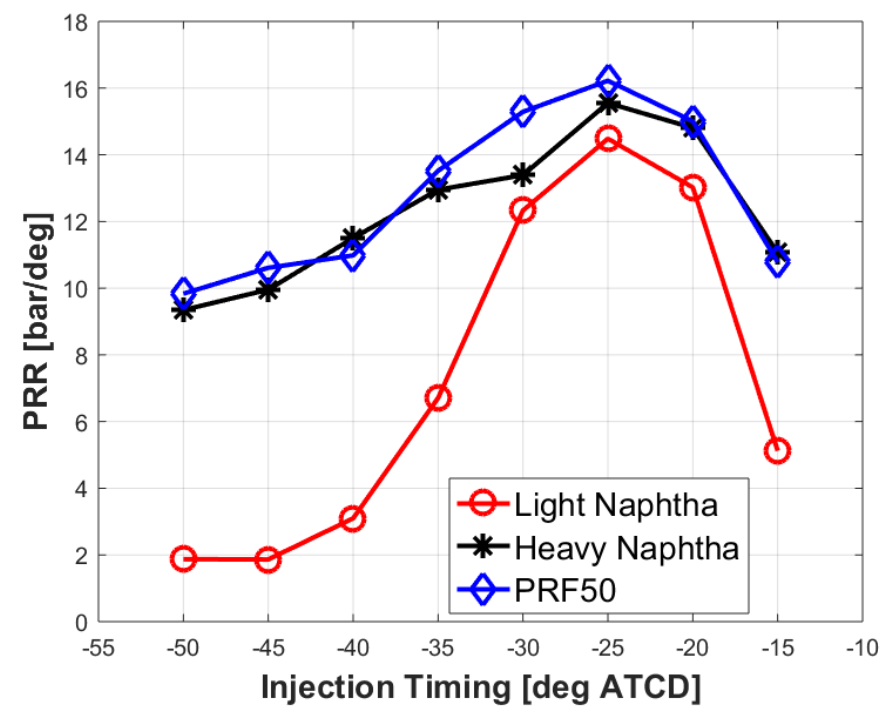

Figure 4-4. Comparison of predicted PRR at various injection timings for three fuels

PRR is affected by premixed combustion and combustion phasing (e.g, CA50). All three fuels show similar pressure rise rate trend similar to the trend of combustion efficiency. Light naphtha is predicted to have lowest PRR over a sweep, whereas PRF50 has highest. The increasing trend for all three fuels is expected as combustion efficiency is increasing. Decreasing trend of PRR in case of light naphtha at injection timings earlier than $-40 \mathrm{deg}$ ATDC is purely due to drop in combustion efficiency. However, a decreasing trend of PRR despite having higher combustion efficiency is the indication of better stratification inside the combustion chamber. Figure 4-5 compares NOx at the EVO for all fuels.

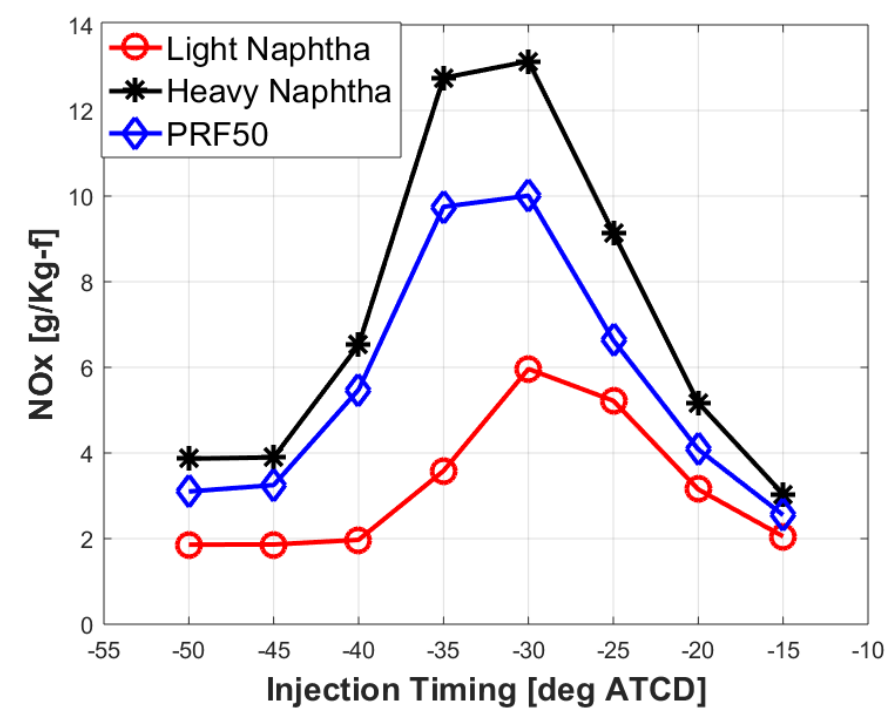

Figure 4-5. Comparison of predicted NOx at various injection timings for three fuels 
All three fuels show the same trend over an injection timing sweeps (see Figure 4-5) and have a maximum amount of NOx at injection timing -30 deg ATDC. Heavy naphtha has highest value of NOx whereas light naphtha has lowest. NOx formation requires oxygen and high temp (approx. $>1200 \mathrm{~K}$ ). Lower combustion temperatures result in NOx reduction due to the high activation energy of NO formation reactions. Lesser values of NOx earlier than -40 deg ATDC injection timing in the light naphtha can be explained by low combustion efficiency and thereby due to lower average temperature. However decreasing values of NOx for fuels at injection timings with higher combustion efficiency indicates that even though good combustion is achieved, the regional temperature remained low preventing the formation of NOx. This confirms LTC operating conditions.

Another important emission to look into is the carbon monoxide. Sweet spot behavior for CO (see Figure 4-6) observed by kook et al [29] for conventional CI engine can be seen here as well. For heavy naphtha and PRF50, amount of CO first decreases and then tend to increase with advance in injection timing. Whereas Light naphtha gives very drastic changes of $\mathrm{CO}$ over the range of injection timings. For all three fuels decreasing trend of $\mathrm{CO}$ at later injection timings indicates the improvement in the combustion quality of fuels due to stratification achieved. An increasing trend of $\mathrm{CO}$ exhibits the reduction in combustion efficiency because of over mixing of fuel. These changes are more pronounced for light naphtha because of its extreme values of combustion efficiency.

As expected trends of unburned hydrocarbon emissions for all three fuels are an exact flip of the combustion efficiency trend and shown in Figure 4-7. Higher the combustion efficiency lowers the UHC emissions. As light naphtha predicted to have lower combustion efficiency at earlier injection timings, UHC for these timings are higher.

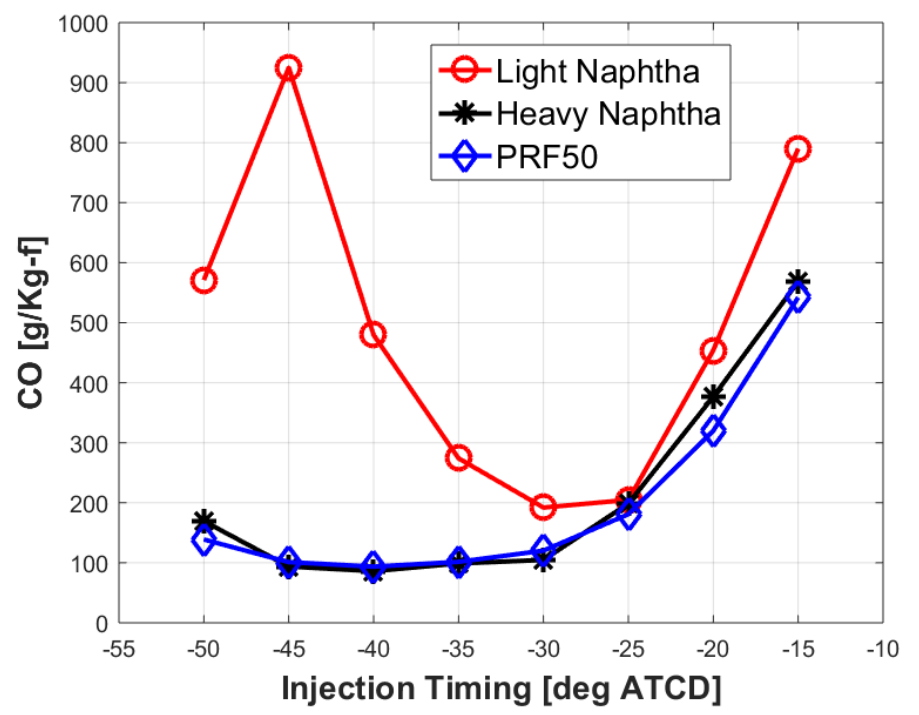

Figure 4-6. Comparison of predicted $\mathrm{CO}$ at various injection timings for three fuels 


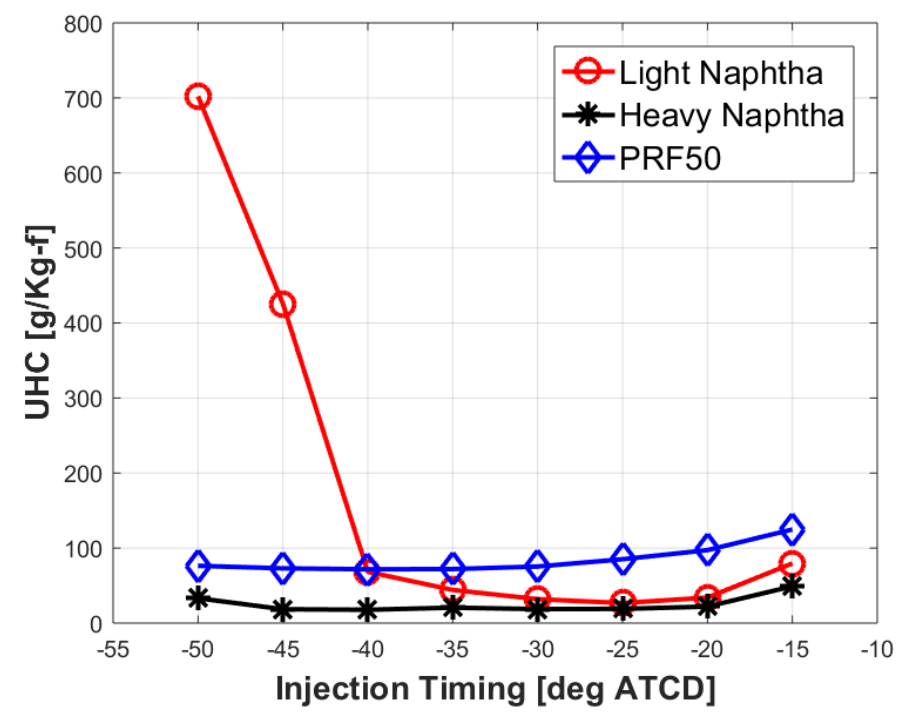

Figure 4-7. Comparison of predicted UHC at various injection timings for three fuels

The decrease for $\mathrm{CO}$ in case of light naphtha between -45 and $-50 \mathrm{deg}$ ATDC injection timings combined with decreasing combustion efficiency and increased UHC indicates that overall conversion of a hydrocarbon to $\mathrm{CO}$ has itself reduced giving less amount $\mathrm{CO}$ at the EVO. By comparing particular injection timing, we can further describe interdependency of ignition delay, combustion efficiency, and fuel properties. Table 4-2 gives some important numbers to compare. At injection timing $-25 \mathrm{deg}$ ATDC, light Naphtha has maximum combustion as well as thermal efficiency despite having lowest reactivity among three fuels, followed by heavy naphtha and PRF50. While the trend for PRR is exact reverse to the combustion efficiency. PRF50 has maximum PRR. In terms of emissions, maximum $\mathrm{CO}$ is formed in case of light naphtha. PRF50 has maximum UHC and heavy naphtha has maximum NOx at EVO.

Table 4-2. Predicted combustion characterstics at -25 deg ATDC injection timing

\begin{tabular}{|c|c|c|c|}
\hline & Light Naphtha & Heavy Naphtha & PRF50 \\
\hline Combustion Efficiency (\%) & 93.07 & 92.77 & 87.08 \\
\hline Ignition Delay (CAD) & 28.03 & 18.54 & 20.05 \\
\hline Thermal Efficiency (\%) & 42.56 & 41.51 & 38.92 \\
\hline PRR (bar/deg) & 14.48 & 15.53 & 16.22 \\
\hline CO (g/Kg-f) & 204.76 & 198.70 & 180.28 \\
\hline UHC (g/Kg-f) & 26.75 & 18.959 & 85.12 \\
\hline NOx (g/Kg-f) & 5.22 & 9.1 & 6.63 \\
\hline
\end{tabular}




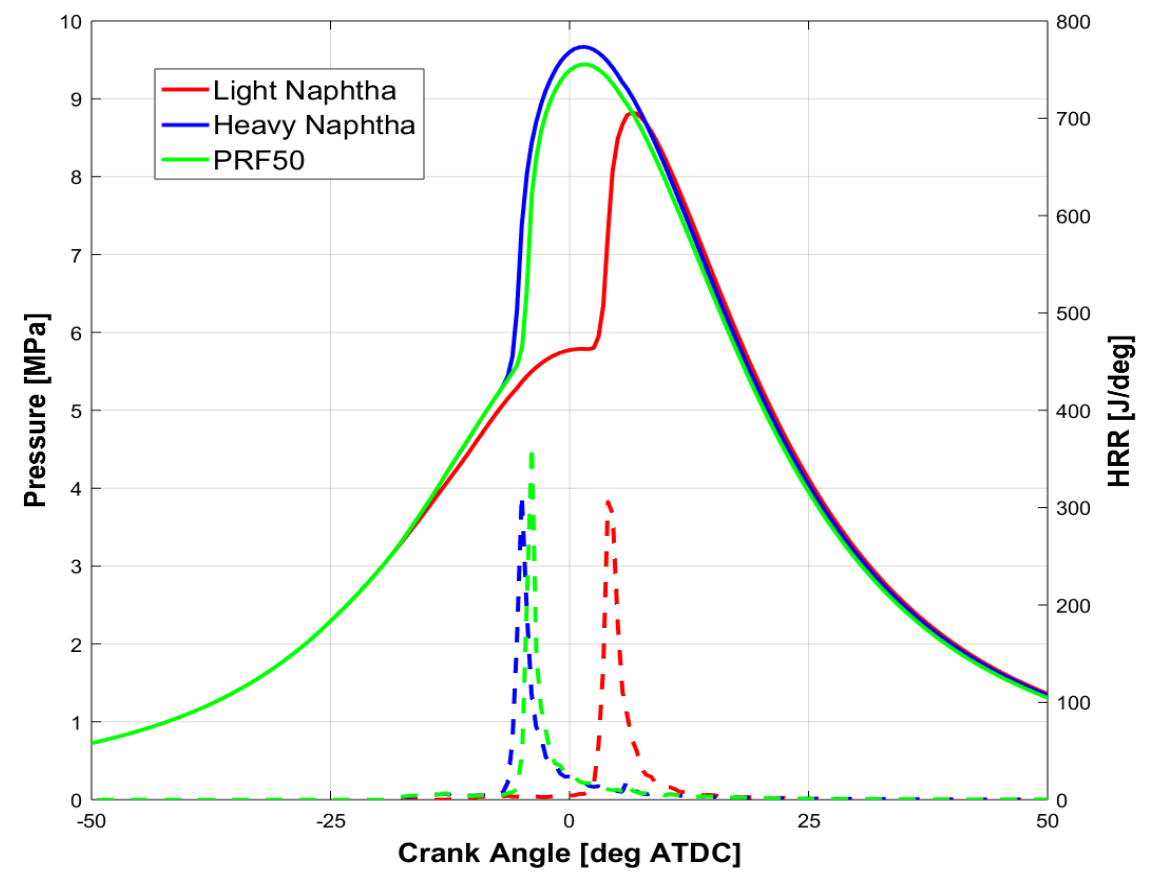

Figure 4-8. Comparison of predicted pressure and HRR at -25 deg ATDC injection timing

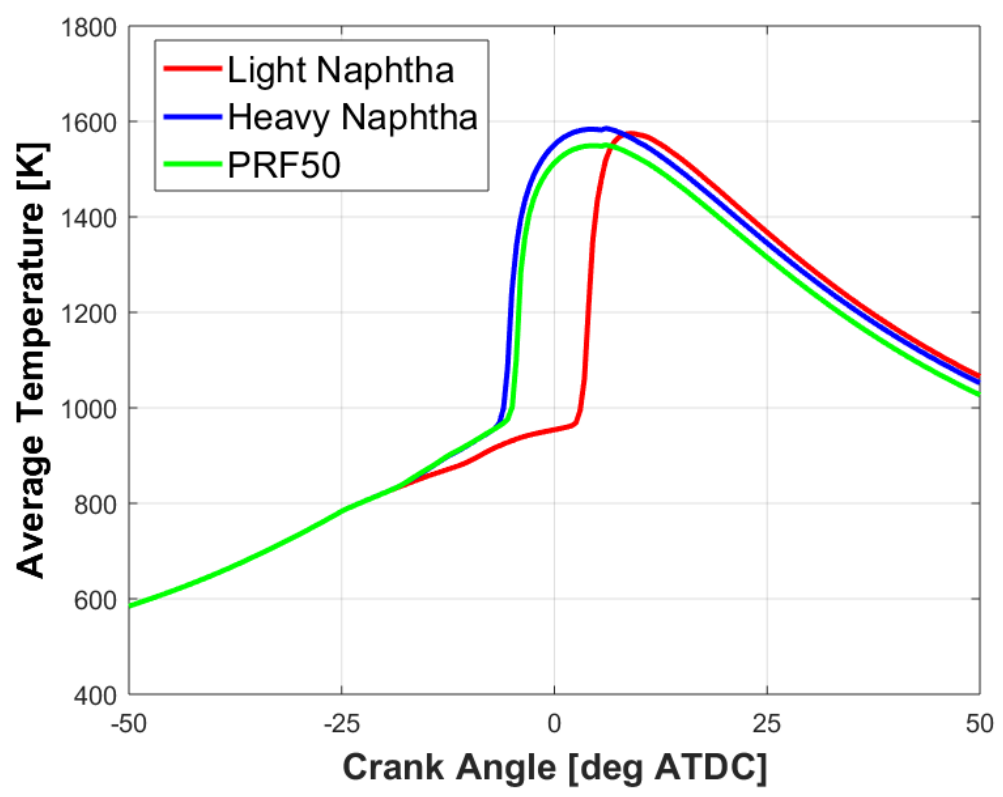

Figure 4-9. Comparison of predicted average temperature at $-25 \mathrm{deg}$ ATDC injection timing 
Figure 4-8 compares pressure and HRR trends for three fuels. Heavy Naphtha and PRF50 show earlier start of combustion. PRF50 has less peak and expansion pressure compared to heavy naphtha resulting into lower combustion as well as thermal efficiency. For HRR profile, PRF50 has the shortest combustion duration where light naphtha has longest. Distinguishable cold flame cannot be seen in either of the fuels.

For same injection timing, average temperature trend given by heavy naphtha and PRF50 starts separate from that of light naphtha earlier indicating an advanced start of combustion due to higher reactivity (ref Figure 4-9).

Vaporization of fuel at this condition is taking place almost at the same rate even though there is variation in the volatility of fuels (see Figure 4-10)

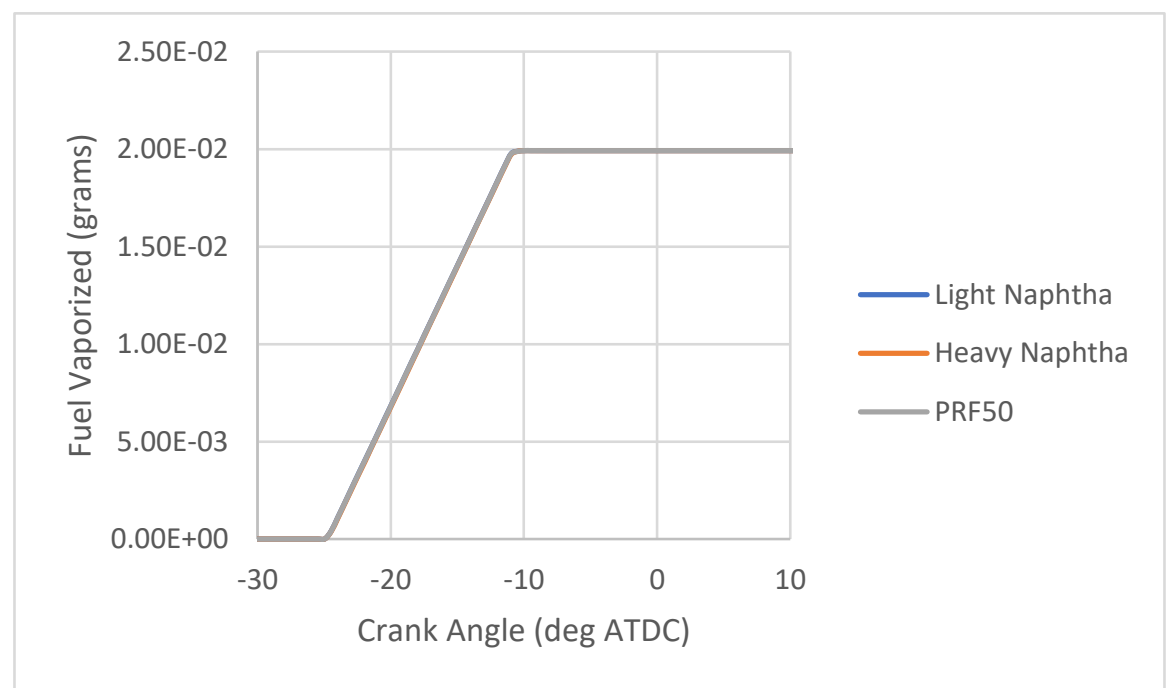

Figure 4-10. Comparison of predicted vaporization rate at -25 deg ATDC injection timing

Ambient pressure and temperatures inside the combustion chamber are sufficient to vaporize all three fuels completely before the start of combustion.

To get an idea how fuel is distributed inside the combustion chamber let's take a look at $\mathrm{Y}=0$ plane. Contours presented in Figure 4-11 are local equivalence ratio. It is not necessary that the start of combustion is always from the rich region located in this plane. These snips are taken at one crank angle deg earlier than start of combustion.

Numerically, heavy naphtha has richest equivalence ratio within the combustion chamber equal to approx. 4.34. For PRF50 and light naphtha, a value of maximum equivalence ration in the chambers are approximately 3.5 and 2.14 respectively. Steep pressure rise, shorter combustion duration, high amount of $\mathrm{CO}$ for all three fuels indicate that ideal stratification was not achieved at this operating condition. Out of three fuels studied, the higher value of combustion efficiency combined with less PRR obtained by light naphtha combustion suggests that light naphtha has more equivalence ratio gradient that other two 
fuels. Equivalence ratio distribution is shown below for three fuels indicate that there is a rich packet of air-fuel mixture near the injector for all three cases.

a)

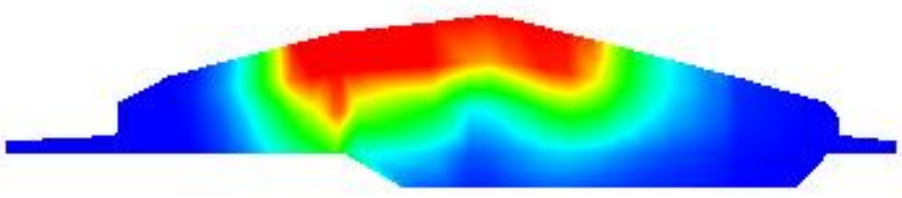

b)

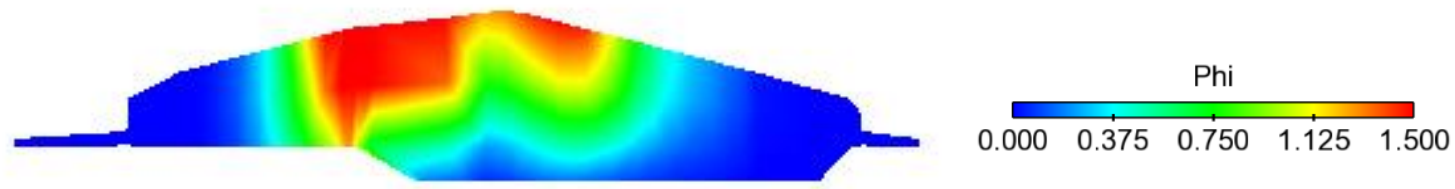

c)

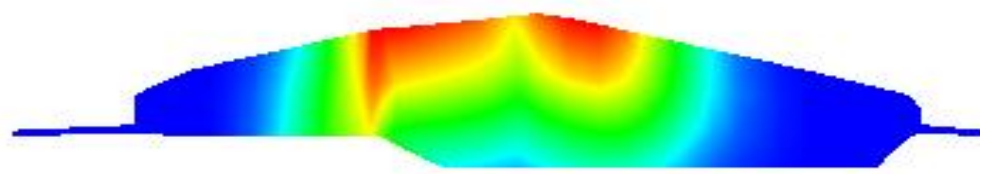

Figure 4-11. Predicted equivalence ratio distribution at -25 deg ATDC injection timing a) heavy naphtha at -6 deg ATDC b) PRF50 at -3 deg ATDC and c) light naphtha at 3 deg ATDC

Since temperature distribution in the cylinder is not much affected by vaporization event of these fuels, ignition delay is solely dependent on fuel reactivity. Light naphtha with the lowest reactivity has longest ignition delay followed by PRF50 and heavy naphtha. Longer ignition delay for light naphtha gives more time for the in-cylinder flows and turbulence (i.e., mixing not produced by the injection process) to form lean regions by transporting fuel out of the main fuel pockets that are generated by the fuel-injection process. As a result, there is more stratification results highest combustion efficiency and lowest PRR. For heavy naphtha, ignition delay is shortest thus not allowing more stratification in the chamber. Entire rich region goes under combustion simultaneously giving steeper PRR. Since its rich combustion, lack of oxygen prevents $\mathrm{CO}$ to $\mathrm{CO}_{2}$ reaction, and thus overall combustion efficiency drops as well. For PRF50 case, average ignition delay between light and heavy naphtha can be seen. That means some fuel does move from rich to a lean area, but lean regions are hugely dilute and below flammability limits resulting into the high amount of UHC and lowering combustion efficiency. Start of combustion near TDC explain highest PRR. Thermal efficiency depends upon the amount of fuel burned and 
combustion phasing. In the case of light naphtha, combustion in power stroke helps to increase thermal efficiency. On the other side, SOC in compression stroke for heavy naphtha and PRF50 cases does affect their thermal efficiency. Even though light naphtha has higher combustion efficiency, the vast amount of $\mathrm{CO}$ indicates that most of the combustion is incomplete. Lean regions of stratified combustion chamber have too low combustion temperatures results into quenching the bulk-gas reactions (particularly COto- $\mathrm{CO}_{2}$ reactions) by the expansion before reaching completion. $\mathrm{CO}$ value for heavy naphtha and PRF50 combustion lies in the same area as that of light naphtha. However, lack of oxygen in the over-rich combustion results into incomplete combustion. Higher UHC for PRF50 case indicates that combustion did not sustain beyond the rich packages because of its lower reactivity. The smaller amount of UHC for heavy naphtha case demonstrates that very less stratification occurred. Amount of NOx formed in globally lea $\mathrm{n}$ combustion depends only on in-cylinder temperature. Heavy naphtha case has highest incylinder temperature because of earlier start of combustion in the compression stroke, and hence predicts to has highest NOx as well. This indicates that more time is needed for sufficient mixing to occur, so no rich NOx-producing regions are present at the time of combustion.

Table 4.3 give combustion characteristics of three fuels when injected at -45 deg ATDC. Light naphtha case has the lowest quality of combustion resulting into poor combustion efficiency. Heavy naphtha and PRF50 cases maintains higher combustion efficiency (> 90\%) with PRR equal to or less than 10 Bar per deg. Thermal efficiency reflects the same trend as of combustion efficiency. Emissions at EVO for light naphtha case indicates incomplete combustion (higher amount of $\mathrm{CO}$ and UHC). On the other hand, for heavy naphtha and PRF50 fuels, lower CO and UHC means complete combustion. The difference in the combustion quality for fuels can be easily identified in the Figure 4-12. Well stratified mixture in case of heavy naphtha and PRF50 shows a long tail ensuing from the peak of the HRR because the prolonged late-combustion reactions (including $\mathrm{CO}$ to $\mathrm{CO}_{2}$ burnout). This is due to the low $\phi$ and the resulting low combustion temperature. For light naphtha case, the small rise of pressure in the expansion stroke can be seen with very minimal heat release throughout the compression and power stroke.

Table 4-3. Predicted combustion characteristics at -45 deg injection timing

\begin{tabular}{|c|c|c|c|}
\hline & Light Naphtha & Heavy Naphtha & PRF50 \\
\hline Injection Timing (deg ATDC) & -45 & -45 & -45 \\
\hline Combustion Efficiency (\%) & 42.57 & 96.5 & 90.56 \\
\hline Ignition Delay (CAD) & 53.00 & 38.05 & 37.51 \\
\hline Thermal Efficiency (\%) & 18.22 & 45.4 & 42.313 \\
\hline PRR (bar/deg) & 1.86 & 9.96 & 10.61 \\
\hline CO (g/Kg-f) & 924.67 & 93.75 & 100.90 \\
\hline UHC (g/Kg-f) & 425.63 & 18.47 & 72.98 \\
\hline NOx (g/Kg-f) & 1.86 & 3.90 & 3.25 \\
\hline
\end{tabular}




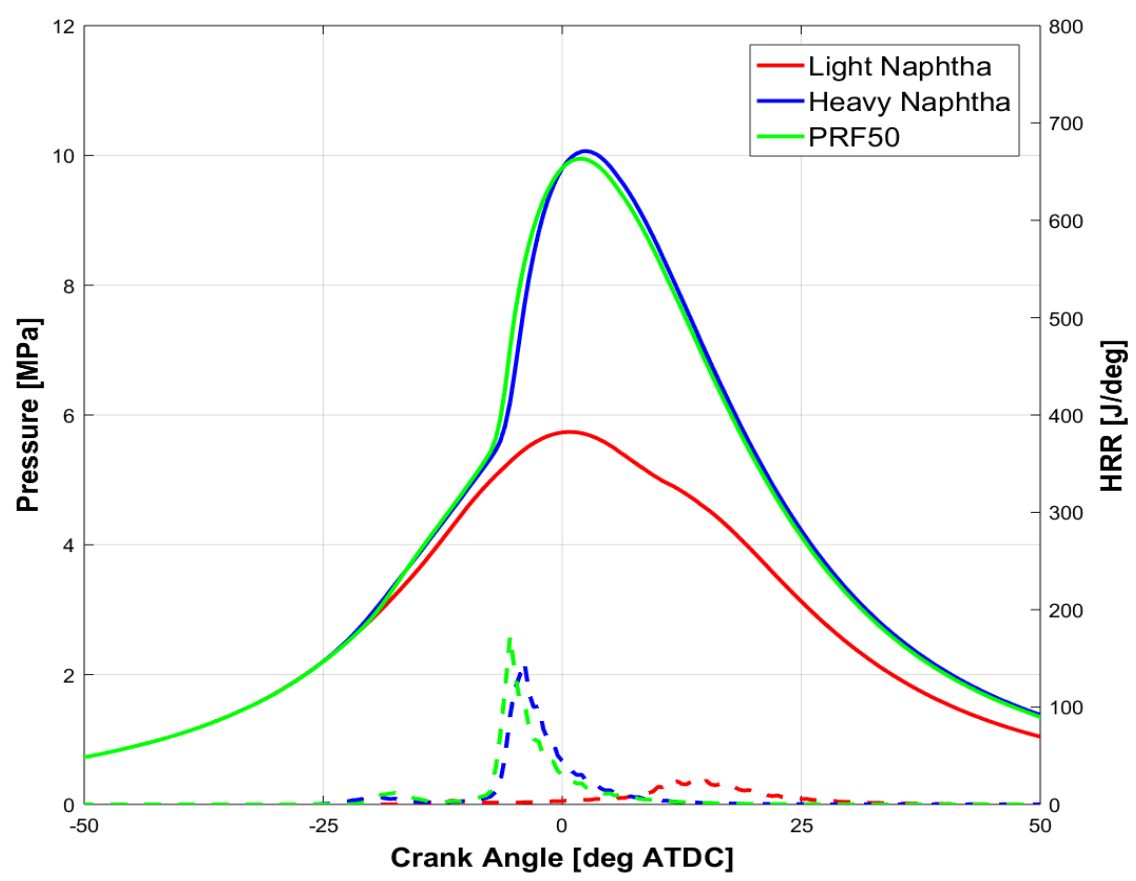

Figure 4-12. Comparison of predicted pressure and HRR at -45 deg ATDC injection timing

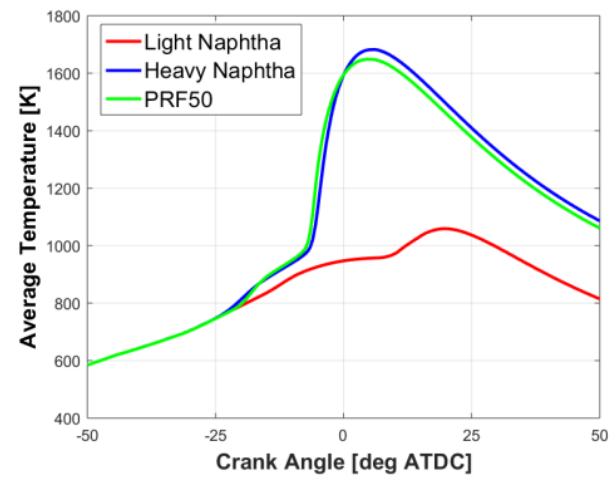

a)

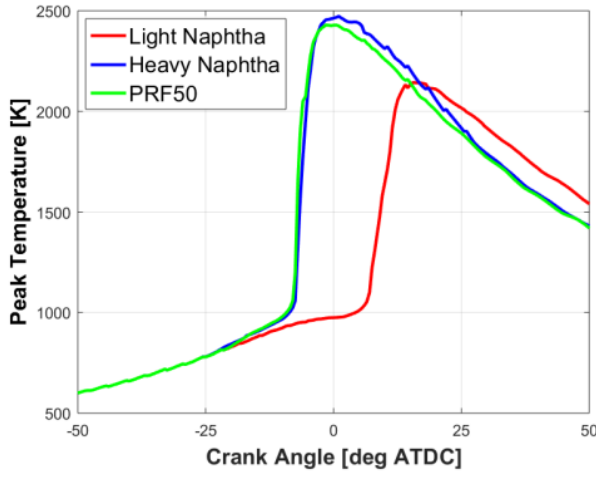

b)

Figure 4-13. Comparison of predicted a) average Temperature b) peak temperature at -45 $\operatorname{deg}$ ATDC injection timing 
For heavy naphtha and PRF50 cases, peak average temperature in the combustion chamber is higher (ref Figure 4-13). However light naphtha combustion shows peak temperature equal to $2100 \mathrm{~K}$, however average temperature at the same time is very less. Its predicted that in case of the light naphtha very small packet of fuel goes under the combustion whereas the entire remaining combustion chamber is cold.

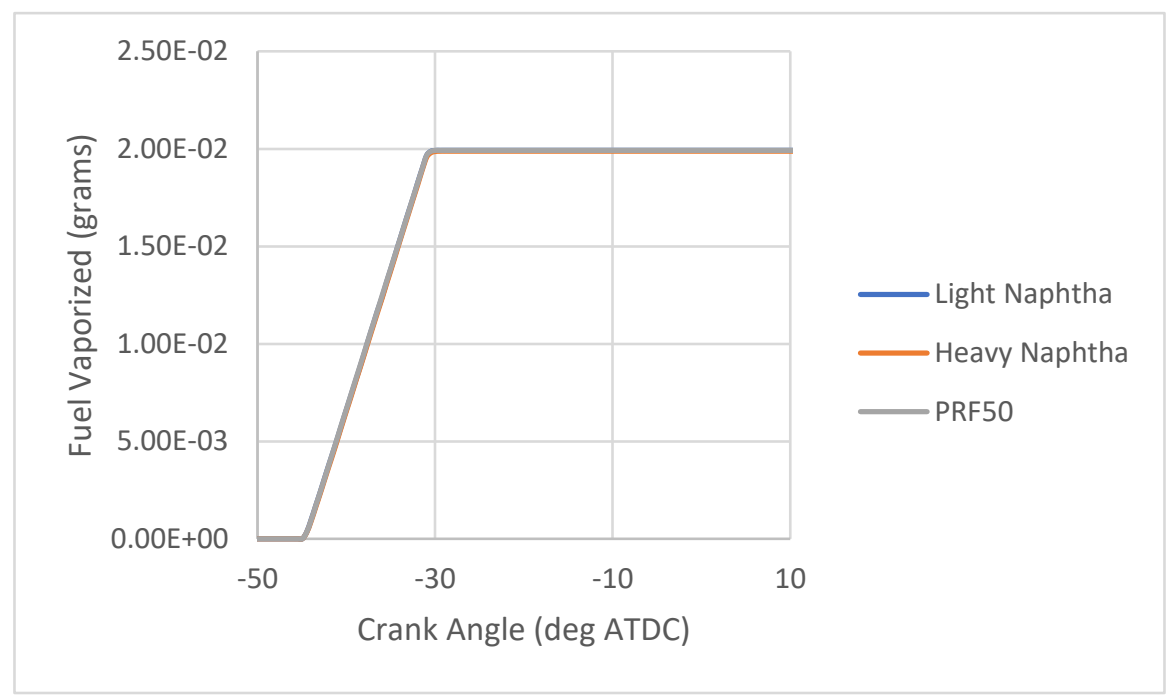

Figure 4-14. Comparison of predicted vaporization trend at -45 deg ATDC injection timing

Despite having different volatility, ambient conditions are enough to vaporize all the fuels as soon as it enters the combustion chamber (see Figure 4-14). All the fuels are well vaporized before the SOC. At this operating condition, special inhomogeneity of the fuel distribution is likely the dominant mechanism controlling the rate of energy released.

Equivalence ratio distribution in Figure 4-15 shows this special inhomogeneity inside the combustion chamber just before the start of combustion for each case. For the operating condition studied here, all three fuels are vaporized well before SOC hence thermal stratification introduced by injection process is very minimal. Also, since all three fuels are injected at same timing, temperature distribution is similar for all cases. As a result, spatial inhomogeneity is dominant parameter controlling combustion. All these cases see fuel moving away from the center of the chamber. In case of light naphtha, fuel cloud is clearly divided into two. 
a)

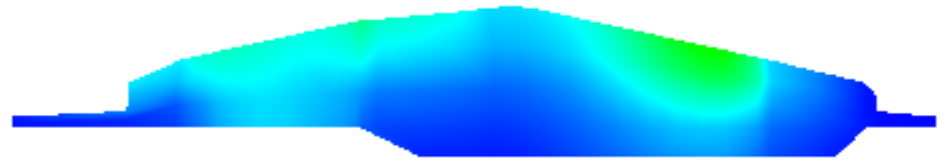

b)

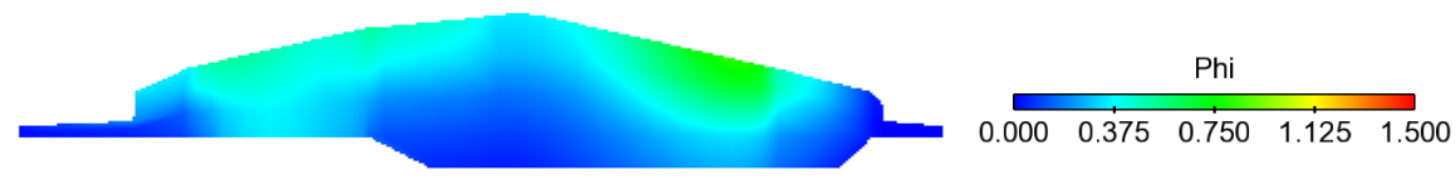

c)

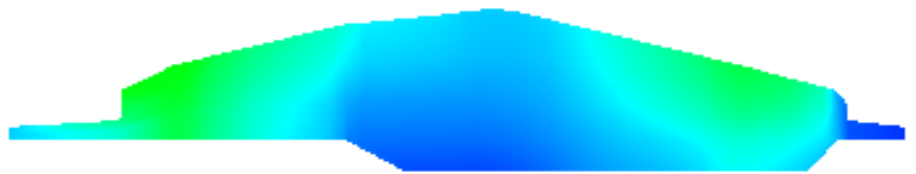

Figure 4-15. Predicted equivalence ratio at -45 deg ATDC injection timing a) heavy Naphtha ta -6 deg ATDC b) PRF50 at -6 deg ATDC c) Light Naphtha at 8 deg ATDC

Swirl created inside the chamber which directs airflow from bowl to head is dividing the fuel region into two. More the ignition delay more distinctive areas can be seen. This separation creates more lean mixture resulting in lower combustion efficiency. This air flow enhances mixing giving lean regions at the center of the combustion where temperatures are higher and rich regions near the wall where temperatures are lower. Such distribution retards start of combustion.

Figure 4-16 shows formation fuel distribution in the combustion chamber. 
a)

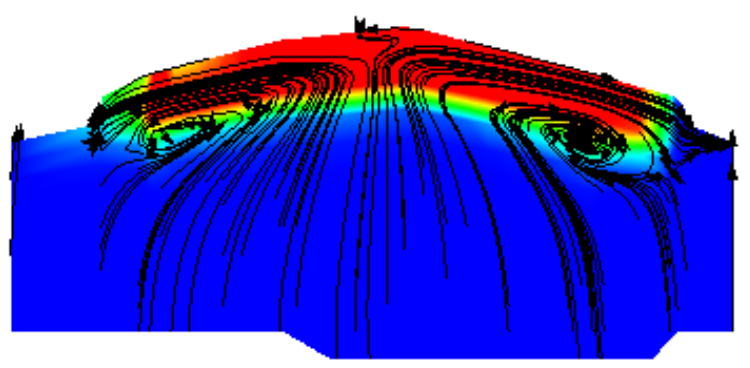

b)
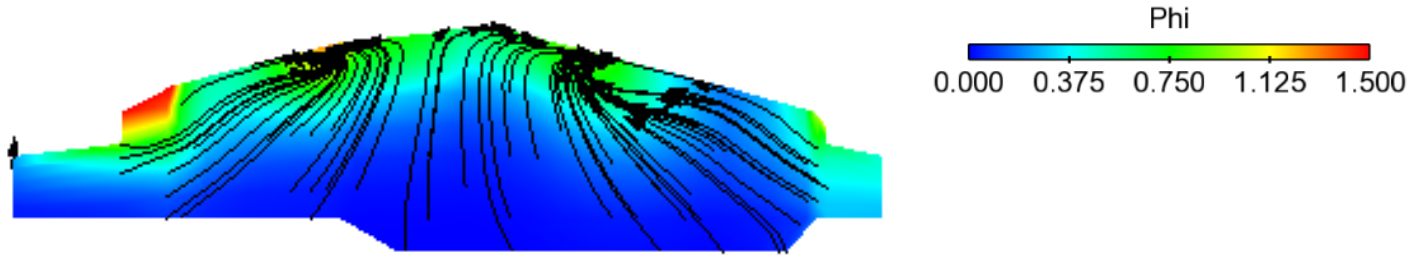

c)

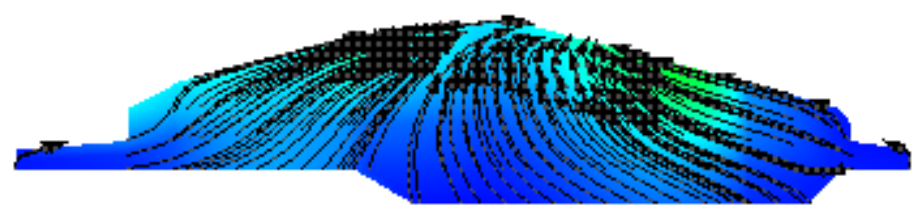

Figure 4-16. Predicted fuel distribution in-cylinder combustion chamber at a) -40 deg ATDC b) -20 deg ATDC and c) -10 deg ATDC

It will be interesting to compare these three fuels for similar ignition delay operating conditions. Heavy naphtha and PRF50 when injected at -45 deg ATDC and light naphtha injected at -35 deg ATDC has similar ignition delay.

Table 4-4 gives the combustion results for three fuels. Despite having almost similar ignition delay for all three fuels, heavy naphtha has substantially higher combustion efficiency than other two fuels. Heavy naphtha also dominates thermal efficiency. However light naphtha has lower PRR which can be explained by combustion phasing and the smaller value of combustion efficiency. The higher $\mathrm{CO}$ for light naphtha indicated that in some regions of combustion chamber air-fuel mixture is hugely dilute resulting into low combustion temperature. Hence late combustion reactions cannot reach completion. 
Combination of lower combustion efficiency, higher PRR and higher UHC indicates that ignition delay is not enough for PRF50 to achieve better stratification

Table 4-4. Predicted combustion characteristics for same ignition delay using three fuels

\begin{tabular}{|c|c|c|c|}
\hline & Light Naphtha & Heavy Naphtha & PRF50 \\
\hline Injection Timing (deg ATDC) & -35 & -45 & -45 \\
\hline Combustion Efficiency (\%) & 90.08 & 96.5 & 90.56 \\
\hline Ignition Delay (CAD) & 38.05 & 38.05 & 37.51 \\
\hline Thermal Efficiency (\%) & 43.00 & 45.4 & 42.313 \\
\hline MPRR (bar/deg) & 6.71 & 9.96 & 10.61 \\
\hline CO (g/Kg-f) & 273.51 & 93.75 & 100.90 \\
\hline UHC (g/Kg-f) & 44.2 & 18.47 & 72.98 \\
\hline NOx (g/Kg-f) & 3.58 & 3.90 & 3.25 \\
\hline
\end{tabular}

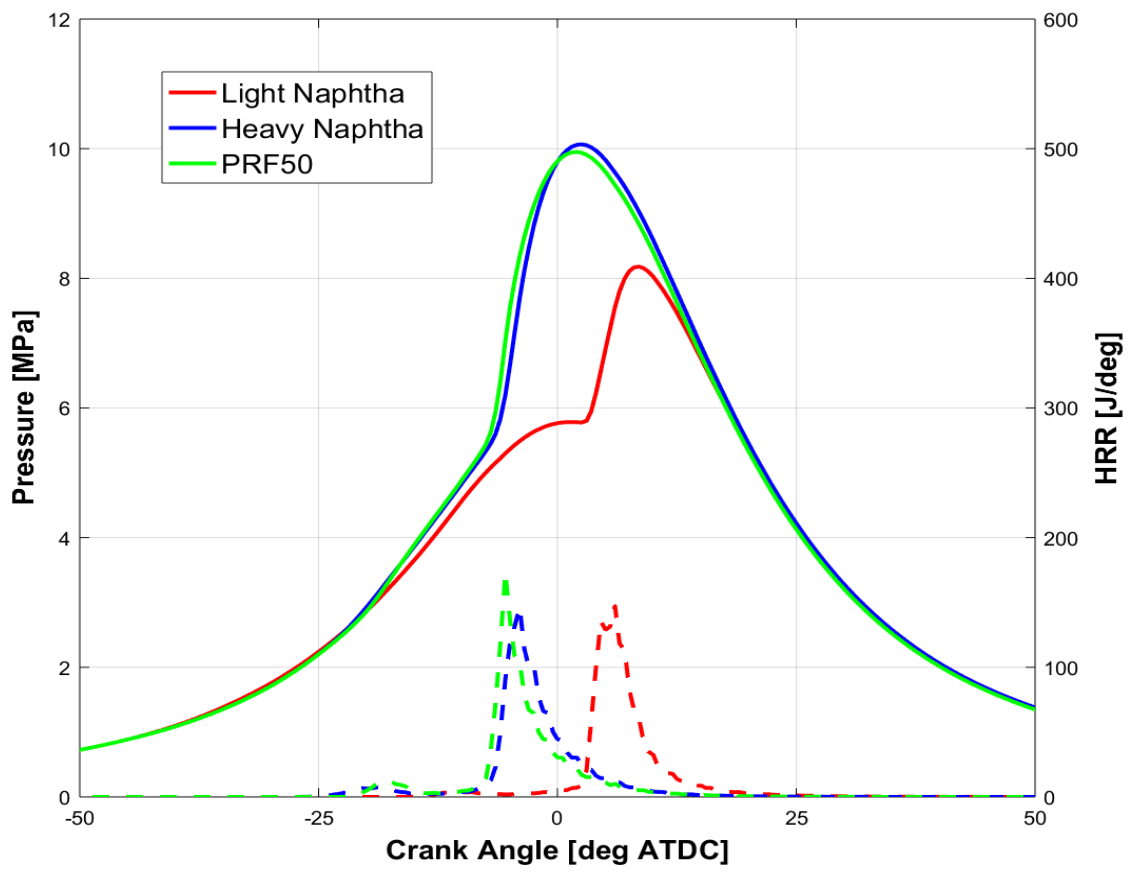

Figure 4-17. Comparison of predicted pressure and HRR for similar ignition delay using three fuels

Figure 4-17 gives pressure traces for all three fuels for similar ignition delay. Start of combustion for Heavy naphtha and PRF50 are in compression stroke whereas for light naphtha is within the expansion stroke. Pressure peak is higher for heavy naphtha followed by PRF50 and light naphtha. Looking at the heat release rate diagram, no fuel shows steep 
heat release rate, indicating that stratification of some sort has been achieved inside the chamber.

For the same ignition delay, let's take a look at the equivalence ratio distribution for all three fuels (see Figure 4-18). In case of light naphtha, maximum equivalence ratio inside the chamber is approximately 1.7. The same value of heavy naphtha and PRF50 is 2 and 1.9 respectively. For light naphtha, within the same ignition delay, more mixing has been achieved. Higher volatility and less molecular weight (in comparison with the remaining two fuels) can be used to explain this observation.

Figure 4-19 gives vaporization for three fuels and show similar rate.

In all three cases resulting in spatial in homogeneities cause the charge to auto-ignite sequentially starting with the richest region, which substantially slows the combustion heat release rate (HRR) compared to an entirely homogeneous charge. Since the gradient of equivalence ratio is different for heavy naphtha and light naphtha, combustion characteristics are different as well resulting into the different value of emissions.

a)

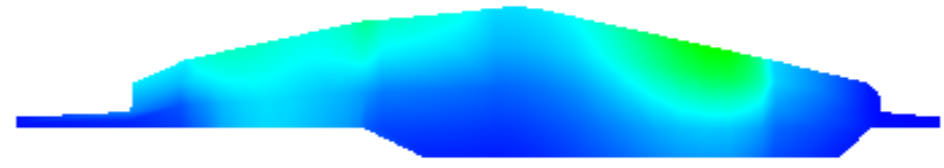

b)

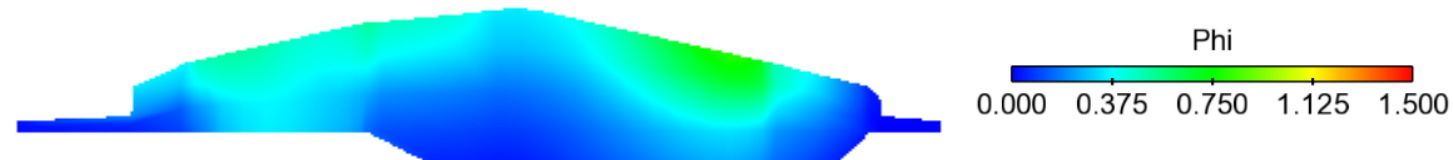

c)

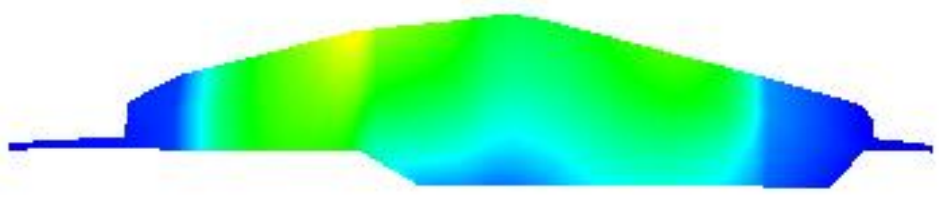

Figure 4-18. Predicted equivalence ratio distribution a) Heavy Naphtha at -6 deg ATDC b) PRF50 at -6 deg ATDC and c) Light Naphtha at 4 deg ATDC 


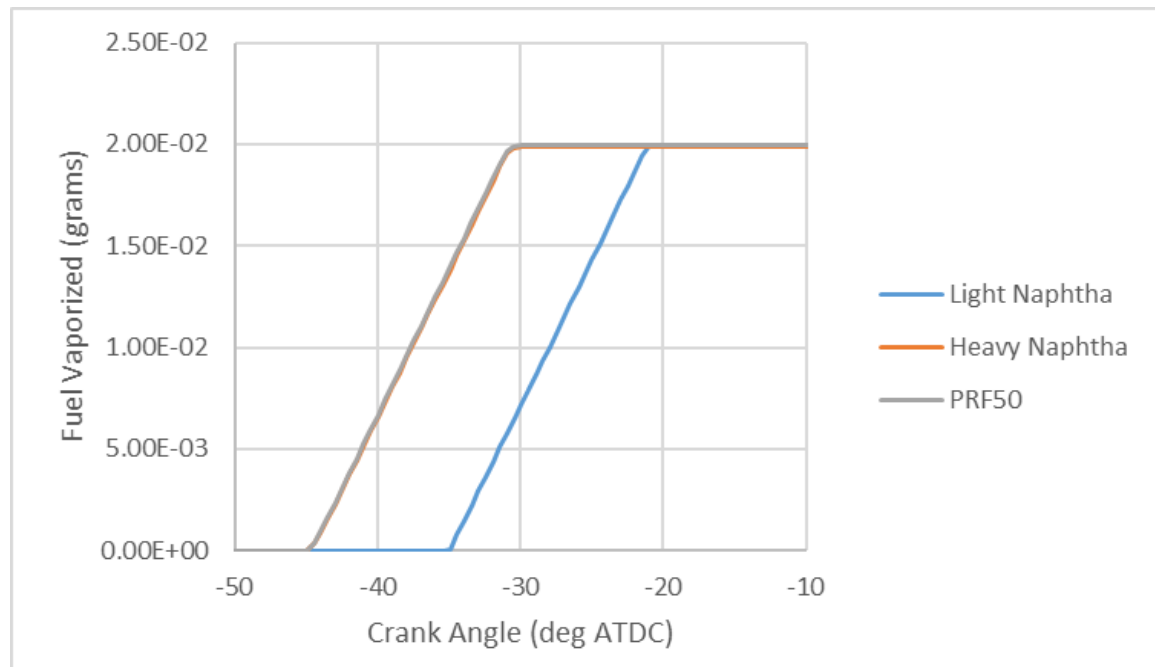

Figure 4-19. Comparison of predicted vaporization trend for similar ignition delay

To study how injection timing dominates the fuel distribution and thereby combustion characteristics let's take a look at cases where single fuel is injected at different injection timings. Two injection timings (-15 deg ATDC and $-45 \mathrm{deg}$ ATDC) are selected for further analysis of combustion efficiency trend for heavy naphtha. Table 4-5 gives essential result values for both simulation cases.

Table 4-5. Predicted combustion characteristics for injection timing -15 deg ATDC and -45 deg ATDC

\begin{tabular}{|c|c|c|}
\hline & Case A & Case B \\
\hline Injection Timing (deg ATCD) & -15 & -45 \\
\hline Combustion Efficiency (\%) & 73.3 & 96.5 \\
\hline Ignition Delay (CAD) & 15.55 & 38.05 \\
\hline Thermal Efficiency $(\%)$ & 32.5 & 45.4 \\
\hline PRR (bar/deg) & 11.06 & 9.96 \\
\hline CO (g/Kg-f) & 568.39 & 93.75 \\
\hline UHC (g/Kg-f) & 49.06 & 18.47 \\
\hline NOx (g/Kg-f) & 3.04 & 3.90 \\
\hline
\end{tabular}

The only difference between case A and B is the injection timings. Regarding efficiency, case A has low combustion as well as thermal efficiency. It is curious that despite having a lower combustion efficiency case, A has higher PRR. Case B has lower CO, and UHC emissions. NOx values are higher for case B. Figure 4-20 shows the pressure and heat release rate trends for both cases for compression and expansion strokes. If we look at the heat release rate profile, a duration for which heat is released is higher for case B. For case A HRR profile is a straight line with the smaller length which indicates that pre-mixed fuel undergoes combustion, though combustion did not sustain afterward. As a result of which peak cylinder pressure for case $\mathrm{A}$ is also low compared to case B. Cold flame for case A 
has also been seen. Figure 4-21 represents peak and average temperature profile which helps to explain reasons behind the variation in the combustion characteristics. Figure 421 a) on the left indicates the average temperature for an entire combustion chamber whereas the figure 4-21 b) at right gives peak temperature values at each crank angle. Smaller dip in the average temperature for case B with injection timing - 45 deg ATDC can be explained with the help of evaporation phenomenon of fuel. Liquid fuel injected absorbs heat from ambient gas for the evaporation causing temperature drop in the ambient temperature. The higher peak temperature and lower value of average temperature for Case A indicates that only a small part of the mixture within the combustion chamber has the very high temperature concerning the remaining cold chamber. This also proves that for case A, combustion is concentrated in a small region and overall oxygen in the chamber is not being utilized effectively. Ignition delay is affected by overall ambient conditions and physical, chemical properties of the fuel. Here for case B, fuel is injected in colder ambient conditions. Thereby more time was taken by case B to reach the auto-ignition temperature of the fuel-air mixture.

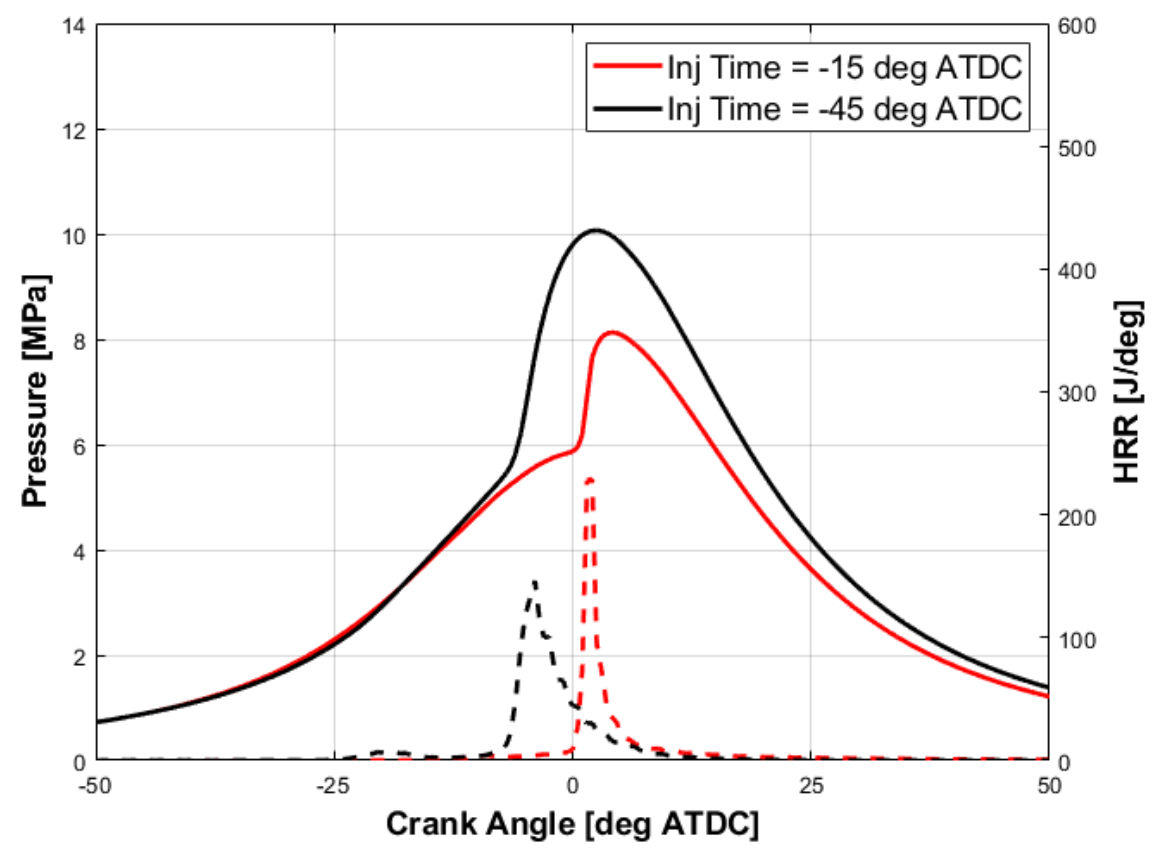

Figure 4-20. Comparison of predicted pressure and HRR for -15 deg ATDC and -45 deg ATDC injection timings 


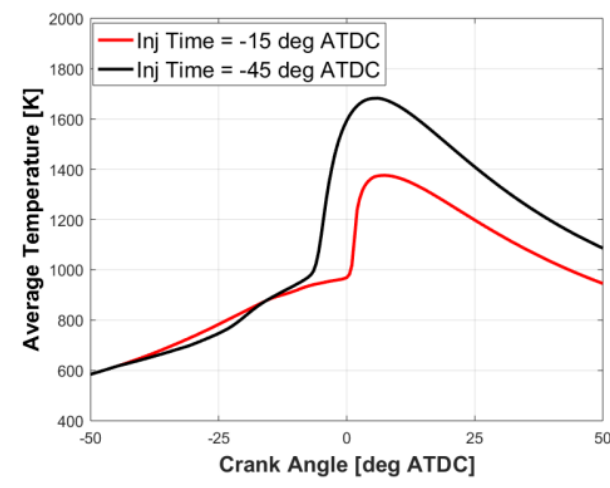

a)

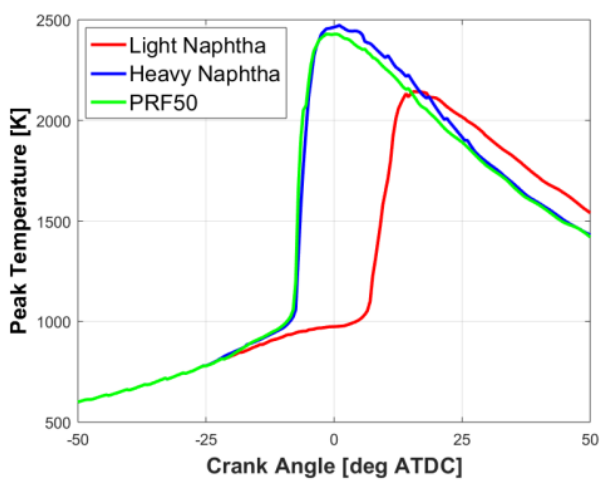

b)

Figure 4-21. Comparison of predicted a) Average Temperature and b) Peak Temperature for -15 deg ATDc and -45 deg ATDC injection timings

Vaporization rate shown in Figure 4-22 indicate that for case A, all the fuel is barely vaporized before the SOC. Hence decidedly less time was available for in-cylinder flows to disintegrate into rich regions.

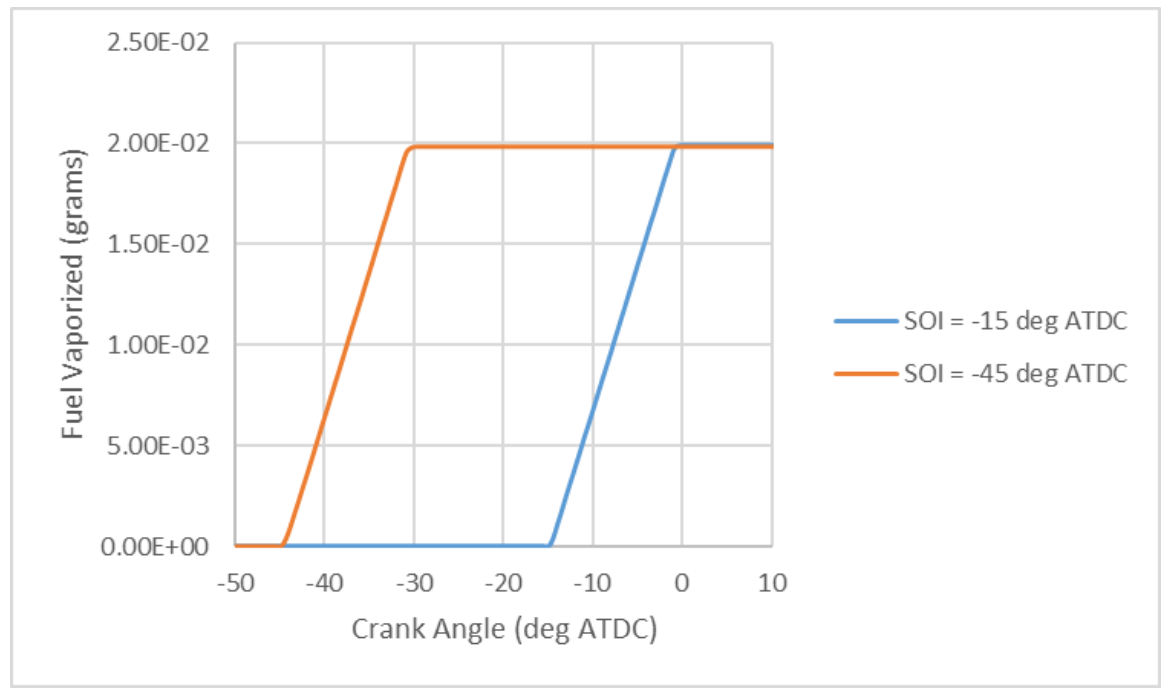

Figure 4-22. Comparison of predicted vaporization rate for $-15 \mathrm{deg}$ ATDC and $-45 \mathrm{deg}$ ATDC injection timing 
a)

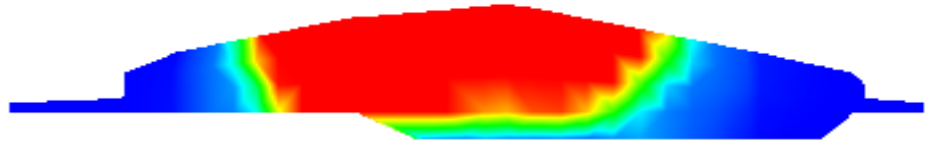

b)
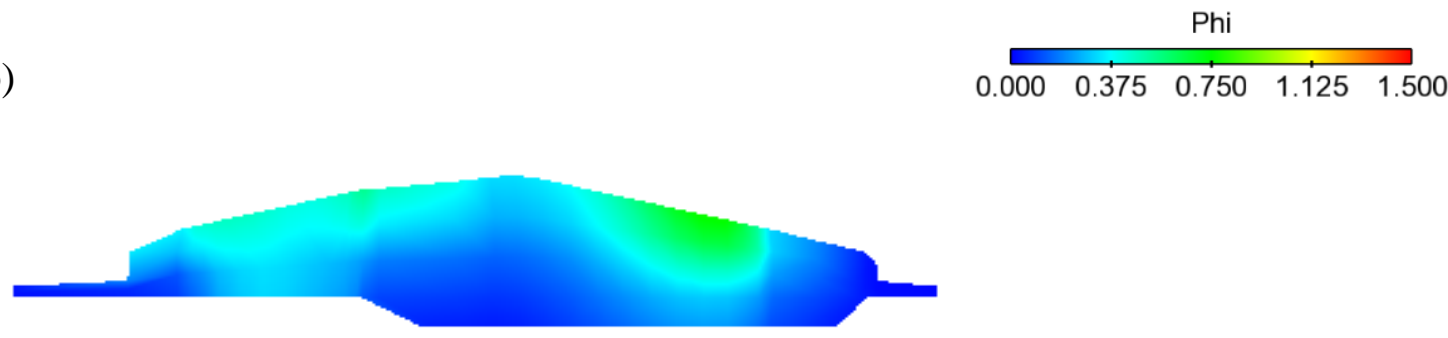

Figure 4-23. Predicted equivalence ratio distribution a) -15 deg ATDC Injection Timing at TDC b) $-45 \operatorname{deg}$ ATDC injection timing at $-6 \operatorname{deg}$ ATDC

With the increase in ignition delay, stratification in the chamber can be indicated by the distribution of equivalence ratio and its given in Figure 4-23. In the case A, all the fuel is trapped in an overly rich region with maximum local $\phi \approx 7.14$ near injector location whereas fuel gradient can be seen in the case $\mathrm{B}$ (local $\phi \approx 2$ ). Spatial inhomogeneity of the fuel distribution is likely the dominant mechanism controlling the rate of energy released. For retarded injection, ignition delay is minimal because of higher temperature and pressure conditions inside the chamber. Shorter ignition delay causes extremely rich fuel to burn. Lack of enough oxygen in the rich pocket of combustion chamber prevents late combustion reactions like a conversion of $\mathrm{CO}$ to $\mathrm{CO}_{2}$ and thereby lowering amount of heat released. High levels of CO, UHC, and NOx at EVO for case A indicates that more time is needed for sufficient mixing to occur, so no rich NOx-producing regions are present at the time of combustion. Rapid heat release in the case $\mathrm{A}$ is the reason of steeper PRR despite having lower combustion efficiency. Since not enough gradient is present for the fuel distribution, the significant amount of fuel undergoes spontaneous combustion giving steep PRR. Oppositely, for case B, advanced injection in the compression stroke provides enough ignition delay to have enough local regions with high $\phi$ that burn hotter, enabling the bulkgas reactions to reach completion and lean regions enough which can sustain the combustion with overall low temperature. Rich areas of the case B have $\phi$ still below $\approx 2$ so that temperature in this region after heat release remains cool enough to avoid the formation of NOx. CO and HC levels are low, and carbon dioxide (CO2) levels are high indicating proper combustion. This example helps to understand how for a particular fuel, the timing at which fuel is injected affects charge composition inside the combustion chamber.

As mentioned before, ideal fuel stratification obtained inside the combustion chamber will initiate sequential auto-ignition giving higher combustion efficiency with lower pressure 
rise rate and lower NOx emissions. For the current study ideal/optimum stratification is defined by combustion characteristics such as combustion efficiency equal to or greater than $90 \%$, PRR equal to or less than $10 \mathrm{bar} / \mathrm{deg}$ and NOx emissions below $5 \mathrm{~g} / \mathrm{kg}$-f. Table 4-6 concludes injection timings for all three fuels which gives the optimum results.

Table 4-6. Optimum combustion cases for three fuels at $400 \mathrm{Bar}$

\begin{tabular}{|c|c|c|c|c|}
\hline Fuel & $\begin{array}{c}\text { Combustion } \\
\text { Efficiency }\end{array}$ & $\begin{array}{l}\text { Injection } \\
\text { Timing }\end{array}$ & NOx & PRR \\
\hline Light Naphtha & 90.08 & -35 & 3.583 & 6.71 \\
\hline Heavy Naphtha & 96.53 & -45 & 3.898 & 9.96 \\
\hline PRF50 & 90.56 & -45 & 3.251 & 10.61 \\
\hline
\end{tabular}

For light naphtha, at baseline operating condition, injection timing -35 deg ATDC gives optimum results, its -45 deg ATDC for heavy naphtha and PRF50. Heavy naphtha has maximum combustion efficiency with acceptable pressure rise rate. As shown in the Figure $4-18$, light naphtha has maximum equivalence ratio of $\approx 1.7$. The same value of heavy naphtha and PRF5 0 is $\approx 2$ and $\approx 1.9$ respectively. It can be concluded that improvements in combustion efficiency are strongly correlated with fuel injection timing for each fuel. For lower reactive fuel, optimum injection timings are more retarded. It can be predicted that with retarded injection, formation of the fuel distribution is dominated by the fuel-injection process, with less time for in-cylinder turbulence to transport fuel out of the main fuel pockets to form overly lean regions. For more reactive fuels like heavy naphtha and PRF50, earlier injection in the compression stroke offers better the combustion quality. The main reason for this is for earlier injection time, longer ignition delay which helps to prevent over rich regions which burn hotter giving high PRR and NOx. Even though light naphtha and PRF50 fits into the criteria of combustion efficiency, PRR and NOx limits, higher values of $\mathrm{CO}$ and $\mathrm{UHC}$ respectively suggest that better stratification can be achieved. Where fuel stratification produced for heavy naphtha, prevents richest regions becoming too rich (avoiding high temperature and thereby NOx) and it also prevents lean regions from becoming overly lean (avoiding incomplete combustion). It is also evident that ideal stratification mentioned earlier varies as fuel reactivity varies. For heavy naphtha, richest regions should have local $\phi=/<2$ to avoid NOx, and the leanest region should have local $\phi$ value as $=/>0.0399$ to prevent the formation of excessive $\mathrm{CO}$ and UHC. The selection of local $\phi=2$ is based on NOx measurements for current operating condition and multi-zone modeling. However, the highest acceptable local $\phi$ depends on several factors, such as combustion phasing, fuel-type, fueling rate, engine speed, EGR/ extra level, and the specific fuel distribution. Therefore, local $\phi=2$ is not a hard limit. Nonetheless, for this study, it offers a numerical insight into how the local gradient is expected. 


\subsubsection{Injection Pressure Variation}

To check the effect of injection pressure on the performance of three fuels, same injection sweep is also done for four more rail pressure values; 200, 300,400,500 and 600 bar.

Table 4-7. Maximum combustion efficiency and respective injection timing for various injection pressure

\begin{tabular}{|c|c|c|c|c|c|c|}
\hline $\begin{array}{c}\text { Injection } \\
\text { Pressure }\end{array}$ & \multicolumn{2}{|c|}{ Light Naphtha } & \multicolumn{2}{c|}{ Heavy Naphtha } & \multicolumn{2}{c|}{ PRF50 } \\
\hline & $\begin{array}{c}\text { Combustion } \\
\text { Efficiency }\end{array}$ & $\begin{array}{c}\text { Injection } \\
\text { Timing }\end{array}$ & $\begin{array}{c}\text { Combustion } \\
\text { Efficiency }\end{array}$ & $\begin{array}{c}\text { Injection } \\
\text { Timing }\end{array}$ & $\begin{array}{c}\text { Combustion } \\
\text { Efficiency }\end{array}$ & $\begin{array}{c}\text { Injection } \\
\text { Timing }\end{array}$ \\
\hline Bar & $\%$ & $\begin{array}{c}\text { deg } \\
\text { ATDC }\end{array}$ & $\%$ & $\begin{array}{c}\text { deg } \\
\text { ATDC }\end{array}$ & $\%$ & $\begin{array}{c}\text { deg } \\
\text { ATDC }\end{array}$ \\
\hline 600 & 92.42 & -25 & 97.12 & -30 & 90.88 & -30 \\
\hline 500 & 92.89 & -25 & 96.48 & -30 & 90.75 & -30 \\
\hline 400 & 93.07 & -25 & 96.66 & -40 & 90.92 & -40 \\
\hline 300 & 93.05 & -30 & 97.11 & -40 & 90.94 & -40 \\
\hline 200 & 92.97 & -35 & 96.31 & -40 & 90.43 & -50 \\
\hline
\end{tabular}

Table 4-7 indicates the value of maximum combustion efficiency achieved by three fuels at different rail pressures and injection timing at which these values are obtained respectively.

Let's compare maximum combustion efficiency obtained at higher pressure and lower pressure as compared to 400 bar for all three fuels. For higher injection pressure, maximum combustion efficiency is generally lower for light naphtha. For lower injection pressure, maximum combustion efficiency is lowered or stays the same for all cases. For higher injection pressure, maximum combustion efficiency occurs at later injection timings. Whereas for lower injection pressure, maximum combustion efficiency is found for earlier injections in compression stroke. Higher injection pressure gives more effective mixing and thus need smaller ignition delay to give stratification. Although, every time higher combustion efficiency does not guarantee better fuel stratifications. Hence instead of studying cases with higher combustion efficiency, let's compare optimum instances with maximum combustion efficiency for fuel at different injection pressure. As mentioned previously, optimum cases will have combustion efficiency equal to or greater than $90 \%$, PRR smaller or equal to $10 \mathrm{bar} / \mathrm{deg}$ and NOx values below $5 \mathrm{~g} / \mathrm{Kg}-\mathrm{f}$.

Let's compare the behavior of each fuel at same injection pressure and injection timing to identify an effect of fuel at higher and lower injection pressure than 400 bar. Here Injection pressure is 600 bar and the injection angle chosen is -25 deg ATDC. Heavy naphtha has maximum combustion efficiency then followed by light naphtha and PRF50. Heavy naphtha and PRF50 has higher MPRR (>10 bar/deg) and higher NOx (>5 g.Kg-f) with combustion efficiency greater than $90 \%$. However light naphtha gives exciting outputs with PRR smaller than $10 \mathrm{bar} / \mathrm{deg}$, NOx smaller than $5 \mathrm{~g} / \mathrm{Kg}$-f and combustion efficiency higher than $90 \%$. 
Table 4-8. Predicted combustion characteristics for three fuels at -25 deg ATCD injection timing and 600 Bar injection pressure

\begin{tabular}{|c|c|c|c|}
\hline Fuel & Light Naphtha & Heavy Naphtha & PRF 50 \\
\hline Combustion Efficiency (\%) & 92.42 & 96.92 & 90.79 \\
\hline Ignition Delay (CAD) & 29.52 & 18.051 & 20.528 \\
\hline Thermal Efficiency (\%) & 43.52 & 43.88 & 40.85 \\
\hline PRR (bar/deg) & 9.36 & 15 & 16.1 \\
\hline CO (g/Kg-f) & 186.26 & 77.68 & 82.05 \\
\hline UHC (g/Kg-f) & 33.26 & 15.10 & 73.97 \\
\hline NOx (g/Kg-f) & 4.8 & 13.32 & 9.91 \\
\hline
\end{tabular}

Figure 4-24 provides pressure and HRR trace by all three fuels for comparison.

Higher HRR for PRF 50 and heavy naphtha indicate that spontaneous auto-ignition of a rich region is taking place (see Figure 4-24). However light naphtha's HRR trace has a lower peak, and more duration of heat release reporting stratified charge. Heavy naphtha and PRF50 also has higher in-cylinder peak pressure with steep pressure rise. Figure 4-25 gives spatial average temperature inside the combustion chamber. Combustion phasing and smaller combustion efficiency have resulted into smaller peak for light naphtha. The higher average temperature for the remaining two fuels aid to the formation of NOx. Figure 4-26 represents vaporization trend for all three fuels and ensure all the fuels are vaporized before SOC.

At the higher-pressure injection, a longer penetration length will profoundly influence airfuel mixing (see Figure 4-27). Heavy naphtha shows the least amount of mixing (local maximum $\phi \approx 3.09$ ) because of smaller ignition delay. While light naphtha shows most mixing with local maximum equivalence ratio approximately equal to 1.5 .

For higher injection pressure, since air-fuel mixing is better lesser ignition delay is desired for all three fuels. Smaller ignition delay can be achieved by injecting fuel later in the compression stroke. After comparing three fuels at one end of injection pressure sweep, let's compare them for smaller injection pressure. 


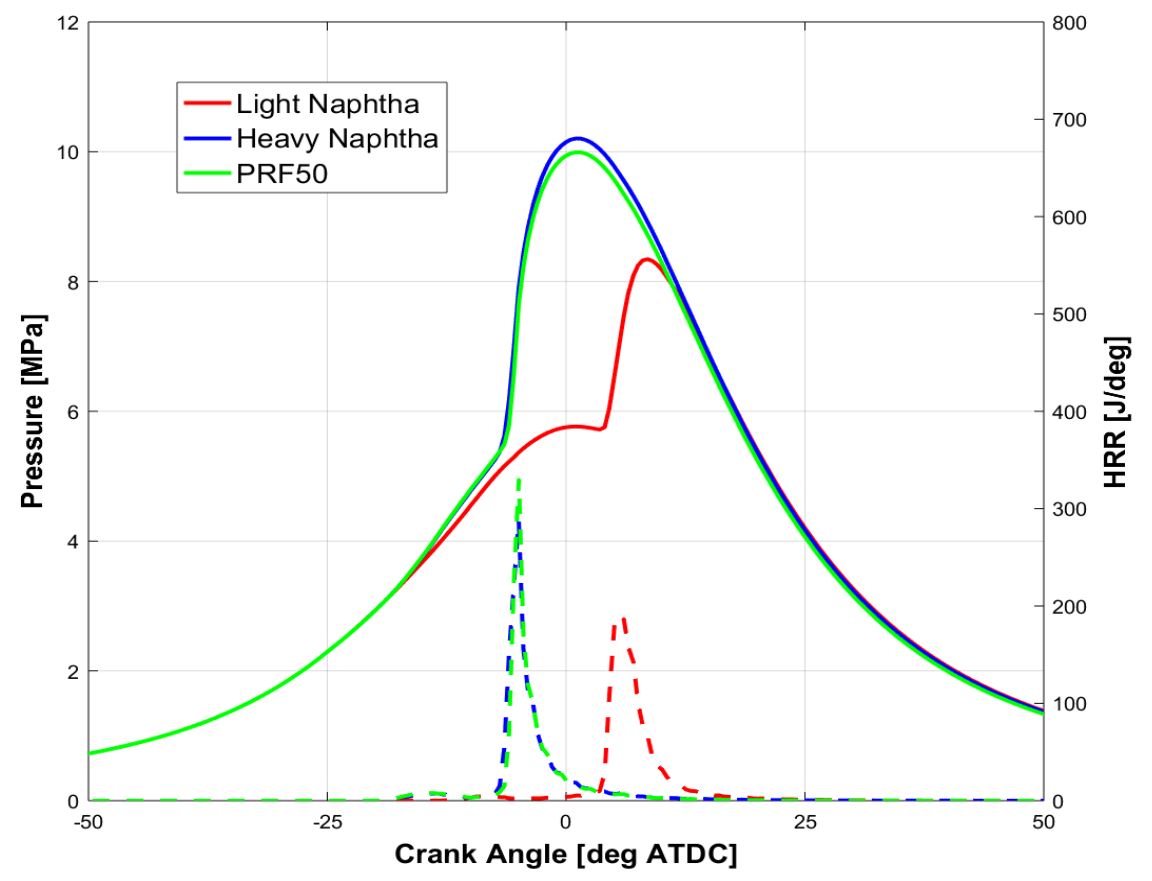

Figure 4-24. Comparison of predicted pressure and HRR for three fuels at -25 deg ATDC injection timing and 600 Bar injection pressure

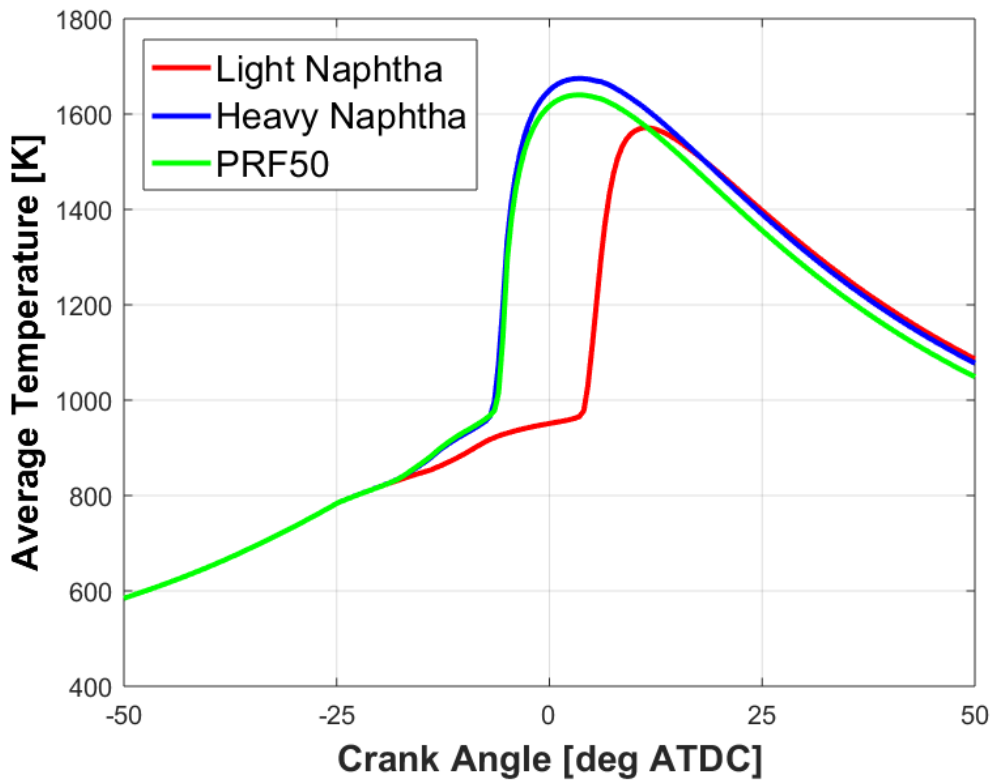

Figure 4-25. Comparison of predicted average temperature for three fuels at -25 deg ATDC injection timing and 600 Bar injection pressure 


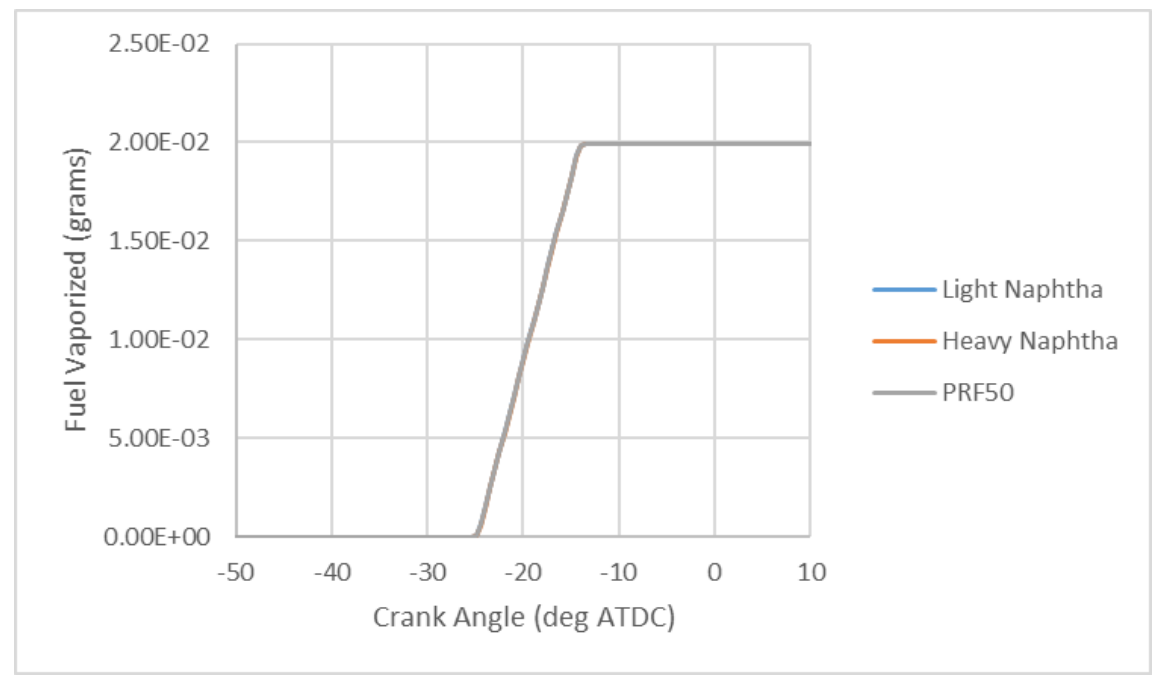

Figure 4-26. Comparison of predicted vaporization rate for three fuels at -25 deg ATDC and 600 Bar injection pressure

a)

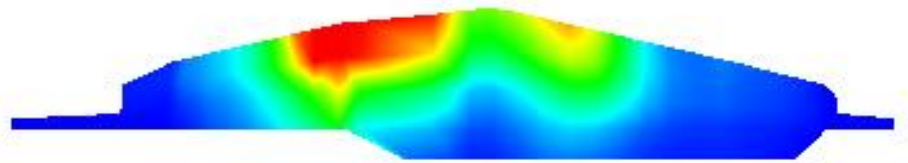

b)
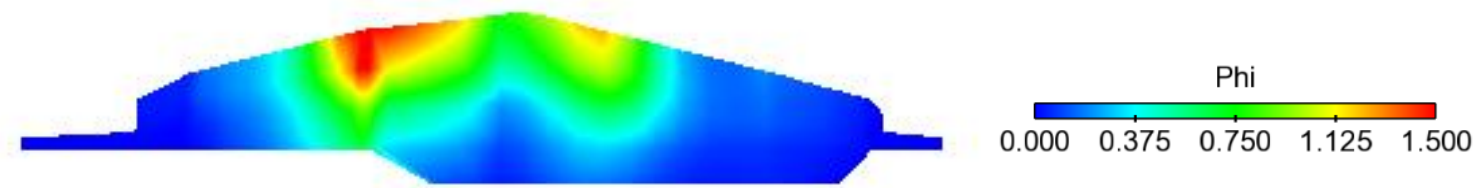

c)

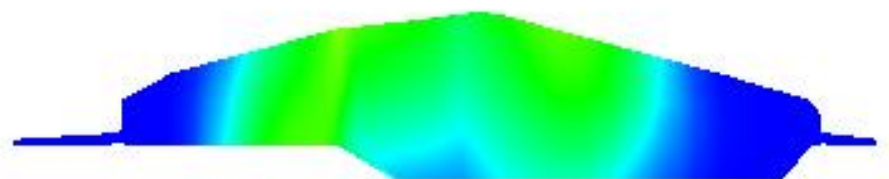

Figure 4-27. Predicted equivalence ratio distribution for a) Heavy Naphtha at -5 deg ATDC b) PRF50 at -6 deg ATDC and c) Light Naphtha at -5 deg ATDC 
Three fuels are analyzed at 200 bar pressures and -40 deg ATDC injection timing. At this injection parameter, heavy naphtha has maximum combustion efficiency at the expense of higher PRR and NOx values. Light naphtha and PRF50 gives acceptable combustion efficiency ( $>90 \%)$, MPRR $(<10 \mathrm{bar} / \mathrm{deg})$ and NOx $(<5 \mathrm{~g} / \mathrm{Kg}-\mathrm{f})$.

Table 4-9. Predicted combustion characteristics for three fuels at -40 deg ATDC and 200 Bar injection pressure

\begin{tabular}{|c|c|c|c|}
\hline Fuel & Light Naphtha & Heavy Naphtha & PRF 50 \\
\hline Combustion Efficiency (\%) & 92.02 & 96.31 & 90.02 \\
\hline Ignition Delay (CAD) & 34.54 & 27.52 & 32.56 \\
\hline Thermal Efficiency (\%) & 44.24 & 44.02 & 41.79 \\
\hline PRR (bar/deg) & 8.89 & 11.49 & 10.12 \\
\hline CO (g/Kg-f) & 206.56 & 97.29 & 117.6 \\
\hline UHC (g/Kg-f) & 30.05 & 21.55 & 74.28 \\
\hline NOx (g/Kg-f) & 4.62 & 14.65 & 3.32 \\
\hline
\end{tabular}

Figure 4-28 gives pressure and HRR trend at this testing condition. Pressure and Heat release rate diagrams show very close resemblance to one seen in previous case. Rapid and early heat release is observed for heavy naphtha and PRF50. Secondary heat release can be seen for all the fuels. However, for light naphtha, HRR peak are comparable but for heavy naphtha and PRF 50 rapid energy release for second time is smaller and distinguishable from first peak. Pressure trace shows that heavy naphtha and PRF50 burn in compression stroke whereas light naphtha in expansion. Cold flame can be seen in heavy naphtha and PRF50.

Average temperature profile in Figure 4-29 confirms cold flame for heavy naphtha and PRF50. Combustion phasing and higher combustion efficiency give heavy naphtha higher temperature peak. However, despite having low efficiency than light naphtha, PRF50 has higher peak temperature. Earlier start of the combustion results into higher peak temperature for PRF50.

Equivalence ratio gradient is shown in Figure 4-30 for three fuels just before SOC. Rich regions are evident for heavy naphtha and PRF50. Maximum local equivalence ratios for these fuels are $\approx 2.787$ and $\approx 2.12$ respectively. Lean regions seen in case of light naphtha confirms more mixing. Maximum local equivalence ratio for the fuel is $\approx 1.26$. 


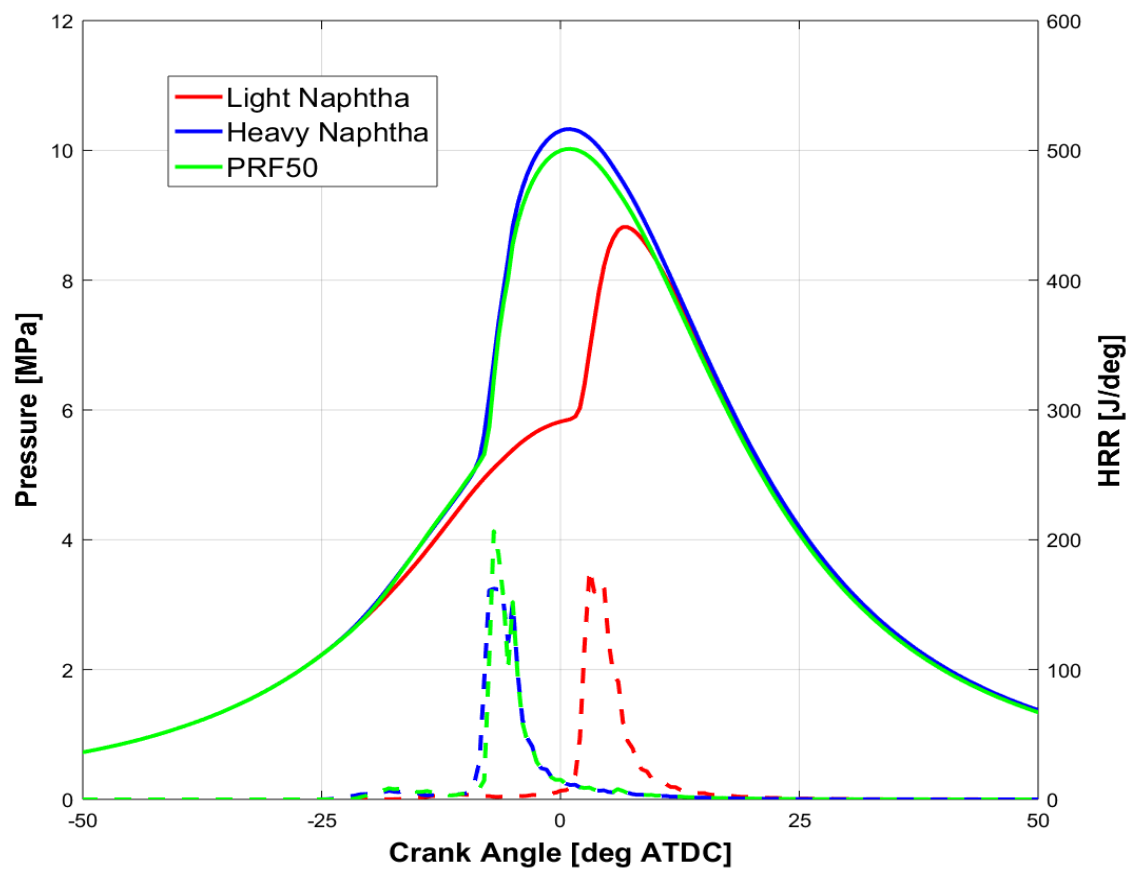

Figure 4-28. Comparison of predicted pressure and HRR for three fuels at -40 deg ATDC injection timing and 200 bar injection pressure

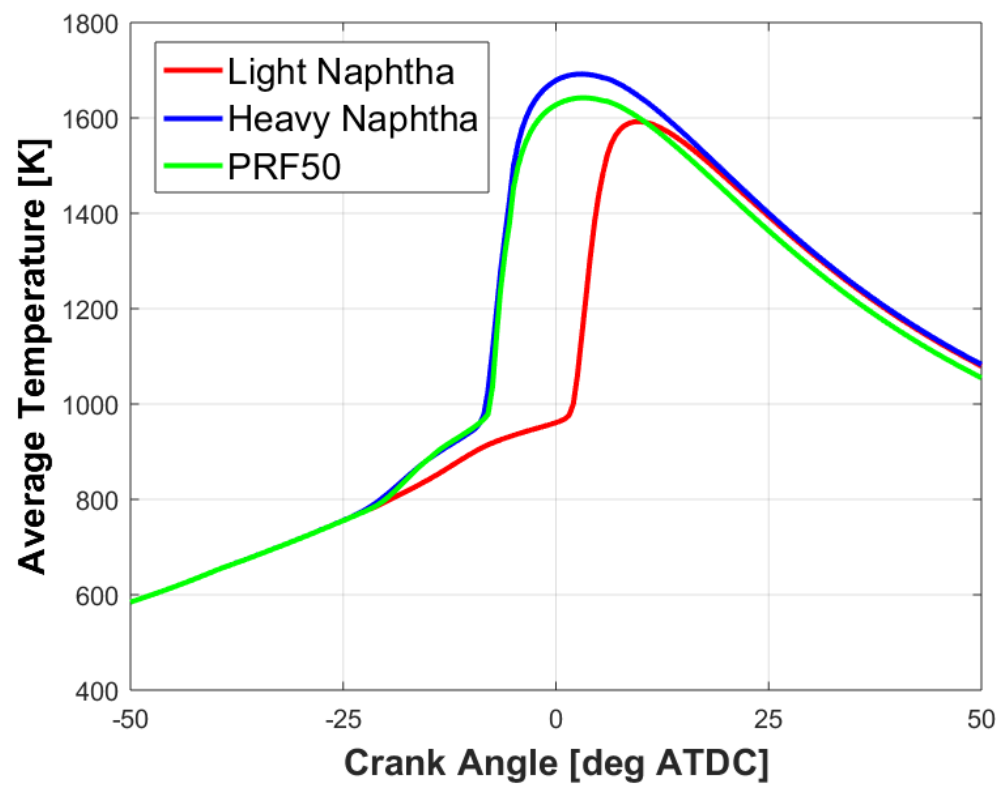

Figure 4-29. Comparison of predicted average temperature for three fuels at -40 deg ATDC injection timing and 200 Bar injection pressure. 
a)

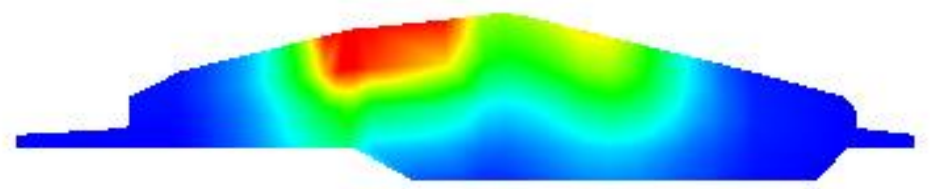

b)

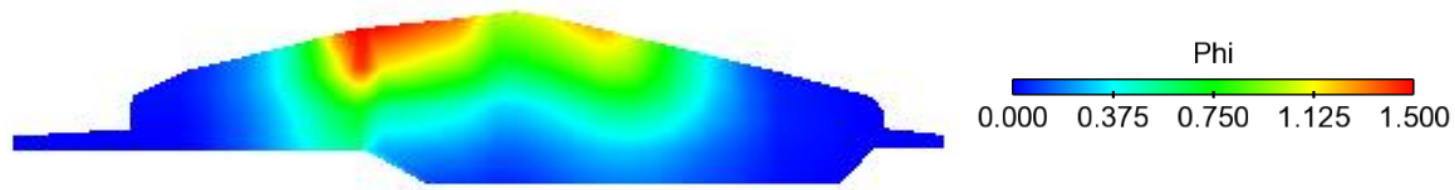

c)

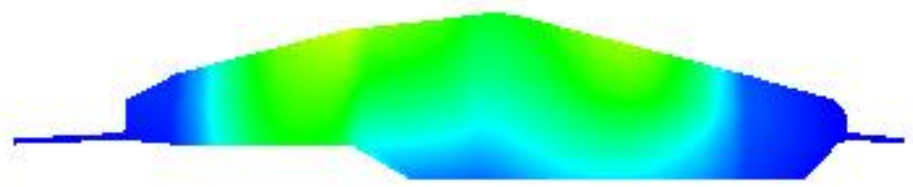

Figure 4-30. Predicted equivalence ratio distribution for a) Heavy Naphtha at -8 deg ATDC b) PRF50 at -8 deg ATDC and c) Light Naphtha at 2 deg ATDC

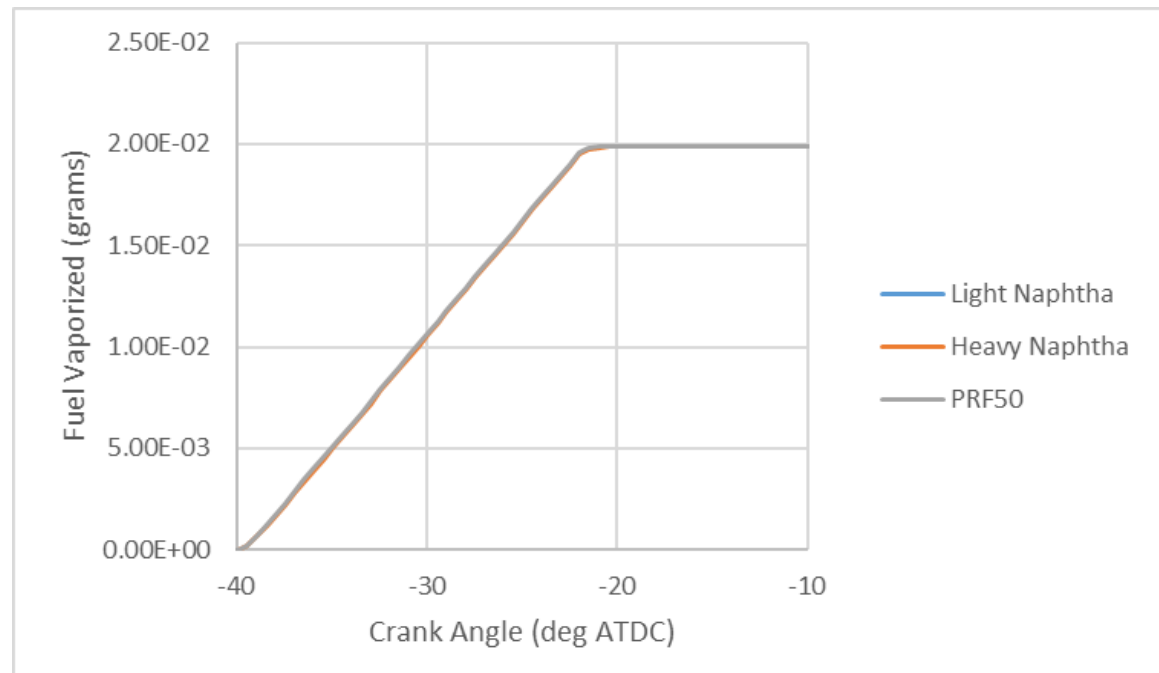

Figure 4-31. Comparison of predicted vaporization rate for three fuels at -40 deg ATDC and 200 Bar injection pressure 
From the vaporization Figure 4-31, all three fuel vaporizes before SOC. Difference in the volatility cannot be seen by rate of vaporization for three fuels.

Even for lower injection pressure, light naphtha has shortest injection delay followed by PRF50 and heavy naphtha seen similarly for 400 bar injection pressure. However, the numeric value of ignition delay is less for all the fuels if we compare those with 400 bar injection pressure and $-40 \mathrm{deg}$ ATDC injection timing. Ignition delay for light naphtha is sufficient to achieve fuel stratification. This can be reasoned by higher combustion efficiency $(>90 \%)$ but lesser PRR $(<10 \mathrm{bar} / \mathrm{deg})$ and NOx $(<5 \mathrm{~g} / \mathrm{kg}-\mathrm{f})$. The higher CO for light naphtha represents incomplete combustion in the lean regions due to low temperature. Peculiar HRR can be seen for heavy naphtha and PRF50. This can be explained as follows. In case of both, first heat release takes place due to combustion of fuel in the rich pockets near injector. Regions around it has low equivalence ratio (in the range of $\approx 1.125$ to 0.75 ). Heat release for the second time occurs as the temperature of this region reaches to auto ignition due to energy release and compression. First Energy release is very steep for both the fuel resulting into higher PRR. Higher combustion efficiency and lower heating value of heavy naphtha results into more NOx. It can be said that for lower injection pressure, less stratification is achieved for given ignition delay. Injection timings should be earlier in the compression stroke as compared to 400 bar for all three fuels to provide more optimum results since longer ignition delay is desired.

To segregate the effect of injection pressure only. Let's compare only fuel for two operating conditions mentioned below in a table. Injection timing is the same for both the cases. In case A fuel is injected at 300 bar for injection timing -45 deg ATDC. Similarly, for case B, injection timing is same except fuel is injected at 500 Bar.

Table 4-10. Predicted combustion characteristics for 300 Bar and 500 Bar injection pressure

\begin{tabular}{|c|c|c|}
\hline & Case A & Case B \\
\hline Injection Pressure (deg ATCD) & 300 & 500 \\
\hline Combustion Efficiency (\%) & 93.11 & 96.88 \\
\hline Ignition Delay (CAD) & 40.01 & 39.08 \\
\hline Thermal Efficiency (\%) & 43.86 & 45.82 \\
\hline PRR (bar/deg) & 9.25 & 10 \\
\hline CO (g/Kg-f) & 163.68 & 87.57 \\
\hline UHC (g/Kg-f) & 31.69 & 17.61 \\
\hline NOx (g/Kg-f) & 3.76 & 4.15 \\
\hline
\end{tabular}

Case B gives higher combustion efficiency, PRR, thermal efficiency and NOx values than case A. Ignition delay for case B is slightly longer. Both the cases can be considered as an optimum operating condition since for both; combustion efficiency is greater than $90 \%$, MPRR is less than or equal to $10 \mathrm{bar} / \mathrm{deg}$ and NOx at engine out is less than $5 \mathrm{~g} / \mathrm{Kg}$-f. 


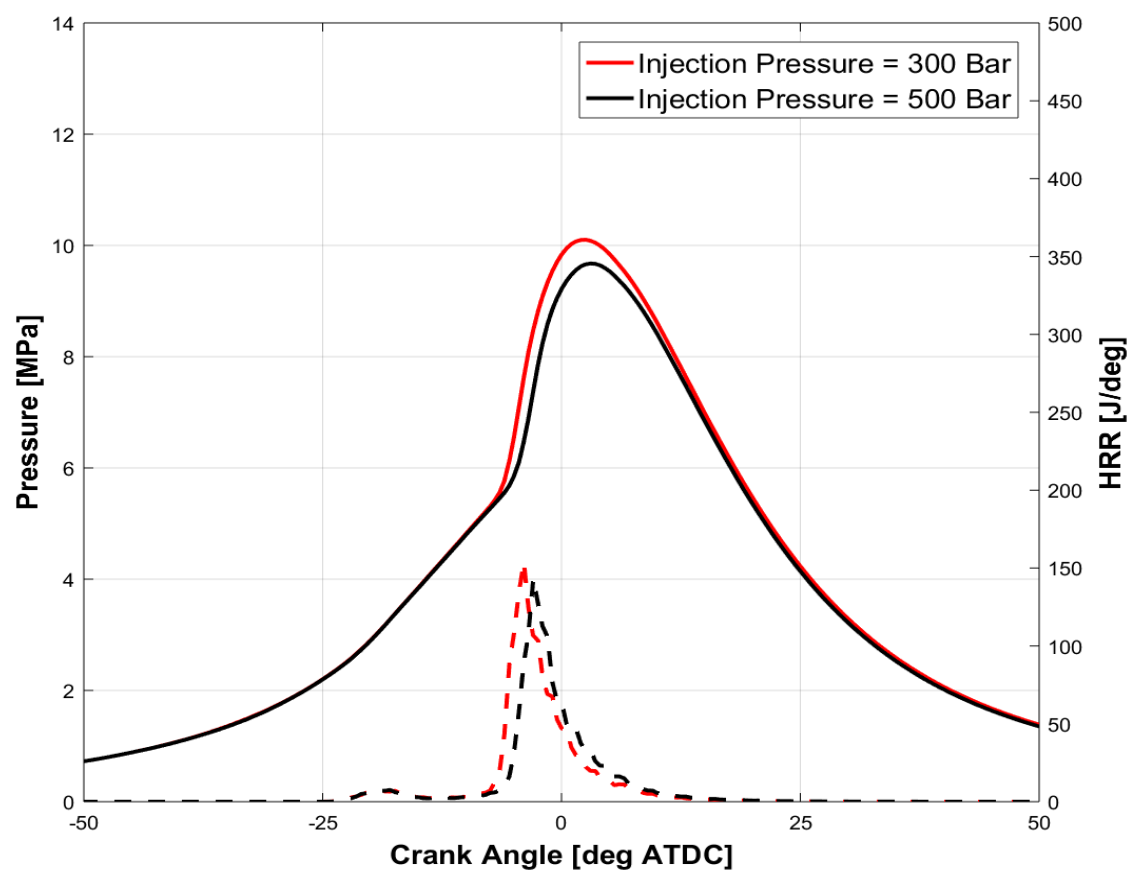

Figure 4-32. Comparison of predicted pressure and HRR at 300 Bar and 500 Bar injection pressure

a)

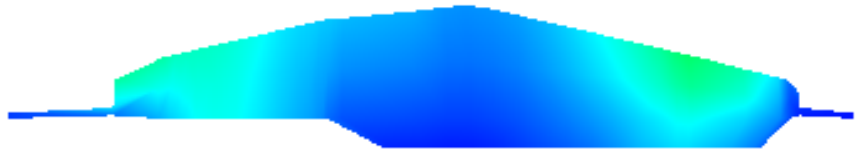

b)
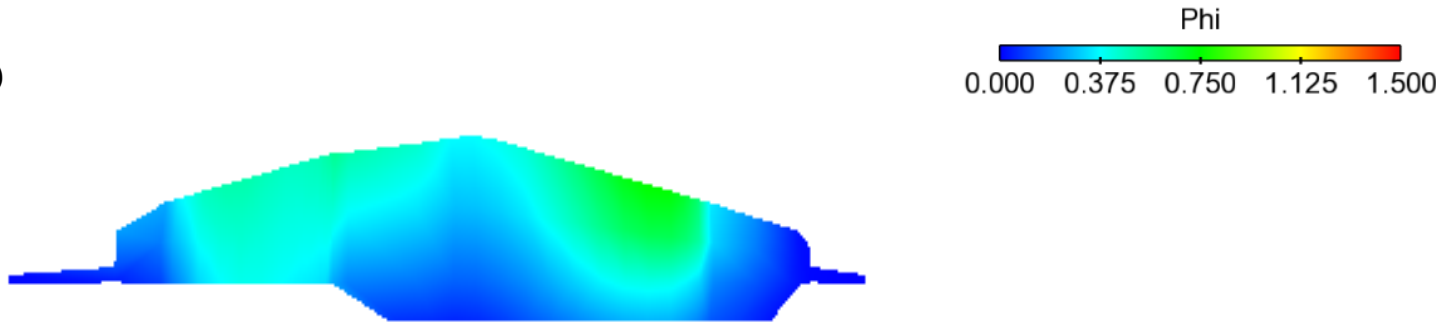

Figure 4-33. Predicted equivalence ratio distribution a) 300 Bar injection pressure at -3 $\operatorname{deg}$ ATDC b) 500 Bar injection pressure at -5 deg ATDC 
Figure 4-32 gives pressure and HRR trace for both the cases. Cold flame can be seen in both operating conditions. Duration and peak of HRR are almost similar. For Case A rapid energy release starts later than Case B. Both heat release rates show extended tail confirming heat release by $\mathrm{CO}$ to $\mathrm{CO} 2$ burn out taking place at low temperature. Peak incylinder pressure is higher for Case $\mathrm{B}$.

Equivalence ratio distribution just before SOC is shown in Figure 4-33. Case A has maximum local equivalence ratio $\approx 2.11$ and the same value for case $\mathrm{B}$ is $\approx 2.26$. Since ignition delay are much separation of fuel can also be seen.

Both the cases fuel is vaporized well before SOC (see Figure 4-34). Higher injection pressure has a shorter ignition delay since an increase in the injection pressure enhances air-fuel mixing. Shorter ignition delay for case B gives less stratification. However evident lack of rich regions (local maximum $\phi>2$ ) in both the instances prevents the high value of NOx and PRR.

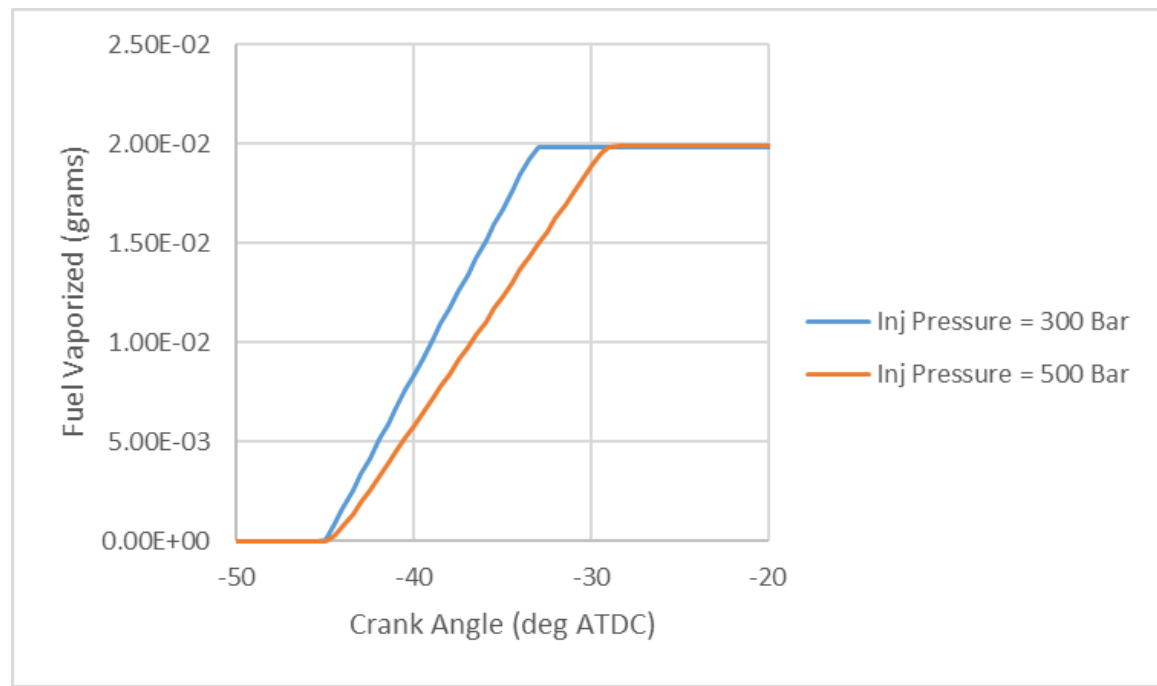

Figure 4-34. Comparison of predicted vaporization trend at 300 Bar and 500 Bar injection pressure

Simulation is conducted for all three fuels at six mentioned injection pressures with injection timing sweep. Table 4-11 lists out best case out of the number of simulated cases studied for each fuel at each injection pressure. For these cases, light naphtha (one with the lower reactivity) gives minimum combustion efficiency for all the injection pressure and heavy naphtha has maximum combustion efficiency. At all injection pressure, light naphtha gets optimum results at injection timing retarded than heavy naphtha and PRF50. Values of PRR and NOx are well within the limit for all the cases. At higher injection pressure than 400 bar, retarded injection timings are desired although at lower injection pressure earlier injection in the compression stroke gives results that are more beneficial. 
Table 4-11. Predicted optimum combustion cases for three fuels with various injection pressure

\begin{tabular}{|c|c|c|c|c|}
\hline & $\begin{array}{l}\text { Injection } \\
\text { Timing }\end{array}$ & $\begin{array}{l}\text { Combustion } \\
\text { Efficiency }\end{array}$ & PRR & NOx \\
\hline & deg ATDC & $\%$ & Bar/deg & g/Kg-f \\
\hline \multicolumn{5}{|c|}{ Injection Pressure :600 Bar } \\
\hline Light Naphtha & -35 & 88.76 & 5.09 & 2.02 \\
\hline Heavy Naphtha & -45 & 92.47 & 9.33 & 3.70 \\
\hline PRF50 & -40 & 90.02 & 10.12 & 3.32 \\
\hline \multicolumn{5}{|c|}{ Injection Pressure :500 Bar } \\
\hline Light Naphtha & -30 & 90.77 & 6.56 & 3.61 \\
\hline Heavy Naphtha & -45 & 93.11 & 9.25 & 3.76 \\
\hline PRF50 & -40 & 90.40 & 10.66 & 3.52 \\
\hline \multicolumn{5}{|c|}{ Injection Pressure :400 Bar } \\
\hline Light Naphtha & -35 & 90.08 & 3.58 & 6.71 \\
\hline Heavy Naphtha & -45 & 96.53 & 3.898 & 9.96 \\
\hline PRF50 & -45 & 90.56 & 3.251 & 10.61 \\
\hline \multicolumn{5}{|c|}{ Injection Pressure :300 Bar } \\
\hline Light Naphtha & -35 & 91.52 & 8.47 & 4.70 \\
\hline Heavy Naphtha & -50 & 94.74 & 9.38 & 3.45 \\
\hline PRF50 & -50 & 90.26 & 10.23 & 2.91 \\
\hline \multicolumn{5}{|c|}{ Injection Pressure :200 Bar } \\
\hline Light Naphtha & -40 & 92.01 & 8.89 & 4.62 \\
\hline Heavy Naphtha & -50 & 96.05 & 9.46 & 3.08 \\
\hline PRF50 & -50 & 90.43 & 10.86 & 3.15 \\
\hline
\end{tabular}




\subsection{Change in charge temperature at IVC}

Comparison of increasing the charge temperature at IVC operating condition with a baseline for each of the fuels is presented below. Let's discuss effects of increasing charge temperature at intake valve closing crank angle on combustion efficiency for all three fuels. Figure 4-35 represents combustion efficiency for injection timing sweep at elevated IVC temperature and baseline condition. The advantage of a rise in charge temperature is evident for earlier injection timings for all the fuels. However, increase in combustion efficiency is prominent for light naphtha at injections earlier in the compression stroke. For injections near TDC, combustion efficiency is less than baseline condition. For heavy naphtha and PRF50, earlier injections in compression gives slightly lower combustion efficiency and injection near TDC exhibit similar combustion efficiency.

As established in previous chapter, ignition delay is an important parameter to study when understanding GDI combustion. Figure 4-36 compares ignition delay profiles for all three fuels at both cases, baseline and increased charge temperature. As expected, at increased IVC temperature condition ignition delay values are lower for all the injection timings for all three fuels. Increased rate of pre-combustion reactions and earlier vaporization of fuel results in the difference between the ignition delay values. For light naphtha, for injection timings earlier in the compression stroke, the difference between ignition delay is more significant than for heavy naphtha and PRF50. At injections earlier in the compression stroke, increased IVC temperature reduces over mixing of the fuel. As shown in Figure 3.1, for lower reactive fuels, the small change in equivalence ratio in the lean region results in more significant changes in the ignition delay. In case of light naphtha, we see these change in the ignition delay at earlier injection timings more dominantly as compared to the other two fuels because of its lower reactivity. Lowered ignition delay for light naphtha at advanced injection timings indicates less over mixing hence shows the drastic increase in the combustion efficiency.

Figure 4-37 indicates thermal efficiency at baseline and IVC condition for all three fuels. As expected, for advanced injection timings for light naphtha, there is a vast increase in the efficiency. Thermal efficiency for injections late in the compression stroke does not show any significant increase. For heavy naphtha and PRF50 overall increase in the thermal efficiency is quite less in coordination with the smaller increase in the combustion efficiency. For these two fuels, thermal efficiency at -50 deg ATDC injection timing at increased charge temperature condition is smaller and equal to the baseline condition value respectively. This can be justified by the start of combustion earlier in the compression stroke as a result of increased charge temperature. 
a) Heavy Naphtha

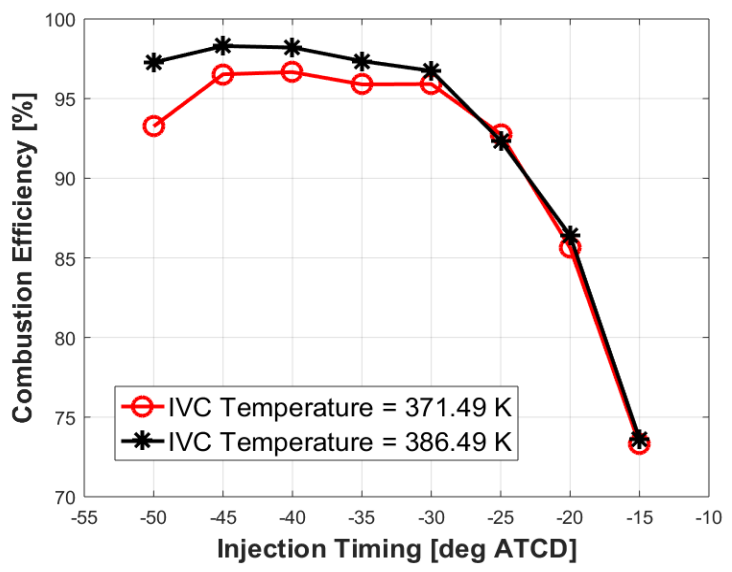

b) Light Naphtha

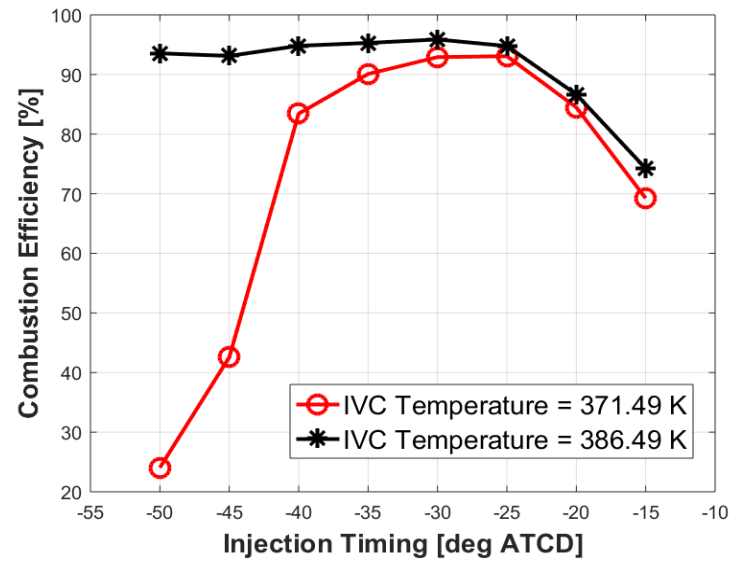

c) PRF50

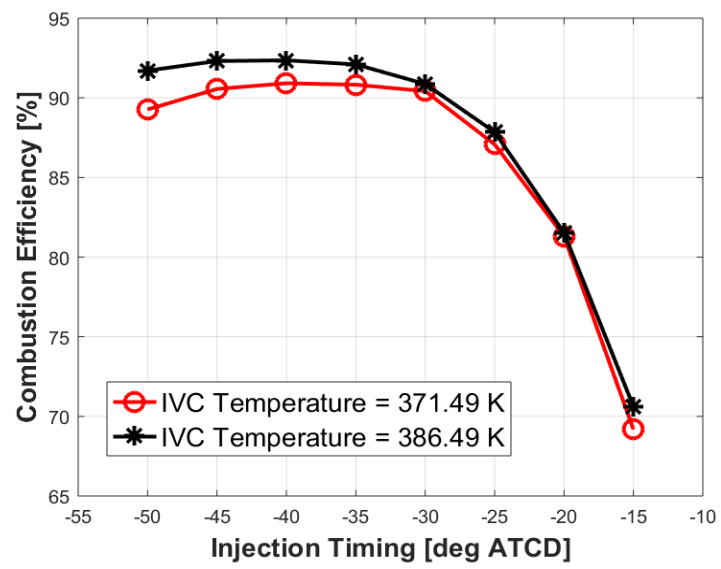

Figure 4-35. Comparison of predicted effect on combustion efficiency due to variation in charge temperature at IVC for various injection timings 
a) Heavy Naphtha

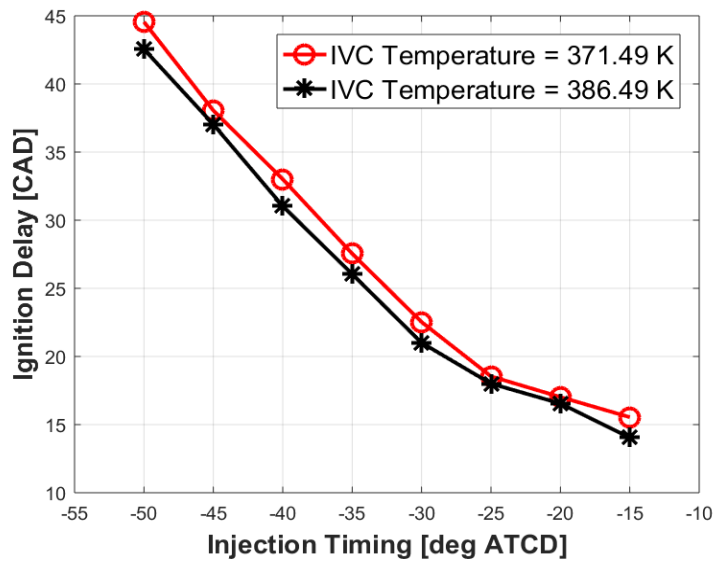

b) Light Naphtha

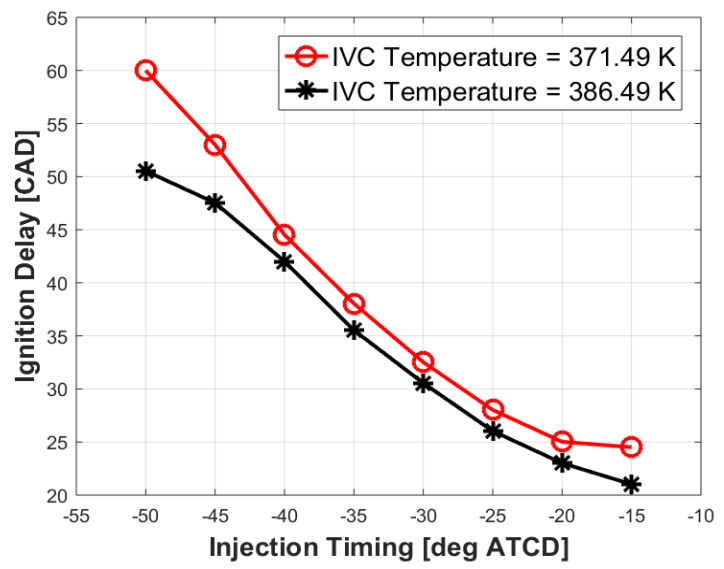

c) PRF50

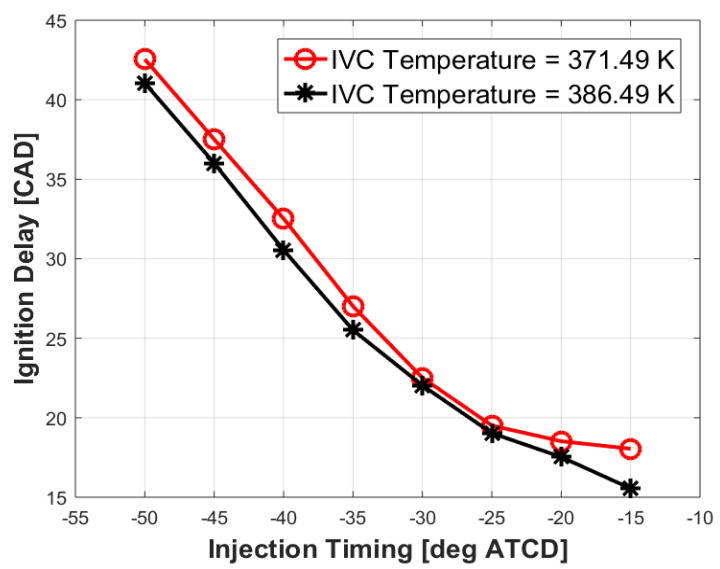

Figure 4-36. Comparison of predicted effect on ignition delay due to variation in charge temperature at IVC for various injection timings 
a) Heavy Naphtha

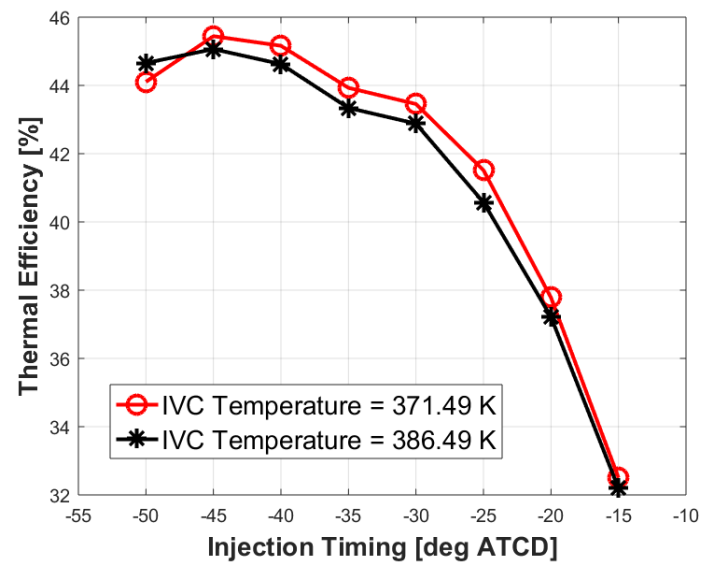

b) Light Naphtha

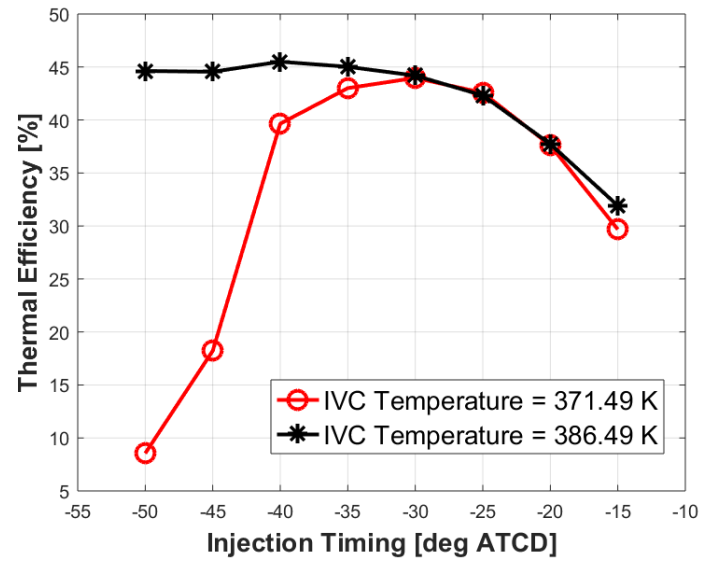

c) PRF50

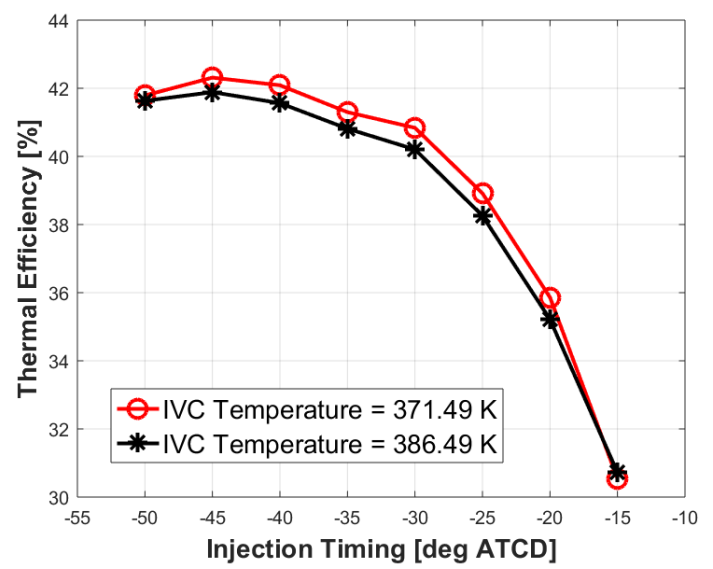

Figure 4-37. Comparison of predicted effect on thermal efficiency due to variation in charge temperature at IVC for various injection timing 
Figure 4-38 enlists maximum pressure rise rates for all three fuels at both the operating condition, baseline and increased charge temperature at IVC. For all three fuels, in general PRR for elevated temperature condition is higher than baseline. Increased combustion efficiency, combustion in compression stroke along with rich combustion are some of the reasons for increased values of PRR. PRR values for heavy naphtha and PRF50 are higher or equal to 10 for an entire injection sweep. The higher value of PRR stipulates that a large amount of fuel undergoes combustion simultaneously which means enough fuel gradient is not present in the combustion chamber.

For heavy naphtha and PRF50, the trend of CO shown in Figure 4-39 at increased ambient temperature is similar to that of baseline conditions. Production of $\mathrm{CO}$ at baseline is always larger. The difference for $\mathrm{CO}$ values is larger for earlier injection timings. This can be explained by quoting increased combustion efficiency at these timings. For light naphtha again, impressive reduction for $\mathrm{CO}$ values can be seen at advanced injection timings. Unburned Hydrocarbon shows similar tend to $\mathrm{CO}$ for all values and its given in Figure 440. Higher temperature reduces ignition delay and thereby avoiding over mixing at the injection timing which causes incomplete combustion. Also, higher charge temperature promotes combustion of fuel within the lean regions which would normally not go under combustion for baseline operating conditions. Increased IVC temperatures enable the completion of late combustion reactions such as conversion of $\mathrm{CO}$ to $\mathrm{CO}$. Consequently, at increased charge temperature at IVC condition, even for earlier injection timings, all the fuels show the tendency of more completed combustion thereby reducing $\mathrm{CO}$ and UHC emissions at EVO. Figure 4-41 shows NOx at EVO for all three fuels. More NOx can be seen at an increased temperature at IVC condition. Formation of NOx is directly proportional to the temperature. Increased charge temperature at IVC and complete combustion results in the more amount of NOx for an entire injection sweep. 
a) Heavy Naphtha

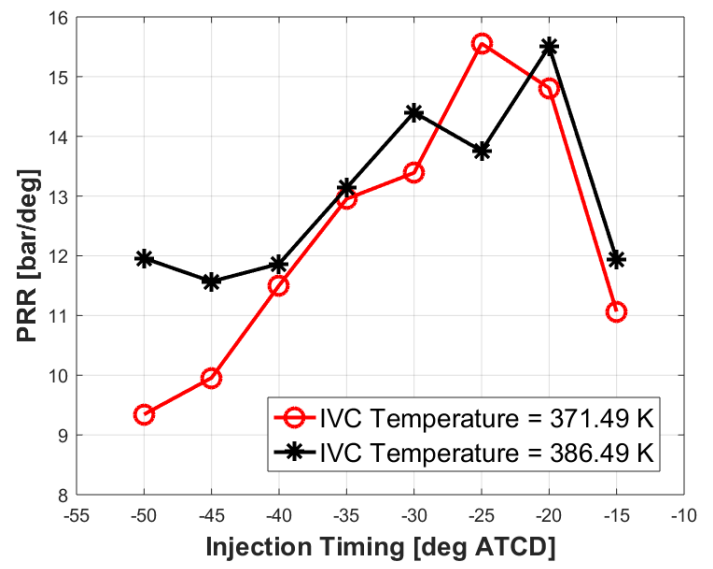

b) Light Naphtha

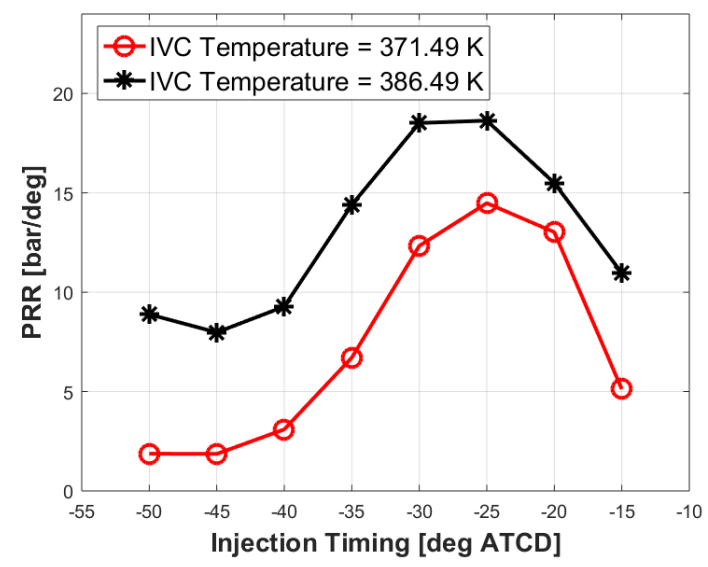

c) PRF50

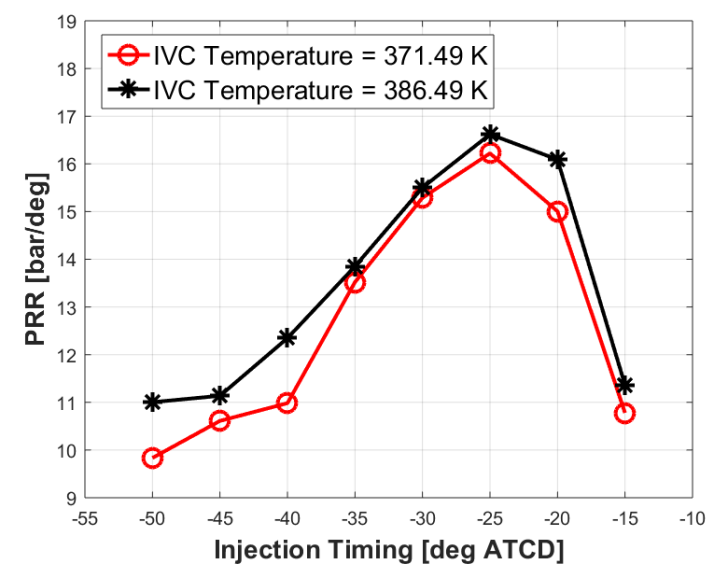

Figure 4-37. Comparison of predicted effect on PRR due to variation in charge temperature at IVC for various injection timing 
a) Heavy Naphtha

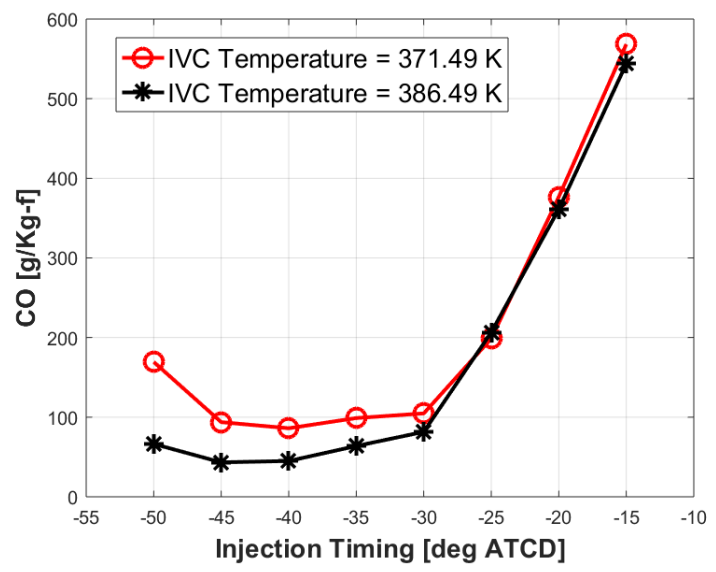

b) Light Naphtha

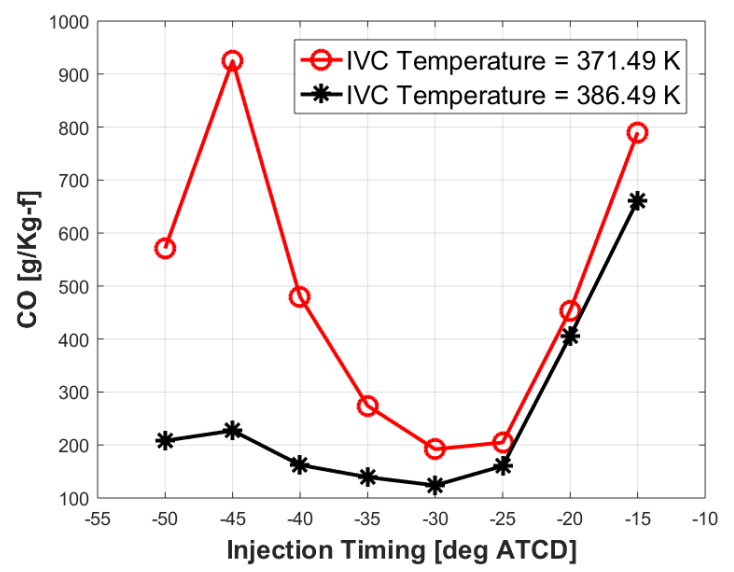

c) PRF50

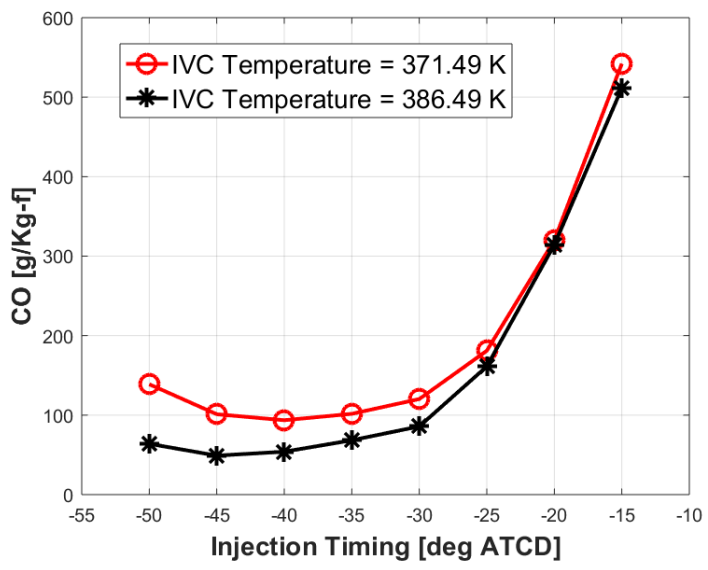

Figure 4-38. Comparison of predicted effect on CO at EVO due to variation in charge temperature at IVC for various injection timings 
a) Heavy Naphtha

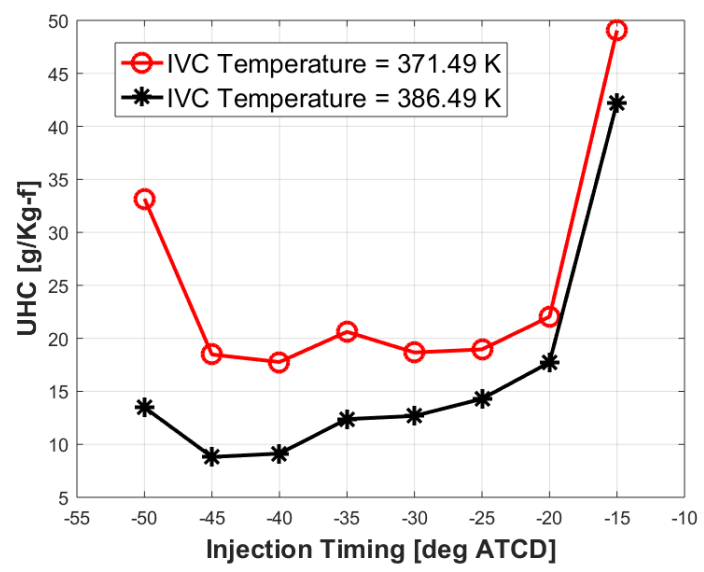

b) Light Naphtha

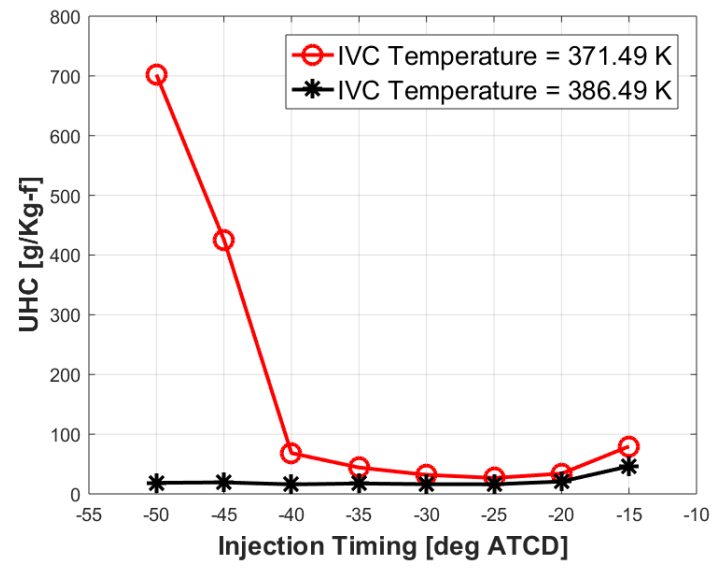

c) PRF50

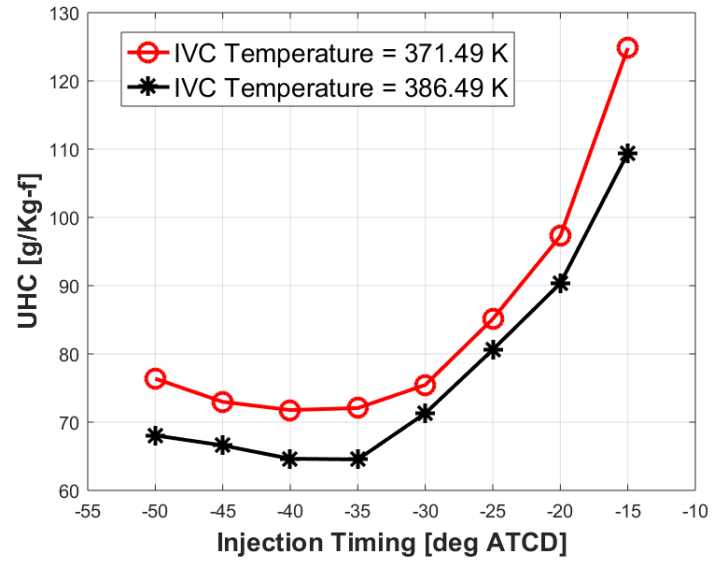

Figure 4-39. Comparison of predicted effect on UHC at EVO due to variation in charge temperature at IVC for various injection timings 
a) Heavy Naphtha

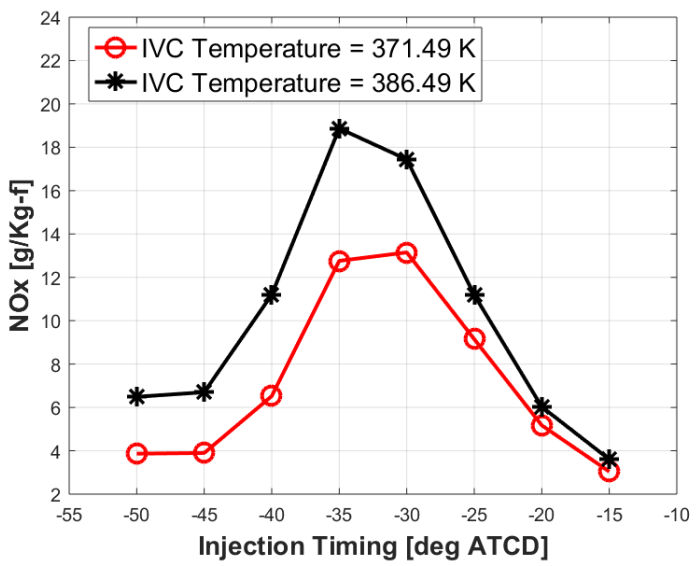

b) Light Naphtha

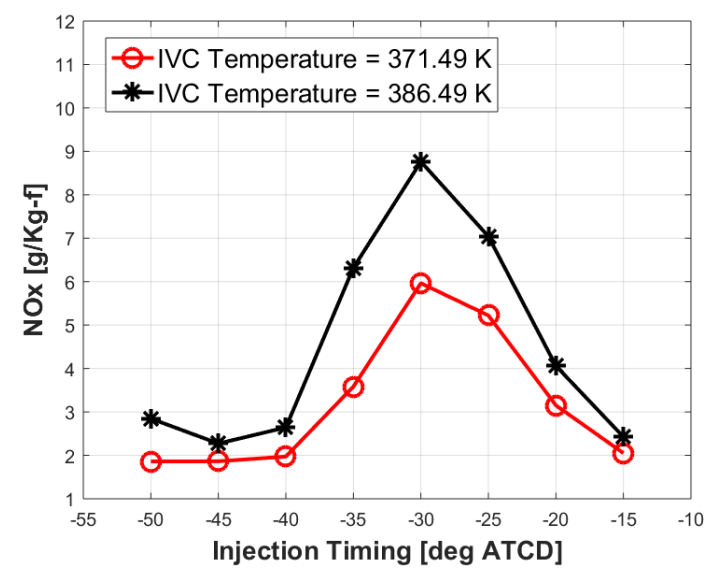

c) PRF50

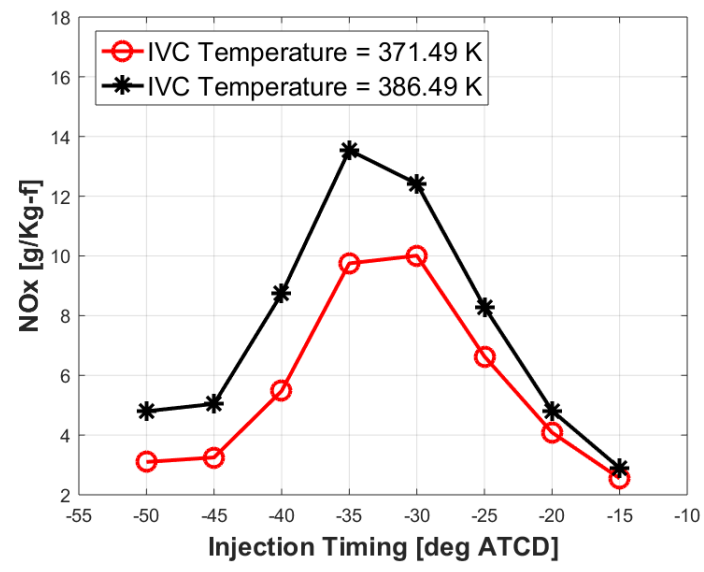

Figure 4-40. Comparison of predicted effect on NOx at EVO due to variation in charge temperature at IVC for various injection timings 
Since the effect of increased charge temperature at IVC is most dominantly can be seen for light naphtha. Let's compare one of the injection timings for baseline and increased IVC temperature operating condition. Table 4-12 summarizes two cases, one at baseline operating condition and other with elevated charge temperature at IVC operating condition. For both the cases, fuel is injected at -45 deg ATDC. For case A, charge temperature at IVC is $371.49 \mathrm{~K}$ (baseline condition) whereas charge temperature for case B at IVC is $386.49 \mathrm{~K}$ (Increased IVC temperature). Ignition delay, thermal and combustion efficiency, all these parameters for case A shows very less values as compared to case B. CO and UHC emissions at exhaust valve opening for case A are higher whereas case B produces more NOx.

Table 4-12. Predicted combustion characteristics at injection timing -45 deg ATDC for different charge temperatures at IVC

\begin{tabular}{|c|c|c|}
\hline & Case A & Case B \\
\hline Charge Temperature at IVC (K) & 371.49 & 386.49 \\
\hline Injection Timing (deg ATCD) & -45 & -45 \\
\hline Combustion Efficiency (\%) & 42.57 & 93.11 \\
\hline Ignition Delay (CAD) & 53.01 & 47.53 \\
\hline Thermal Efficiency (\%) & 18.22 & 44.55 \\
\hline PRR (bar/deg) & 1.86 & 7.98 \\
\hline CO (g/Kg-f) & 925.00 & 227.13 \\
\hline UHC (g/Kg-f) & 425.63 & 19.30 \\
\hline NOx (g/Kg-f) & 1.86 & 2.27 \\
\hline
\end{tabular}

Figure 4-42 represents pressure and heat release rate trace for both the conditions. Case B has a rapid and more heat release rate as compared to Case A. This difference in combustion quality can also be seen in the pressure trace. For increased charge temperature case $\mathrm{B}$, combustion takes place near TDC in power stroke resulting into higher expansion pressure. Whereas minimal pressure rise can be seen for case A late in the expansion stroke.

Figure4-43 indicate vaporization rate for case A and case B. For both the cases, the fuel vaporization rate is the same. Ambient temperature at which fuel is injected even at baseline condition is sufficient to vaporize the fuel as soon as it enters the combustion chamber. 


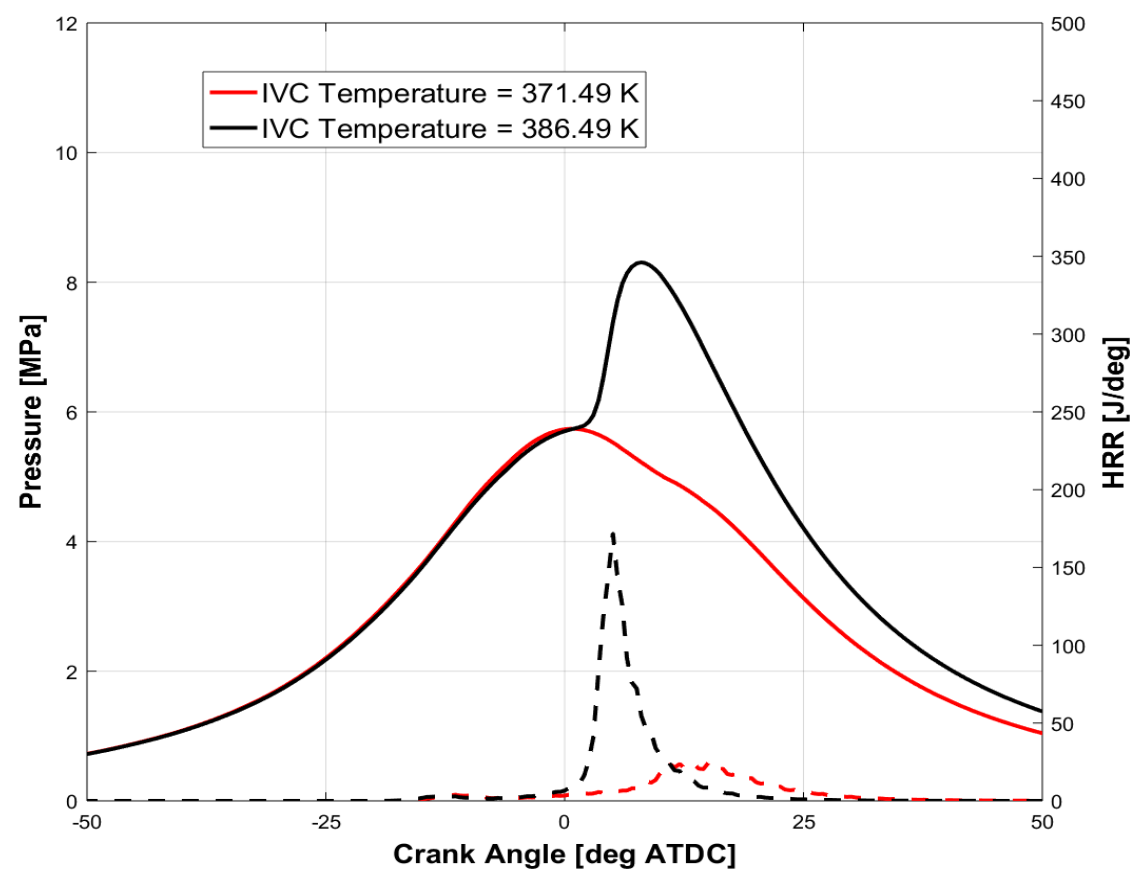

Figure 4-41. Comparison of predicted pressure and HRR at injection timing -45 deg ATDC for charge temperatures $371.49 \mathrm{~K}$ and $386.49 \mathrm{~K}$

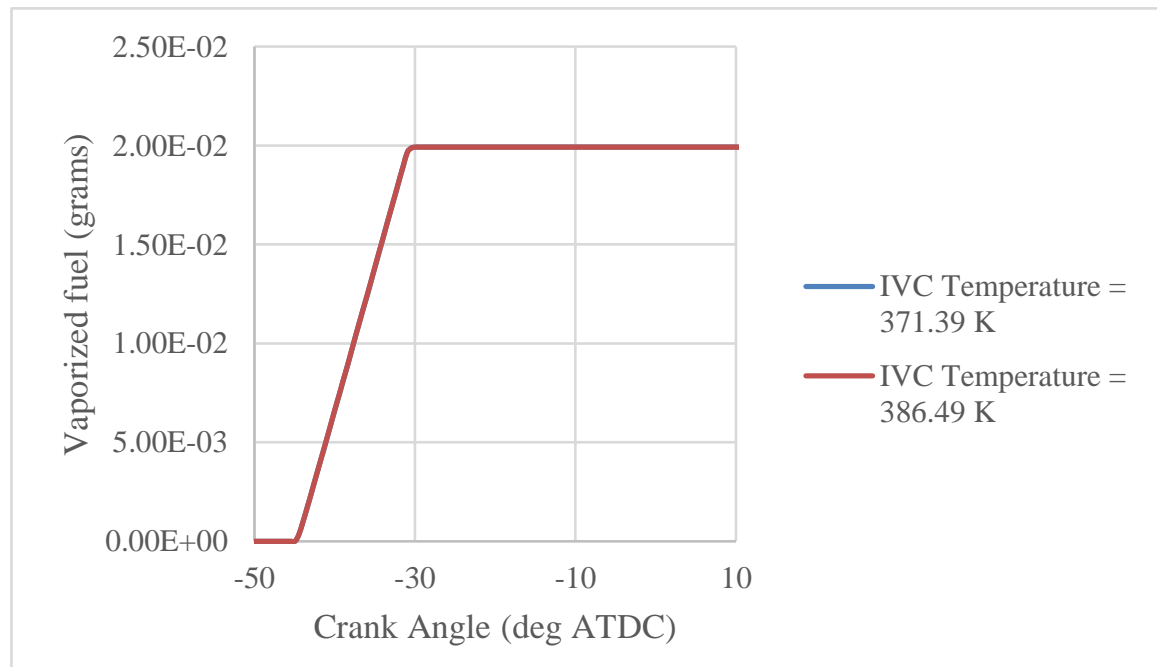

Figure 4-42. Comparison of predicted fuel vaporization rate at injection timing -45 deg ATDC for charge temperatures $371.49 \mathrm{~K}$ and $386.49 \mathrm{~K}$

Variation in the combustion quality can be better explained using equivalence ratio distribution within the combustion chamber. Figure 4-44 shown below indicates stratification inside the cut section of the combustion chamber. The snip is taken just before combustion starts for both the cases. 
a)

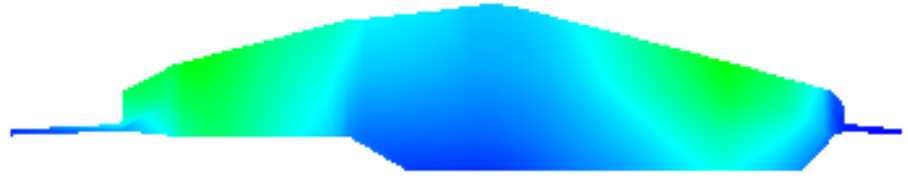

b)
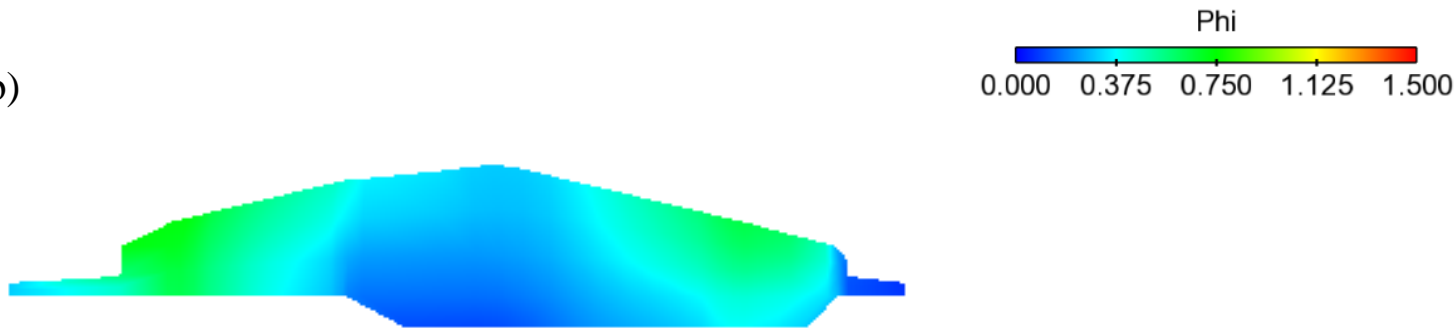

Figure 4-43. Predicted equivalence ratio distribution at injection timing -45 deg ATDC for a) charge temperatures $386.49 \mathrm{Kat}-2 \mathrm{deg}$ ATDC b) $371.49 \mathrm{~K}$ at $8 \mathrm{deg}$ ATDC

Both the cases show similar fuel distribution. As discussed in the baseline case study, charge swirl created within the combustion chamber moves fuel from centers of the combustion chamber towards cylinder walls at corners. Numerically speaking maximum equivalence ratio for the baseline condition is $\approx 1.4$. Although similar value for elevated temperature is $\approx 1.536$, variation in the ignition delay between two cases has resulted into variation in the equivalence ratio distribution.

Case A has lower charge temperature at IVC than case B. As a result, longer ignition delay value is recorded for case A. longer ignition delay means case A has more mixing than case B. Equivalence ratio distribution within the combustion chamber indicate that more lean regions are present in case A. From pressure and HRR trace it's clear that, even though rich areas in case A undergoes combustion, fuel in lean regions remains unburned. This phenomenon is because of over mixing of air and fuel. Lower quality of combustion in case A results in lower combustion and thermal efficiency. Emission values at EVO also prove the hypothesis of over mixing in regards with case A. More CO and UHC for case A collaborates the theory that all the fuel in case A does not undergo complete combustion. On the contrary for case B, lower ignition delay (because of higher charge temperature) ensures enough stratification in the chamber so that combustion is sustained from rich regions to the lean regions.

Let's compare the performance of three fuels at elevated charge temperature at IVC operating condition. Figure 4-45 indicates combustion efficiency for injection timing sweep for all three fuels. 


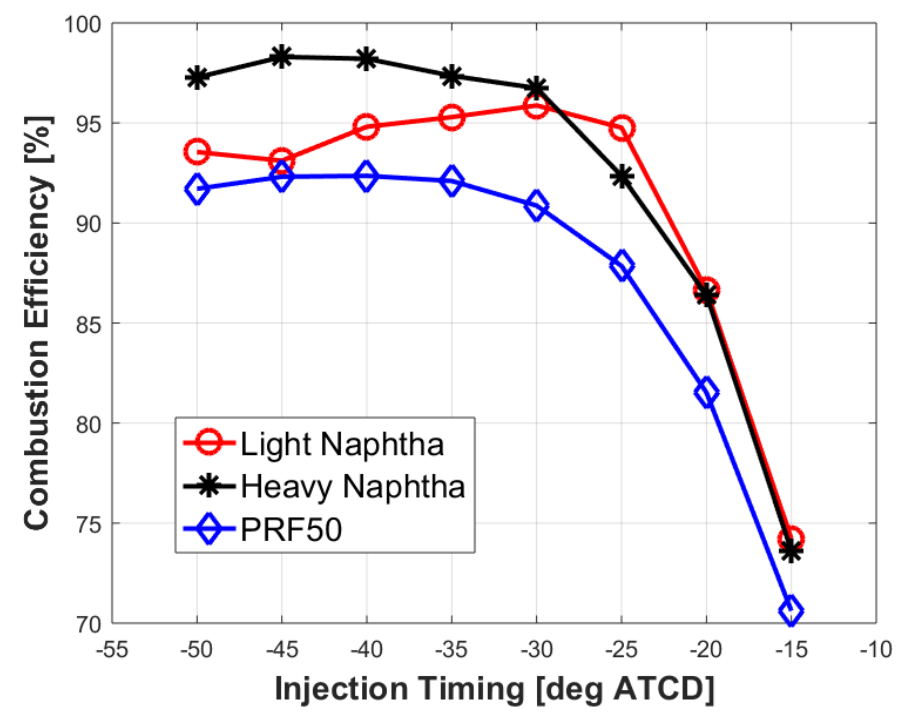

Figure 4-44. Comparison of predicted combustion efficiencies for charge temperature $386.49 \mathrm{~K}$ at various injection timings using three fuels

Even with higher charge temperature at IVC, all three fuels give similar trend for combustion efficiency for injection timing sweep. Combustion efficiency first increases with advanced injection timing followed by constant line and then decreases. The rate for an increase of combustion efficiency is highest for light naphtha, but it shows an early drop in the value. For injection timings earlier in the compression stroke, heavy naphtha has highest combustion efficiency, and PRF50 has lowest. However, for injection timings near TDC, combustion efficiency values are similar for heavy and light naphtha whereas PRF50 maintains lower combustion efficiency. PRF50 and Heavy naphtha have the parallel trend.

Ignition delay comparison of three fuel is shown in Figure 4-46. Same as baseline operating condition, light naphtha has higher ignition delay as compared to the other two fuels because of its lower reactivity. PRF50 and heavy naphtha maintains exhibits similar ignition delay values over an entire injection timing sweep. 


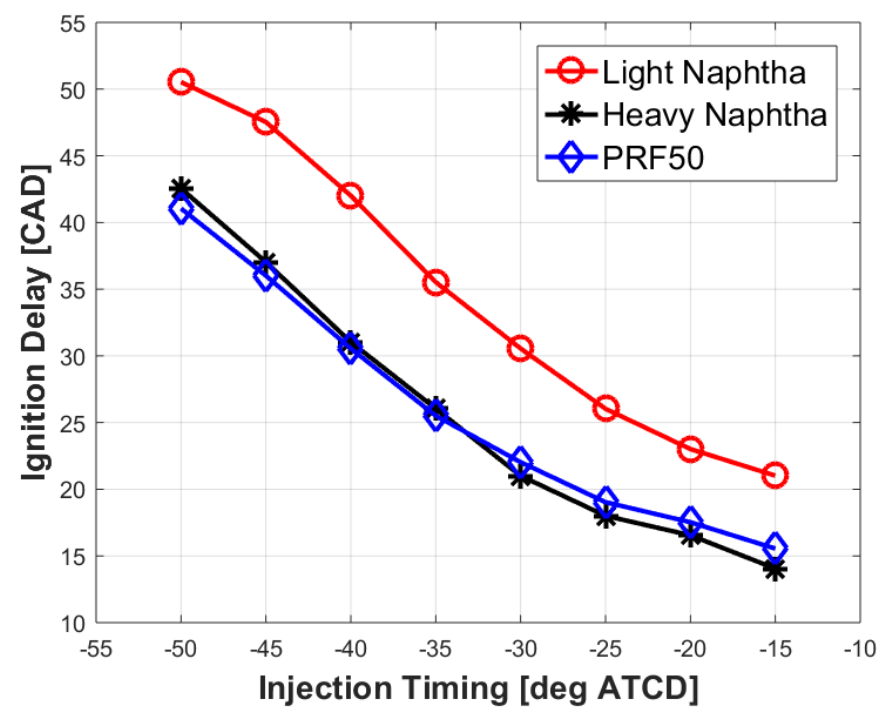

Figure 4-45. Comparison of predicted ignition delay for charge temperature $386.49 \mathrm{~K}$ at various injection timings using three fuels

Thermal efficiency for this injection sweep is shown in the Figure 4-47. Light naphtha maintains higher thermal efficiency whereas PRF50 has the smallest values.

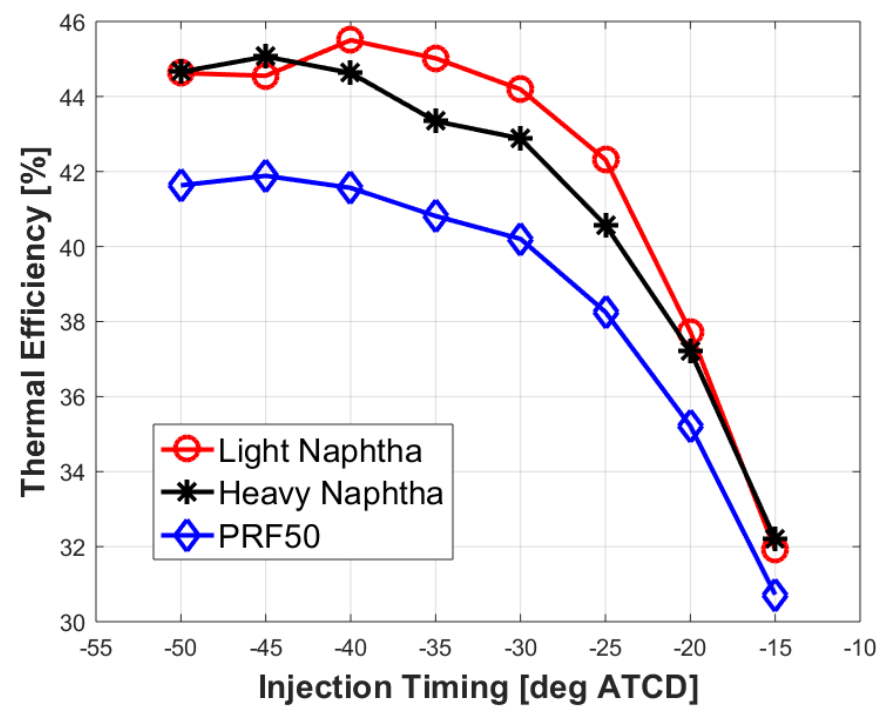

Figure 4-46. Comparison of predicted thermal efficiencies for charge temperature 386.49 $\mathrm{K}$ at various injection timings using three fuels

Maximum pressure rise rate does not give any definite trend at higher charge temperatures at IVC for all fuels. Variation in the PRR value for light naphtha is more as compare to the other two values. However, looking at the scale of PRR, PRF50 and heavy Naphtha has PRR more than $10 \mathrm{bar} / \mathrm{deg}$ for entire injection timing sweep. 


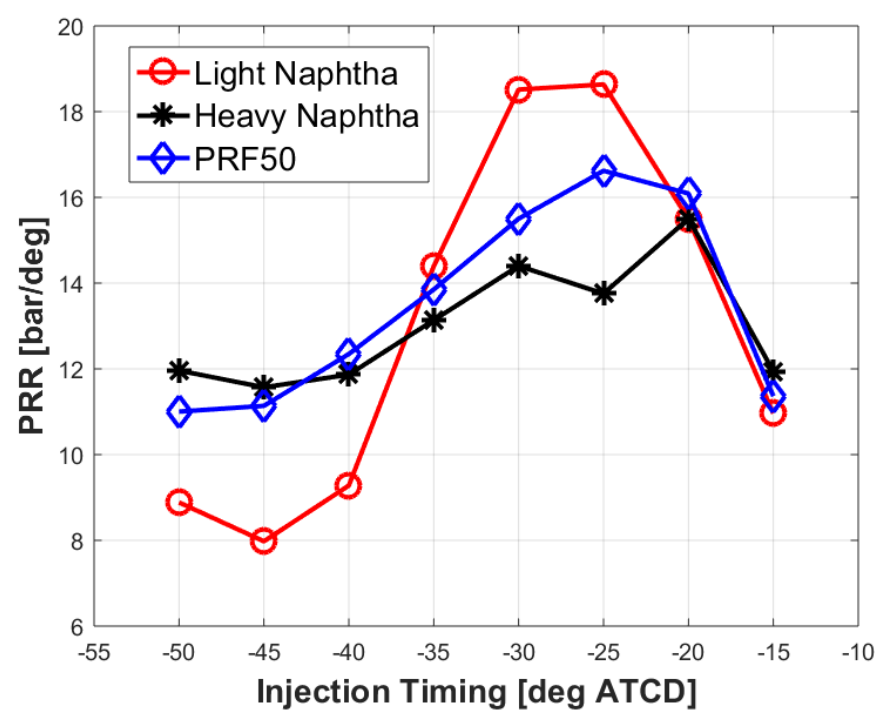

Figure 4-47. Comparison of predicted pressure rise rates for charge temperature $386.49 \mathrm{~K}$ at various injection timings using three fuels

Heavy naphtha has the more NOx at EVO for all the injection timing sweep whereas light naphtha has lower NOx production. Values of NOx at EVO are summarized in a Figure 4-49 shown below.

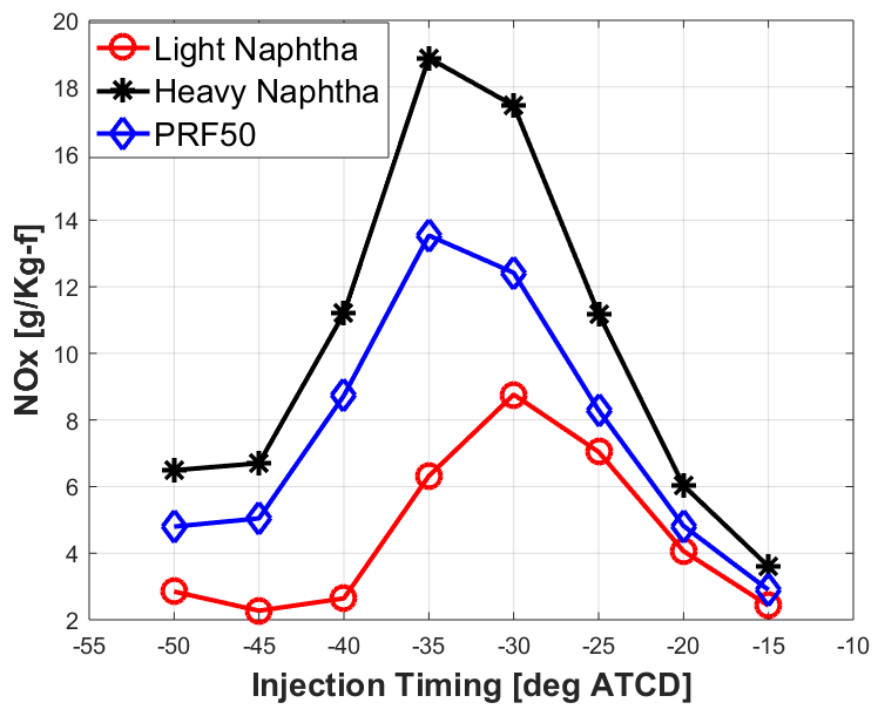

Figure 4-48. Comparison of predicted NOx for charge temperature $386.49 \mathrm{~K}$ at various injection timings using three fuels

Unburned hydrocarbon produced by combustion of PRF50 is much more as compared to other two fuels (see Figure 4-50). 


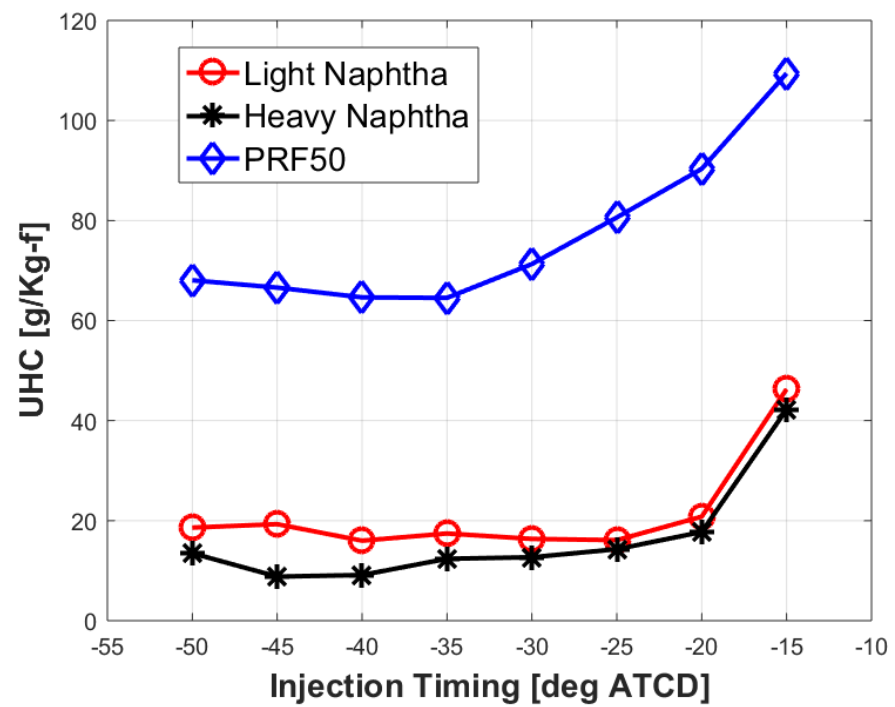

Figure 4-49. Comparison of predicted UHC for charge temperature $386.49 \mathrm{~K}$ at various injection timings using three fuels

All three fuels show a similar trend for the $\mathrm{CO}$ in Figure 4-51. As injection timings are advanced, $\mathrm{CO}$ goes on decreasing followed by increasing trend. For earlier injection timing, light naphtha has more CO then heavy naphtha and PRF50.

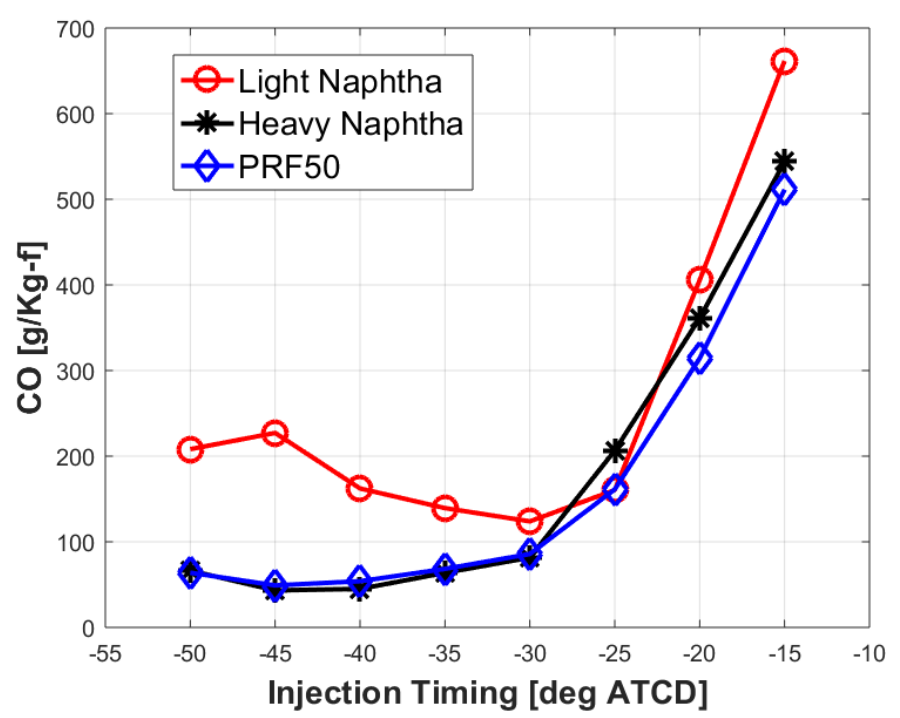

Figure 4-50. Comparison of predicted $\mathrm{CO}$ for charge temperature $386.49 \mathrm{~K}$ at various injection timings using three fuels

Good stratified combustion is hypothesized be achieved when combustion efficiency is more than or equal to $90 \%$, maximum pressure rise rates is less than or equal to $10 \mathrm{bar} / \mathrm{deg}$ 
and NOx values less than or equal to $5 \mathrm{~g} / \mathrm{Kg}$-f. For heavy naphtha, higher combustion efficiency is achieved, but these cases also have higher PRR and NOx. These values indicate that stratified combustion is not attained when heavy naphtha is used as fuel. The higher value of PRR is due to simultaneous auto-ignition of a large amount of fuel in the combustion chamber. Higher localized temperature arises due to rich combustion giving a boost to NOx production. Among all the injection timings cases studied none shows characteristics of well-stratified combustion for heavy naphtha. PRF50 shows similar combustion parameters as that of heavy naphtha. More PRR and NOx for all injection timings can be seen for PRF50 as well. A large amount of UHC produced indicates that combustion has not sustained within lean regions. For light naphtha combustion quality is promising. Combustion efficiency values for fuel is more than $90 \%$ for earlier injection timings. Also, for these earlier injection timings, a value of PRR are less $(<10 \mathrm{bar} / \mathrm{deg})$ along with lower values of NOx $(<5 \mathrm{~g} / \mathrm{kg}-\mathrm{f})$. Therefore, injection timings equal to and advanced than -40 deg ATDC fits into the criteria for optimum combustion cases for light naphtha. For better comparison of three fuels, let's study combustion characteristics of all the fuels at same injection timing in detail. Table 4-13 gives some critical parameters to compare at -15 deg ATDC injection timing operating case

Table 4-13. Predicted combustion characteristics at -15 deg ATDC injection timing using three fuels

\begin{tabular}{|c|c|c|c|}
\hline & Light Naphtha & Heavy Naphtha & PRF50 \\
\hline Combustion Efficiency (\%) & 74.23 & 73.64 & 70.62 \\
\hline Ignition Delay (CAD) & 21.019 & 14.05 & 15.55 \\
\hline Thermal Efficiency (\%) & 31.91 & 32.20 & 30.72 \\
\hline PRR (bar/deg) & 6.71 & 9.96 & 10.61 \\
\hline CO (g/Kg-f) & 661.57 & 543.84 & 511.28 \\
\hline UHC (g/Kg-f) & 46.31 & 42.244 & 109.43 \\
\hline NOx (g/Kg-f) & 2.43 & 3.6 & 2.9 \\
\hline
\end{tabular}

Operating conditions are the same for all the fuels. All three fuels have a combustion efficiency of less than $90 \%$. Light naphtha gives higher combustion efficiency among three with longer ignition delay and lower maximum pressure rise rate. Heavy naphtha dominates the thermal efficiency. For emissions at EVO, light naphtha has maximum $\mathrm{CO}$, heavy naphtha has maximum NOx and PRF50 has maximum UHC. Following Figure 452 gives pressure and HRR trace for three fuels. PRF50 and Heavy naphtha show rapid heat release closer to TDC. For light naphtha sudden heat release takes place later in the power stroke. 


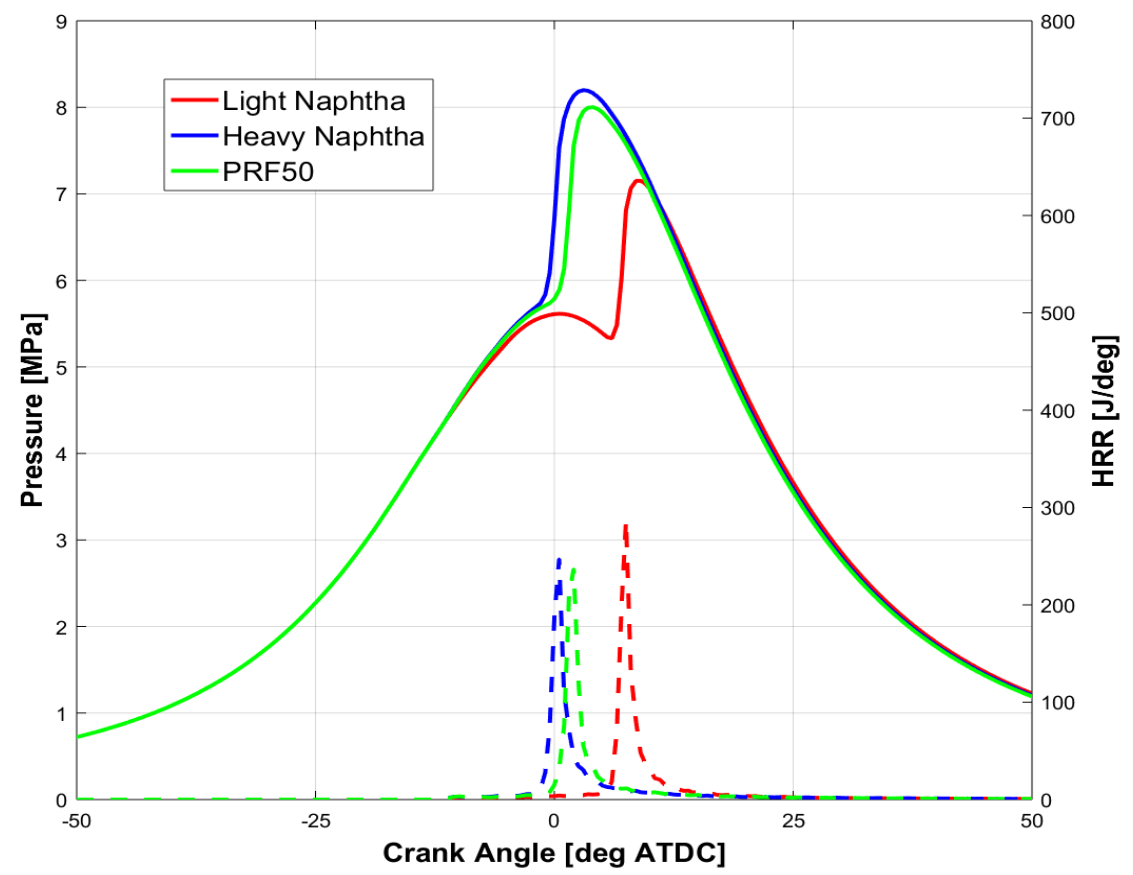

Figure 4-51. Comparison of predicted pressure and HRR at charge temperature $386.49 \mathrm{~K}$ at IVC with $-15 \mathrm{deg}$ ATDC injection timing using three fuels

The Figure 4-53 given below gives vaporization rate for three fuels when injected at -15 deg ATDC within same ambient conditions.

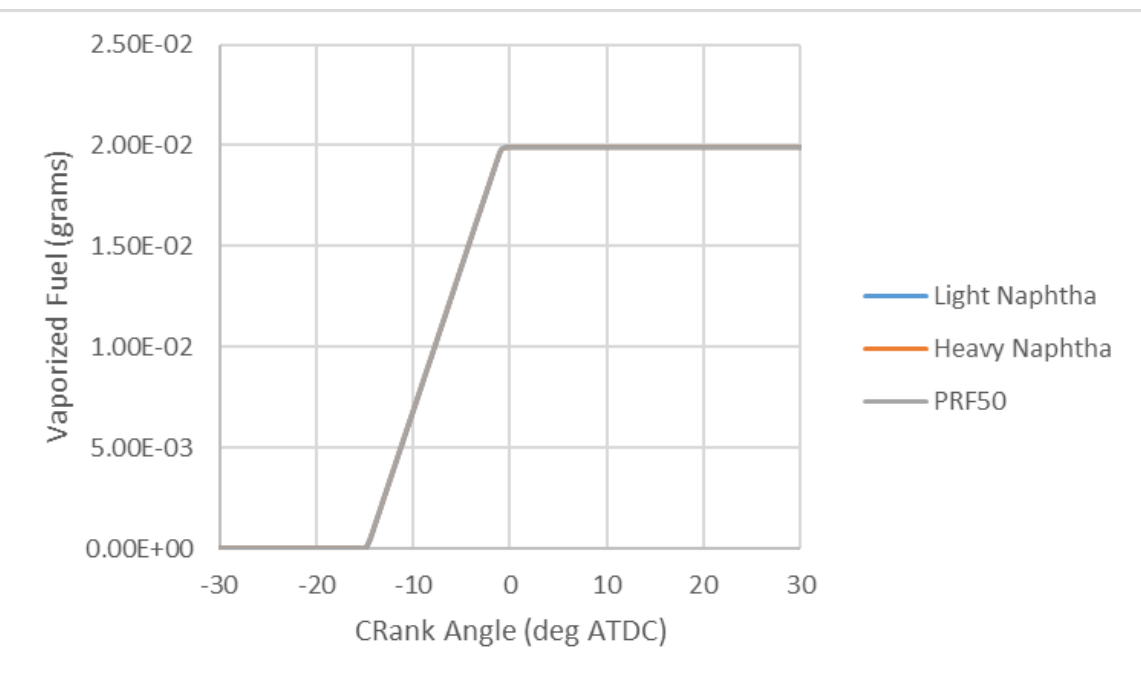

Figure 4-52. Comparison of predicted vaporization rate at charge temperature $386.49 \mathrm{~K}$ at IVC with $-15 \mathrm{deg}$ ATDC injection timing using three fuels 
All three fuels vaporize as soon as they enter the combustion chamber because of high ambient temperatures.

Figure 4-54 gives an average temperature for three fuels. The maximum average temperature achieved within the combustion chamber is higher for heavy naphtha whereas average temperature during expansion is higher for light naphtha.

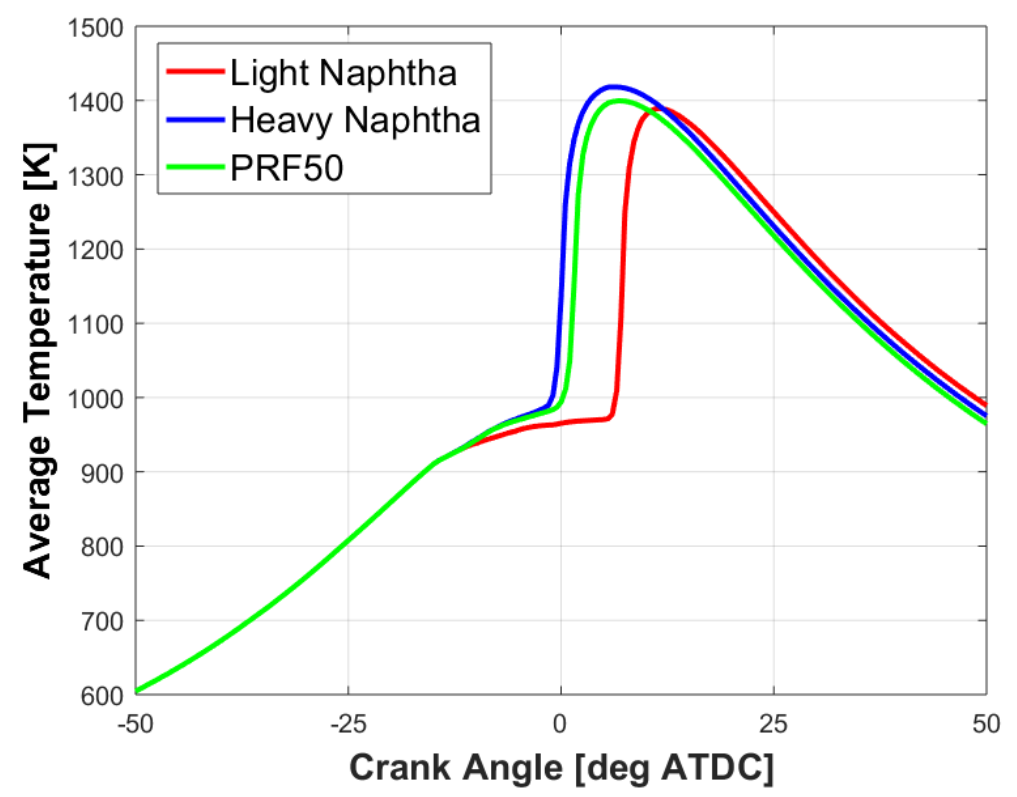

Figure 4-53. Comparison of predicted average temperature at charge temperature 386.49 $\mathrm{K}$ at IVC with -15 deg ATDC injection timing using three fuels

Figure 4-55 shows the y-axis cut planes of the combustion chamber just before combustion starts for all three fuels. All three fuels show a rich area near the injector. Maximum equivalence ratio in the combustion chamber for heavy naphtha, light naphtha and PRF50 are equal to $6.27,4.43$ and 5.96 respectively.

Light naphtha has highest ignition delay owning to its lowest reactivity among three fuels. As shown for the baseline conditions, higher ignition delay is desired for injection near TDC to allow more mixing. Same can be said for increased charge temperature at IVC operating condition. Higher ignition delay means more fuel stratification which gives a combination with higher combustion efficiency along with lower PRR and NOx. Here, equivalence ratio value comparison shows that for light naphtha more fuel has flown from rich regions near the nozzle to the remaining combustion chamber. However available ignition delay is not sufficient to give well-stratified charge and thereby the good quality of combustion. For heavy naphtha and PRF50, larger values of $\phi$ show even less mixing. Fuel within the rich pockets undergoes simultaneous auto ignition giving high PRR. Combustion at these operating conditions has higher $\mathrm{CO}$ and UHC due to lack of oxygen (rich equivalence ratio). For PRF50, average ignition delay between two naphthas can be seen. That means some fuel does move from rich to a lean area, but lean regions are hugely 
diluted and below the flammability limit, resulting into the high amount of UHC and lowering combustion efficiency. Heavy naphtha has higher lower heating value than light naphtha. Hence despite having slightly lower combustion efficiency has higher peak average temperature. Combustion for heavy naphtha takes place during the compression stroke; this also contributes in the higher peak average temperature giving higher NOx. In general, when fuel is injected at $-15 \mathrm{deg}$ ATDC, none of the fuel shows characteristics of good combustion (higher combustion efficiency, lower PRR). Lower ignition delay avoids stratification. Fuel remains in heavily rich pockets, giving incomplete combustion (high $\mathrm{CO}$ and $\mathrm{UHC})$.

a)

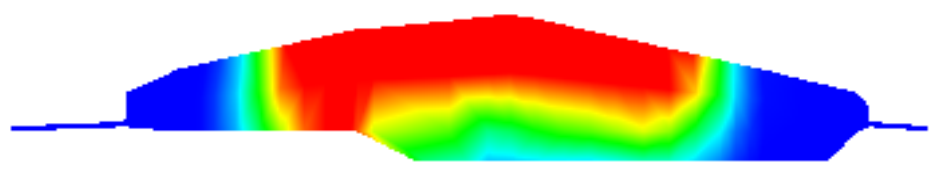

b)

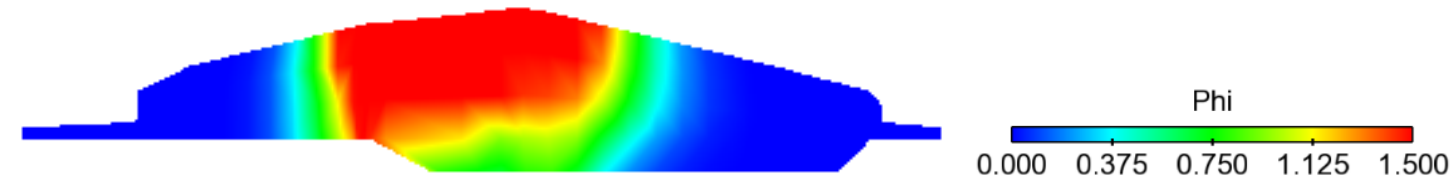

c)

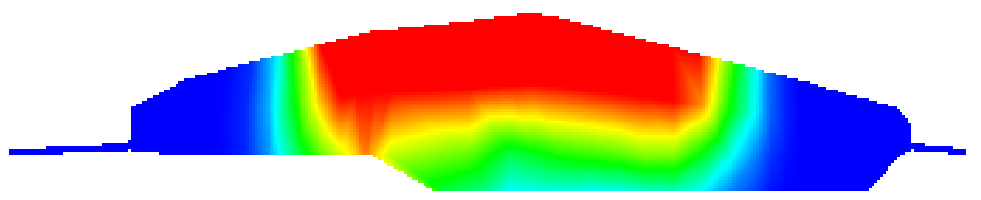

Figure 4-54. Predicted equivalence ratio distribution at charge temperature $386.49 \mathrm{~K}$ at IVC with -15 deg ATDC injection timing for a) Heavy Naphtha at TDC b) Light Naphtha at $6 \operatorname{deg}$ ATDC c) PRF50 at $1 \mathrm{deg}$ ATDC

Let's look at the Table 4.14 which gives combustion parameters for all three fuels at -25 deg ATDC. Light naphtha gives maximum combustion and thermal efficiency. Although it has the highest value of the maximum pressure rise rate as well. PRF50 gives the minimum combustion efficiency with maximum UHC at EVO. Combustion of heavy naphtha at this operating condition gives maximum $\mathrm{CO}$ and NOx at exhaust valve opening. 
Table 4-14 Predicted combustion characteristics at -25 deg ATDC injection timing using three fuels

\begin{tabular}{|c|c|c|c|}
\hline & Light Naphtha & Heavy Naphtha & PRF50 \\
\hline Combustion Efficiency (\%) & 94.77 & 92.36 & 87.85 \\
\hline Ignition Delay (CAD) & 26.03 & 18.01 & 19.03 \\
\hline Thermal Efficiency (\%) & 42.32 & 40.57 & 38.26 \\
\hline PRR (bar/deg) & 18.63 & 13.76 & 16.62 \\
\hline CO (g/Kg-f) & 160.44 & 206.52 & 161.25 \\
\hline UHC (g/Kg-f) & 16.10 & 14.29 & 80.62 \\
\hline NOx (g/Kg-f) & 7.04 & 11.19 & 8.29 \\
\hline
\end{tabular}

Following Figure 4-56 shows pressure and heat release rate. Rapid heat release for light naphtha is seen later as compared to two other fuels. Steep pressure rise rates are observed for all three fuels. Light naphtha gives the highest peak for heat release rate.

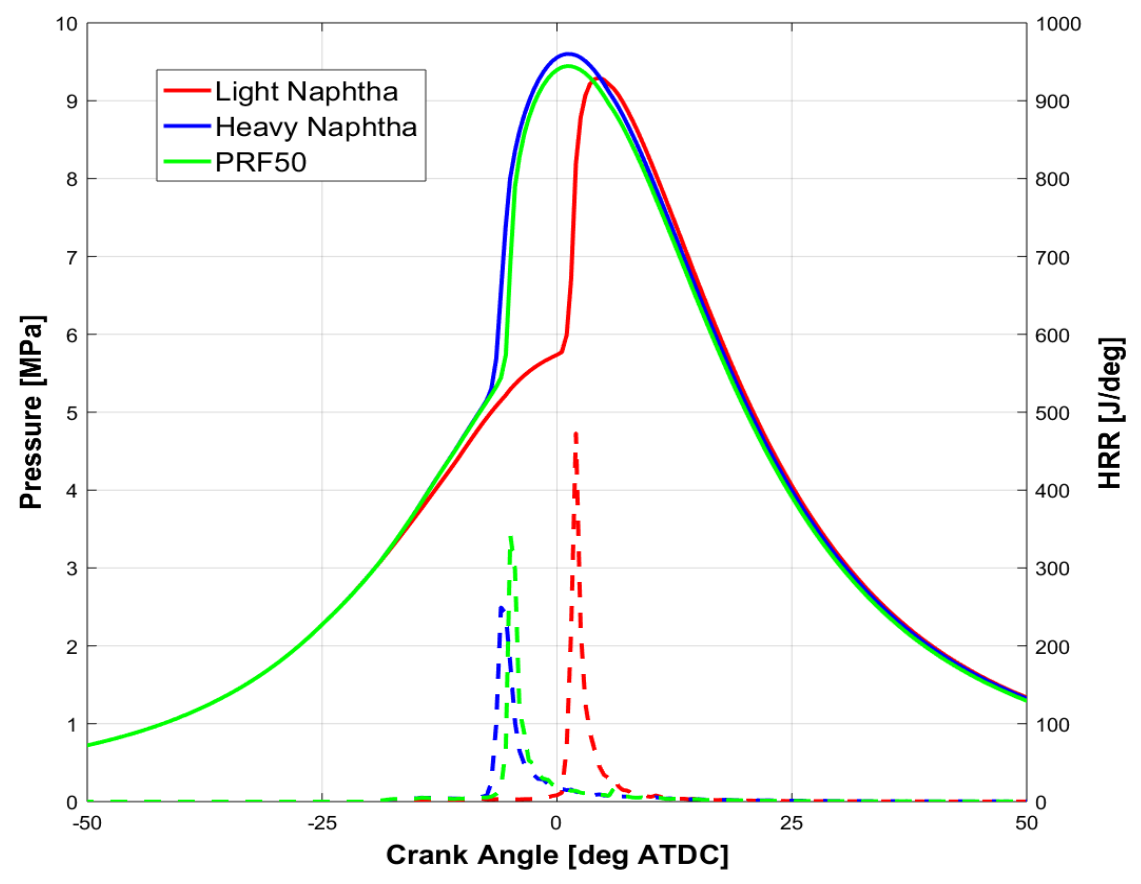

Figure 4-55. Comparison of predicted pressure and HRR at charge temperature $386.49 \mathrm{~K}$ at IVC with -25 deg ATDC injection timing using three fuels

Figure 4-57 shows the vaporization rate for three fuels. 


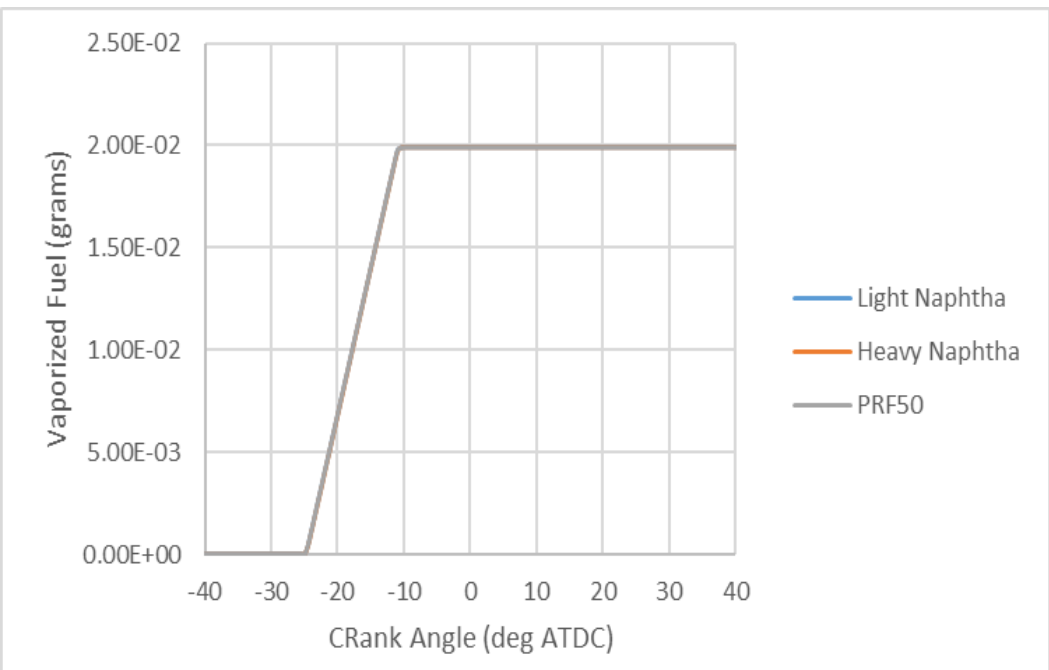

Figure 4-56. Comparison of predicted vaporization rate at charge temperature $386.49 \mathrm{~K}$ at IVC with $-25 \operatorname{deg}$ ATDC

As expected all three fuels are vaporized at the same rate despite having different volatility because of higher charge temperature. All the fuels are vaporized before the start of combustion.

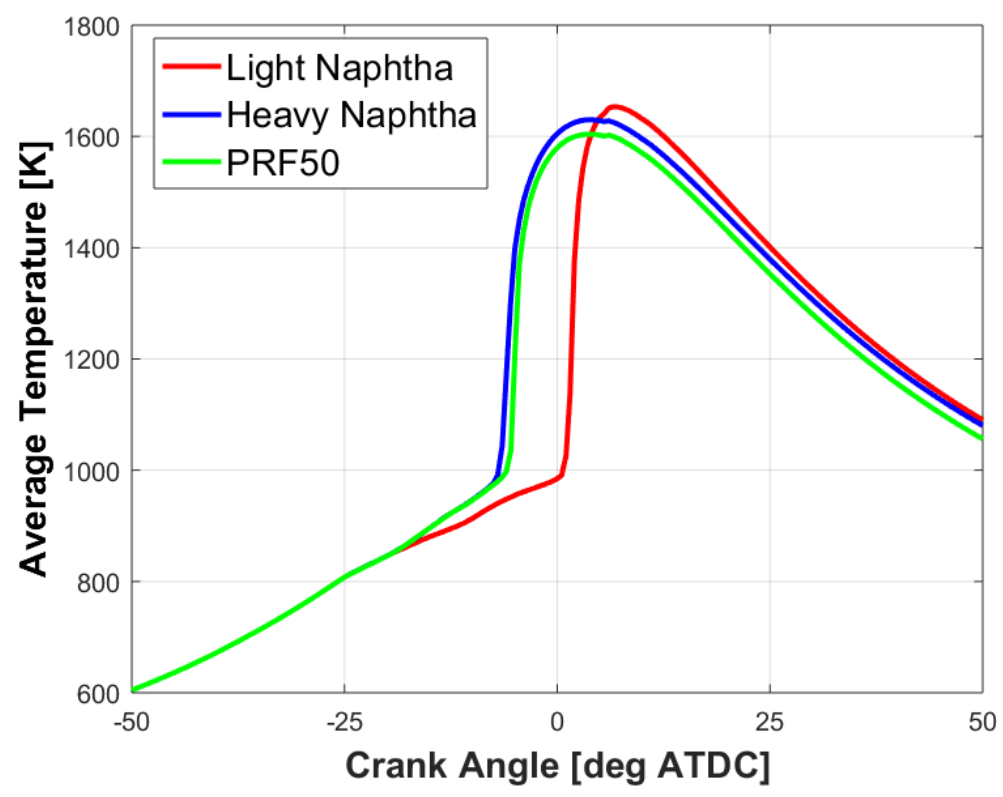

Figure 4-57. Comparison of predicted average temperature at charge temperature 386.49 $\mathrm{K}$ at IVC with -25 deg ATDC injection timing using three fuels

Figure 4-58 above gives average temperature within the combustion chamber at each crank angle. Maximum average temperature is shown by light naphtha along with higher 
expansion temperature. Fuel distribution in the chamber can be explained by equivalence ratio distribution shown on y-axis cut plane shown below in Figure 4-59.

a)

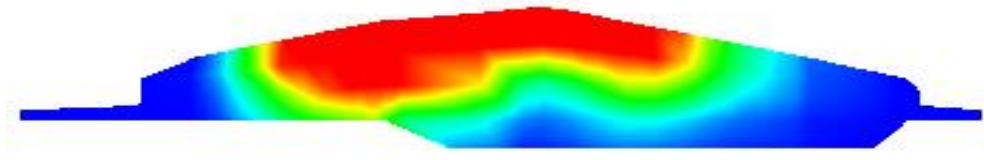

b)

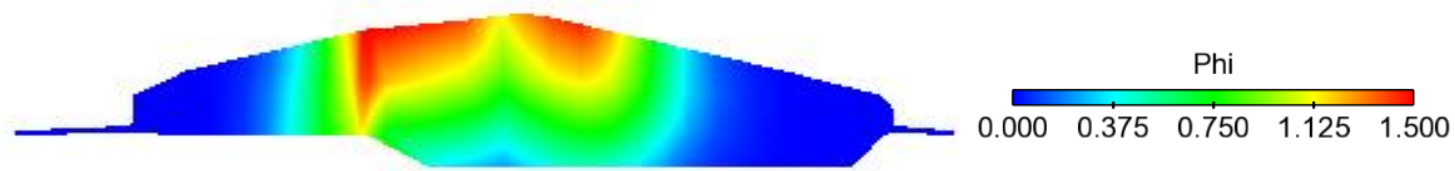

c)

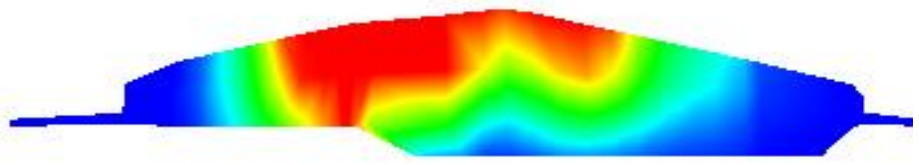

Figure 4-58. Predicted equivalence ratio distribution at charge temperature $386.49 \mathrm{~K}$ at IVC with -25 deg ATDC injection timing for a) Heavy Naphtha at -6 deg ATDC b) Light Naphtha at $1 \mathrm{deg}$ ATDC c) PRF50 at $1 \mathrm{deg}$ ATDC

Numerically, maximum equivalence ratio for heavy naphtha is equal to 5.18, for light naphtha it is approximately equal to 2.19, and for PRF50 it's 3.86. Rich regions for light naphtha has lower values of $\phi$, which indicates more mixing for the fuel.

Similar to the previous cases, light naphtha has a longer ignition delay due to its lower reactivity than other two fuels. longer ignition delay implies more mixing and hence more stratification for light naphtha. Steeper pressure rise rate that accompanies higher combustion efficiency for light naphtha indicates that combustion is not due to the stratified air-fuel mixture instead because of simultaneous autoignition of a large amount of fuel. The similar combination of higher combustion efficiency and higher PRR is found for heavy naphtha and PRF50. The higher CO can be seen for all three fuels. More CO implies incomplete combustion which can be due to lack of oxygen in the rich combustion. UHC amount at EVO is less for all three fuels. More NOx is precisely in accordance with the higher temperature in the chamber. In summary, all three fuels have higher combustion efficiency but with higher PRR and NOx. Increased charge temperature promotes reduced ignition delay and widens the flammability limit range. Here all three fuels show 
homogeneous combustion because of higher ambient temperature and lack of stratified charge.

Table 4-15 presented below gives combustion characteristics for three fuels at -40 deg ATDC injection timing. Among three fuels heavy naphtha has highest combustion efficiency followed by light naphtha and PRF50. Light naphtha gives highest thermal efficiency with highest ignition delay. Corresponding to -25 deg ATDC injection timing cases, highest $\mathrm{CO}$ is provided by light naphtha, highest NOx by heavy naphtha and highest UHC by PRF50.

Table 4-15. Predicted combustion characteristics at -40 deg ATDC injection timing using three fuels

\begin{tabular}{|c|c|c|c|}
\hline & Light Naphtha & Heavy Naphtha & PRF50 \\
\hline Combustion Efficiency (\%) & 94.81203 & 98.20911 & 92.35772 \\
\hline Ignition Delay (CAD) & 42.01 & 31.03 & 30.55 \\
\hline Thermal Efficiency (\%) & 45.50046 & 44.62583 & 41.5641 \\
\hline PRR (bar/deg) & 9.278604 & 11.86574 & 12.34645 \\
\hline CO (g/Kg-f) & 162.27 & 44.96242 & 53.96 \\
\hline UHC (g/Kg-f) & 15.99 & 9.1276 & 64.64 \\
\hline NOx (g/Kg-f) & 2.643 & 11.2 & 8.73 \\
\hline
\end{tabular}

The difference in combustion characteristics can be seen in pressure and HRR trace shown in Figure 4-60. For heavy naphtha, combustion duration is highest with two peaks. Light Naphtha shows rapid heat release in expansion stroke with large combustion duration indicating stratified combustion.

Figure 4-61 gives vaporization rate and as expected show a similar rate for all three fuels. Again, higher ambient temperature results in vaporization of all three fuels with different volatility at the same rate. 


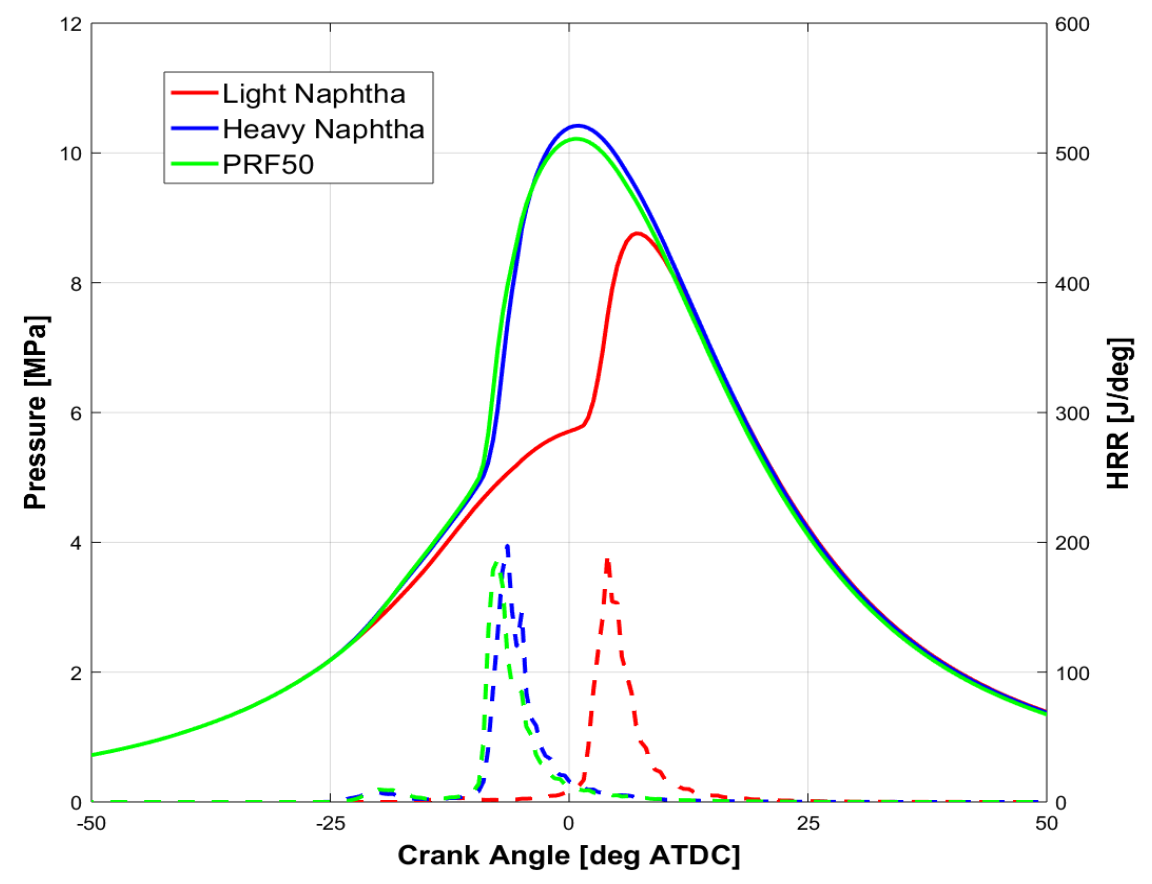

Figure 4-59. Comparison of predicted pressure and HRR at charge temperature $386.49 \mathrm{~K}$ at IVC with $-40 \mathrm{deg}$ ATDC injection timing using three fuels

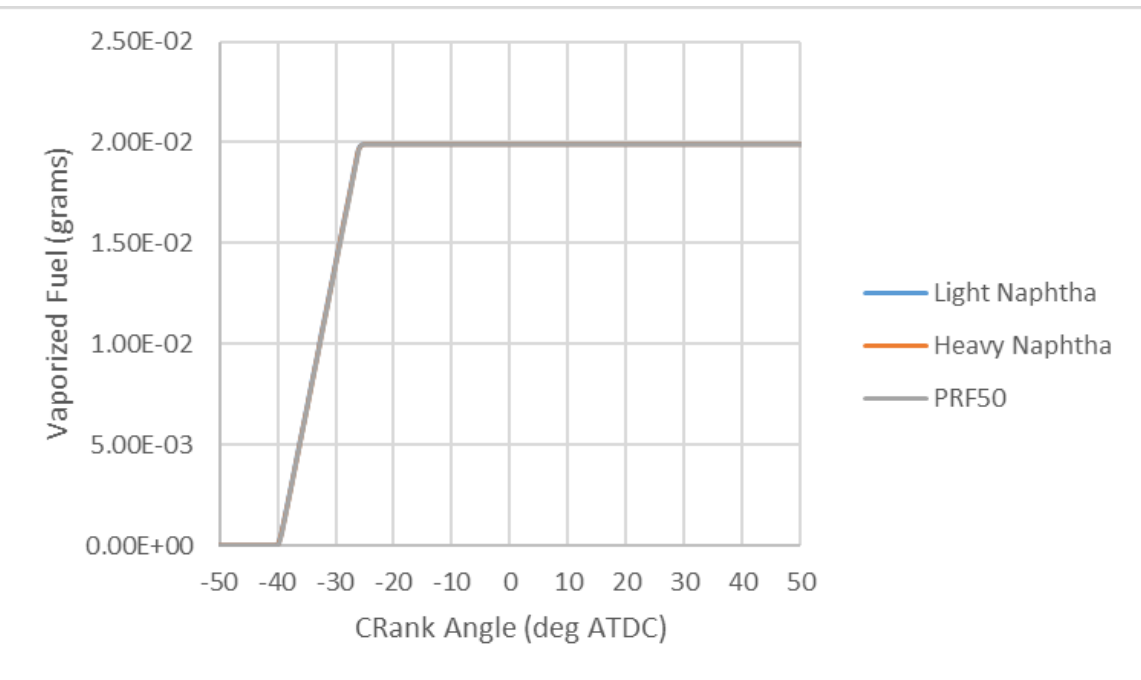

Figure 4-60. Comparison of predicted vaporization rate at charge temperature $386.49 \mathrm{~K}$ at IVC with -40 deg ATDC injection timing using three fuels

Average temperature within the combustion chamber shows the peculiar trend and its given by Figure 4-62. Heavy Naphtha has maximum average temperature whereas light naphtha has the lowest maximum temperature. 


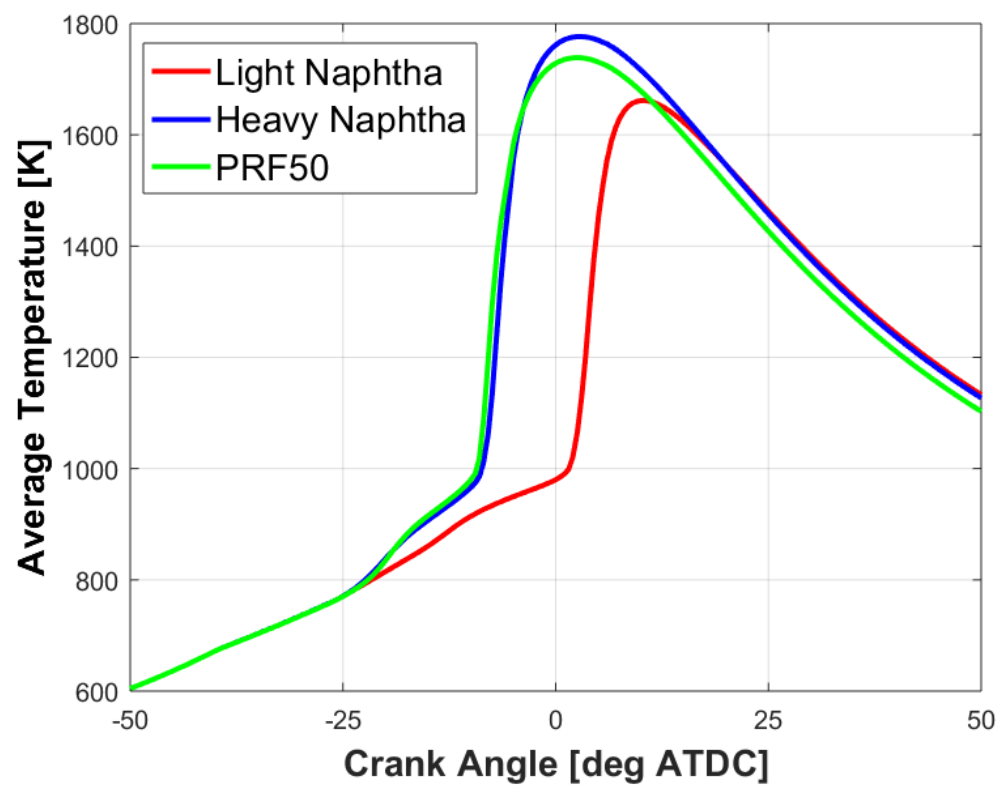

Figure 4-61. Comparison of predicted average temperature at charge temperature 386.49 $\mathrm{K}$ at IVC with -40 deg ATDC injection timing using three fuels

Numerically maximum equivalence ratio values for heavy naphtha, light naphtha and PRF 50 are 2.07, 1.41 and 1.97 respectively (see figure 4-63). For PRF50 and heavy naphtha more fuel is concentrated near injector in contrast to light naphtha.

Even when three fuels are injected as early as -40 deg ATDC in the compression stroke, only light naphtha, fuel with the lowest reactivity, successfully give higher combustion efficiency (>90\%) with low PRR ( $<10 \mathrm{bar} / \mathrm{deg})$ and low NOx $(<5 \mathrm{~g} / \mathrm{Kg}-\mathrm{f})$. More substantial ignition delay in case of light naphtha is sufficient to achieve fuel stratification in such way that sequential auto-ignition takes place giving higher efficiency and lower PRR and NOx. Heavy Naphtha has a higher value of combustion efficiency than light naphtha. But higher PRR value accompanying suggests that combustion for heavy naphtha fuel is not sequential but simultaneous auto-ignition of fuel within the rich region. High NOx at EVO for heavy naphtha is due to a higher localized temperature within the rich airfuel pocket. 
a)

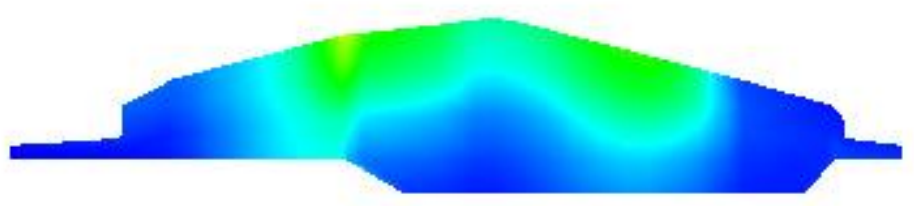

b)

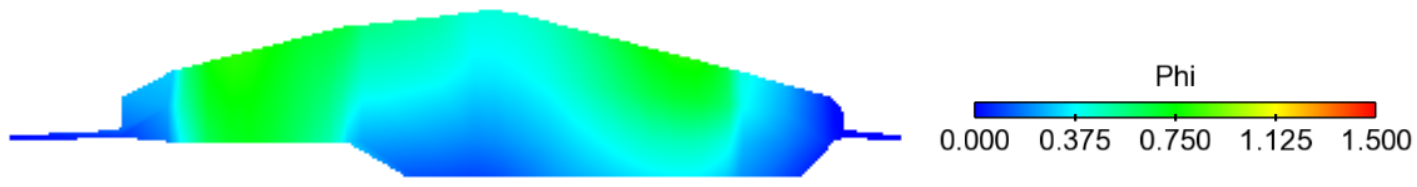

c)

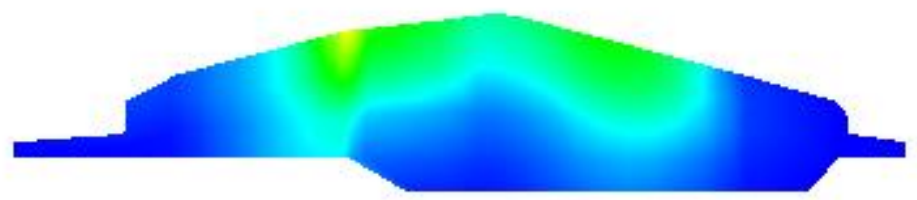

Figure 4-62. Predicted equivalence ration distribution at charge temperature $386.49 \mathrm{~K}$ at IVC with -40 deg ATDC injection timing for a) Heavy Naphtha at -2 deg ATDC b) Light Naphtha at 2 deg ATDC c) PRF50 at -9 deg ATDC

To investigate the effect of initial gas temperature, the temperature at IVC was increased by $15 \mathrm{~K}$. Amount of fuel injected into the cylinder is kept same. Increase in the charge temperature has affected the maximum combustion efficiency for all three fuels.

Table 4-16. Maximum Combustion Efficiency for heavy naphtha

\begin{tabular}{|c|c|c|c|}
\hline & $\begin{array}{c}\text { Combustion } \\
\text { efficiency }\end{array}$ & $\begin{array}{c}\text { Injection } \\
\text { timing }\end{array}$ & PRR \\
\hline & $(\%)$ & $($ deg ATDC) & $(\mathrm{bar} / \mathrm{deg})$ \\
\hline Baseline & 96.66 & -40 & 11.50 \\
\hline Increased Charge Temperature & 98.3 & -45 & 11.56 \\
\hline
\end{tabular}


For heavy naphtha, operating condition with increased charge temperature does have higher maximum combustion efficiency, and it is obtained at earlier injection timing. A similar effect can be seen in the other two fuels as well.

Table 4-17. Maximum Combustion Efficiency for light naphtha

\begin{tabular}{|c|c|c|c|}
\hline & $\begin{array}{c}\text { Combustion } \\
\text { efficiency }\end{array}$ & $\begin{array}{c}\text { Injection } \\
\text { timing }\end{array}$ & PRR \\
\hline & $(\%)$ & (deg ATDC) & (bar/deg) \\
\hline Baseline & 93.07 & -25 & 14.48 \\
\hline Increased Charge Temperature & 95.87 & -30 & 18.51 \\
\hline
\end{tabular}

Table 4-18. Maximum Combustion Efficiency for PRF50

\begin{tabular}{|c|c|c|c|}
\hline & $\begin{array}{c}\text { Combustion } \\
\text { efficiency }\end{array}$ & $\begin{array}{c}\text { Injection } \\
\text { timing }\end{array}$ & PRR \\
\hline & $(\%)$ & (deg ATDC) & (bar/deg) \\
\hline Baseline & 90.91 & -40 & 10.98 \\
\hline Increased Charge Temperature & 92.36 & -40 & 13.85 \\
\hline
\end{tabular}

Maximum combustion efficiency obtained for both the operating conditions is governed by spontaneous combustion and not sequential auto-ignition. (Higher combustion efficiency with higher PRR). For the cases mentioned above the fuel in the rich region burns spontaneously giving higher PRR. Therefore, instead of talking about cases with maximum combustion efficiency, let's talk about cases with optimum combustion. Advantages of reduction in ignition delay thus reduction in the air-fuel mixing have been seen for light naphtha when injected earlier in the compression stroke. For baseline cases, combustion for light naphtha for advanced injection timings is limited by over mixing of air and fuel. Increased charge temperature increases the rate of reaction thereby reducing ignition delay as compared to the baseline condition. Reduced ignition delay avoids lean regions from becoming overly lean (avoiding incomplete combustion). For light naphtha, injection timing -40 deg ATDC gives higher combustion efficiency (>90\%) with lower PRR ( $<10 \mathrm{bar} / \mathrm{deg})$ and lower NOx $(<5 \mathrm{~g} / \mathrm{Kg}-\mathrm{f})$. As mentioned in baseline results ideal stratification varies with the change in fuel, injection properties, and ambient conditions. For light naphtha, richest regions should have local $\phi=/<1.4$ to avoid NOx, and the leanest region should have local value as $\phi=/>0.0031$ to prevent the formation of excessive $\mathrm{CO}$ and UHC. However, the other two fuels do not show any case with optimum combustion characteristics throughout the injection sweep. Higher reactivity combined with higher charge temperature does not give sufficient stratification to achieve sequential autoignition. Hence to conclude, an increase in charge temperature is only profitable for lower reactivity fuel at earlier injection timings.

\subsubsection{Injection Pressure Variation}

Similar injection timing sweep is done for four other injection pressure values, which are 600, 500, 300 and 200 bar. Table 4-19 compare maximum combustion efficiency and 
injection timings for which maximum efficiency is obtained for all three fuels under increased charge temperature at IVC operating conditions.

Table 4-19. Maximum combustion efficiency and injection timing for injection pressure sweep

\begin{tabular}{|c|c|c|c|c|c|c|}
\hline $\begin{array}{c}\text { Injection } \\
\text { Pressure }\end{array}$ & \multicolumn{2}{|c|}{ Light Naphtha } & \multicolumn{2}{c|}{ Heavy Naphtha } & \multicolumn{2}{c|}{ PRF50 } \\
\hline & $\begin{array}{c}\text { Combustion } \\
\text { Efficiency }\end{array}$ & $\begin{array}{c}\text { Injection } \\
\text { Timing }\end{array}$ & $\begin{array}{c}\text { Combustion } \\
\text { Efficiency }\end{array}$ & $\begin{array}{c}\text { Injection } \\
\text { Timing }\end{array}$ & $\begin{array}{c}\text { Combustion } \\
\text { Efficiency }\end{array}$ & $\begin{array}{c}\text { Injection } \\
\text { Timing }\end{array}$ \\
\hline Bar & $\%$ & $\begin{array}{c}\text { deg } \\
\text { ATDC }\end{array}$ & $\%$ & $\begin{array}{c}\text { deg } \\
\text { ATDC }\end{array}$ & $\%$ & $\begin{array}{c}\text { deg } \\
\text { ATDC }\end{array}$ \\
\hline 600 & 95.87 & -25 & 98.25 & -30 & 92.37 & -30 \\
\hline 500 & 95.57 & -25 & 98.62 & -50 & 91.83 & -35 \\
\hline 400 & 95.87 & -30 & 97.28 & -50 & 92.36 & -40 \\
\hline 300 & 96.31 & -40 & 98.62 & -55 & 92.23 & -45 \\
\hline 200 & 95.68 & -45 & 98.20 & -50 & 92.02 & -50 \\
\hline
\end{tabular}

All three fuels don't show much variation in the value of maximum combustion efficiency with variation in the injection pressure. Heavy naphtha shows the highest values of maximum combustion efficiency followed by light naphtha and PRF50. Injection timings at which maximum combustion efficiency is achieved are advanced for higher injection pressure (compared to $400 \mathrm{Bar}$ ) and retarded for reduced injection pressure. As discussed previously in baseline case studies, higher injection pressure compared to 400 Bar results into more mixing (for same injection timing). As a result, for higher injection pressures, injection timings later in the compression stroke gives proper air-fuel mixture for maximum combustion efficiency. Injection timings at which over mixing of fuel takes place are retarded as compared to injection timings at 400 Bar.

However, in the case of higher charge temperature at IVC, all the fuels tend to burn spontaneously instead of sequential autoignition. Therefore, let's discuss optimum case conditions instead of studying cases with maximum combustion efficiency. Increased charge temperature combined with heavy naphtha always gave homogeneous charge combustion for the injection timing range considered here for all injection pressures. Higher reactivity of heavy naphtha gives shorter ignition delay. Shorter ignition delay results into rich regions of an air-fuel mixture which burns homogeneously under the influence of increased charge temperature. To check if it is possible to achieve stratified charge for heavy naphtha, injection timing sweep for heavy naphtha is extended to -70 deg ATDC. As expected earlier fuel injection granted more mixing time and hence obtained combustion without steep pressure rise rates and a large amount of NOx at EVO. Table 420 includes characteristics of good combustion cases for all three fuels at different injection pressures.

Theory illustrated about injection pressure and its variation is again underlined by the results shown above. All the injection timings included in the table for all the injection pressure values are earlier in the compression stroke. As earlier the injection, longer 
ignition delay. Longer ignition delay, more stratified charge thus results in good combustion quality.

Table 4-20. Optimum case condition for each fuel at injection pressure sweep

\begin{tabular}{|c|c|c|c|c|}
\hline & Injection Timing & $\begin{array}{l}\text { Combustion } \\
\text { Efficiency }\end{array}$ & PRR & NOx \\
\hline & deg ATDC & $\%$ & Bar/deg & $g / K g-f$ \\
\hline \multicolumn{5}{|c|}{ Injection Pressure :600 Bar } \\
\hline Light Naphtha & -35 & 94.50 & 9.23 & 2.43 \\
\hline Heavy Naphtha & -65 & 95.31 & 9.87 & 3.42 \\
\hline PRF50 & \multicolumn{4}{|c|}{ NA } \\
\hline \multicolumn{5}{|c|}{ Injection Pressure :500 Bar } \\
\hline Light Naphtha & -40 & 94.57 & 9.46 & 2.44 \\
\hline Heavy Naphtha & -70 & 94.78 & 9.61 & 3.31 \\
\hline PRF50 & \multicolumn{4}{|c|}{ NA } \\
\hline \multicolumn{5}{|c|}{ Injection Pressure :400 Bar } \\
\hline Light Naphtha & -40 & 94.81 & 9.28 & 2.64 \\
\hline Heavy Naphtha & -70 & 96.60 & 10.19 & 2.88 \\
\hline PRF50 & \multicolumn{4}{|c|}{ NA } \\
\hline \multicolumn{5}{|c|}{ Injection Pressure :300 Bar } \\
\hline Light Naphtha & -45 & 95.11 & 9.34 & 2.39 \\
\hline Heavy Naphtha & -70 & 96.28 & 10.22 & 4.85 \\
\hline PRF50 & \multicolumn{4}{|c|}{ NA } \\
\hline \multicolumn{5}{|c|}{ Injection Pressure :200 Bar } \\
\hline Light Naphtha & \multicolumn{4}{|c|}{ NA } \\
\hline Heavy Naphtha & -70 & 96.53 & 8.87 & 1.83 \\
\hline PRF50 & \multicolumn{4}{|c|}{ NA } \\
\hline
\end{tabular}

For light naphtha with the reduction in the injection pressure, the stratified charge is obtained at advanced timings. Reduced pressure will give lesser mixing, hence higher ignition delay is required to get the stratified mixture. Higher ignition delay is apparent when fuel is injected earlier in the compression stroke. The lower value of PRR and NOX manifest stratification inside the combustion chamber for light naphtha. For heavy naphtha, to achieve optimum quality of combustion fuel must be injected very early in the compression stroke for all injection pressure values. Higher charge temperature combined with higher reactivity of fuel gives smaller ignition delay and rich combustion. 


\subsection{Change in EGR fraction:}

Here to study effects of EGR, EGR fraction has increased from 37 to $45 \%$. This increase in EGR fraction has caused to drop oxygen mass fraction from $17 \%$ to $15.7 \%$. EGR composition is kept for baseline as well as high EGR cases. As more exhaust gases are recirculated within the chamber, NOx fraction at IVC also increases. For Baseline case $\mathrm{NOx}$ at IVC is $1.88 \mathrm{~g} / \mathrm{Kg}-\mathrm{f}$ and that is for EGR case is $2.33 \mathrm{~g} / \mathrm{Kg}-\mathrm{f}$.

Let's discuss the effects of increasing EGR percentage on combustion efficiency for all three fuels. Figure 4-64 compares combustion efficiency for injection timing sweep at elevated EGR amount and baseline condition. All three fuels show a decrease in combustion efficiency with increase in EGR percentage. They also follow a similar combustion efficiency tendency for higher EGR percentages as injection timings are advanced.

Figure 4-65 shows ignition delay over injection timing sweep. For all three fuels, ignition delay is directly proportional to EGR percentage which is expected. In the case of light naphtha, for injection timings -45 and -50 deg ATDC combustion never reached to CA10 and hence ignition delay is not shown in Figure 4-65.

Thermal efficiency shown in Figure 4-66 is clearly affected by combustion efficiency and hence follows the same trend. Thermal efficiency increases with an advance in injection timings. Elevation in EGR percentage reflects in the reduction of thermal efficiency at all injection events for all three fuels.

Pressure rise rate (PRR) is a parameter used to predict combustion noise. Figure 4-67 shows PRR for all injection timings for all three fuels. PRR is lower for a higher percentage of EGR. Lowered combustion efficiency is one of the main reason causing reduced PRR.

Reduction in the NOx is the main aim for using higher EGR level. Figure 4-68 presents a comparison of NOx over an injection timing sweep. All three fuels show considerably lower engine-out NOx for all injection timings. CO formation at EVO for higher EGR fraction operating conditions follows a trend similar to the baseline for all three fuels. Figure 4-69 represents that increase in EGR percentage also increases production of $\mathrm{CO}$ at EVO for all three fuels. This trend in $\mathrm{CO}$ for all three fuels indicates incomplete combustion, Light naphtha shows erratic behavior in terms of $\mathrm{CO}$ for advanced injection timings with $45 \%$ EGR. Unburned hydrocarbons are also another indicator of incomplete or misfired combustion. Figure 4-70 show UHC trend for all three fuels. Like CO, UHC quantity is also higher for higher EGR fraction thus prove the hypothesis of incomplete combustion. 
a) Heavy Naphtha

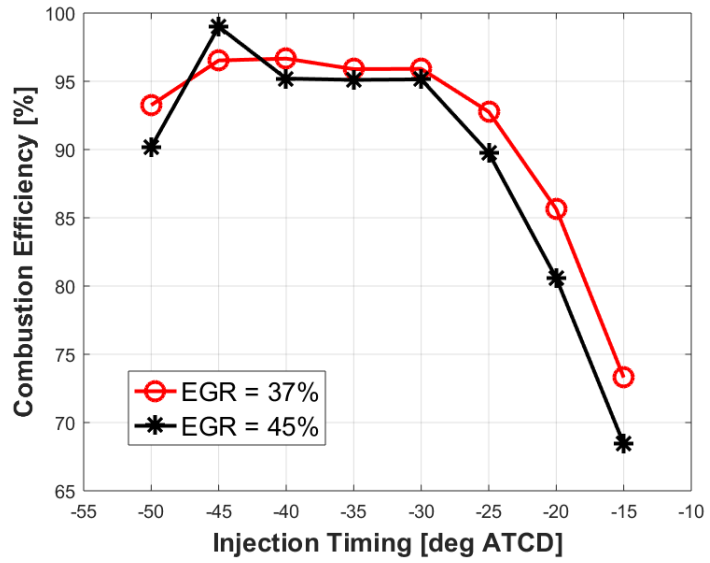

b) Light Naphtha

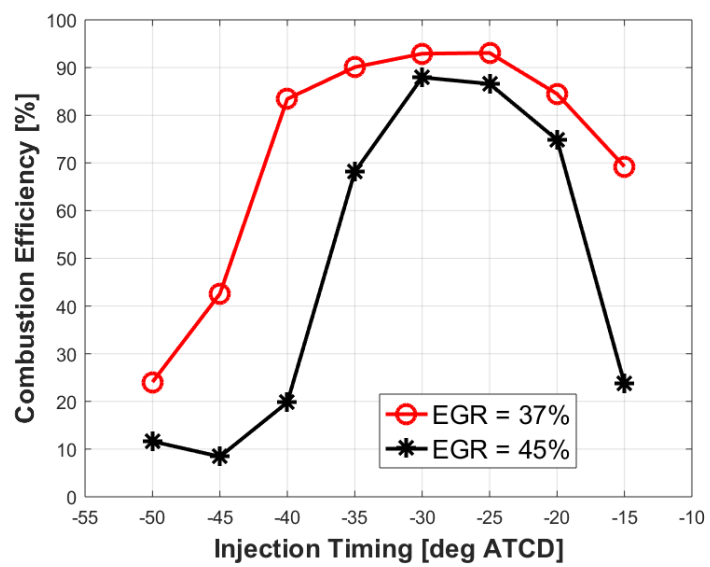

c) PRF50

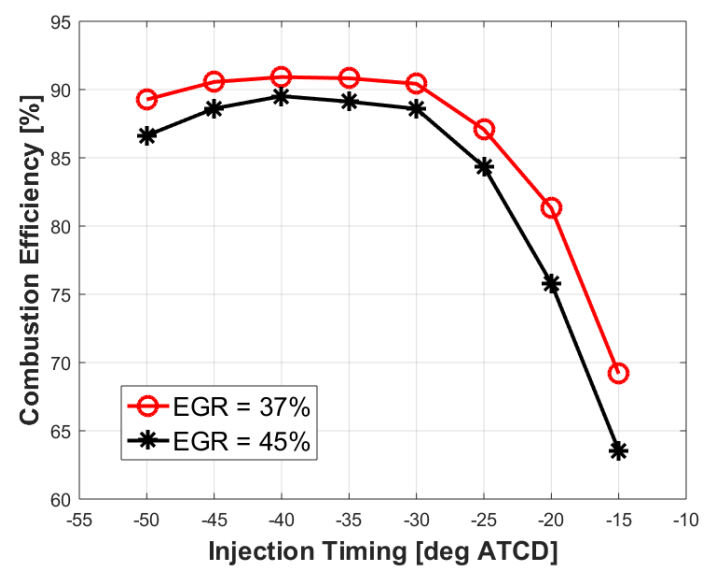

Figure 4-63. Comparison of predicted effect on combustion efficiency due to variation in EGR fraction for various injection timings 
a) Heavy Naphtha

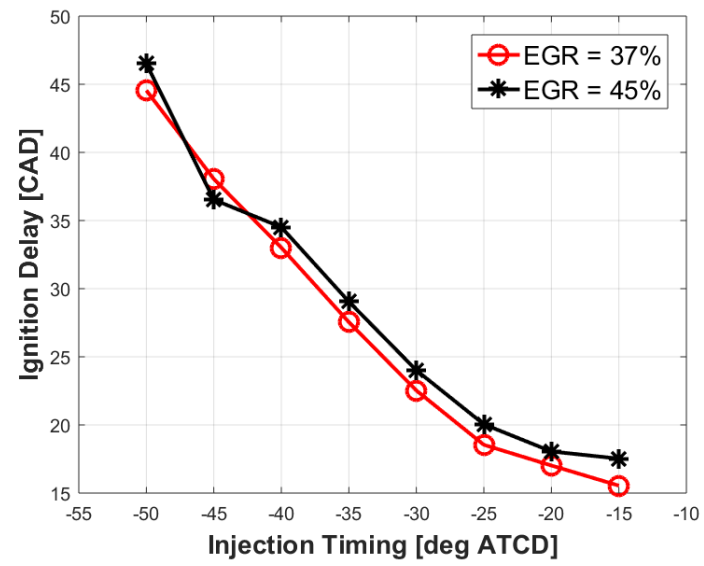

b) Light Naphtha

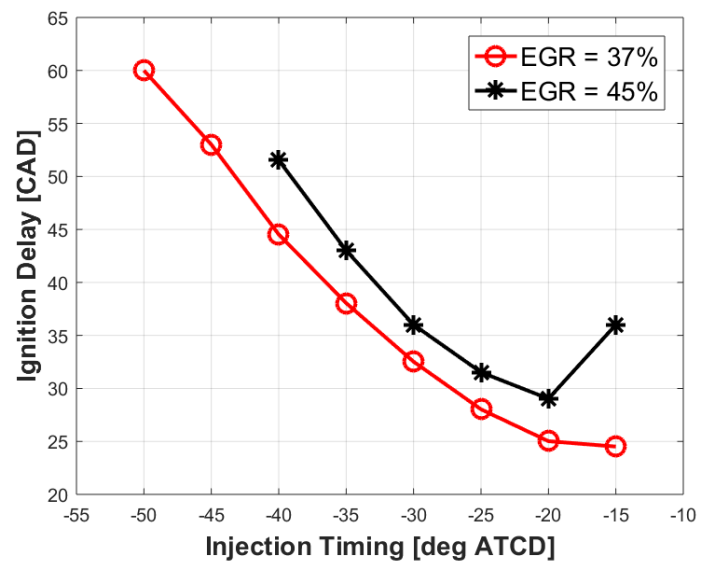

c) PRF50

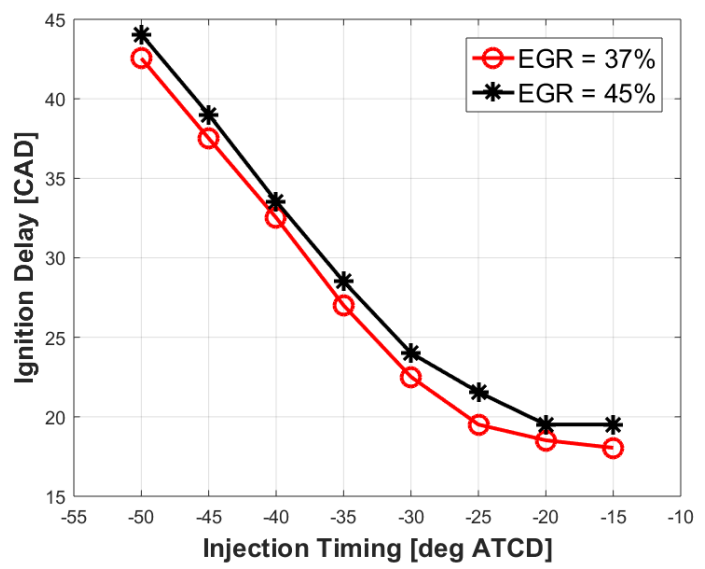

Figure 4-64. Comparison of predicted effect on ignition delay due to variation in EGR fraction for various injection timings 
a) Heavy Naphtha

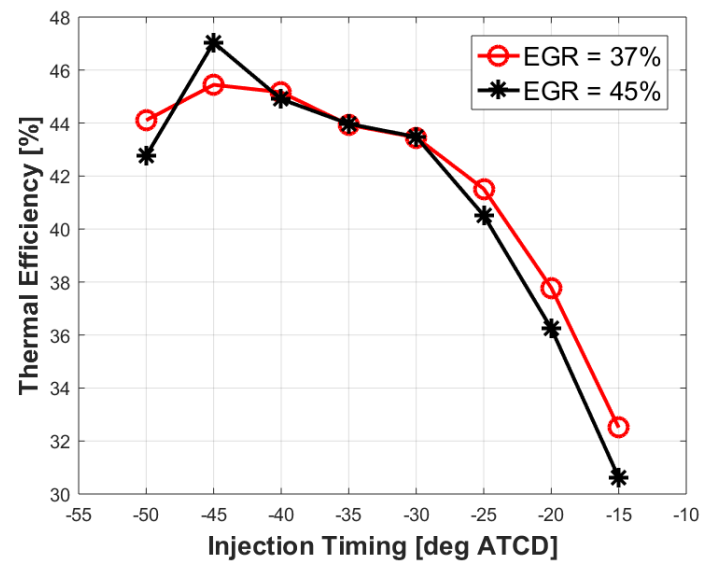

b) Light Naphtha

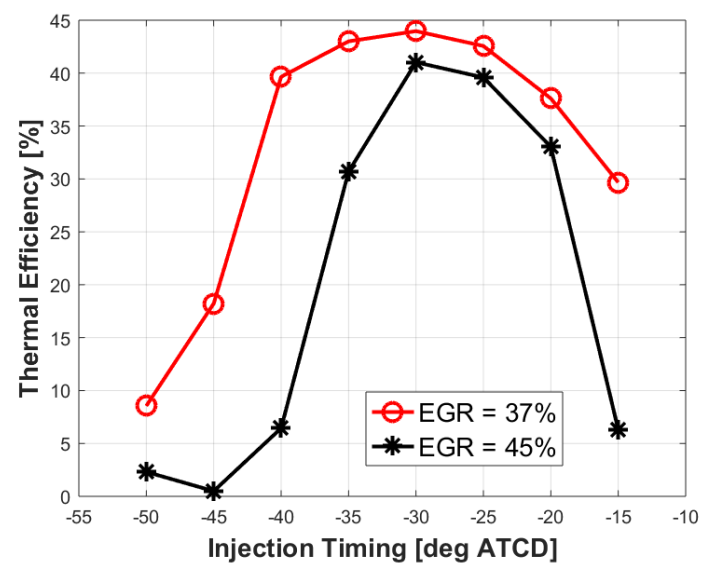

c) PRF50

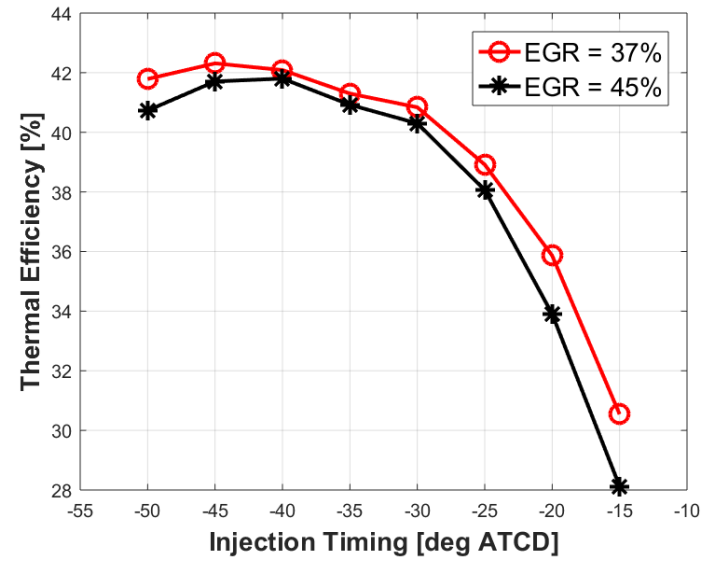

Figure 4-65. Comparison of predicted effect on thermal efficiency due to variation in EGR fraction for various injection timings 
a) Heavy Naphtha

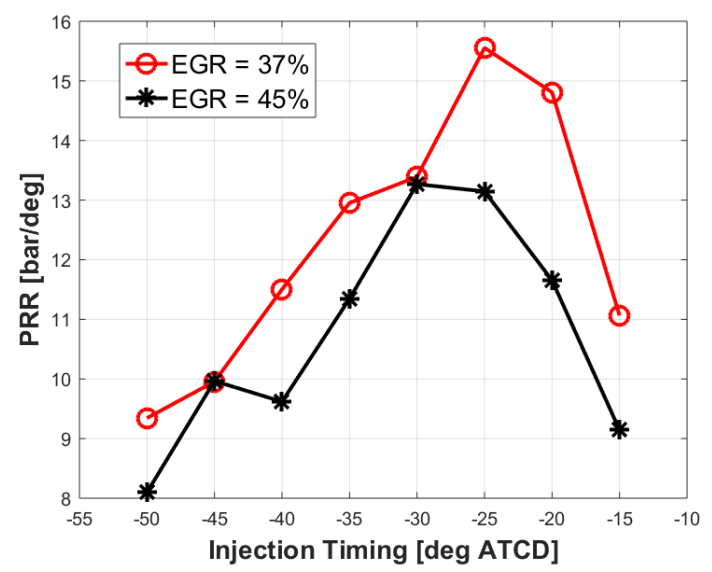

b) Light Naphtha

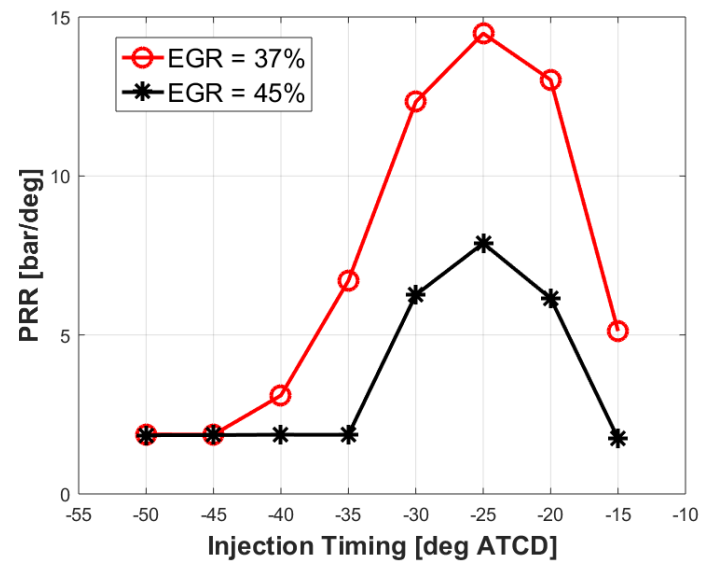

c) PRF50

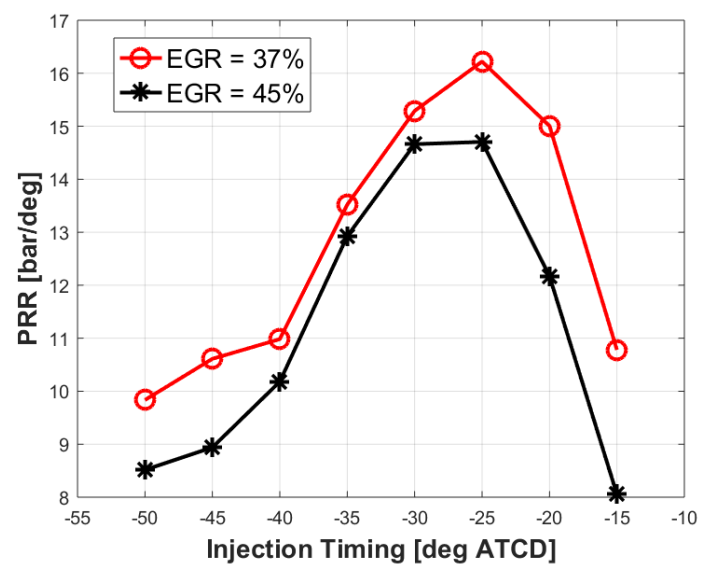

Figure 4-66. Comparison of predicted effect on pressure rise rate due to variation in EGR fraction for various injection timings 
a) Heavy Naphtha

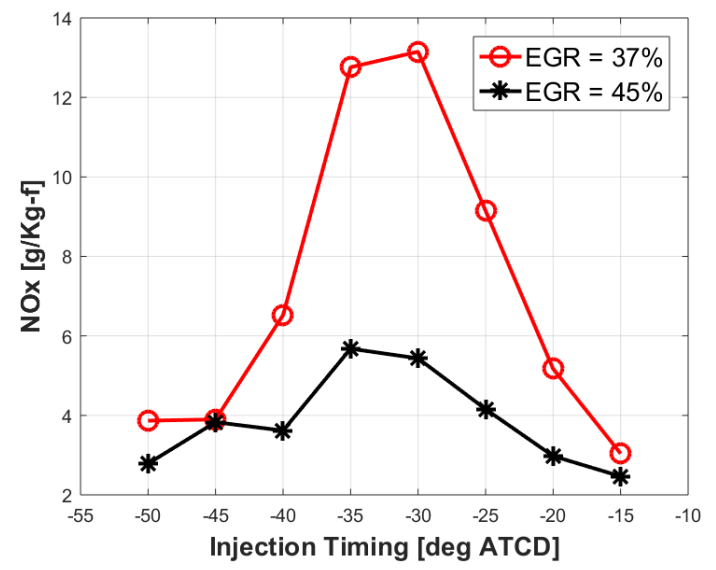

b) Light Naphtha

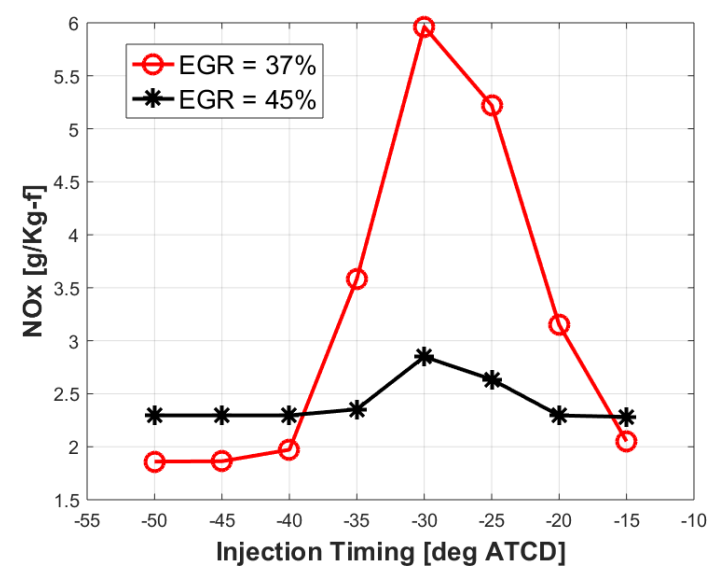

c) PRF50

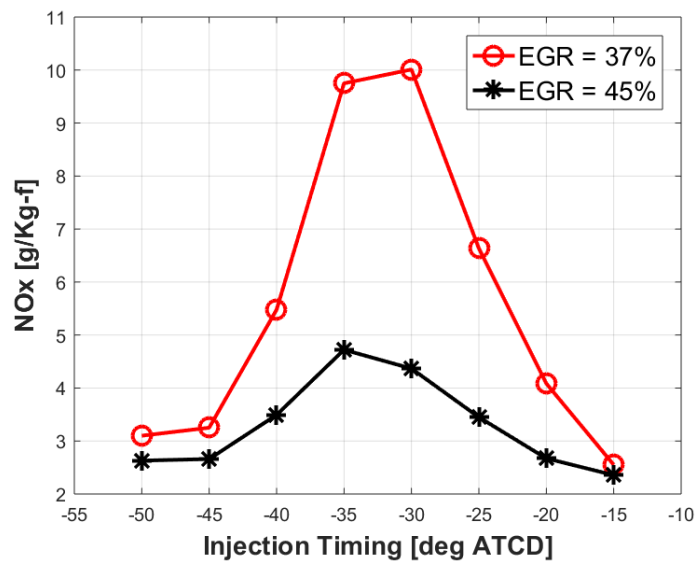

Figure 4-67. Comparison of predicted effect on NOX at EVO due to variation in EGR fraction for various injection timings 
a) Heavy Naphtha

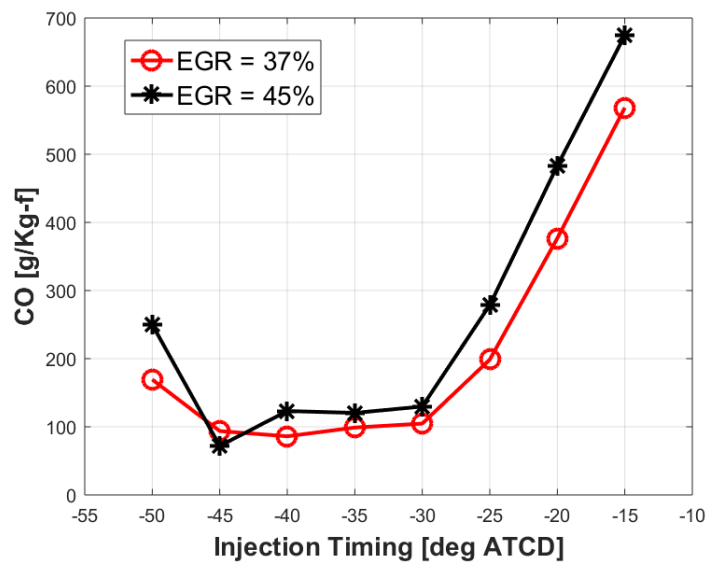

b) Light Naphtha

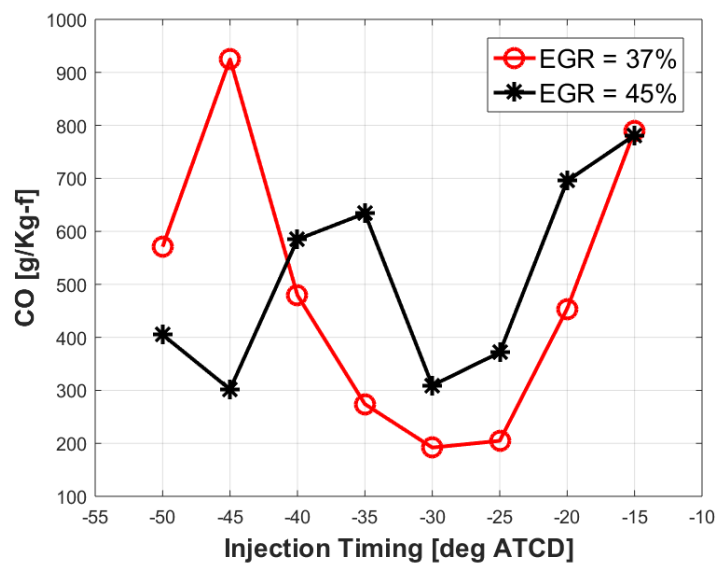

c) PRF50

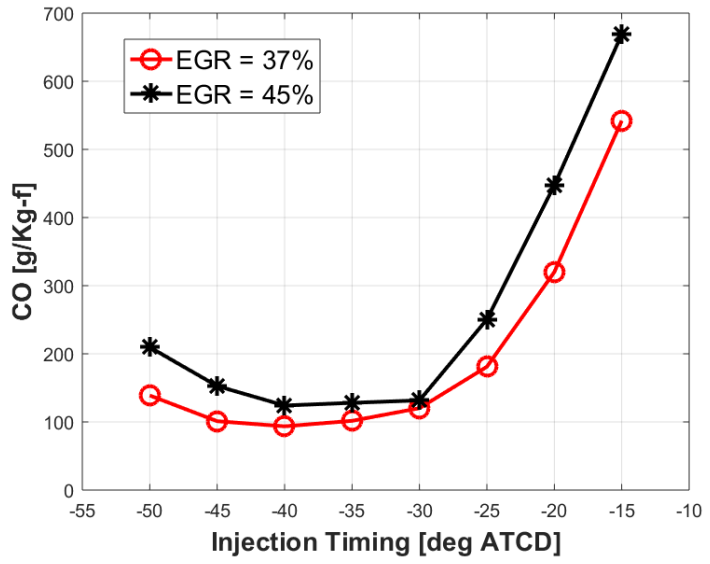

Figure 4-68. Comparison of predicted effect on $\mathrm{CO}$ at EVO due to variation in EGR fraction for various injection timings 
a) Heavy Naphtha

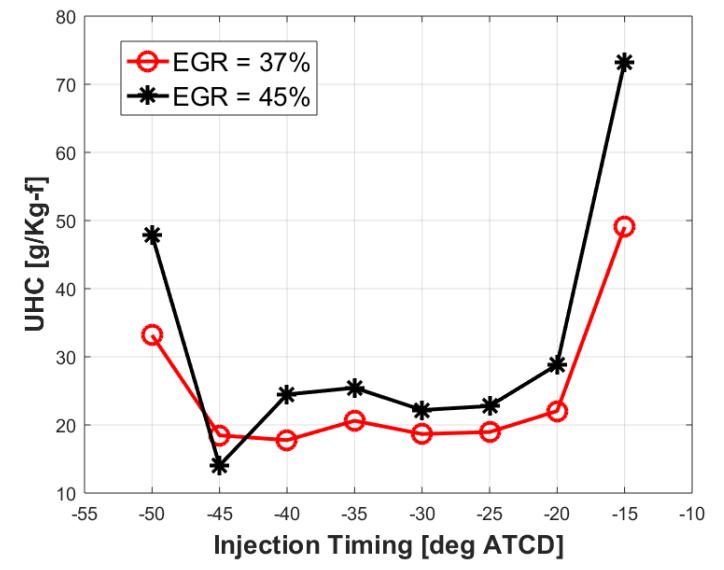

b) Light Naphtha

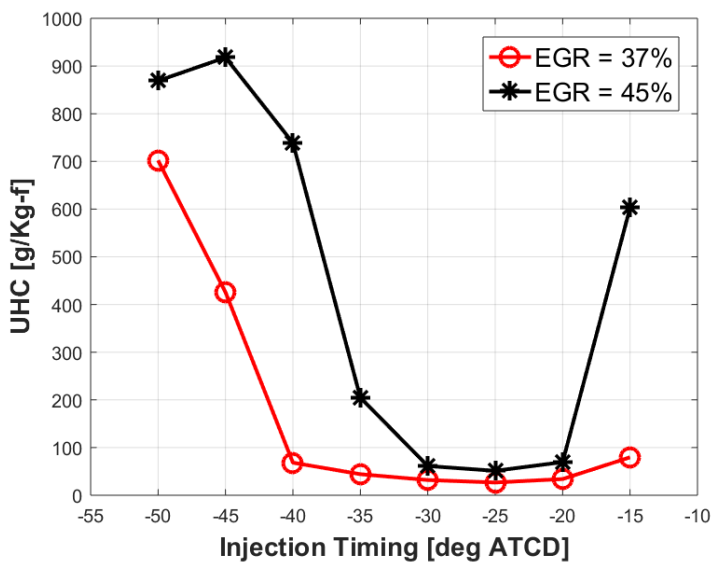

c) PRF50

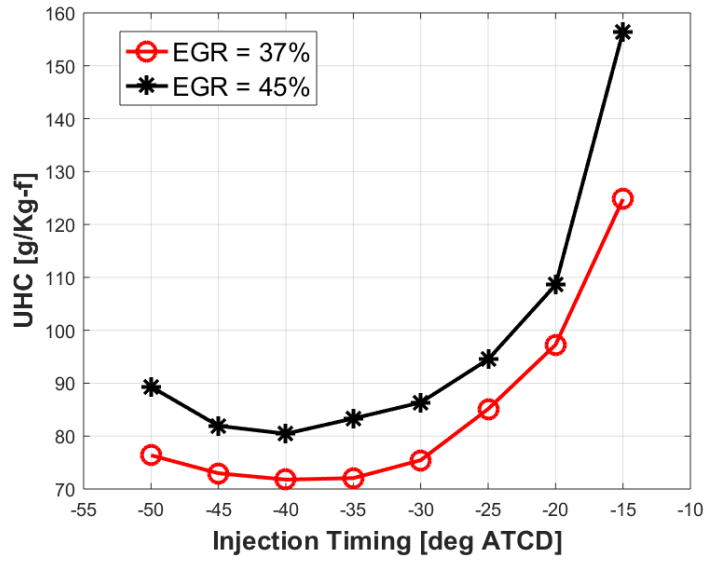

Figure 4-69. Comparison of predicted effect on UHC at EVO due to variation in EGR fraction for various injection timings 
Let's try to understand the overall picture of the effects of increased EGR. Simulations predicted lowered NOx, combustion efficiency and PRR and increased UHC and CO with an increase in EGR. As discussed in previous sections, ignition delay, equivalence ratio, and temperature are interrelated. Ambient temperatures are less due to higher heat capacity of the mixture with more burned gas content. Thus, we see lengthened ignition delay. Reduced availability of oxygen and reduced surrounding temperature shows the combined effect of lowered combustion efficiency. Like baseline condition, light naphtha, fuel which has the smallest reactivity and thus highest ignition delay, shows more prominent incomplete combustion at advanced injection timings. An in-depth comparison between baseline and elevated EGR cases by keeping injection timing and fuel constant will help further understanding EGR fraction effect. Following is the case of light naphtha when injected at $-40 \mathrm{deg}$ ATDC under baseline as well as higher EGR fraction operating conditions. Table 4-21 represents important combustion characteristics for same.

Table 4-21. Predicted Combustion Characteristics at injection timing -40 deg ATDC for different EGR Fractions

\begin{tabular}{|c|c|c|}
\hline & CASE A & CASE B \\
\hline EGR Percentage & 37 & 45 \\
\hline Combustion Efficiency (\%) & 83.43 & 19.80 \\
\hline Ignition Delay (CAD) & 44.53 & 51.53 \\
\hline Thermal Efficiency (\%) & 39.65 & 6.44 \\
\hline PRR (bar/deg) & 3.09 & 1.86 \\
\hline CO (g/Kg-f) & 479.46 & 584.75 \\
\hline UHC (g/Kg-f) & 68.34 & 738.86 \\
\hline NOx (g/Kg-f) & 1.972 & 2.296 \\
\hline
\end{tabular}

Baseline case (Case A) shows significant higher combustion efficiency than EGR case (Case B). Higher combustion efficiency also leads to higher thermal efficiency for Case A. Let's talk about engine out emissions for scenarios in question. Even with the higher amount of EGR, case B shows higher engine-out NOx. Values of engine-out CO and UHC are also on the higher side. Figure 4-71 shows the comparison of pressure trace and heat release rates for both the cases. Expansion pressure for Case A is higher than case B. Heat release rate for baseline case (A) also has higher peak value. Both the parameters compared above underlines difference in combustion quality. One of the parameters affected by EGR is temperature. Figure 4-72 shows the average over combustion chamber temperature value at each crank angle degree. The maximum average temperature is higher for baseline cases. Higher combustion efficiency ensures the inflated expansion temperature for case A. Figure 4.73 shows vaporization trend of fuel when injected. For both operating conditions, fuel vaporizes as soon as it enters the chamber due high in-cylinder charge temperature. 


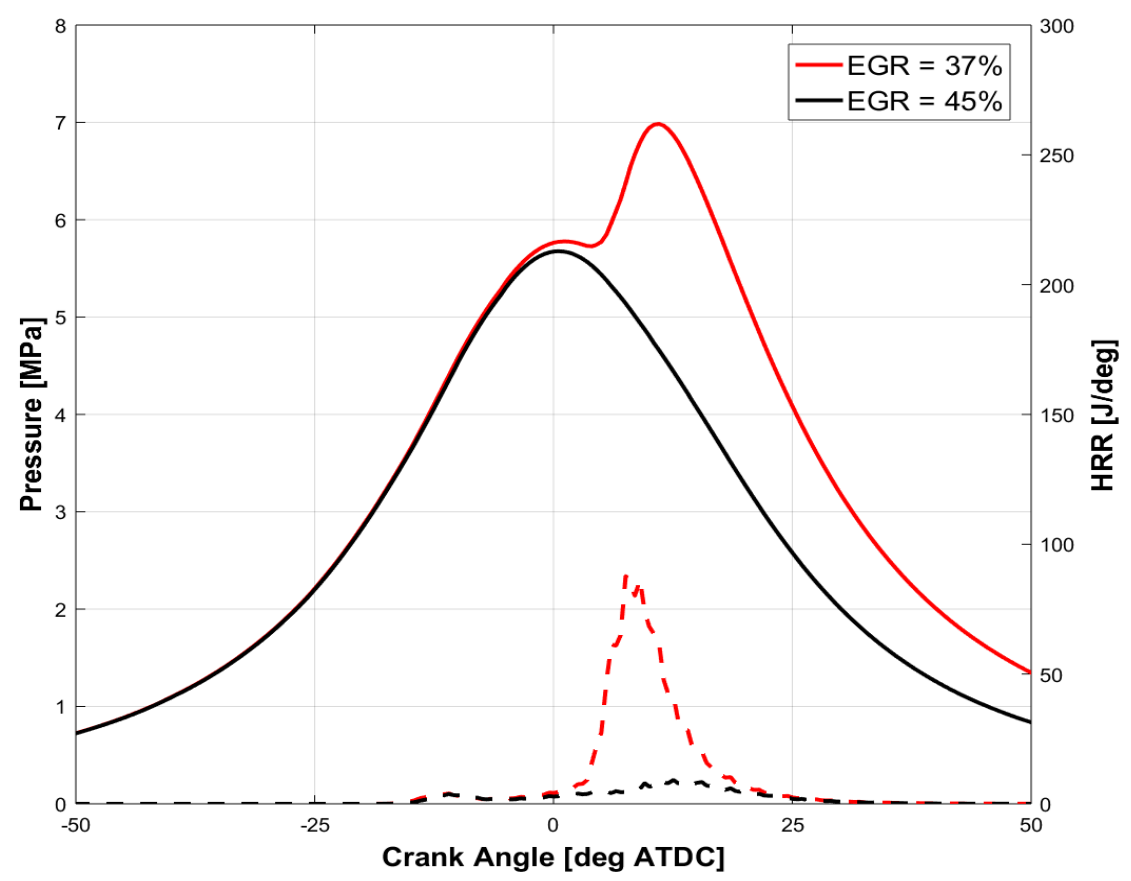

Figure 4-70. Comparison of predicted pressure and HRR at injection timing -40 deg ATDC for EGR Fraction $37 \%$ and $45 \%$

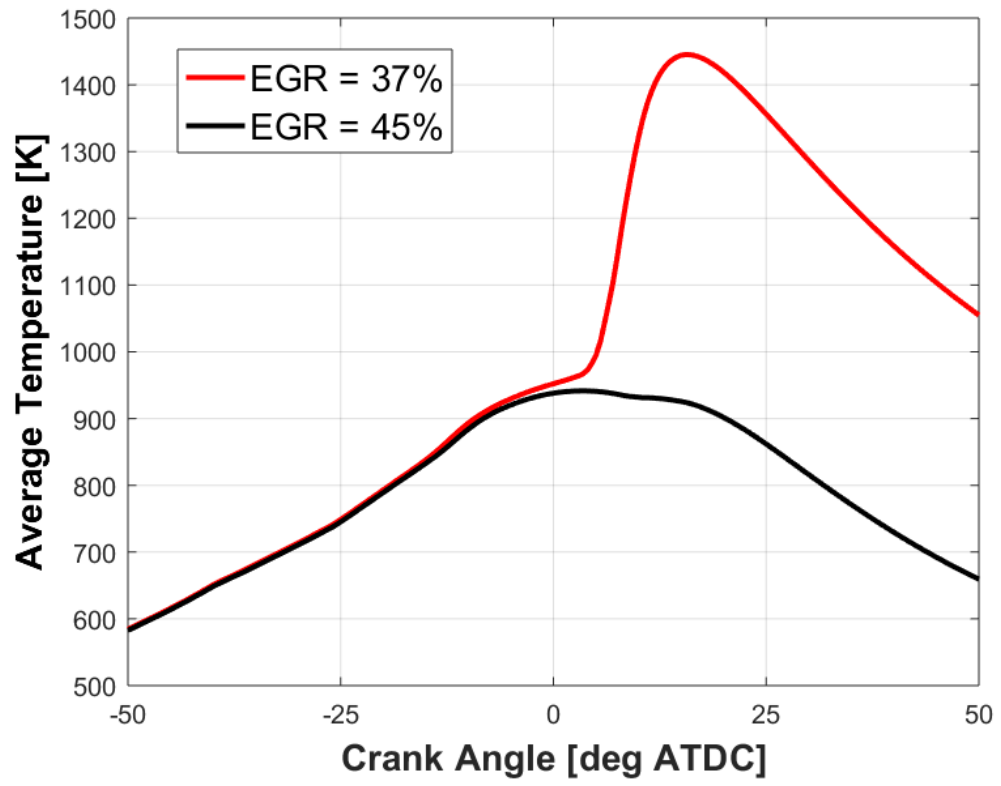

Figure 4-71. Comparison of predicted average temperature at injection timing $-40 \mathrm{deg}$ ATDC for EGR Fraction $37 \%$ and $45 \%$ 


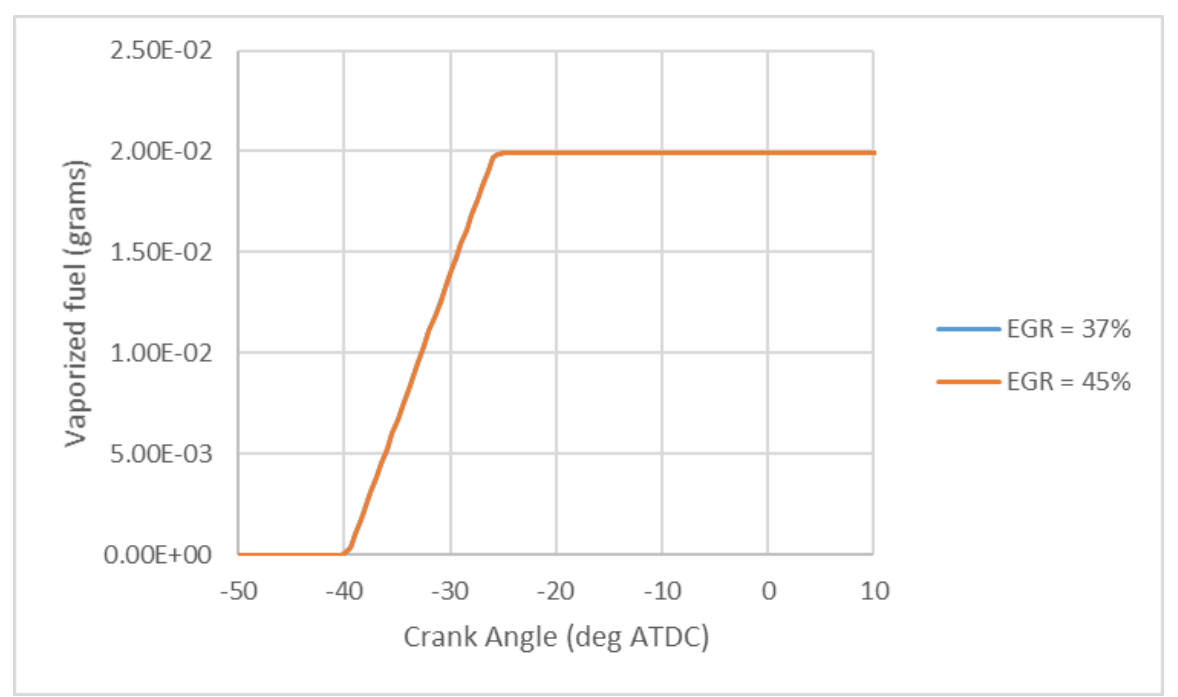

Figure 4-72. Comparison of predicted vaporization trend at injection timing -40 deg ATDC for EGR Fraction $37 \%$ and $45 \%$

One of the parameters that will help explaining combustion chamber mixture is equivalence ratio. Figure 4-74 shows y axis clip for both the cases just before instantaneous heat release takes place. Case B is an equivalence ratio distribution at $7 \mathrm{deg}$ ATDC and case $\mathrm{A}$ is at $2 \mathrm{deg}$ ATDC. Baseline case A undergoes early combustion as compared to other.

a)

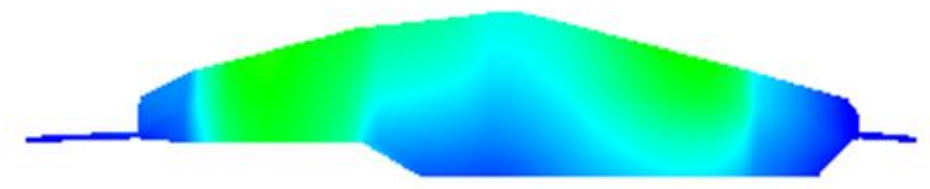

b)
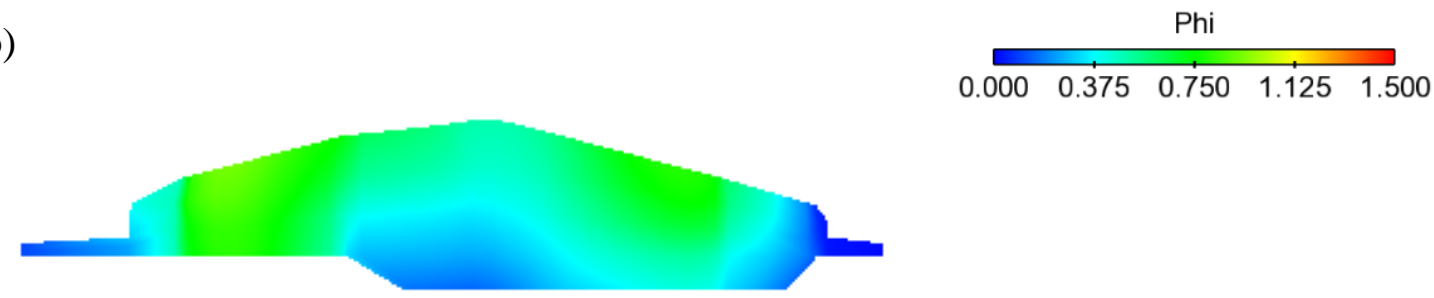

Figure 4-73. Predicted equivalence ratio distribution at injection timing -40 deg ATDC for EGR Fraction a) $37 \%$ at $2 \mathrm{deg}$ ATDC and b) $45 \%$ at $7 \mathrm{deg}$ ATDC

For both the cases, equivalence ratio distribution indicates a lean mixture. Maximum equivalence ratio for baseline case is $\approx 1.372$ and that is for EGR case is $\approx 1.45$. Even though 
a difference between $\phi$ values is not large, this is very interesting and contradictory of what has been observed in the last two sections. For baseline and IVC temperature cases lengthier ignition delay will result into a leaner mixture. This can be explained by lowered availability of oxygen. For advanced injection timings, lower combustion efficiency for baseline case was argued to be because of over lean mixture. According to the same principle, richer equivalence ratio should give higher combustion efficiency. However, chamber temperature plays an important part here. As case B has the lower in-cylinder temperature, combustion cannot be sustained in lean regions resulting in low combustion efficiency. This case study clearly represents all the unfavorable effects of higher EGR fractions. Reduction in oxygen availability and temperature adversely affects combustion efficiency. NOx also shows higher value at EVO. In order to explain it is important to take under consideration the EGR composition. Since EGR composition is the same for both the cases, a higher value of NOx at IVC for case B couldn't be surpassed by the baseline. Let's compare three fuels at elevated EGR levels to see how higher EGR fraction affects fuels with varying reactivity. Figure 4-75 shows the combustion efficiency trends for injection timing sweep.

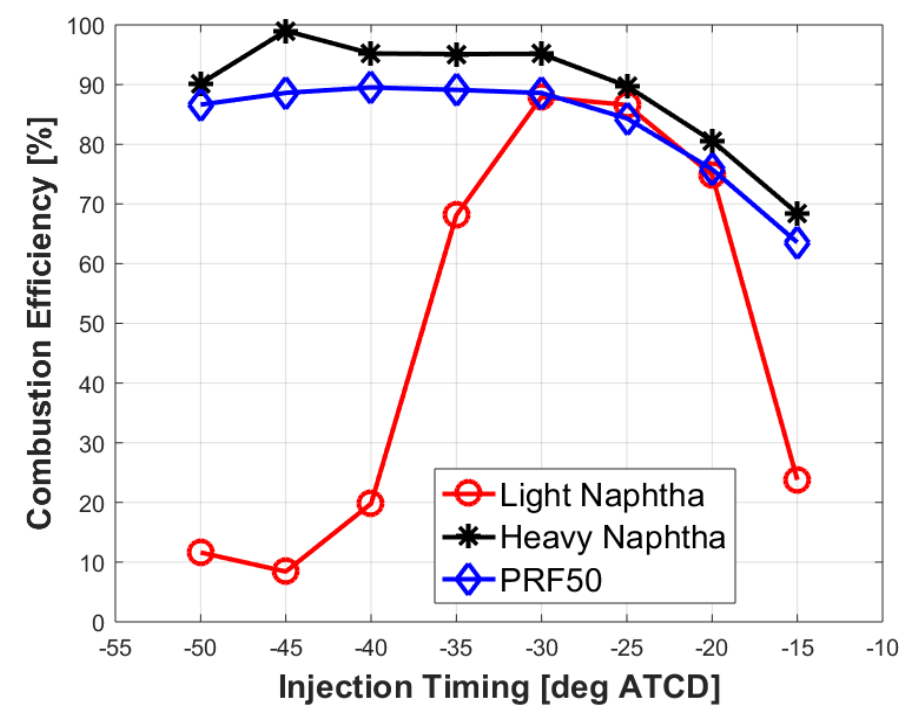

Figure 4-74. Comparison of predicted combustion efficiencies for $45 \%$ EGR fraction cases at various injection timings using three fuels

Combustion efficiency in the diagram above shows similar trend as that of baseline case. It increases as injection timings are advanced from TDC for all three fuels. Further efficiency stays constant for heavy naphtha and PRF50. However, for light naphtha, advanced injection timings show significant reduction in the combustion efficiency. 


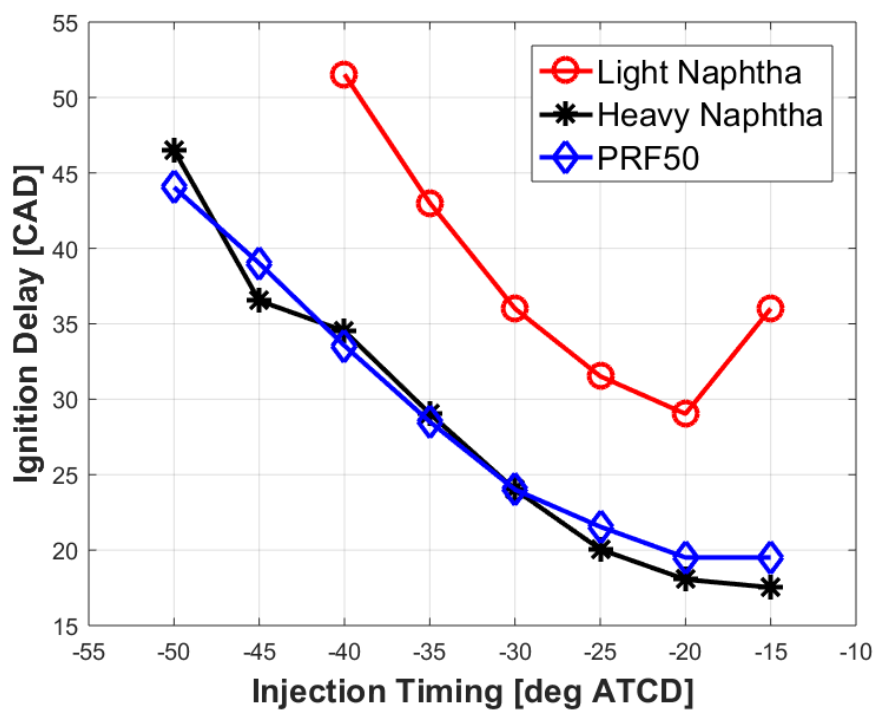

Figure 4-75. Comparison of predicted ignition delay for $45 \%$ EGR fraction cases at various injection timings using three fuels

As expected, Light naphtha has considerable higher ignition delay than remaining two fuels. Ignition delay increases as we advance injection timing (see Figure 4-76). All three fuels show this similar trend. Thermal efficiency follows combustion efficiency trends and is given in Figure 4-77. As injections are advanced from TDC, it increases for all the fuels. For more advanced timings, heavy naphtha and PRF50 shows approximately constant thermal efficiency whereas light naphtha shows decreasing trends.

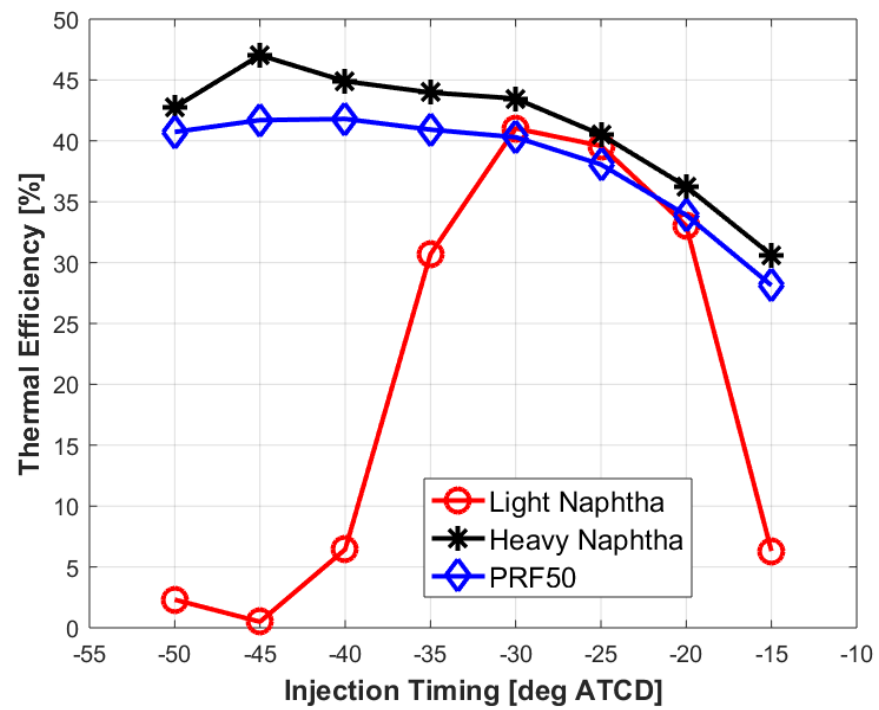

Figure 4-76. Comparison of predicted thermal efficiencies for $45 \%$ EGR fraction cases at various injection timings using three fuels 


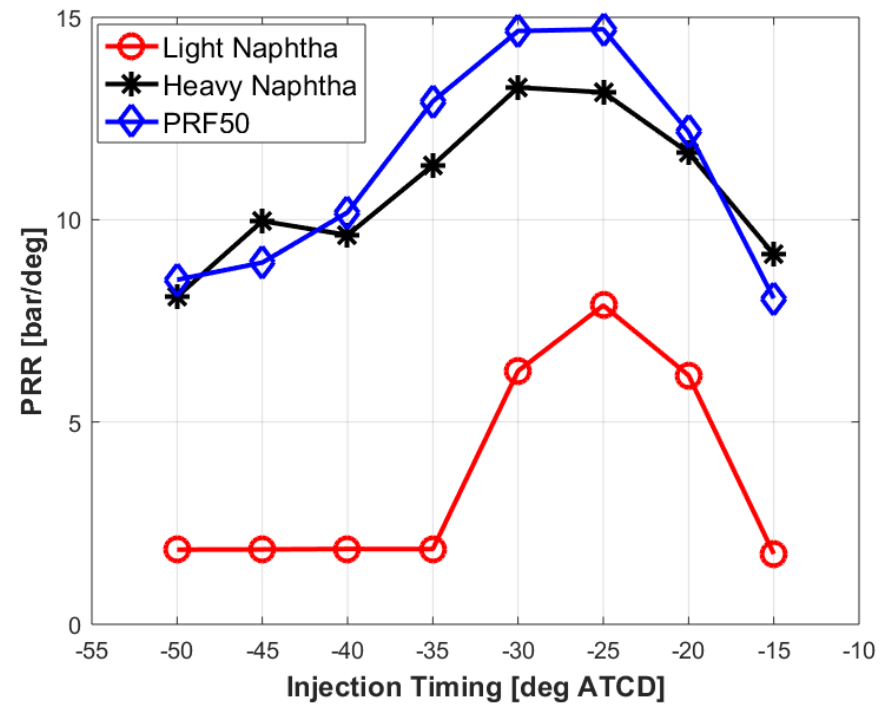

Figure 4-77. Comparison of predicted pressure rise rate for $45 \%$ EGR fraction cases at various injection timings using three fuels

Clearly Light Naphtha gives lower PRR than other two fuels for all the injection timings. And general trend seen in Figure 4-78 is same for all three fuels. Let's study emissions at EVO for different fuels.

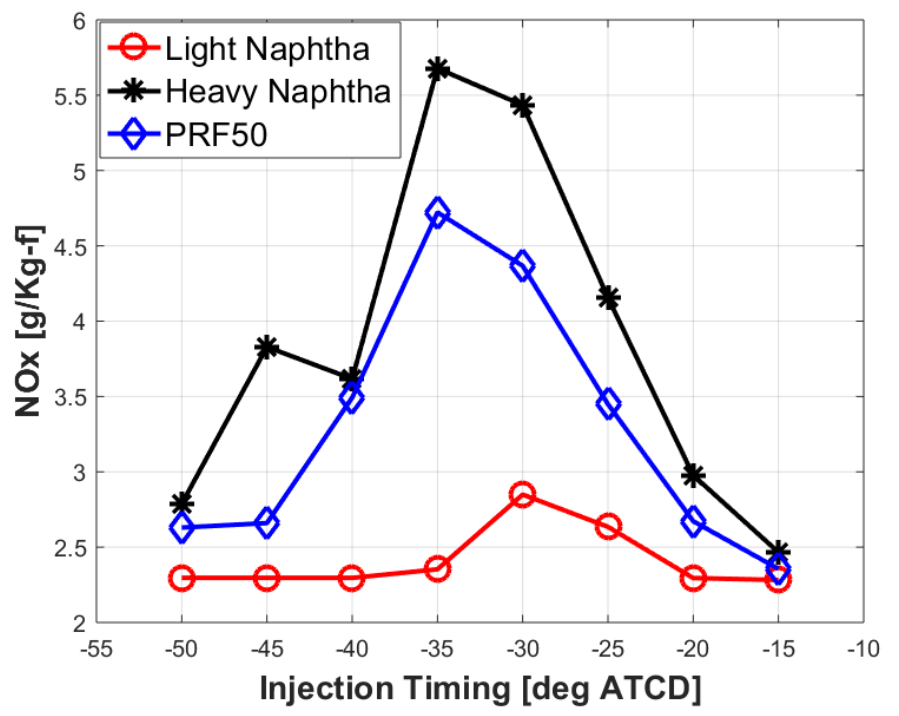

Figure 4-78. Comparison of predicted NOx for $45 \%$ EGR fraction cases at various injection timings using three fuels

NOx at EVO for three fuels at higher EGR fraction is shown in Figure 4-79. Light naphtha maintains lower NOx (less than $5 \mathrm{~g} / \mathrm{K}-\mathrm{g}$ f) for all injection timings. NOx first increases and then decreases followed by a flat line as we advance injection timing. PRF50 and heavy 
naphtha has higher NOx at EVO than light naphtha. For these two fuels, NOx increase as injection timings are advanced and tends to decrease afterwards. NOx at EVO for most of the injection timings for heavy Naphtha and PRF50 is also less than $5 \mathrm{~g} / \mathrm{Kg}$-f.

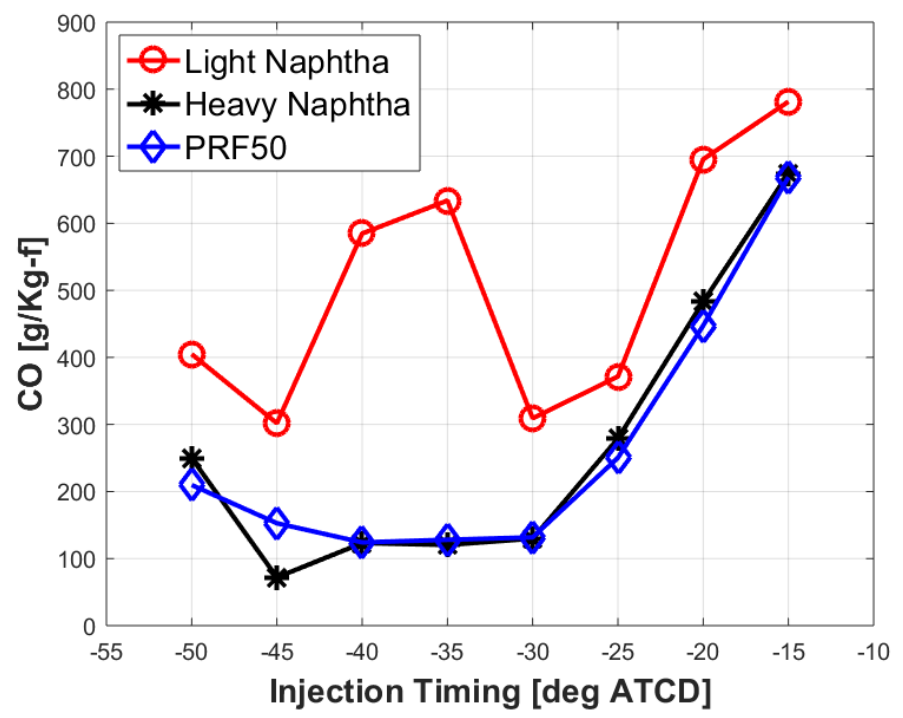

Figure 4-79. Comparison of predicted CO for $45 \%$ EGR fraction cases at various injection timings using three fuels

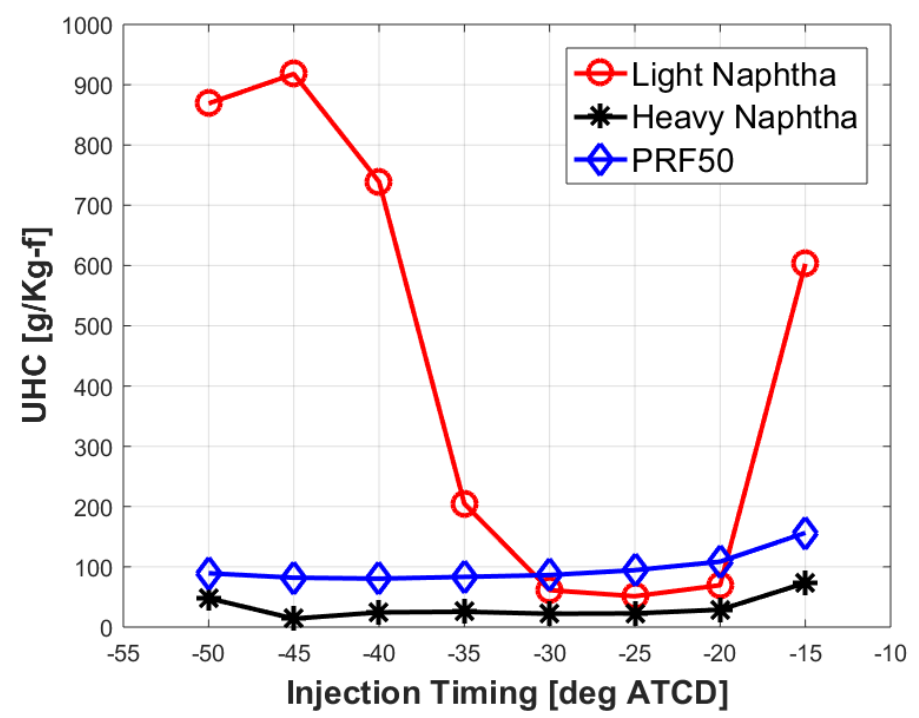

Figure 4-80. Comparison of predicted UHC for $45 \%$ EGR fraction cases at various injection timings using three fuels

Light Naphtha as expected gives higher values of $\mathrm{CO}$ at EVO than other two fuels (see Figure 4-80). CO values first decreases for all three fuels as we inject fuel at advanced timings. All three fuels show increasing tendency for further advanced injections. 
Figure 4-81 gives UHC for three fuels. For light naphtha more UHC can be seen at injections earlier in compression stroke. Heavy Naphtha and PRF50 maintains UHC trend similar to baseline.

It is interesting to see for injection timings with higher combustion efficiency ( >90\%) is because of well stratification as described earlier or because of homogeneous combustion. Fuels are compared at -35 deg ATDC injection timings, to study in depth combustion for elevated EGR levels. Table 4-22 summarize combustion characteristics for all three fuels when injected at $-35 \mathrm{deg}$ ATDC with $45 \%$ EGR fraction. Heavy Naphtha has maximum combustion efficiency followed by PRF50 and light Naphtha. As expected light naphtha shows lengthiest residence time.

Table 4-22 predicted combustion characteristics at -35 deg ATDC injection timing using three fuels

\begin{tabular}{|c|c|c|c|}
\hline & Light Naphtha & Heavy Naphtha & PRF50 \\
\hline Combustion Efficiency (\%) & 68.11 & 95.11 & 89.12 \\
\hline Ignition Delay (CAD) & 43.018 & 29.05 & 28.51 \\
\hline Thermal Efficiency (\%) & 30.68 & 43.97 & 40.92 \\
\hline PRR (bar/deg) & 1.86 & 11.34 & 12.93 \\
\hline CO (g/Kg-f) & 633.93 & 120.38 & 128.02 \\
\hline UHC (g/Kg-f) & 204.83 & 25.45 & 83.33 \\
\hline NOx (g/Kg-f) & 2.353 & 5.678 & 4.722 \\
\hline
\end{tabular}

Thermal efficiency follows the same trend as that of combustion efficiency. The higher combustion efficiency of heavy naphtha is accompanied by larger PRR. Let's take a look at emissions at EVO. Low quality of combustion for light naphtha is indicated by maximum $\mathrm{CO}$ and UHC at EVO. Heavy Naphtha produces maximum NOx at EVO. Pressure and heat release rate trace shown in Figure 4-82 are one of the indicators of combustion quality. Here, heavy naphtha and PRF50 shows the start of combustion in the compression stroke. Whereas it is late in the expansion stroke for light naphtha. As a result, heavy naphtha and PRF50 has a higher peak for pressure as well as heat release rate. Combustion duration is higher for light naphtha. The existence of cold flame can be seen for more reactive fuels.

Average temperature trace traces shown in Figure 4-83 indicates late combustion start for light naphtha as compared to other two fuels. Again, peak for average temperature is higher for heavy naphtha and PRF50. Early combustion starts and more heat release gives elevated expansion temperature for heavy naphtha and PRF50. 


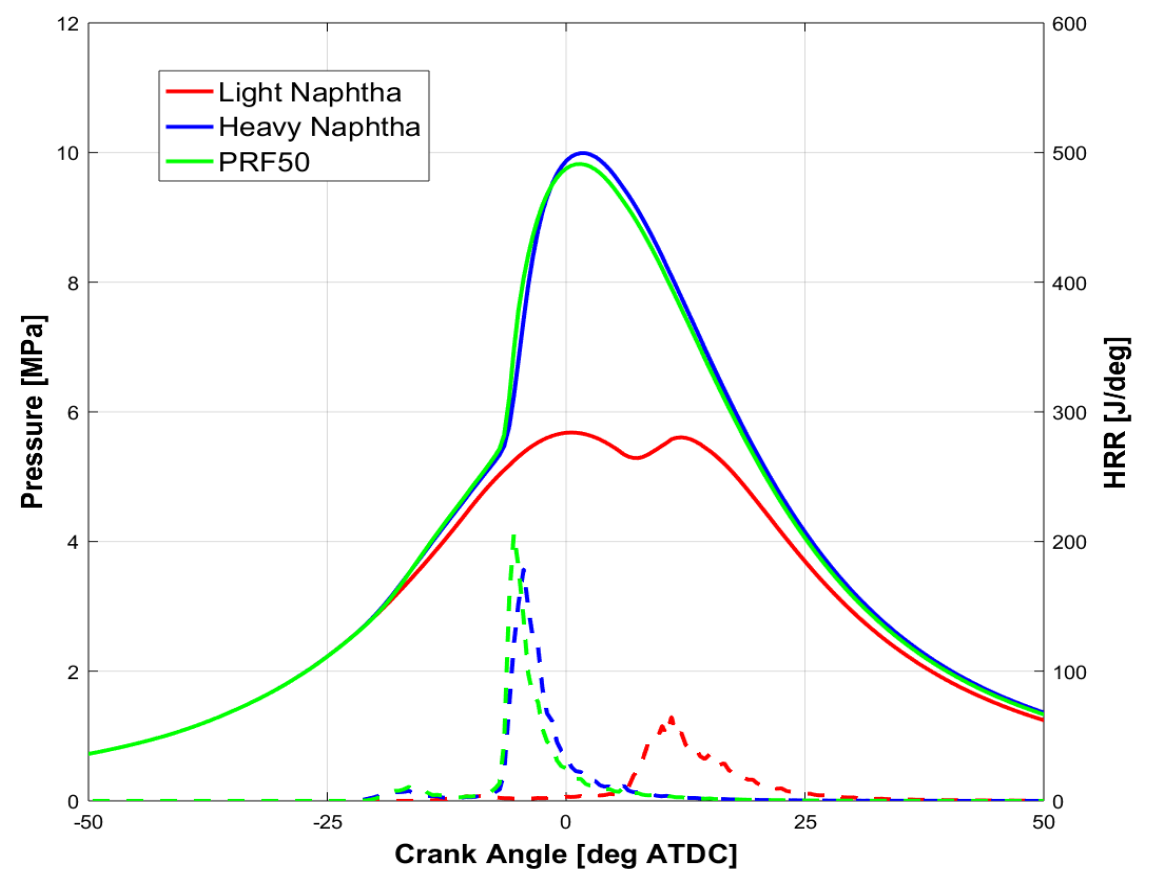

Figure 4-81. Comparison of predicted pressure and HRR for $45 \%$ EGR fraction with -35 deg ATDC injection timing using three fuels

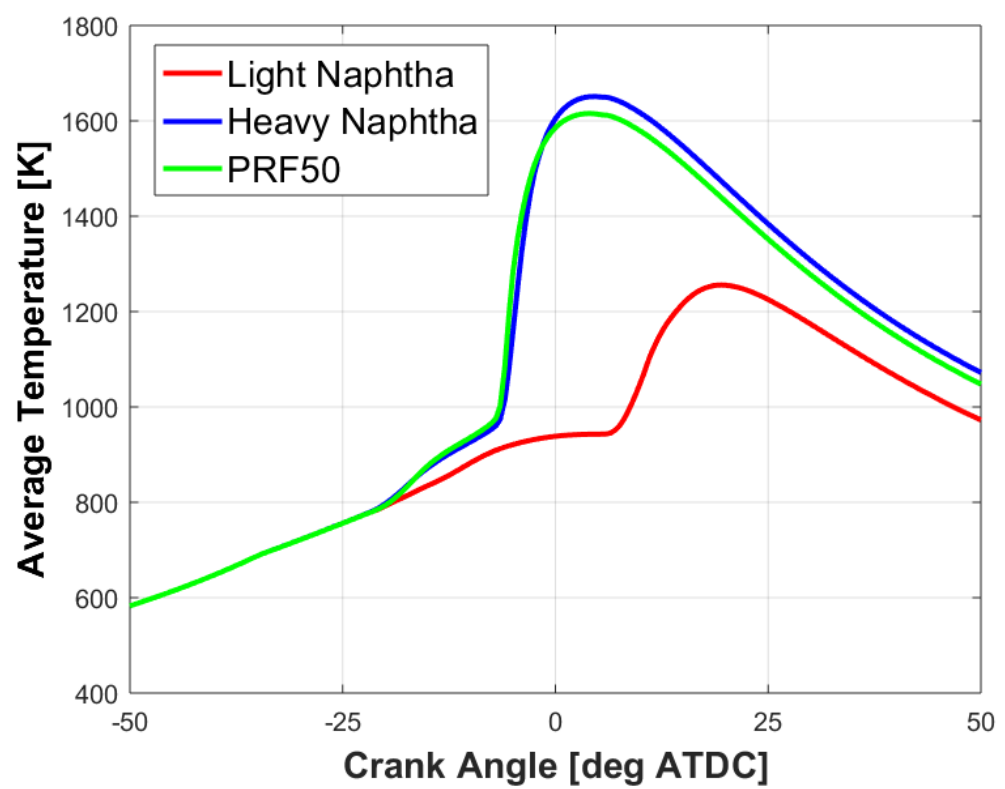

Figure 4-82. Comparison of predicted average temperature for $45 \%$ EGR fraction with 35 deg ATDC injection timing using three fuels

Three fuels with different volatility shows similar vaporization trend (see Figure 4-84) at the current operating condition. 


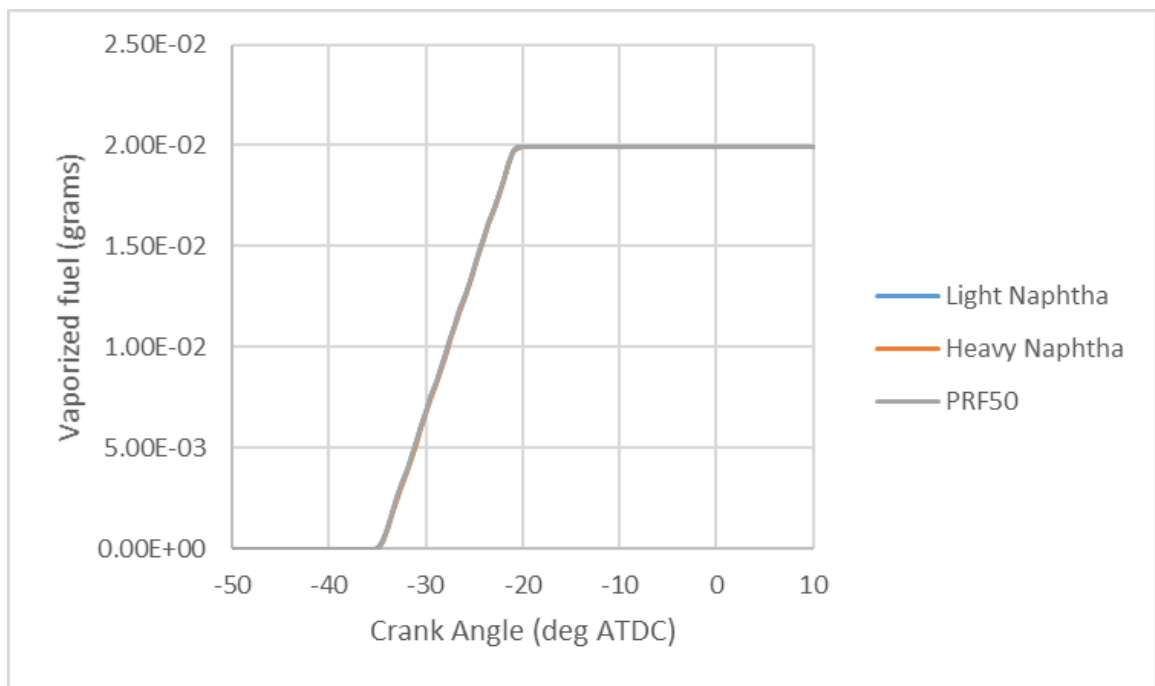

Figure 4-83. Comparison of predicted vaporization trend for $45 \%$ EGR fraction with -35 deg ATDC injection timing using three fuels

a)

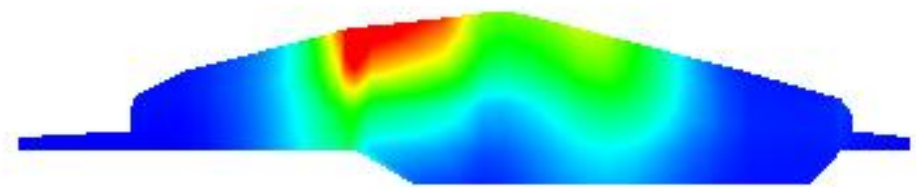

b)
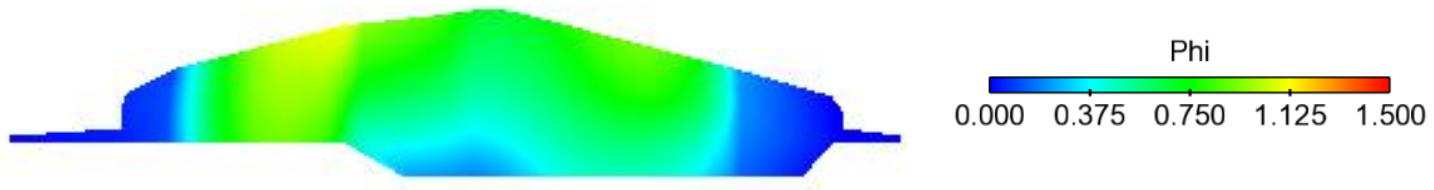

c)

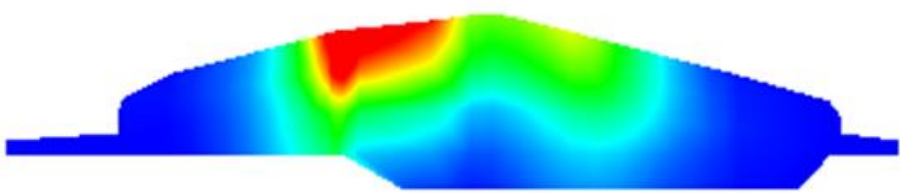

Figure 4-84. Predicted equivalence ratio distribution with $45 \%$ EGR naphtha fraction and -35 deg ATDC injection timing for a) Heavy Naphtha at -7 deg ATDC b) Light Naphtha at 5 deg ATDC c) PRF50 at -7 deg ATDC 
Heavy Naphtha and PRF50 have higher reactivity than light naphtha resulting in lower residence time. Because of shorter ignition delay, over mixing is avoided in the combustion chamber. Equivalence ratio distribution (see Figure 4-85) does confirm that. Maximum $\phi$ approximately is 2.07 and 3.89 respectively. Both the fuels (heavy naphtha and PRF50) burns giving higher combustion efficiency. However steep pressure rise has caused higher PRR (>10 bar/deg) and higher localized temperature results into large NOx (> 5g/kg-f). So even though combustion efficiency is high, this is not well-stratified combustion. Hence in case of heavy naphtha and PRF50 when injected at -35 deg ATDC, homogeneous combustion takes place. On the other hand, in case of light naphtha, ignition delay is longer resulting in to lean mixture. Maximum equivalence ratio for light naphtha is equal to 1.27(see Figure 4-85). Thus, combustion started but cannot be sustained giving low combustion efficiency. Increase in EGR percentage has adversely affected combustion efficiency for light naphtha. Increase in the ignition delay results into over mixing and thus lowered combustion efficiency.

If higher EGR fraction shows adverse effects on combustion efficiency on light naphtha, it's interesting to see how lower reactive fuels affected by reduced EGR percentage.

Table 4-23. Predicted combustion characteristics at -40 deg ATDC injection timing using three fuels

\begin{tabular}{|c|c|c|}
\hline & CASE A & CASE B \\
\hline EGR Percentage & 37 & 17 \\
\hline Combustion Efficiency (\%) & 83.43 & 95.94 \\
\hline Ignition Delay (CAD) & 44.53 & 40.51 \\
\hline Thermal Efficiency (\%) & 39.65 & 46.98 \\
\hline PRR (bar/deg) & 3.09 & 12.43 \\
\hline CO (g/Kg-f) & 479.46 & 120.49 \\
\hline UHC (g/Kg-f) & 68.34 & 12.28 \\
\hline NOx (g/Kg-f) & 1.972 & 4.26 \\
\hline
\end{tabular}

Table 4-23 compares combustion characteristics when light naphtha is injected at -40 deg ATDC for 37\% and 17\% EGR fraction. Case A is baseline operating condition case and B is one with lower EGR fraction (17\%). Case B gives considerable higher combustion and thermal efficiency along with stepper PRR. Case B produces less $\mathrm{CO}$ and UHC at EVO with more NOx. Difference between combustion quality between two cases is underlined in the Figure 4-86 shown below.

Combustion duration is higher for the baseline case whereas $17 \%$ EGR case shows sudden and fast heat release. Combustion starts early for case A giving higher expansion pressure. Temperature traces shown in Figure 4-87 reconfirms the theory mentioned at the start of the section. Case B has higher average temperature overall all the crank angle degrees. Higher combustion efficiency and lower specific heat of the mixture (due to reduced EGR fraction) are important factors responsible for temperature rise. 


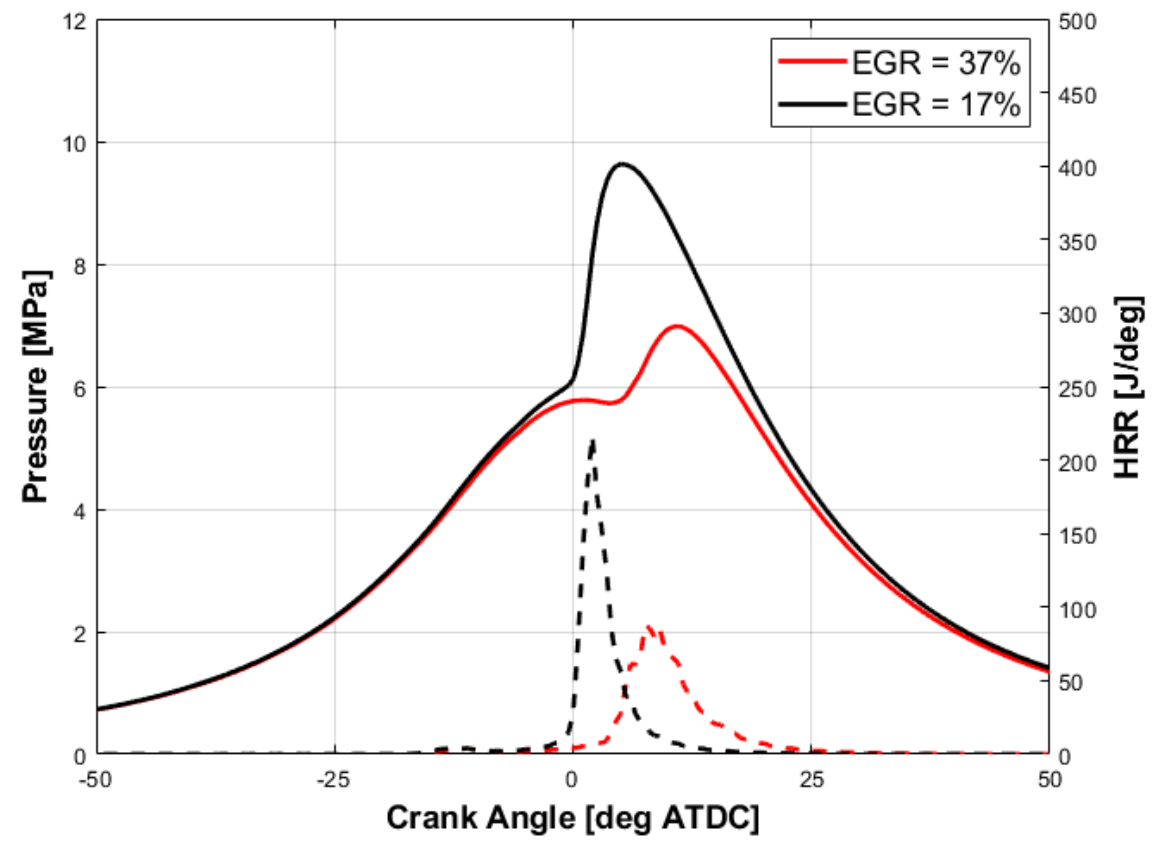

Figure 4-85. Comparison of predicted pressure and HRR at injection timing -40 deg ATDC EGR Fraction $17 \%$ and $37 \%$

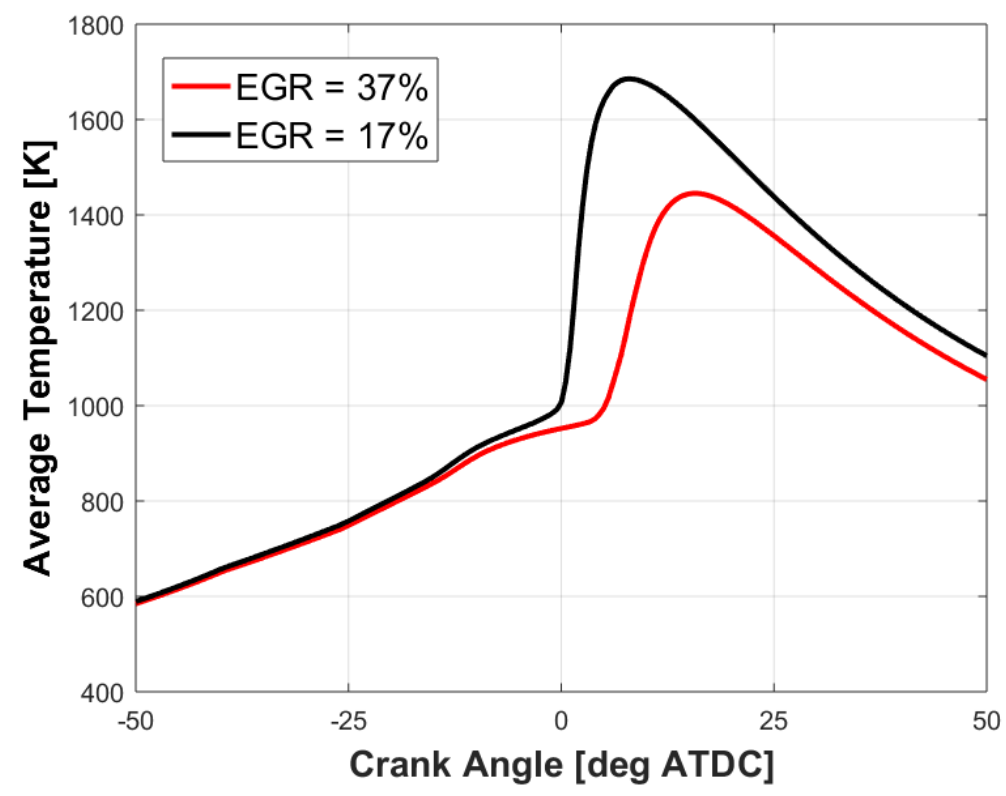

Figure 4-86. Comparison of average temperature at injection timing -40 deg ATDC for EGR Fraction $17 \%$ and $37 \%$ 
Even with lowered EFR fraction, light naphtha vaporizes with similar trend to baseline operating condition (see Figure 4-88).

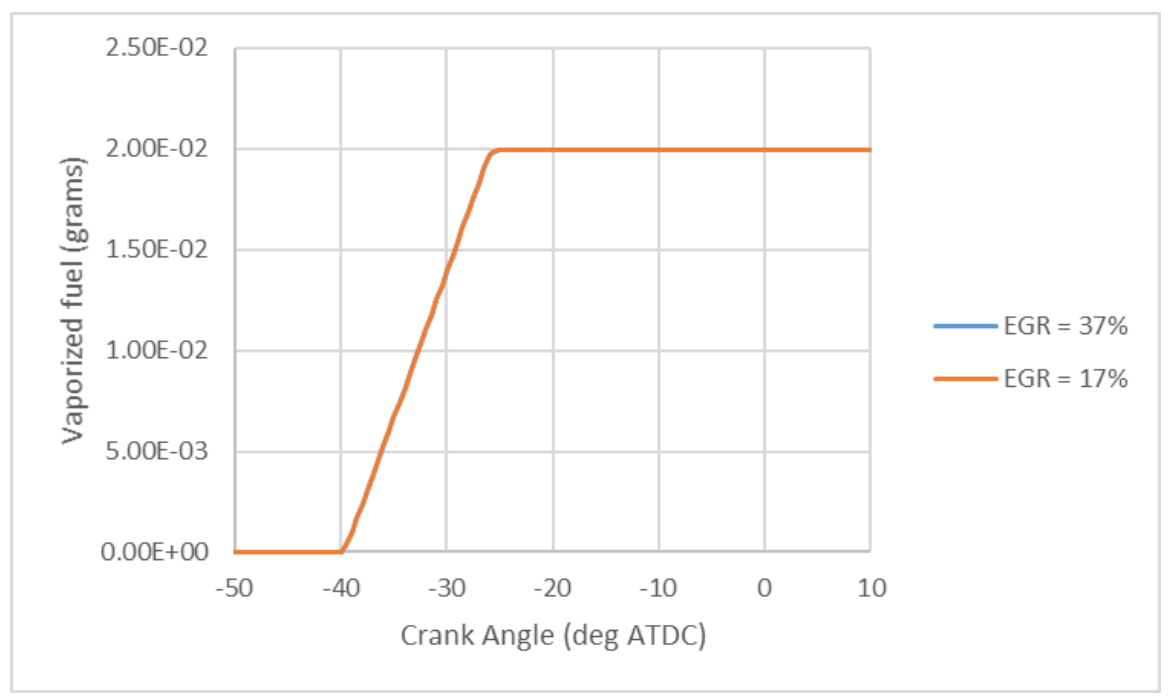

Figure 4-87. Comparison of predicted vaporization trend at injection timing -40 deg ATDC for EGR Fraction 17\% and 37\%

Figure 4-89 gives equivalence ratio distribution just before combustion for both operating conditions. Case $\mathrm{B}$ has maximum equivalence ratio $\approx 1.116$ whereas $\mathrm{A}$ has it equal $\approx 1.372$. Case $\mathrm{B}$ has shorter ignition delay even though has more mixed mixture. This can be explained by different $\mathrm{O}_{2}$ percentage. With lowered amount EGR, $\mathrm{O}_{2}$ percentage increases from $17 \%$ to $20 \%$. However, this distribution in the combustion chamber is similar.

a)

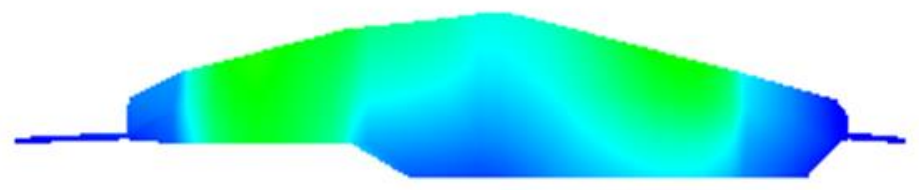

b)
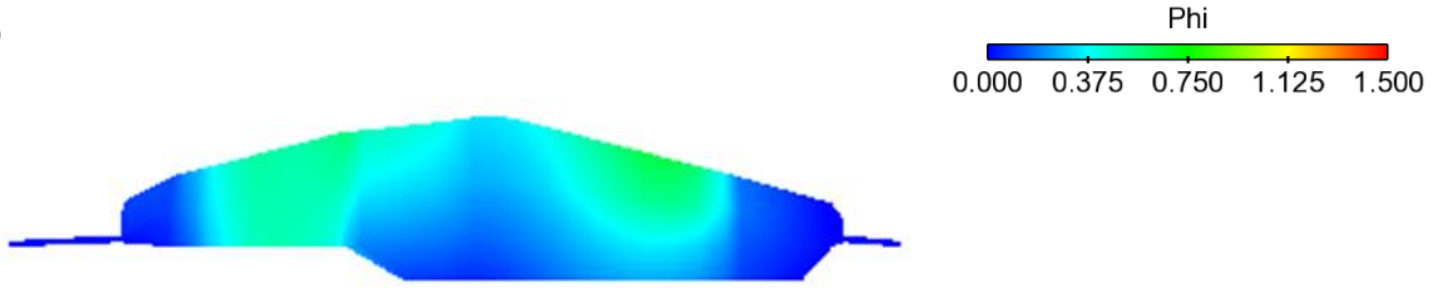

Figure 4-88. Predicted equivalence ratio distribution at injection timing -40 deg ATDC for EGR Fraction a) $37 \%$ at $2 \mathrm{deg}$ ATDC and b) $17 \%$ at $-7 \mathrm{deg}$ ATDC 
Lowering the EGR percentage helps to lift the combustion efficiency for earlier injection in the compression stroke despite having lean equivalence ratio. However, this increases in combustion efficiency come along with the high PRR. When EGR fraction reduces, the specific heat of the mixture reduces, resulting in overall higher temperature inside the chamber. Increase in temperature and more availability of oxygen makes combustion more efficient. However, a higher value of PPR strongly suggests that this combustion is homogeneous (a large amount of fuel combusts simultaneously) and not stratified (sequential combustion from rich to lean regions). CO and UHC at exhaust valve opening, are less and NOx is higher for smaller EGR fraction. Less CO and UHC can be justified with higher combustion efficiency. Also, high temperatures promote completion of late $\mathrm{CO}$ to $\mathrm{CO}_{2}$ conversion giving low $\mathrm{CO}$. Large amount of fuel burns simultaneously giving hightemperature zones and hence NOx increases for $17 \%$ EGR case. I

Effect of EGR is studied here by increasing EGR fraction at IVC from $37 \%$ to $45 \%$. Again, the amount of fuel kept the same for both the conditions. Increasing EGR fraction has affected maximum combustion efficiency, an angle at which maximum efficiency has achieved and emissions at EVO. For heavy naphtha, maximum combustion efficiency achieved with higher EGR fraction is less than baseline with smaller PRR (see Table 424). Its obtained at similar injection timing.

Table 4-24. Maximum Combustion Efficiency for heavy naphtha

\begin{tabular}{|c|c|c|c|}
\hline & $\begin{array}{c}\text { Combustion } \\
\text { efficiency }\end{array}$ & $\begin{array}{c}\text { Injection } \\
\text { timing }\end{array}$ & PRR \\
\hline & $(\%)$ & $($ deg ATDC) & $(\mathrm{bar} / \mathrm{deg})$ \\
\hline Baseline & 96.66 & -40 & 11.50 \\
\hline Increased EGR Fraction & 95.2 & -40 & 9.61 \\
\hline
\end{tabular}

Table 4-25. Maximum Combustion Efficiency for light naphtha

\begin{tabular}{|c|c|c|c|}
\hline & $\begin{array}{c}\text { Combustion } \\
\text { efficiency }\end{array}$ & $\begin{array}{c}\text { Injection } \\
\text { timing }\end{array}$ & PRR \\
\hline & $(\%)$ & (deg ATDC) & (bar/deg) \\
\hline Baseline & 93.07 & -25 & 14.48 \\
\hline Increased EGR Fraction & 87.93 & -30 & 6.26 \\
\hline
\end{tabular}

For light naphtha, effect of higher EGR fraction is more enhanced (see Table 4-25). Increased EGR case shows substantial drop in maximum combustion efficiency. This efficiency is achieved at advanced injection timing with lower PRR.

Effect of EGR fraction on PRF50 combustion is similar to the heavy naphtha (See Table 4-26). Combustion with higher EGR fraction is characterized by lower combustion efficiency with lower PRR value. Injection timing is the same for PRF50. 
Table 4-26. Maximum Combustion Efficiency for PRF50

\begin{tabular}{|c|c|c|c|}
\hline & $\begin{array}{c}\text { Combustion } \\
\text { efficiency }\end{array}$ & $\begin{array}{c}\text { Injection } \\
\text { timing }\end{array}$ & PRR \\
\hline & $(\%)$ & (deg ATDC) & (bar/deg) \\
\hline Baseline & 90.01 & -40 & 10.98 \\
\hline Increased EGR Fraction & 89.51 & -40 & 10.18 \\
\hline
\end{tabular}

Higher EGR fraction lowers overall temperature in the chamber as a result of lower heat capacity. Availability of oxygen is also less as EGR fraction increases. Thus, despite having lengthier ignition delay, cases with increased EGR operating conditions shows richer equivalence ratio. Lower $\mathrm{O}_{2} \%$ and reduced temperature have caused maximum combustion efficiency to drop for increased EGR as compared to baseline operating case. However, higher PRR values for maximum combustion efficiency cases underline the fact, this higher combustion efficiency can be because of homogeneous combustion and not stratified. Therefore, instead of studying maximum combustion efficiency cases let's look at optimum cases. As per the definition we are using for good/optimum combustion is the case where combustion efficiency is equal to or greater than $90 \%$ with PRR less than or equal to $10 \mathrm{bar} / \mathrm{deg}$ and EVO NOx less than $5 \mathrm{~g} / \mathrm{kg}$-f. Such a scenario can be only seen with heavy naphtha fuel. For heavy naphtha, cases with injection timing equal or advanced than -40 deg ATDC can be said as good combustion cases. Whereas the other two fuels fail to meet the combustion efficiency criteria. For combustion cases with heavy naphtha, major advantage of higher EGR fraction that is lowered NOx at EVO. As mentioned earlier, equivalence ratio distribution in the combustion chamber required to achieve stratified combustion depends upon many parameters such as IVC temperature, pressure, charge composition etc. For a particular operating condition with EGR fraction $45 \%$, heavy naphtha has to have maximum $\phi=k 1.72$ to avoid high-temperature zones (curbing NOx at EVO and less PRR) and minimum $\phi=/>0.00132$ (to avoid incomplete combustion by over mixing fuel). Looking at the Light naphtha result, $45 \%$ EGR fraction has adversely affected fuel combustion. Hence $45 \%$ EGR is not suitable for lower reactive fuels. In efforts to try to get optimum cases EGR fraction $17 \%$ cases were also studied for light naphtha. Even though clearly it increases combustion efficiency, stratified combustion cannot be achieved. Further investigation is necessary to pinpoint the EGR fraction (higher than $17 \%$ but lower than $37 \%$ ) to satisfy optimum case requirements.

\subsubsection{Injection Pressure Variation}

Injection timing sweep is done for four other injection pressure values, which are 600, 500, 300 and 200 bar. Following Table 4-27 compare maximum combustion efficiency and injection timings for which maximum efficiency is obtained for all three fuels under increased IVC temperature conditions. 
Table 4-27. Maximum combustion efficiency and injection timing for injection pressure sweep

\begin{tabular}{|c|c|c|c|c|c|c|}
\hline $\begin{array}{c}\text { Injection } \\
\text { Pressure }\end{array}$ & \multicolumn{2}{|c|}{ Light Naphtha } & \multicolumn{2}{c|}{ Heavy Naphtha } & \multicolumn{2}{c|}{ PRF50 } \\
\hline Bar & $\begin{array}{c}\text { Combustion } \\
\text { Efficiency }\end{array}$ & $\begin{array}{c}\text { Injection } \\
\text { Timing }\end{array}$ & $\begin{array}{c}\text { Combustion } \\
\text { Efficiency }\end{array}$ & $\begin{array}{c}\text { Injection } \\
\text { Timing }\end{array}$ & $\begin{array}{c}\text { Combustion } \\
\text { Efficiency }\end{array}$ & $\begin{array}{c}\text { Injection } \\
\text { Timing }\end{array}$ \\
\hline & $\%$ & & $\%$ & & $\%$ & \\
\hline 600 & 85.81 & -25 & 96.36 & -30 & 90.02 & -30 \\
\hline 400 & 87.94 & -30 & 99.93 & -45 & 89.52 & -40 \\
\hline 300 & 88.46 & -30 & 95.05 & -45 & 89.56 & -45 \\
\hline 200 & 86.39 & -35 & 95.47 & -45 & 88.88 & -45 \\
\hline
\end{tabular}

A range of maximum combustion efficiency more or less remains the same for all three fuels. Heavy Naphtha maintains higher efficiency trend for all injection pressures. Injection timings for which this efficiency has achieved advances as injection pressure is being reduced. Lower the pressure lesser the mixing and hence longer ignition delay is required to achieves ideal stratification. Even with different injection pressure lets focus on optimum cases instead maximum combustion efficiency cases. Following Table 4-28 includes characteristics of good combustion cases for all three fuels at different injection pressures.

Table 4-28. Optimum case condition for each fuel at injection pressure sweep

\begin{tabular}{|l|c|c|c|c|}
\hline & $\begin{array}{c}\text { Injection } \\
\text { Timing }\end{array}$ & $\begin{array}{c}\text { Combustion } \\
\text { Efficiency }\end{array}$ & PRR & NOx \\
\hline & deg ATDC & $\%$ & bar/deg & g/Kg-f \\
\hline \multicolumn{7}{|c|}{ Injection Pressure :600 Bar } \\
\hline Heavy Naphtha & -35 & 94.92 & 9.47 & 4 \\
\hline \multicolumn{7}{|c|}{ Injection Pressure :500 Bar } \\
\hline Heavy Naphtha & -35 & 94.44 & 9.95 & 4.71 \\
\hline \multicolumn{7}{|c|}{ Injection Pressure :400 Bar } \\
\hline Heavy Naphtha & -45 & 99.93 & 9.96 & 3.83 \\
\hline \multicolumn{7}{|c|}{ Injection Pressure :300 Bar } \\
\hline Heavy Naphtha & -45 & 95.05 & 9.12 & 3.02 \\
\hline \multicolumn{7}{|c|}{ Injection Pressure :200 Bar } \\
\hline Heavy Naphtha & -45 & 95.47 & 4.43 \\
\hline
\end{tabular}

From the table above its clear that neither light naphtha nor PEF50 can achieve stratified combustion with any injection pressure studied above with $45 \%$ EGR fraction. Adverse effects Lower reactivity of fuels combined with lower $\mathrm{O}_{2}$ availability and in-cylinder charge temperature cannot be overcome by varying injection pressure at the current operating condition. 


\subsection{Change in charge pressure at IVC}

Effect of increasing boost pressure level is studied by increasing charge pressure at IVC form 1.41 Bar to 2.41. The result of the comparison for each of the fuels is discussed below. All other operating conditions are kept constant. Therefore, by increasing pressure, more oxygen is available to burn the same amount of fuel.

Figure 4-90 represent combustion efficiency for injection timing sweep at elevated charge pressure and baseline condition. Increasing charge pressure at IVC has increased combustion efficiency for all injection timings for light Naphtha. The difference can be more pronouncedly seen at earlier injection timings. In case of heavy naphtha and PRF50, for earlier injections in the compression stroke, increased charge pressure reduces combustion efficiency however for injection timings near TDC, higher charge pressure increases it as compared to baseline.

Ignition delay for three fuels is compared in Figure 4-91. Ignition delay for all three fuels shortens as charge pressure at IVC increases. Trends shown by fuel is similar to the baseline case. Ignition delay increases as we advance fuel injection timings.

Figure 4-92 gives thermal efficiency comparison for higher charge pressure and baselines operating conditions. For heavy naphtha and PRF50, thermal efficiency for higher charge pressure cases are similar to baseline for injection timings near TDC. Whereas with advancement in injection timings higher charge pressure at IVC results into lower thermal efficiency. When light naphtha is used as fuel at injections near TDC, thermal efficiency for higher charge pressure at IVC operating condition is lower however it is more for advanced injection timing.

For light naphtha, PRR has a higher value for increased charge pressure condition for entire injection timing sweep. Figure 4-93 gives a comparison of PRR for three fuels. For heavy naphtha, most of the injection timings give stepper PRR for baseline cases and PRF50 does not show any clear trend in regards with PRR.

Figure 4-95 indicates NOx at exhaust valve opening. Similar behavior can be seen by all three fuels in regards to NOx at EVO. NOx for higher charge pressure operating condition is more for entire injection timing sweep. A trend for $\mathrm{CO}$ as injection timings are being advanced is similar for all the operating condition and fuel and its shown in Figure 4-96. With light naphtha as fuel, the baseline has more CO at EVO. Heavy naphtha and PRF50 shows lower $\mathrm{CO}$ at injections near TDC with higher charge pressure. On the contrary for earlier injections in the compression stroke, higher charge pressure results into more $\mathrm{CO}$ at EVO. Figure 4-97 gives information about UHC at EVO. UHC as expected follows trend opposite to the combustion efficiency. Light naphtha shows very high UHC at injections earlier in a compression stroke. For heavy naphtha and PRF50, both the operating

conditions show less UHC for higher combustion efficiency. 
a) Heavy Naphtha

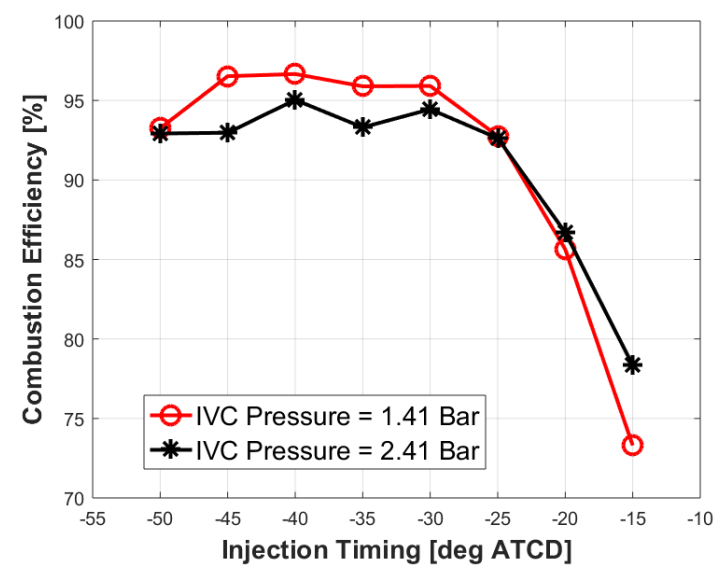

b) Light Naphtha

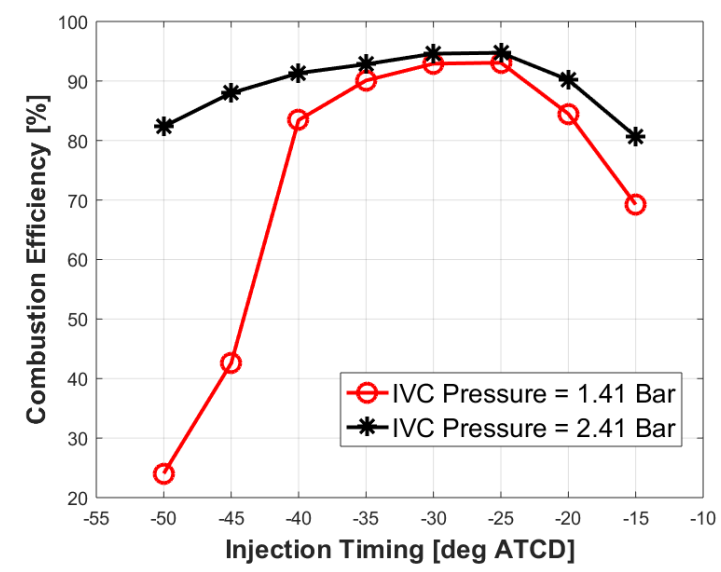

c) PRF50

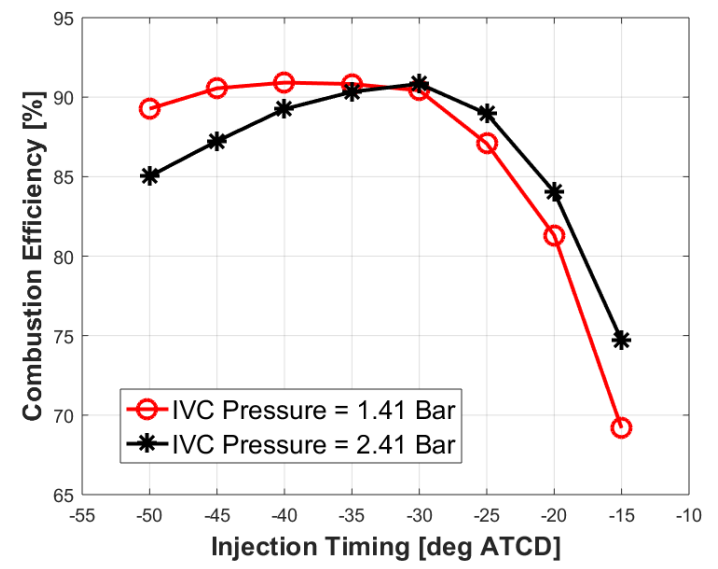

Figure 4-89. Comparison of predicted effect on combustion efficiency due to variation in charge pressure at IVC for various injection timings 
a) Heavy Naphtha

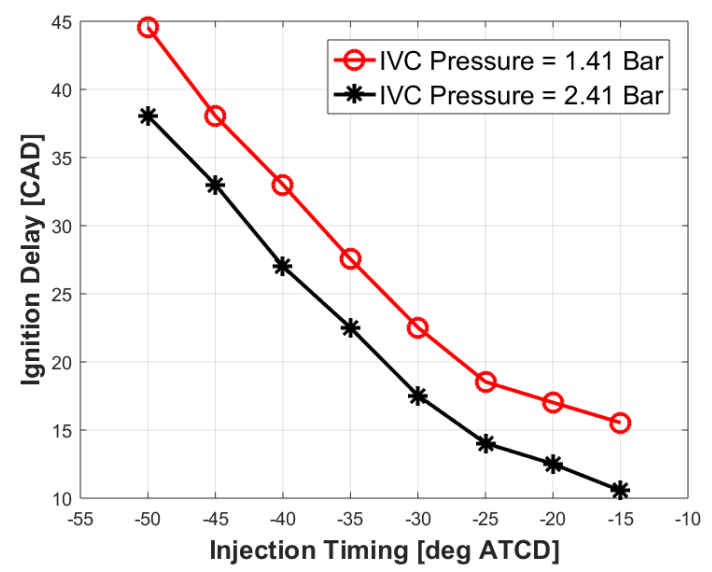

b) Light Naphtha

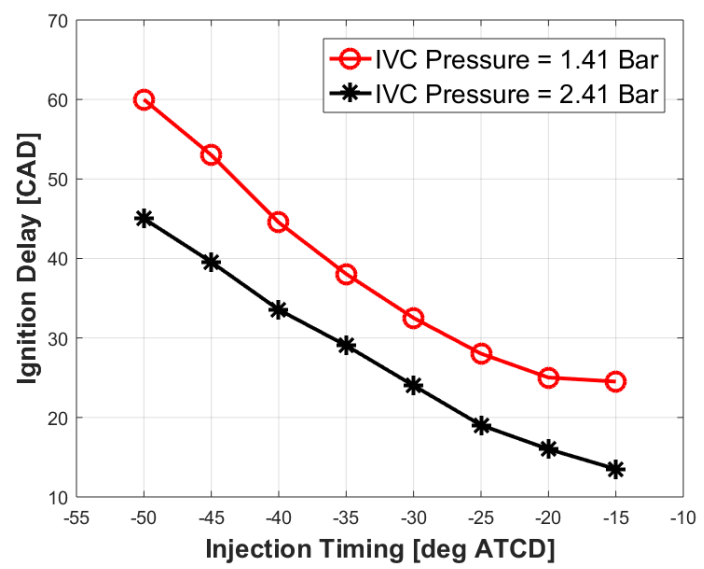

c) PRF50

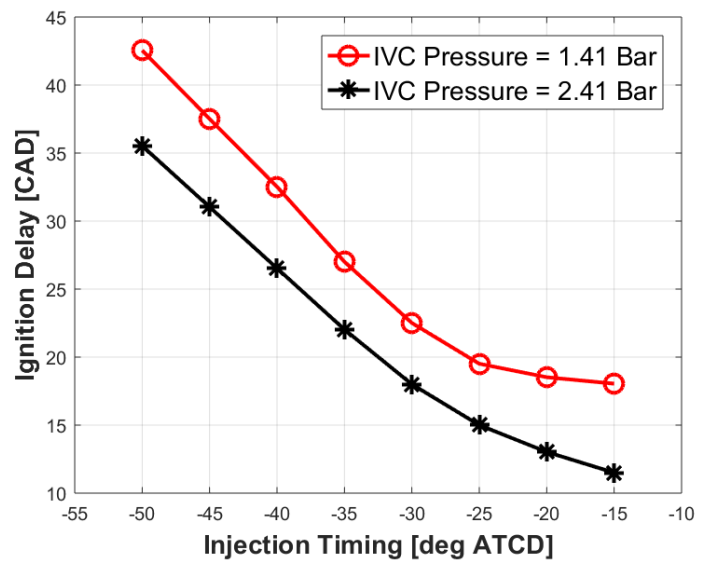

Figure 4-90. Comparison of predicted effect on ignition delay due to variation in charge pressure at IVC for various injection timings 
a) Heavy Naphtha

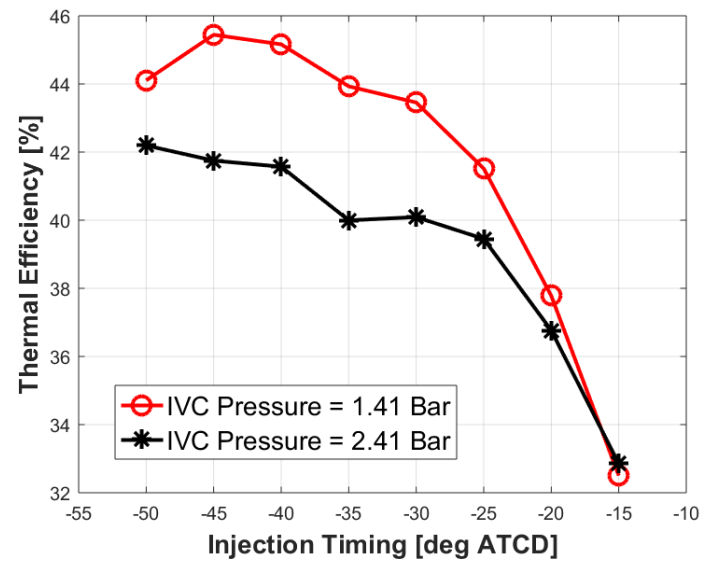

b) Light Naphtha

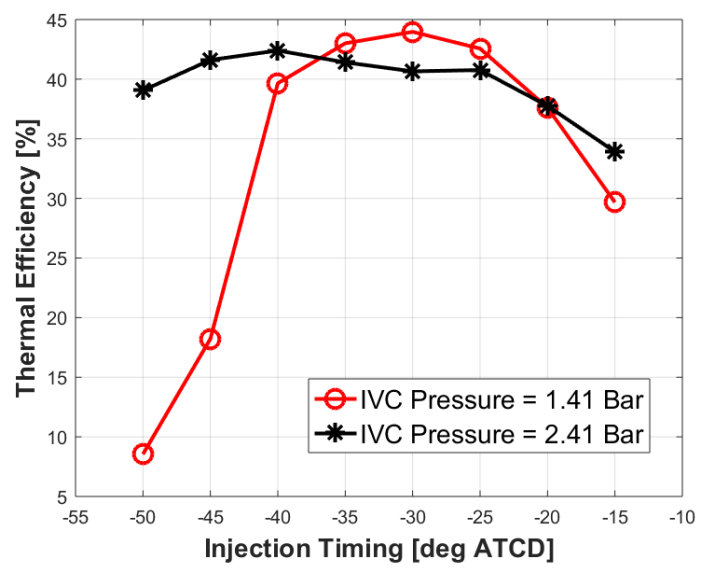

c) PRF50

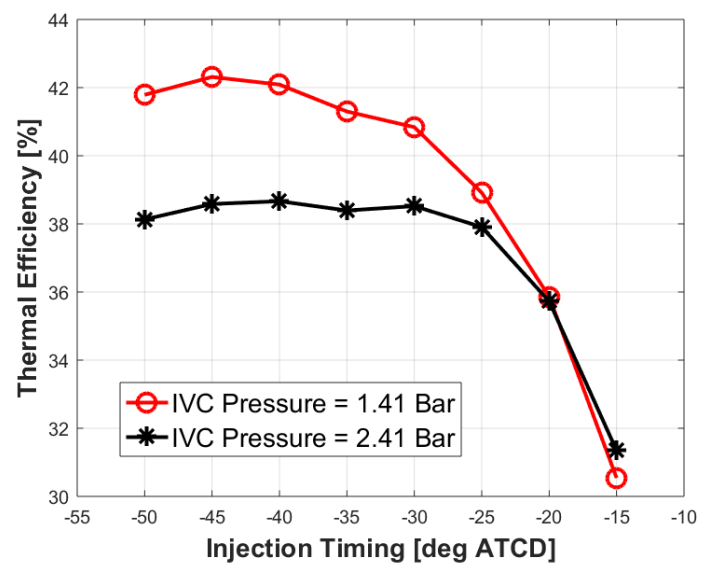

Figure 4-91. Comparison of predicted effect on thermal efficiency due to variation in charge pressure at IVC for various injection timings 
a) Heavy Naphtha

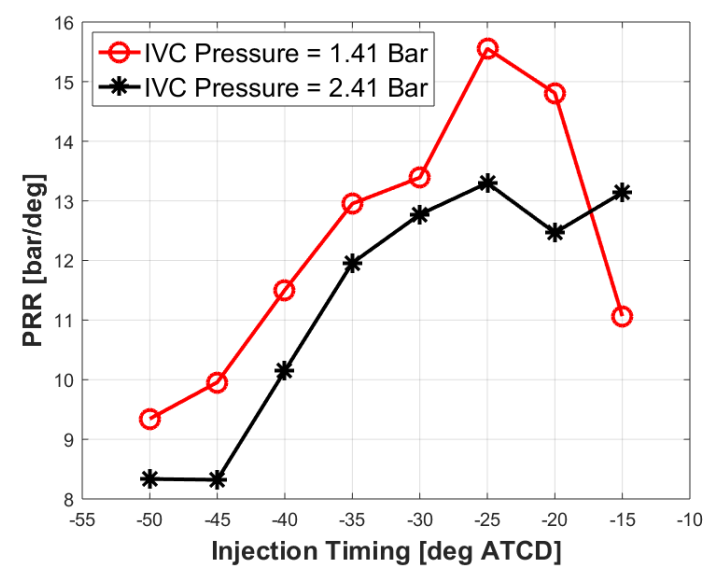

b) Light Naphtha

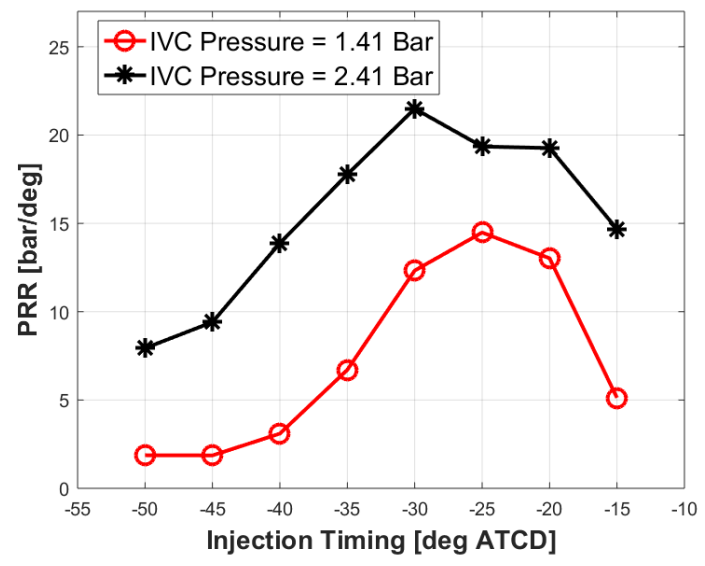

c) PRF50

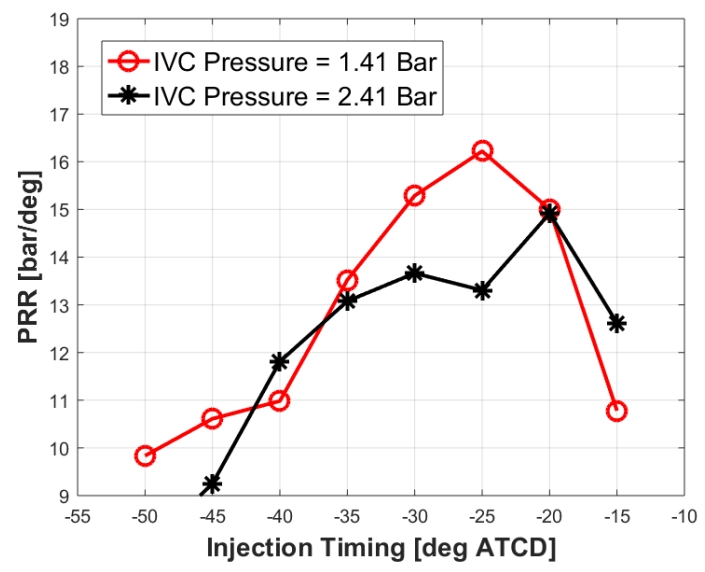

Figure 4-92. Comparison of predicted effect on pressure rise rate due to variation in charge pressure at IVC for various injection timings 
a) Heavy Naphtha

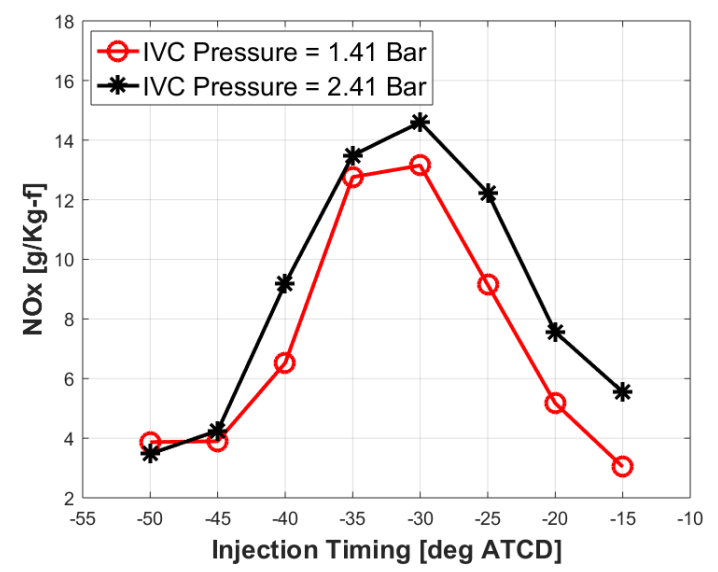

b) Light Naphtha

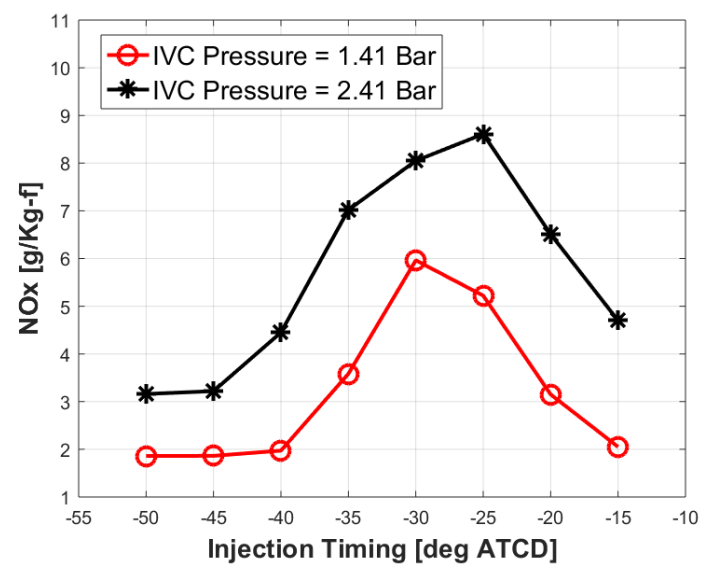

c) PRF50

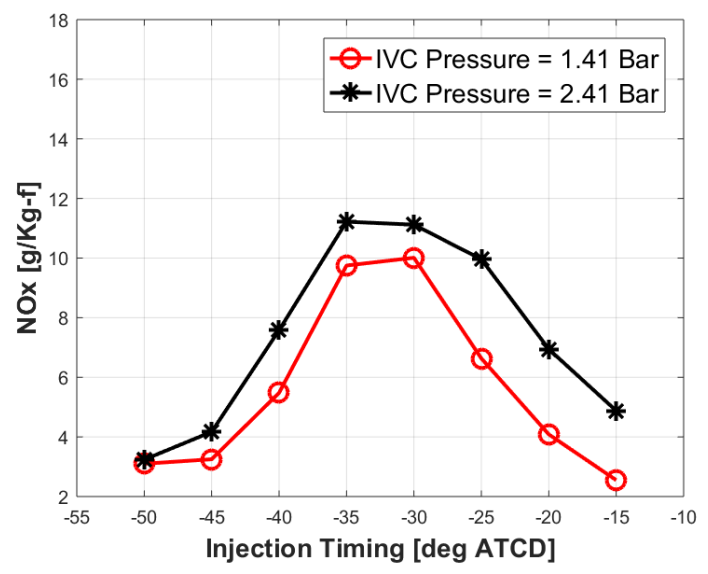

Figure 4-93. Comparison of predicted effect on NOx due to variation in charge pressure at IVC for various injection timings 
a) Heavy Naphtha

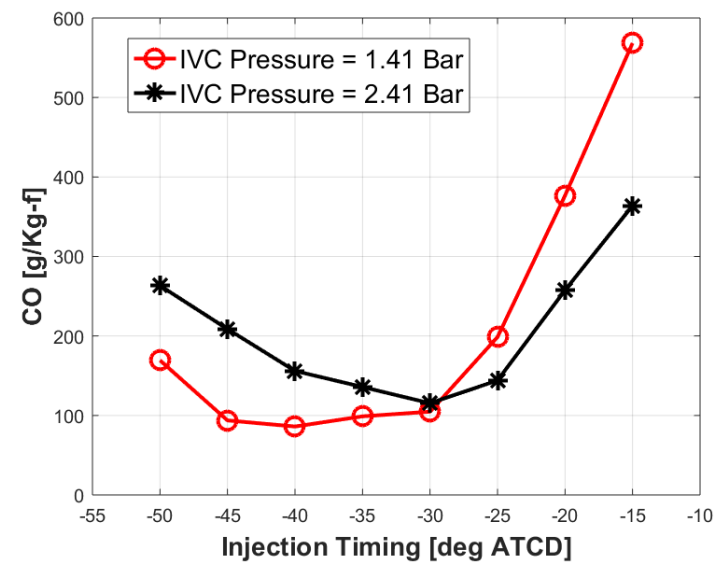

b) Light Naphtha

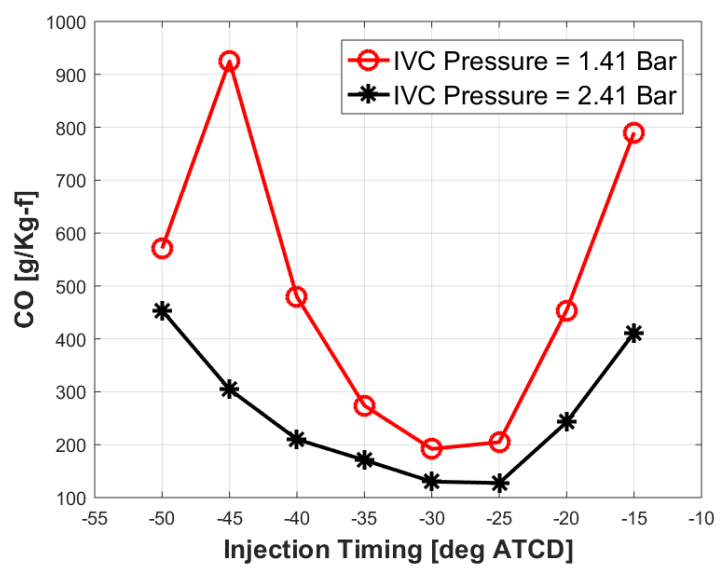

c) PRF50

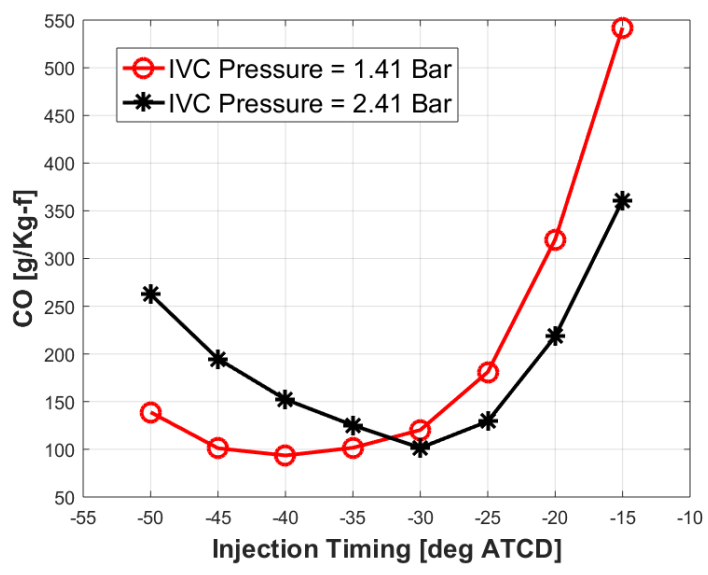

Figure 4-94. Comparison of predicted effect on $\mathrm{CO}$ due to variation in charge pressure at IVC for various injection timings 
a) Heavy Naphtha

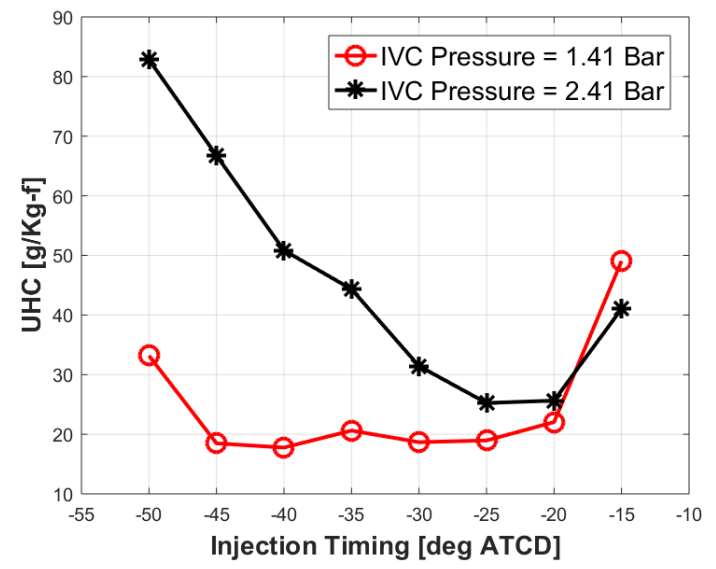

b) Light Naphtha

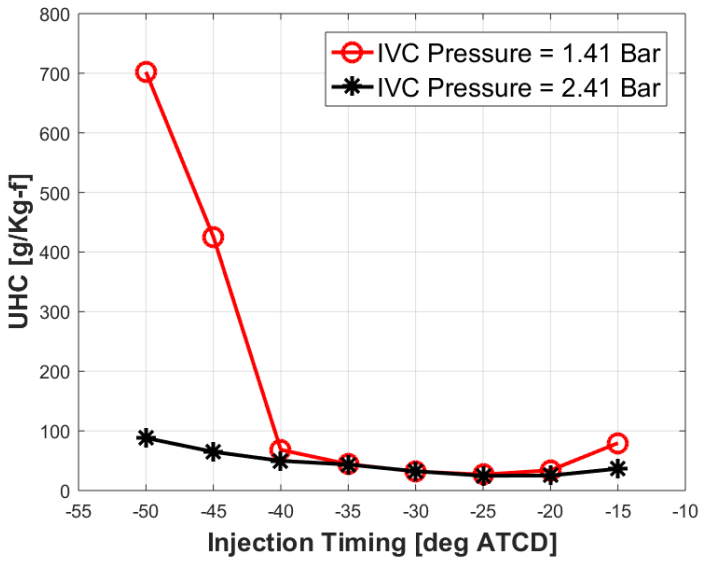

c) PRF50

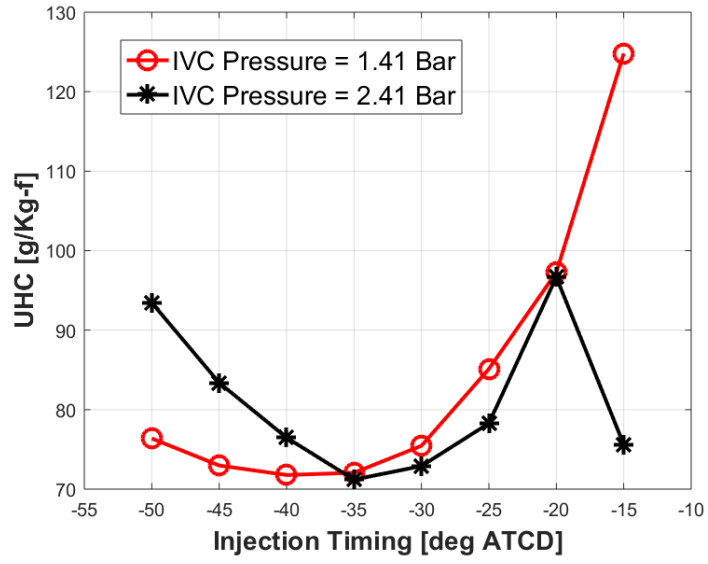

Figure 4-95. Predicted effect on UHC due to variation in charge pressure at IVC for various injection timings 
For the same temperature, more oxygen is available for combustion. Higher the boost level, the charge-fuel mixture becomes more reactive due to increased $\mathrm{O}_{2}$. More reactivity implies that ignition delay reduces. Hence all higher boost level cases show reduced ignition delay. All the earlier injection timings are marked by the availability of more oxygen and less residence time to mix the mixture. For light naphtha, less mixing at advanced injection timing is advantageous, results into higher combustion efficiency. Heavy naphtha and PRF50 shows a different trend. For these fuels, reduced ignition delay means more fuel concentrated in a region and less stratification thus resulting in lower combustion efficiency. For injection timings near TDC, Higher availability of oxygen thus higher reactivity of fuel helps to burn more fuel in rich combustion. Hence combustion efficiency for all three fuels at elevated charge pressure is higher than baseline operating conditions at these injection timings. Thermal efficiency depends upon amount heat release and combustion phasing. In case of heavy naphtha and PRF50, for advanced injection timings, lower combustion efficiency causes lower thermal efficiency. For light naphtha, injection timings between -25 deg ATDC and -35 deg ATDC has higher thermal efficiency for baseline operating condition despite having lower combustion efficiency. This is because the difference between combustion efficiency at these injection timings is less and higher boost pressure results into the start of combustion in the compression stroke. Steeper PRR is evidently because of higher combustion efficiency. NOx formation is controlled by the availability of oxygen and temperature. Higher availability of oxygen at higher boost level results into more NOx formation. Amount of $\mathrm{CO}$ for fuels is bound by combustion efficiency values. Higher combustion efficiency implies more $\mathrm{CO}$ to $\mathrm{CO}_{2}$ conversion thus reducing $\mathrm{CO}$ at EVO. UHC follows a trend similar to $\mathrm{CO}$.

In cases studied below, PRF50 is injected at -15 deg ATDC with charge pressure equal to 1.41 Bar (Baseline) and charge pressure equal to 2.41 Bar (elevated boost level). Table 429 below compares combustion characteristics.

Table 4-29. Predicted combustion characteristics at injection timing -15 deg ATDC for different charge pressure at IVC

\begin{tabular}{|c|c|c|}
\hline & CASE A & CASE B \\
\hline Charge Pressure at IVC (Bar) & 1.41 & 2.41 \\
\hline Combustion Efficiency (\%) & 69.18 & 74.71 \\
\hline Ignition Delay (CAD) & 18.05 & 11.50 \\
\hline Thermal Efficiency (\%) & 30.54 & 31.34 \\
\hline PRR (bar/deg) & 10.78 & 12.62 \\
\hline CO (g/Kg-f) & 542.09 & 360.93 \\
\hline UHC (g/Kg-f) & 124.80 & 75.61 \\
\hline NOx (g/Kg-f) & 2.55 & 4.88 \\
\hline
\end{tabular}

Case A is baseline operating condition where charge pressure at IVC in case B is higher. Case B gives higher combustion and thermal efficiency and PRR. CO and UHC at EVO for case B are less whereas NOx is more. Difference in combustion quality between two cases can be seen using pressure and heat release traces 


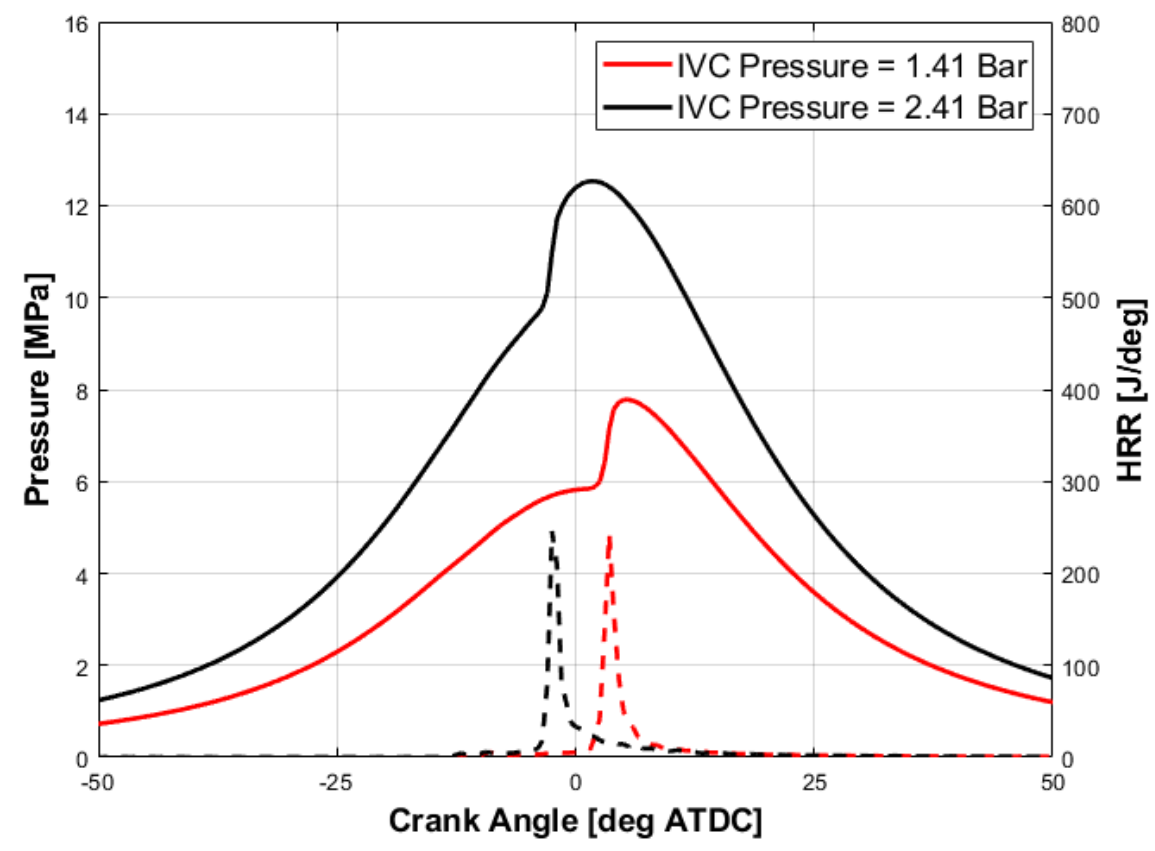

Figure 4-96. Comparison of predicted pressure and HRR for injection timing -15 deg ATDC for charge pressure 1.41 Bar and 2.41 Bar

Case B always has higher charge pressure, that results into higher peak cylinder pressure. Heat release in both the cases is steep. Case B undergoes early release of heat. Despite having a difference in the values, both the cases show the sudden release of heat energy which indicates spontaneous homogeneous combustion.

Temperature is kept constant at IVC for both operating condition and it can be seen in Figure 4-98. Case B has higher combustion efficiency but case A has higher peak cylinder and expansion temperature. Higher combustion efficiency for case B does not maintain higher average expansion temperature. More amount of charge in the combustion chamber of case B require more amount of heat energy to show a rise in temperature.

Vaporization trend for both cases is shown in Figure 4-99. Different charge pressure does not affect vaporization.

Fuel distribution in the combustion chamber is an important parameter in describing difference between combustion characteristics for two cases. Figure 4-100 below shows y axis snip of combustion chamber with equivalence ratio just before start of combustion. Both the cases show highly rich regions within the combustion chamber. Numerically speaking, case $\mathrm{B}$ has maximum equivalence ratio $\approx 5.08$ and that is for case $\mathrm{A}$ is $\approx 6.59$. Despite having lower ignition delay, case B has leaner equivalence ratio compared to case A. This can be explained by higher availability of oxygen for case B. 


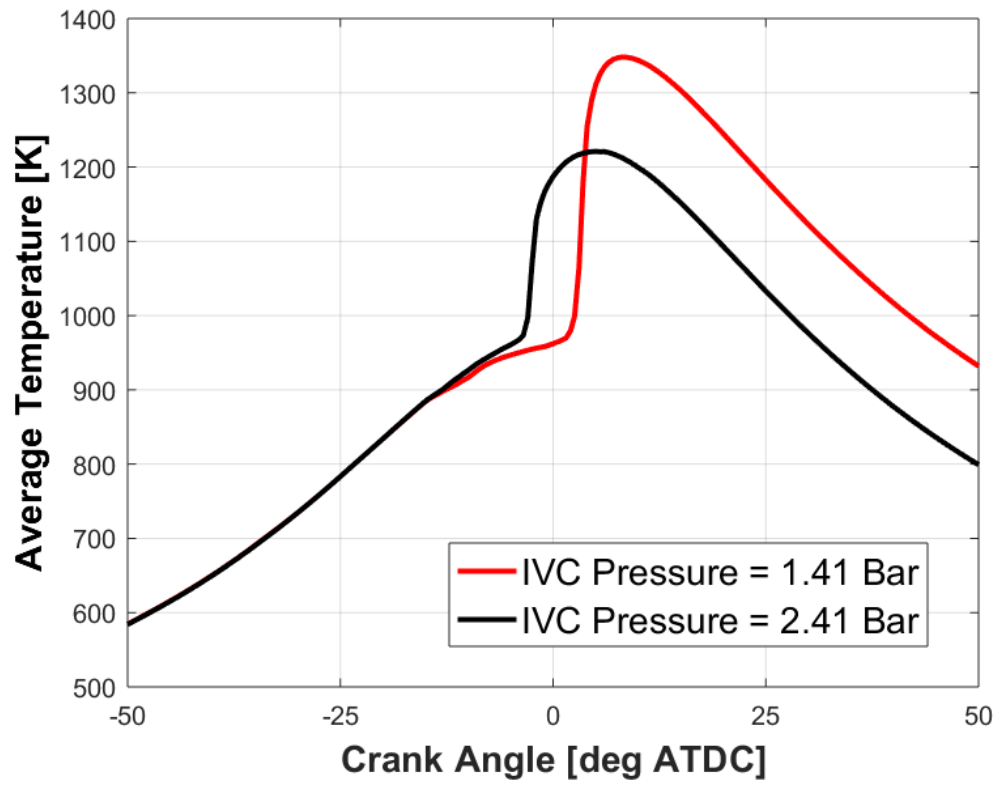

Figure 4-97. Comparison of predicted average temperature for injection timing $-15 \mathrm{deg}$ ATDC for charge pressure 1.41 Bar and 2.41 Bar

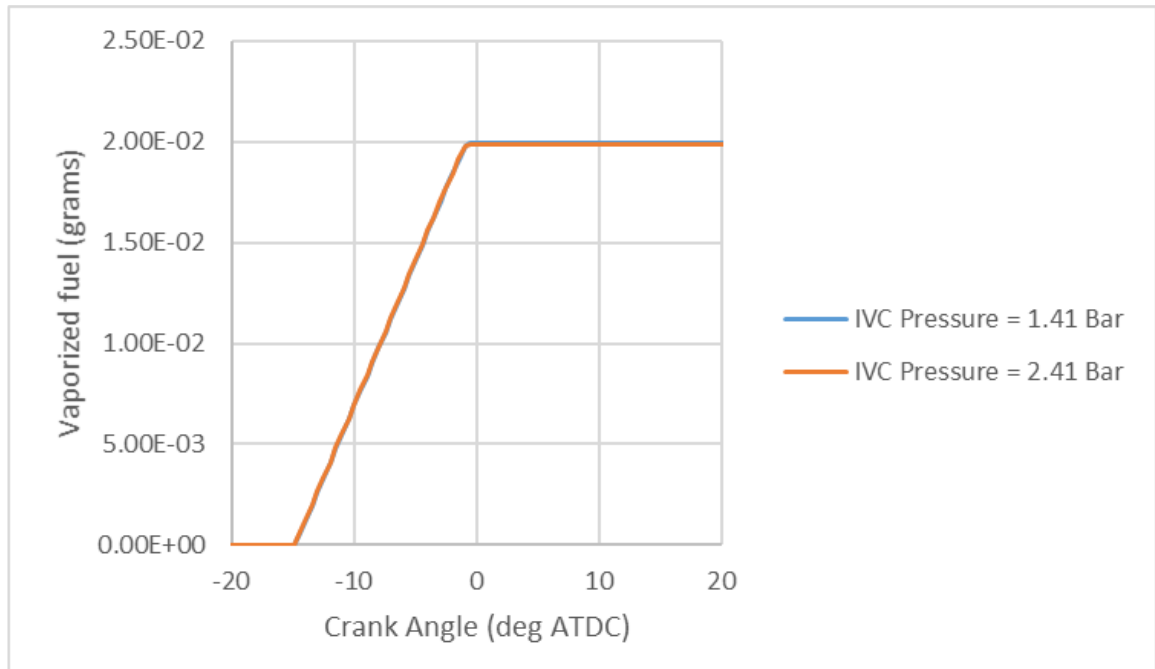

Figure 4-98. Comparison of predicted vaporization trend for injection timing -15 deg ATDC for charge pressure 1.41 Bar and 2.41 Bar 
a)

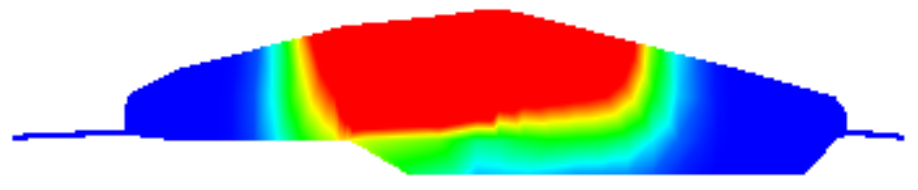

b)
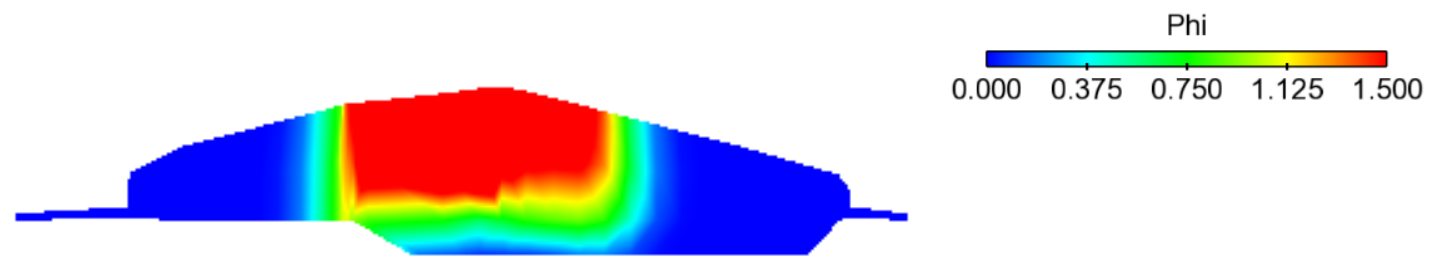

Figure 4-99. Predicted equivalence ratio distribution for injection timing -15 deg ATDC for charge pressure a) 1.41 Bar at TDC and b) 2.41 Bar at -4 deg ATDC

It is clear from the steep increase in heat release rate and pressure along with PRR values, both the case does not achieve enough charge-fuel mixing to get stratified combustion. Higher $\mathrm{O}_{2}$ concentration makes highly rich combustion more effective. For Case, B amount of fuel undergoes more effective rich combustion giving lower $\mathrm{CO}$ and UHC. Higher $\mathrm{O}_{2}$ availability and higher combustion efficiency (thus higher localized temperature) give higher NOx value at EVO.

Table 4-30. Predicted combustion characteristics at injection timing -45 deg ATDC for different charge pressure at IVC

\begin{tabular}{|c|c|c|}
\hline & CASE A & CASE B \\
\hline Charge Pressure at IVC (Bar) & 1.41 & 2.41 \\
\hline Combustion Efficiency (\%) & 90.56 & 87.24 \\
\hline Ignition Delay (CAD) & 37.51 & 31.03 \\
\hline Thermal Efficiency $(\%)$ & 42.31 & 38.58 \\
\hline PRR (bar/deg) & 10.61 & 9.25 \\
\hline CO (g/Kg-f) & 101.11 & 194.78 \\
\hline UHC (g/Kg-f) & 72.98 & 83.38 \\
\hline NOx (g/Kg-f) & 3.25 & 4.17 \\
\hline
\end{tabular}

As combustion efficiency trend is reversed for advanced injection timings for heavy naphtha and PRF50, next injection timing to be compared is $-45 \mathrm{deg}$ ATDC and fuel used is PRF50 only. Table 4-30 summarize combustion characteristics. Case A is baseline operating condition and case B is with higher charge pressure at IVC. Case A has higher combustion and thermal efficiency with higher PRR. However, case A has low all three engine-out emissions. 
Pressure and heat release trace is shown in Figure 4-101. Similar to the previous case B has higher charge pressure for entire compression and expansion stroke. Both cases show steep pressure rise rates. Case A has slightly longer combustion duration.

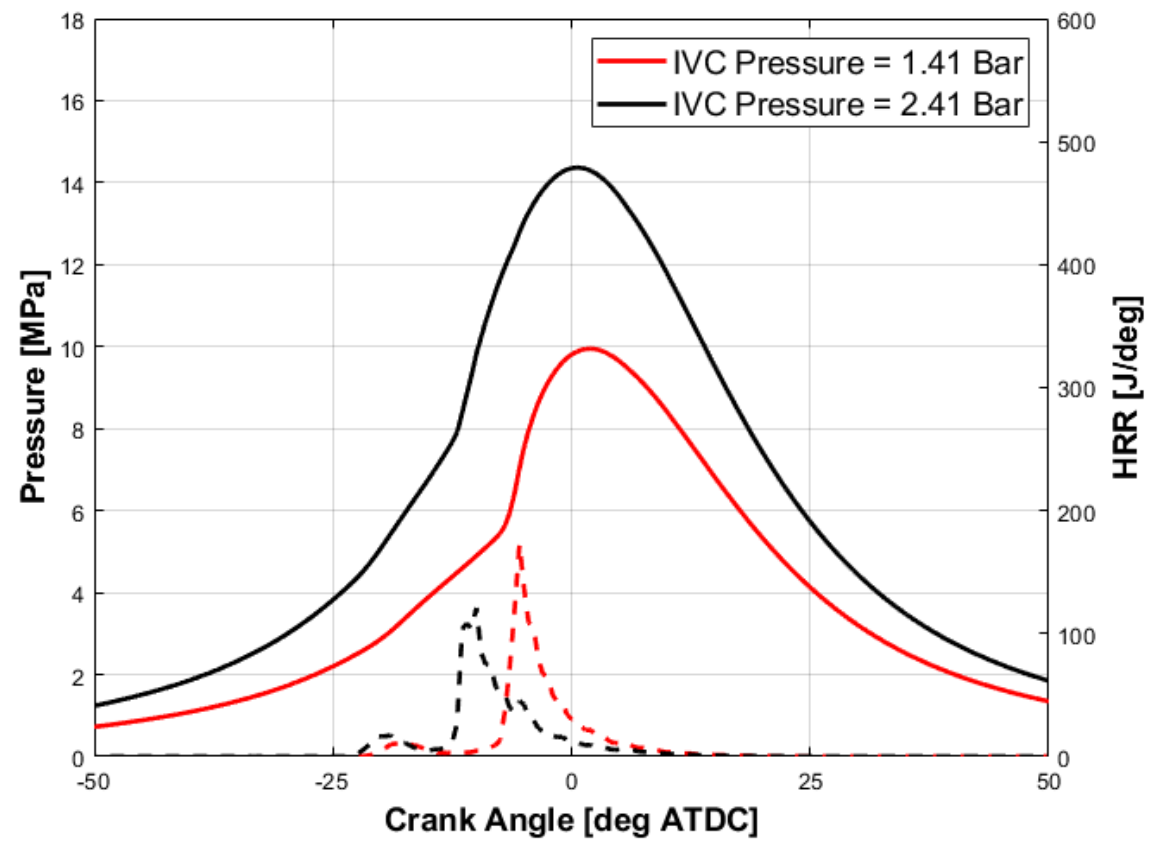

Figure 4-100. Comparison of predicted pressure and HRR for injection timing -45 deg ATDC for charge pressure 1.41 Bar and 2.41 Bar

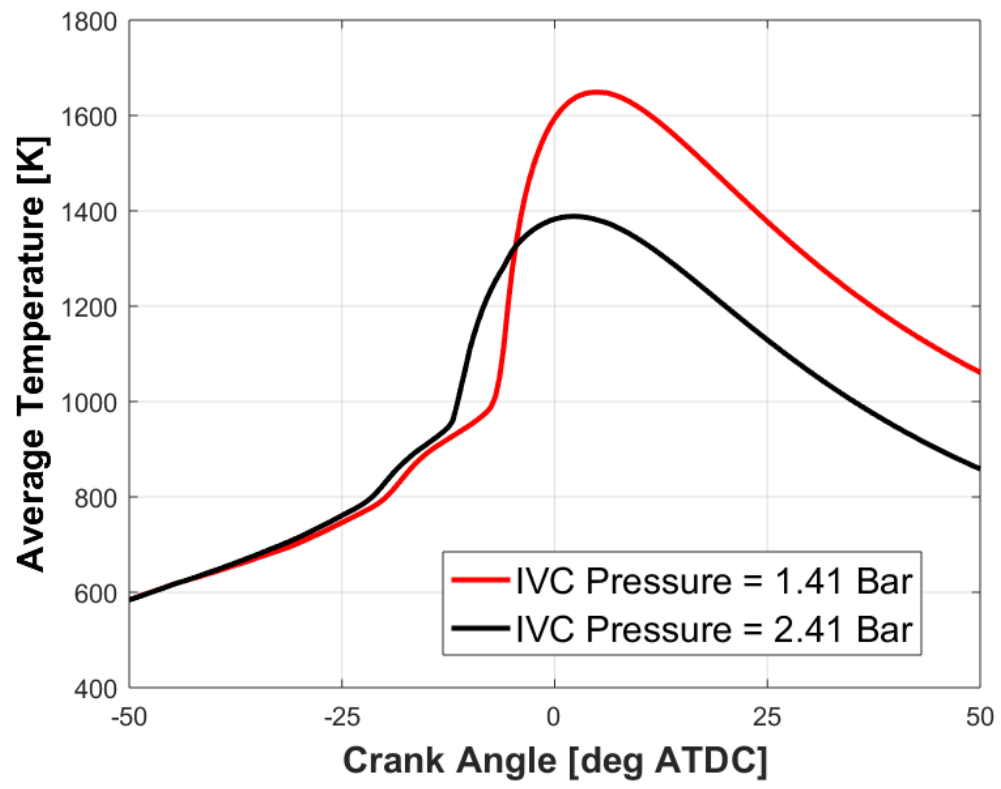

Figure 4-101. Comparison of predicted average temperature for injection timing $-45 \mathrm{deg}$ ATDC for charge pressure 1.41 Bar and 2.41 Bar 
Average temperature trend is shown in Figure 4-102. Here as well, case A has higher peak cylinder and expansion temperature. Lower combustion efficiency combined with higher charge is a cause of lower expansion temperature for case B.

Vaporization trend in Figure 4-103 shown is same for both the operating conditions.

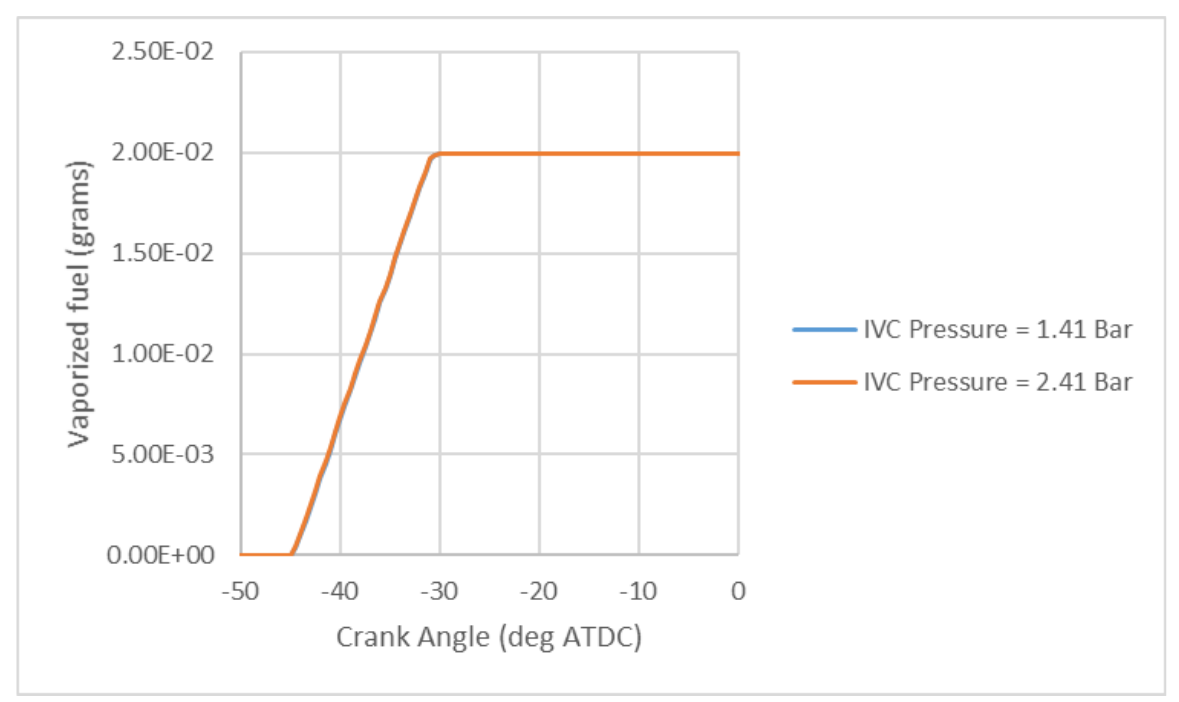

Figure 4-102. Comparison of predicted vaporization trend for injection timing -45 deg ATDC for charge pressure 1.41 Bar and 2.41 Bar

Again, difference in combustion quality can be described with the help of equivalence distribution.

a)

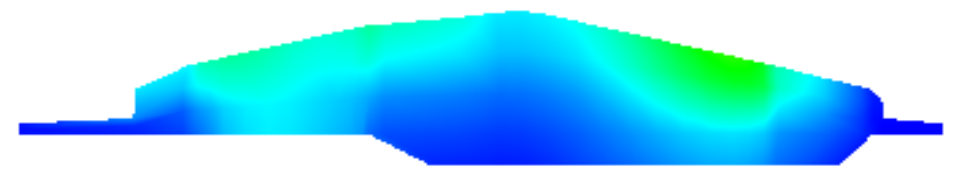

b)
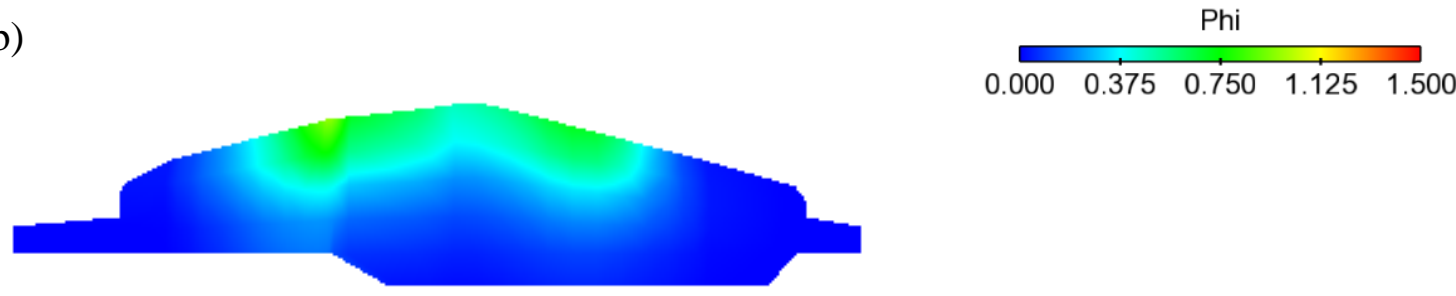

Figure 4-103. Predicted equivalence ratio distribution for injection timing -45 deg ATDC for charge pressure a) 1.41 Bar at -6 deg ATCD and b) 2.41 Bar at -13 deg ATDC 
Numerically maximum equivalence ratio for case $\mathrm{A}$ and $\mathrm{B}$ are respectively equal to $\approx 1.9$ and $\approx 1.5$. Different fuel distribution can be seen in Figure 4-104. For Case B, fuel is more located whereas case A shows more dispersed fuel conditions. This difference can be due to variation in the residence time. Higher reactivity of case B gives lower ignition delay and lower mixing time. Higher availability of oxygen makes maximum $\phi$ value leaner that case B. In this study both case A and B undergo a similar type of combustion. A lower value of PRR and equivalence ratio distribution shows that PRF50 is undergoing stratified combustion at both operating conditions. However, case A has slightly more stratification giving higher combustion efficiency and lower $\mathrm{CO}$ and UHC. Higher NOx for higher boost level despite having low in-cylinder temperature is explained by more availability of $\mathrm{O}_{2}$.

Since light naphtha gives a different trend than remaining two high reactive fuels, let's compare one injection timing case for baseline and higher charge pressure operating conditions. Light naphtha is injected at -45 deg ATDC for both operating conditions. Table 4-31 gives important combustion characteristics. In accordance with previous case studies, case A is baseline and case B is higher boost pressure. Case B has substantially higher combustion and thermal efficiency. $\mathrm{CO}$ and $\mathrm{UHC}$ at EVO are lower for case $\mathrm{B}$ whereas NOx is lower for case A.

Pressure and heat release rate for both the cases is shown in Figure 4-105. Case A has very late combustion and not a large amount of heat release. As a result, the heat release rate and peak cylinder pressure are lower.

Table 4-31. Predicted combustion characteristics at injection timing -45 deg ATDC for different charge pressure at IVC

\begin{tabular}{|c|c|c|}
\hline & CASE A & CASE B \\
\hline Charge Pressure at IVC (Bar) & 1.41 & 2.41 \\
\hline Combustion Efficiency (\%) & 42.57 & 87.97 \\
\hline Ignition Delay (CAD) & 53.01 & 39.55 \\
\hline Thermal Efficiency $(\%)$ & 18.22 & 41.61 \\
\hline PRR (bar/deg) & 1.86 & 9.41 \\
\hline CO (g/Kg-f) & 925 & 304.57 \\
\hline UHC (g/Kg-f) & 425.63 & 64.93 \\
\hline NOx (g/Kg-f) & 1.86 & 3.22 \\
\hline
\end{tabular}

Contrary to two cases studied above, here baseline case has lower peak cylinder and expansion temperature. Average temperature trend is shown in Figure 4-106. 


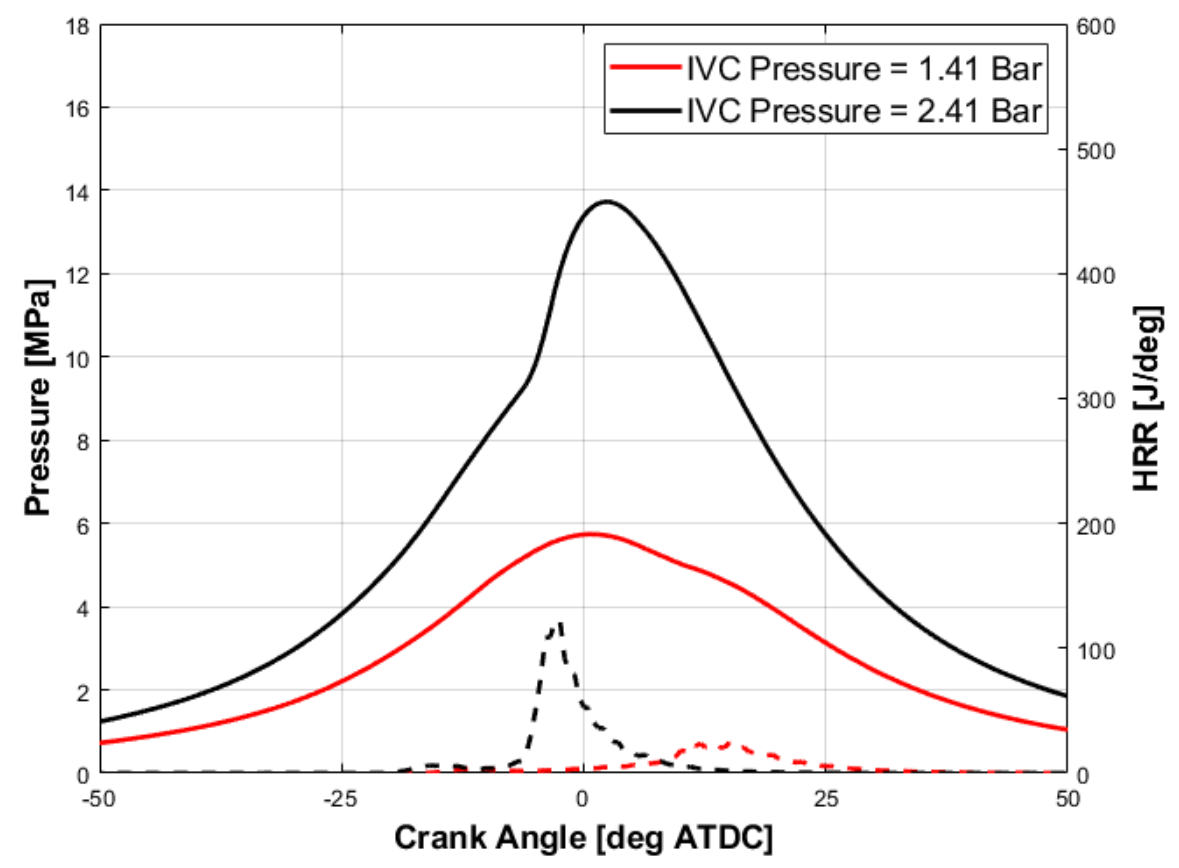

Figure 4-104. Comparison of predicted pressure and HRR for injection timing -45 deg ATDC for charge pressure 1.41 Bar and 2.41 Bar

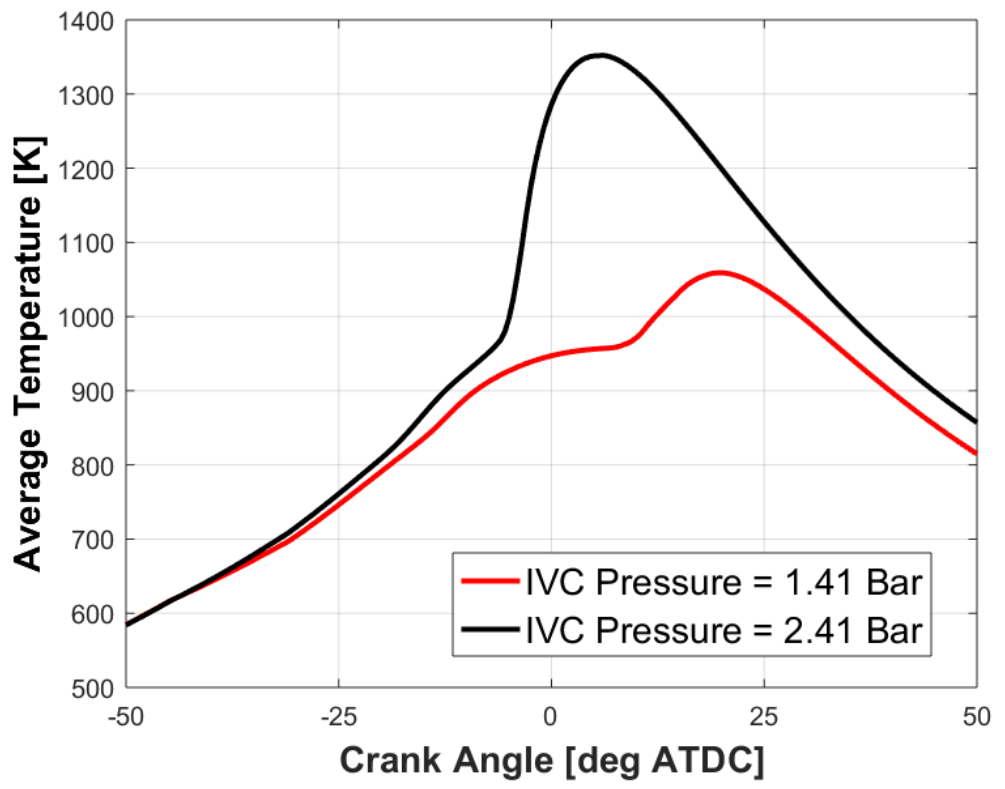

Figure 4-105. Comparison of predicted average temperature for injection timing $-45 \mathrm{deg}$ ATDC for charge pressure 1.41 Bar and 2.41 Bar 
Again, vaporization trend (see Figure 4-107) shows no variation.

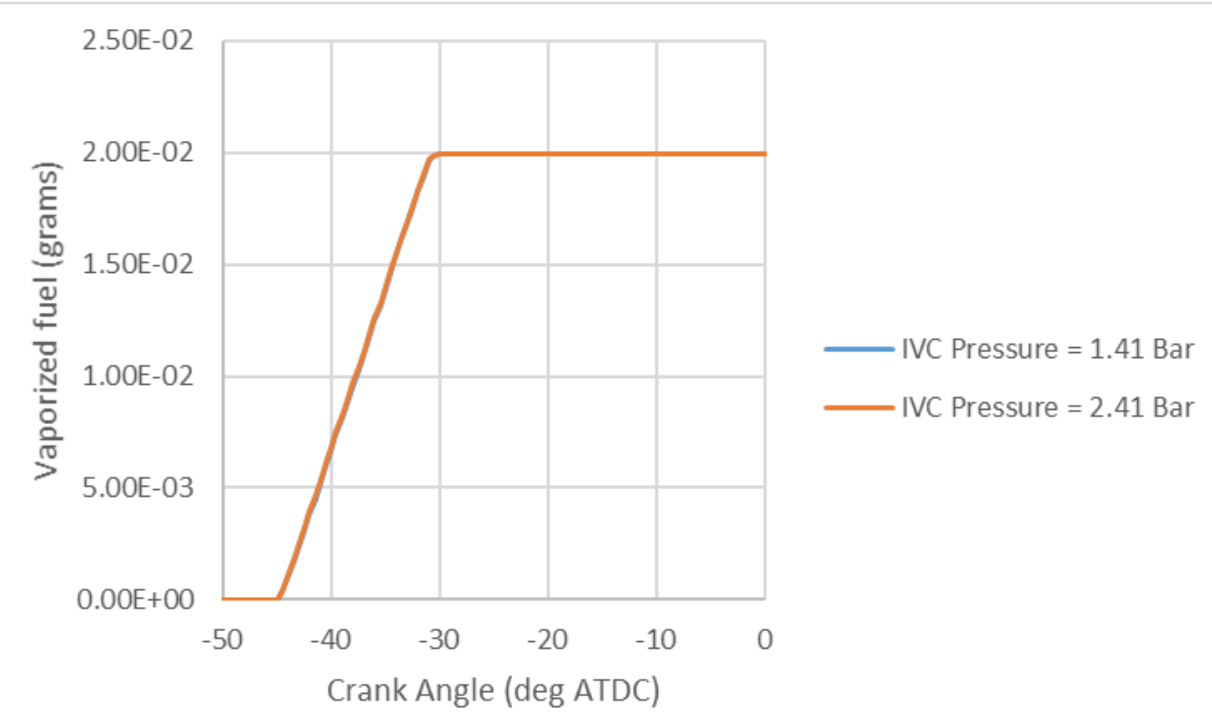

Figure 4-106. Comparison of predicted vaporization trend for injection timing $-45 \mathrm{deg}$ ATDC for charge pressure 1.41 Bar and 2.41 Bar

High difference in combustion quality can be explained by fuel distribution). Cut plane at y- axis shown in Figure 4-108 for both the cases shows striking variation in the air-fuel mixture in the combustion chamber.

a)

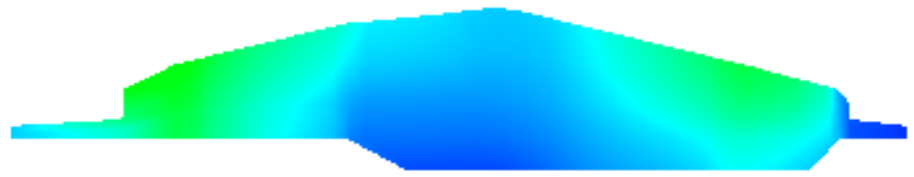

b)
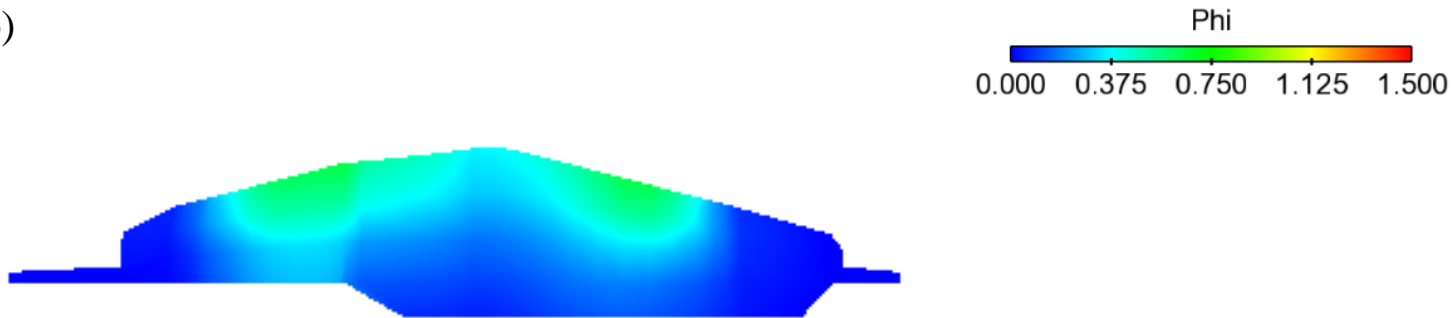

Figure 4-107. Predicted equivalence ratio distribution for injection timing -45 deg ATDC for charge pressure a) 1.41 Bar at 8 deg ATDC and b) 2.41 Bar at -6 deg ATDC

Higher boost pressure case $\mathrm{B}$ has a shorter ignition delay time owing to its higher reactive mixture. Lower ignition delay for case $\mathrm{B}$ avoids overmixing of fuel like in case A. maximum equivalence ratio for case $\mathrm{A}$ is $\approx 1.4$ whereas case $\mathrm{B}$ is $\approx 0.95$. Leaner equivalence 
ratio is due to higher $\mathrm{O} 2$. As discussed previously, overmixed mixtures either does not burn fuel at all or results into incomplete combustion. Higher $\mathrm{O}_{2}$ and lesser ignition delay at advanced injection timing result in better combustion for case $\mathrm{B}$ with lower $\mathrm{CO}$ and UHC. Case A has a low temperature (due to less heat release) and low $\mathrm{O}_{2}$ (less charge pressure at IVC) hence low NOx.

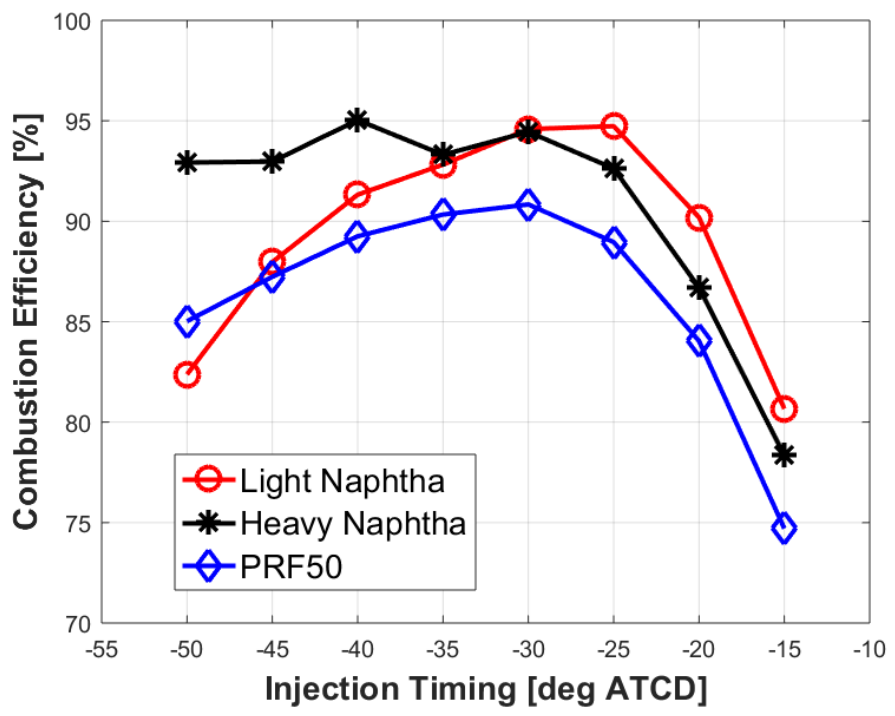

Figure 4-108. Comparison of combustion efficiencies for charge pressure $2.41 \mathrm{Bar}$ at various injection timings using three fuels

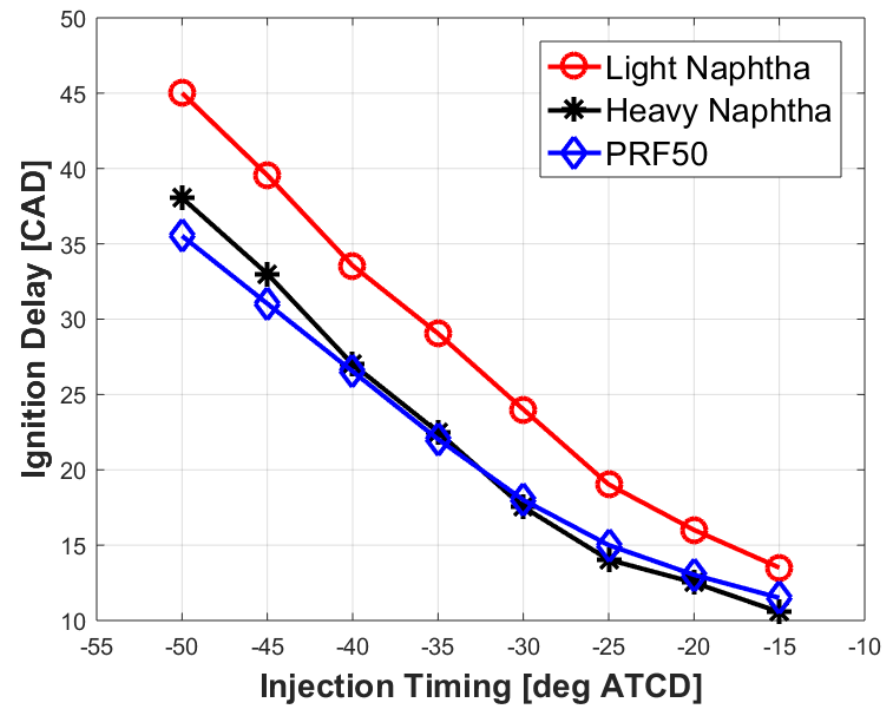

Figure 4-109. Comparison of ignition delay for charge pressure $2.41 \mathrm{Bar}$ at various injection timings using three fuels

Lower reactive light naphtha has longer ignition delay than remaining two and the comparison is given in Figure 4-110. 


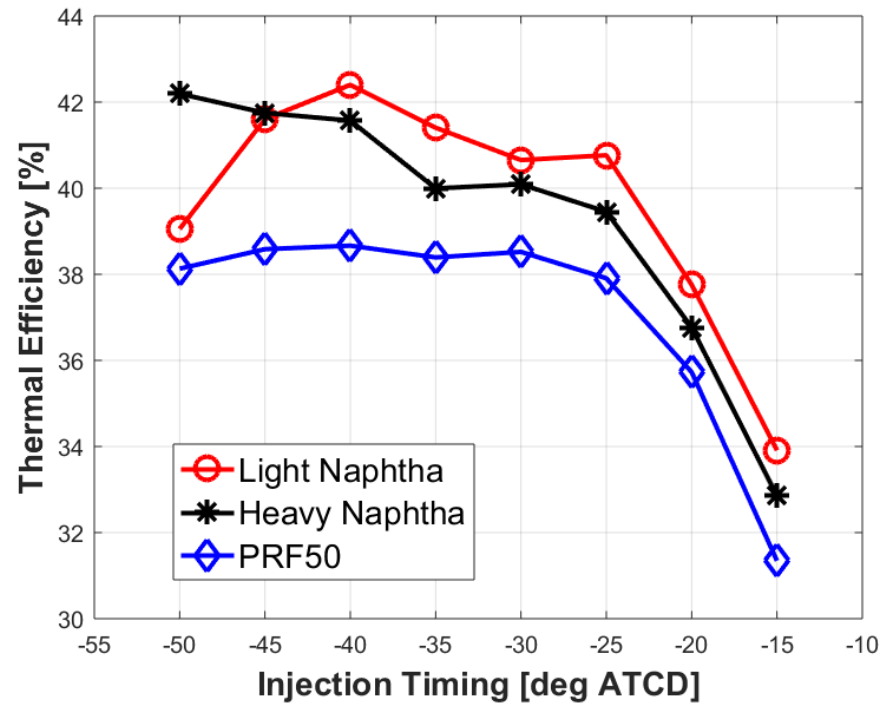

Figure 4-110. Comparison of thermal efficiencies for charge pressure 2.41 Bar at various injection timings using three fuels

Thermal efficiency shows an interesting trend (see Figure 4-111). For all three fuels, it increases as injection timing are advanced from TDC. Light naphtha has higher thermal efficiency for almost entire injection timing sweep except for extremely early injections.

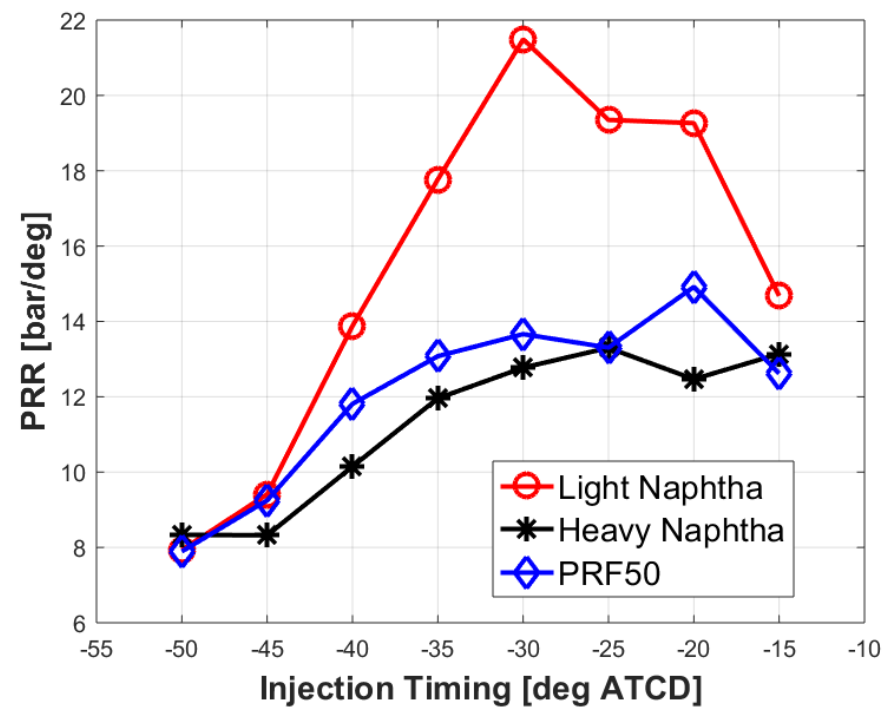

Figure 4-111. Comparison of pressure rise rates for charge pressure 2.41 Bar at various injection timings using three fuels

Light naphtha has higher PRR whereas heavy naphtha maintains lower value (see Figure 4-112). Emission value trends at EVO are shown below. 


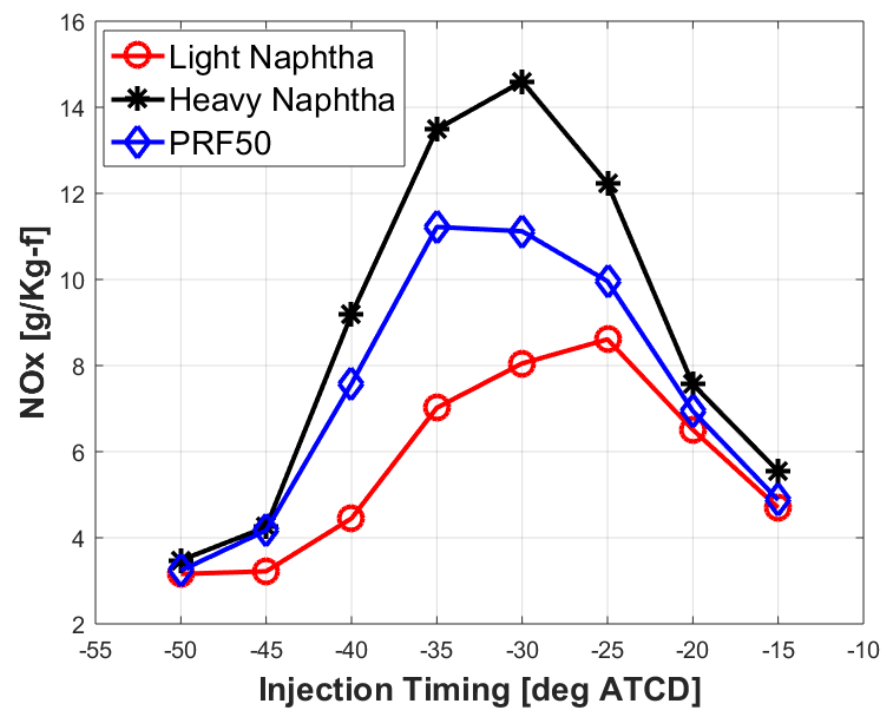

Figure 4-112. Comparison of NOx for charge pressure 2.41 Bar at various injection timings using three fuels

NOx comparison is given by Figur 4-113. Through entire injection timing sweep, heavy naphtha gives higher NOx and light naphtha has lower. Despite having different range, all fuels give first increasing and then decreasing trends as advance injection timings are advanced.

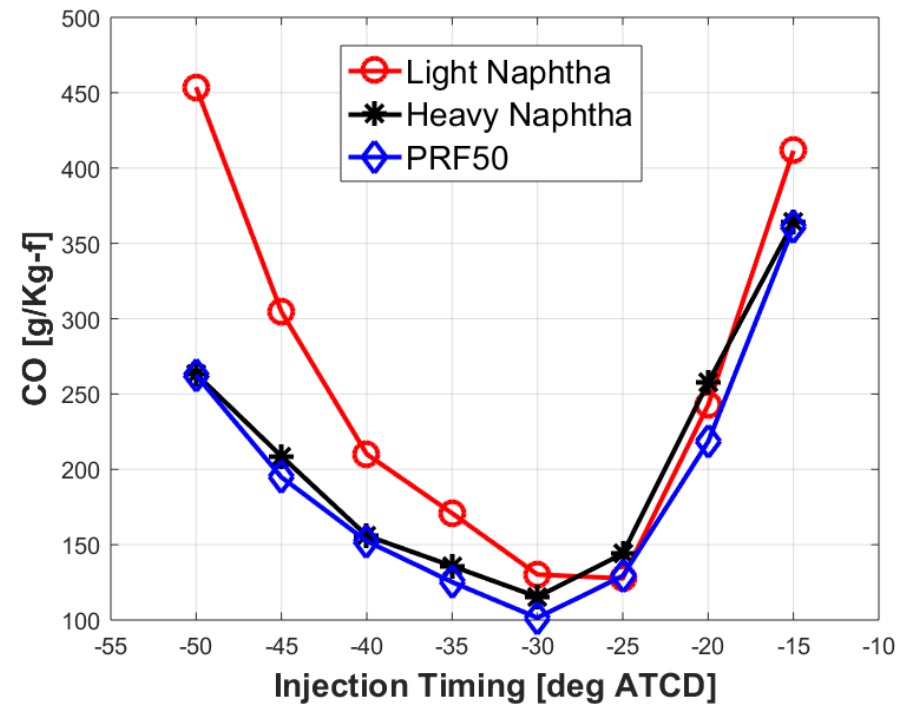

Figure 4-113. Comparison of for charge pressure 2.41 Bar at various injection timings using three fuels

Sweet spot behavior of CO can be seen for all three fuels and its shown in Figure 4-114. For injection very early in the compression stroke, light naphtha has higher CO. 
Despite having different values trend shown by all three fuels are similar to the baseline. Lower reactive fuels tend to give more effective combustion at injections near TDC and higher reactive fuels at early injections in the compression stroke. Ignition delay values align with combustion efficiency trends. Light naphtha because of having lower reactive has longer ignition delay times and ignition delay time increases as injection timings are advanced. Light naphtha dominates thermal efficiency except for very advanced injections. Ignition delay times are in such a way that light naphtha gets its CA50 near TDC reducing compression work and increasing expansion work hence giving higher thermal efficiency. For advanced injection timings, the amount of heat release starts to drop considerably compared to other two fuels due to over mixing and hence thermal efficiency starts to drop as well. As CO and UHC are indicators of incomplete combustion, they adapt trend opposite to combustion efficiency. For NOx, higher values by heavy naphtha can be explained by the higher heating value of the fuel. More amount of heat is released for heavy naphtha giving more localized temperature and hence more NOx.

All three fuels are compared at -25 deg ATDC injection timing with higher charge pressure operating conditions. Table 4-32 enumerates different parameter values to compare.

Table 4-32. Predicted combustion characteristics at -25 deg ATDC injection timing using three fuels

\begin{tabular}{|c|c|c|c|}
\hline & Light Naphtha & Heavy Naphtha & PRF50 \\
\hline Combustion Efficiency (\%) & 94.73 & 92.63 & 88.96 \\
\hline Ignition Delay (CAD) & 19.03 & 14.035 & 15.002 \\
\hline Thermal Efficiency (\%) & 40.76 & 39.45 & 37.91 \\
\hline PRR (bar/deg) & 19.35 & 13.3 & 13.3 \\
\hline CO (g/Kg-f) & 127.62 & 144.07 & 129.26 \\
\hline UHC (g/Kg-f) & 24.82 & 25.242 & 72.905 \\
\hline NOx (g/Kg-f) & 8.609 & 12.23 & 9.959 \\
\hline
\end{tabular}

Light naphtha gives higher combustion and thermal efficiency with higher PRR. On the other hand, it maintains lower emissions at EVO. Light naphtha shows steep pressure rise rate in pressure trace shown above. Figure 4-115 below also shows that heat release takes place late for light naphtha with higher peak value. Although having different values, all three fuel shows sudden heat release with steep pressure rise rates and smaller combustion duration.

Figure 4-116 shows average temperature for all fuels and it does not show much variation. All three fuels with different volatility show similar vaporization trend (See Figure 4-117). 


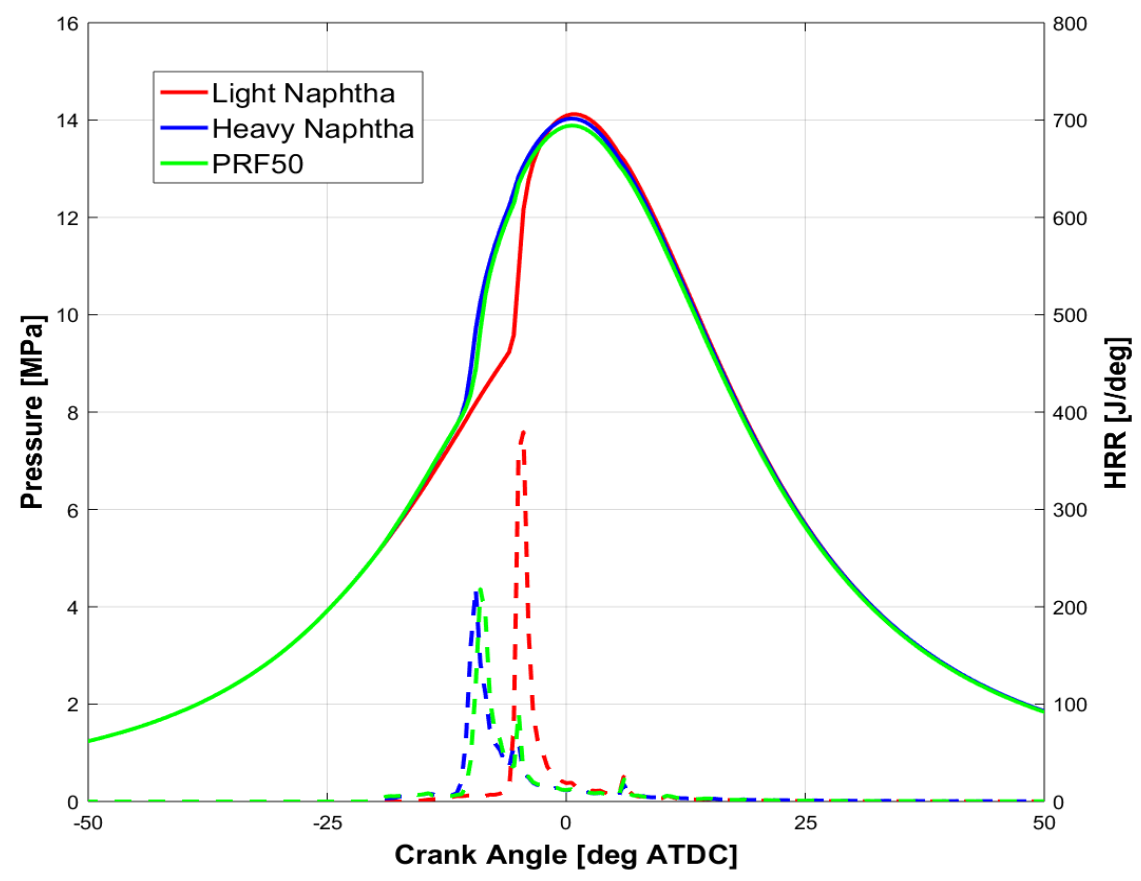

Figure 4-114. Comparison of predicted pressure and HRR at charge pressure 2.41 Bar at IVC with -25 deg ATDC injection timing using three fuels

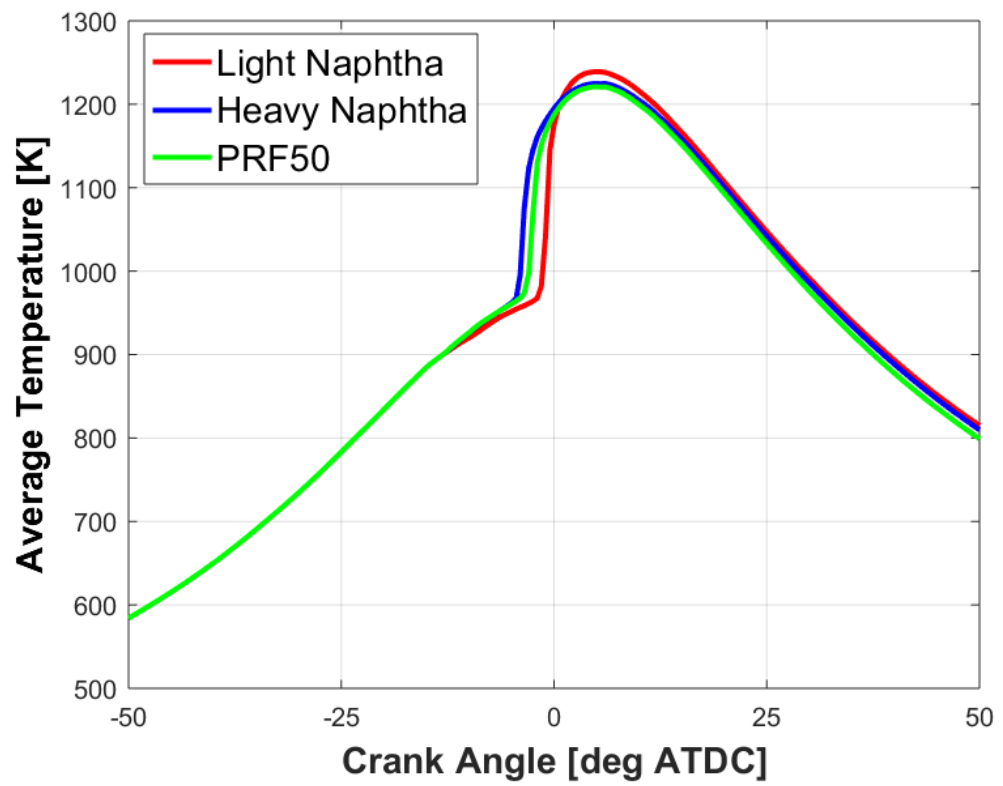

Figure 4-115. Comparison of predicted average temperature at charge pressure 2.41 Bar at IVC with -25 deg ATDC injection timing using three fuels 


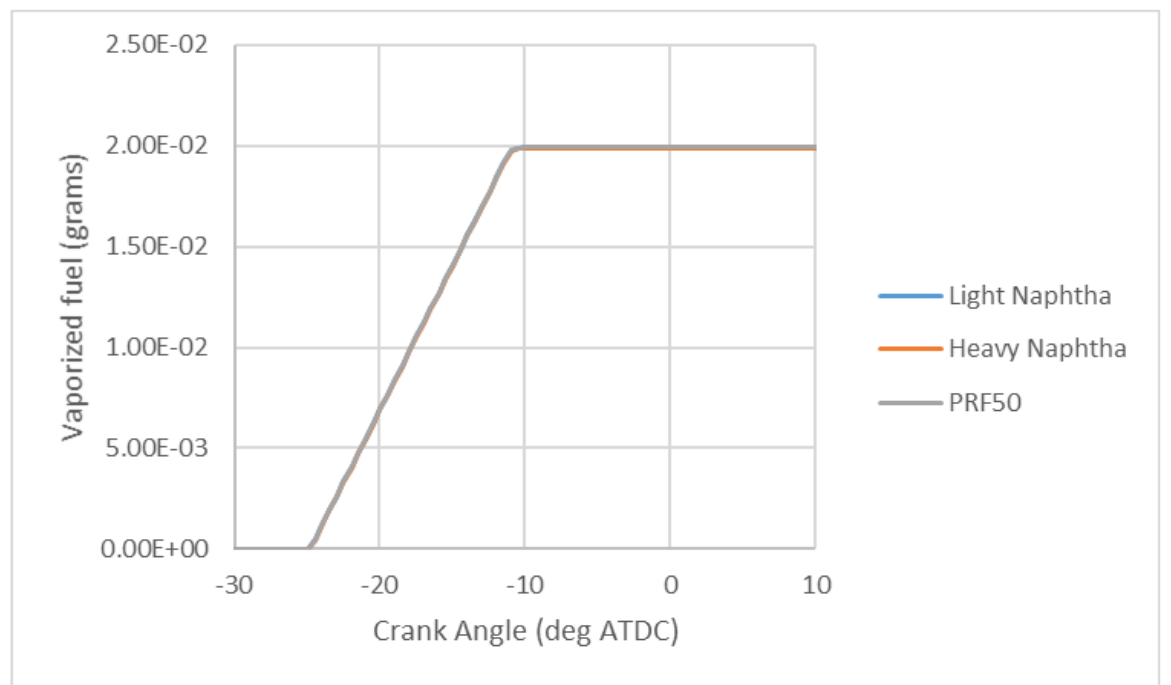

Figure 4-116. Comparison of predicted vaporization trend at charge pressure $2.41 \mathrm{Bar}$ at IVC with -25 deg ATDC injection timing using three fuels

a)

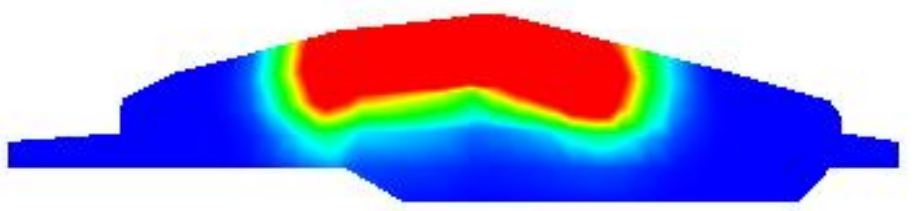

b)
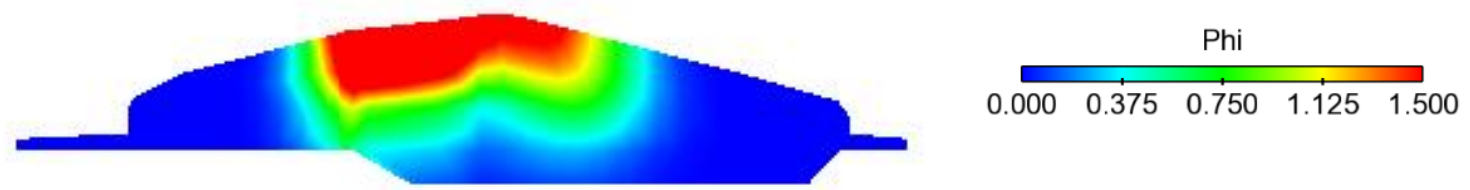

c)

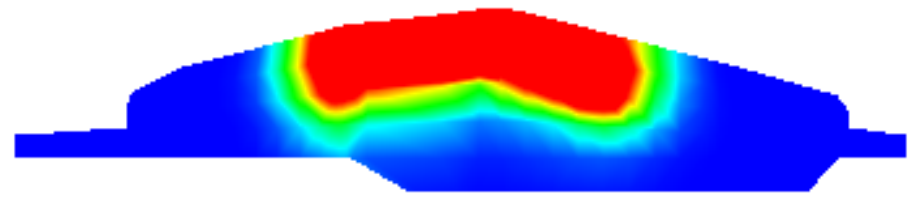

Figure 4-117. Comparison of predicted equivalence ratio distribution at charge pressure 2.41 Bar at IVC with $-25 \mathrm{deg}$ ATDC injection timing for a) Heavy Naphtha at -12 deg ATDC b) $-6 \operatorname{deg}$ ATDC c) $-11 \operatorname{deg}$ ATDC 
Studying fuel distribution within the combustion chamber can help to understand variation in combustion quality. All three Y-axis cut plane shown in Figure 4-117 represent fuel distribution which is similar. A rich region can be seen near injectors for all fuels. Numerically, maximum equivalence ratio for heavy naphtha, light naphtha, and PRF50 is $\approx 7,2.98$ and 6.33 respectively.

Light naphtha because of its lower reactivity gets more ignition delay. Higher ignition delay helps to mix fuel by transporting fuel from rich regions to lean areas. As a result, achieves better combustion than other two fuels. However, an ignition delay time for light naphtha is not enough to get stratified combustion. Other two fuels also undergo spontaneous combustion of fuel in the rich region taking a toll on combustion efficiency giving higher PRR.

Now, all three fuels are studied when injected in higher charge pressure at advanced injection timing ( -45 deg ATDC). Heavy naphtha has higher combustion efficiency and light naphtha has higher thermal efficiency. Heavy naphtha manages to keep low PRR. Heavy naphtha has higher NOx. However light naphtha has higher CO. However, UHC is lowest for light Naphtha.

Table 4-33. Predicted combustion characteristics at -45 deg ATDC injection timing using three fuels

\begin{tabular}{|c|c|c|c|}
\hline & Light Naphtha & Heavy Naphtha & PRF50 \\
\hline Combustion Efficiency (\%) & 91.32 & 95.04 & 89.25 \\
\hline Ignition Delay (CAD) & 33.55 & 27.01 & 26.53 \\
\hline Thermal Efficiency $(\%)$ & 42.40 & 41.57 & 38.66 \\
\hline PRR (bar/deg) & 13.88 & 10.15 & 11.81 \\
\hline CO (g/Kg-f) & 210.08 & 155.99 & 152.33 \\
\hline UHC (g/Kg-f) & 49.79 & 50.85 & 83.38 \\
\hline NOx (g/Kg-f) & 4.451 & 9.19 & 7.58 \\
\hline
\end{tabular}

Heat release rate trace for heavy naphtha shows longer combustion duration than other two fuels (see Figure 4-119). It is evident that heavy naphtha has different combustion quality than other two fuels. Light naphtha and PRF50 gives steep heat release rates. 


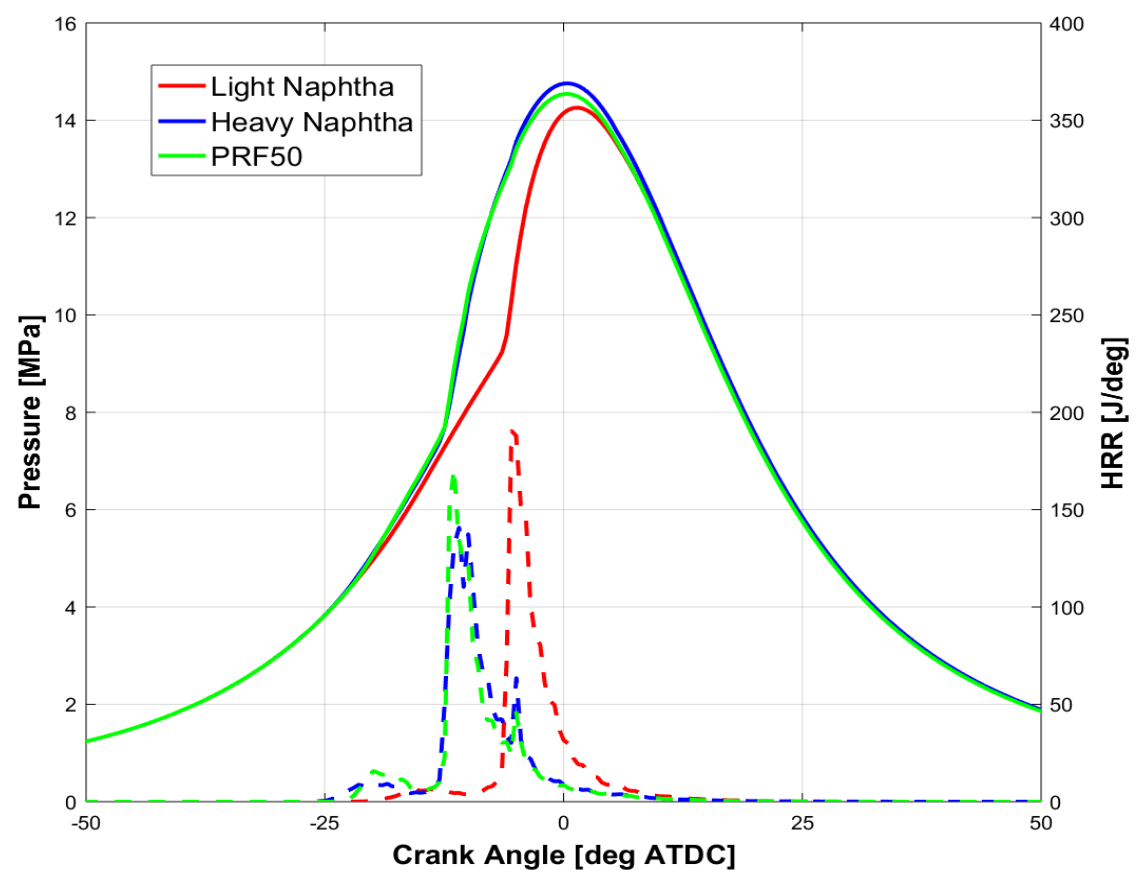

Figure 4-118. Comparison of predicted pressure and HRR at charge pressure 2.41 Bar at IVC with -40 deg ATDC injection timing using three fuels

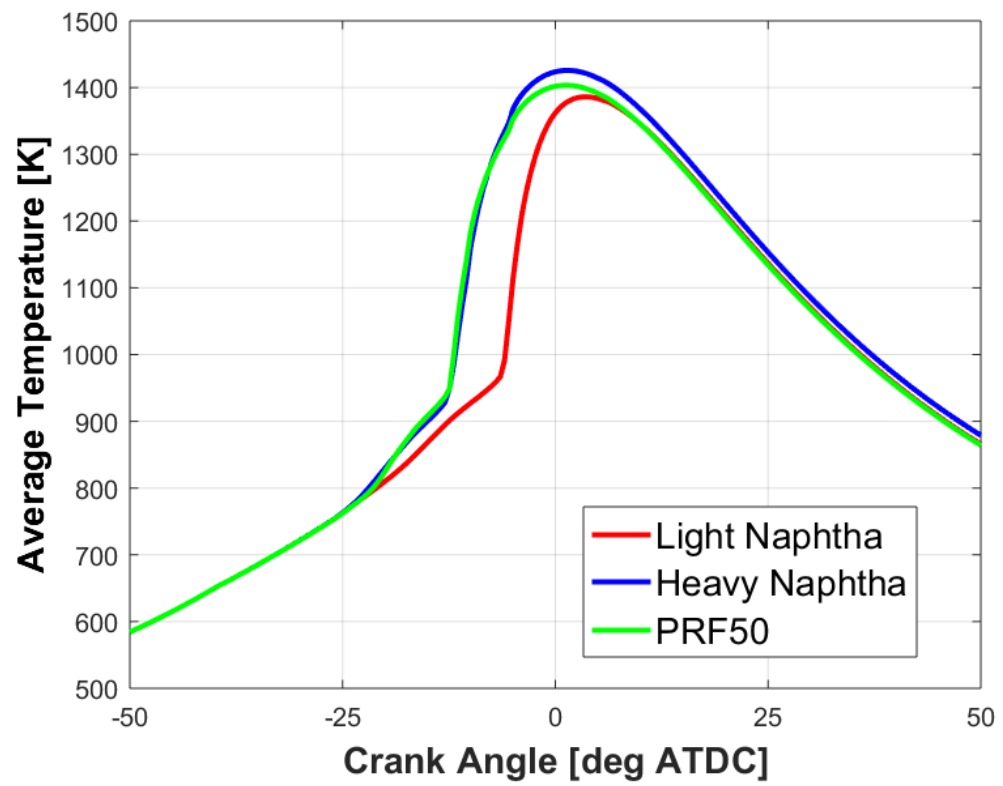

Figure 4-119. Comparison of predicted average temperature at charge pressure 2.41 Bar at IVC with -40 deg ATDC injection timing using three fuels 
Due to higher combustion efficiency, heavy naphtha has higher expansion average temperature than rest of the two fuels and its given in Figure 4-120.

Fuel distribution can be seen in Figure 4-122 for all three fuels. PRF50 and heavy naphtha shows similar fuel distribution. Whereas light naphtha show leaner mixture. Maximum equivalence ratio for heavy naphtha, light naphtha and PRF50 are $\approx 1.88,1.31$ and 1.85. Light naphtha shows higher ignition delay and leaner equivalence ratio. Even though light naphtha has lean equivalence ratio, it shows steep pressure rise and sudden heat release. Combustion duration is also less. This indicates that even though fuel in rich region burns, combustion cannot be sustained in lean regions due to over lean mixture. Heavy naphtha shows periodic heat release, a sign of stratified combustion. Despite stratified combustion, heavy naphtha shows higher NOx. Higher availability of $\mathrm{O}_{2}$ is the main reason for NOx.

a)

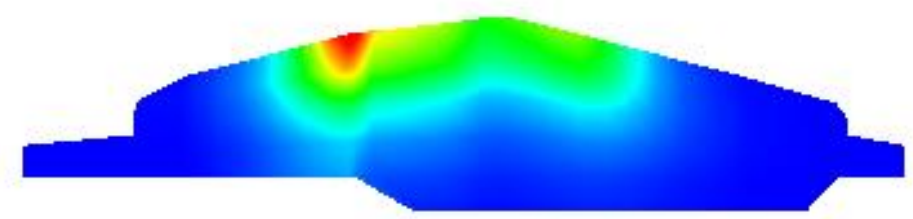

b)

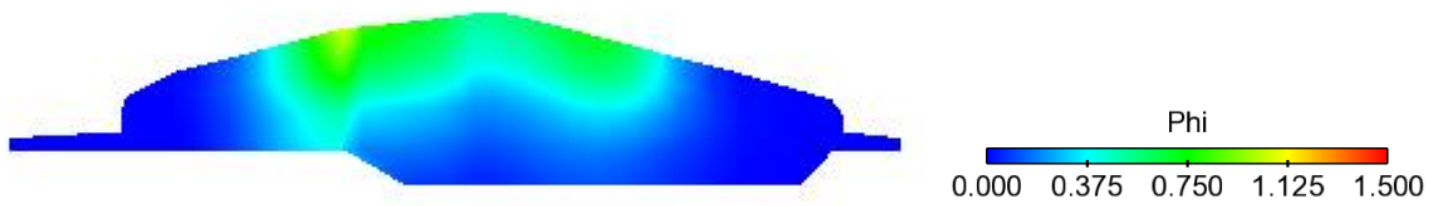

c)

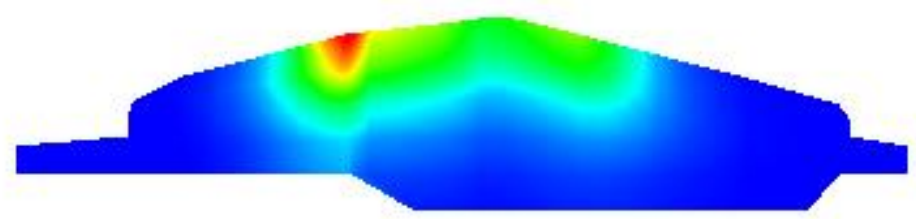

Figure 4-120. Predicted equivalence ratio distribution at charge pressure 2.41 Bar at IVC with -40 deg ATDC injection timing for a) Heavy Naphtha at -14 deg ATDC b) Light Naphtha at -7 deg ATDC c) PRF50 at -13 deg ATDC

No variation can be seen on vaporization trend (see Figure 4-122). 


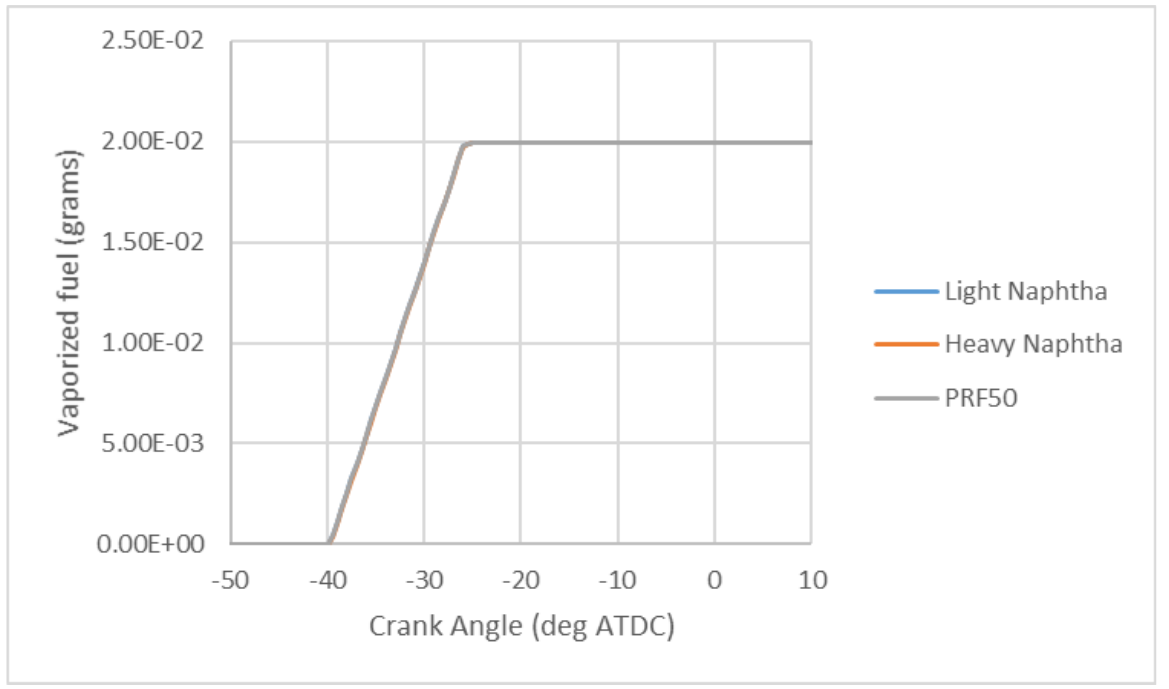

Figure 4-121. Comparison of predicted vaporization rate at charge pressure 2.41 Bar at IVC with -40 deg ATDC injection timing using three fuels

Following tables list maximum combustion efficiency, injection timing at which it is achieved and PRR for all three fuels at both baseline and elevated charge pressure operating conditions.

Table 4-34. Maximum Combustion Efficiency for heavy naphtha

\begin{tabular}{|c|c|c|c|}
\hline & $\begin{array}{c}\text { Combustion } \\
\text { efficiency }\end{array}$ & $\begin{array}{c}\text { Injection } \\
\text { timing }\end{array}$ & PRR \\
\hline & $(\%)$ & $($ deg ATDC) & (bar/deg) \\
\hline Baseline & 96.66 & -40 & 11.50 \\
\hline Increased Charge Pressure & 95.03 & -40 & 10.15 \\
\hline
\end{tabular}

Heavy naphtha, baseline condition gives higher maximum combustion efficiency at same injection timing with steep PRR.

Table 4-35. Maximum Combustion Efficiency for light naphtha

\begin{tabular}{|c|c|c|c|}
\hline & $\begin{array}{c}\text { Combustion } \\
\text { efficiency }\end{array}$ & $\begin{array}{c}\text { Injection } \\
\text { timing }\end{array}$ & PRR \\
\hline & $(\%)$ & $(\operatorname{deg}$ ATDC) & (bar/deg) \\
\hline Baseline & 93.07 & -25 & 14.48 \\
\hline Increased Charge Pressure & 94.73 & -25 & 19.35 \\
\hline
\end{tabular}

Both the conditions for light naphtha has higher PRR. Increased charge pressure gives higher maximum combustion efficiency. 
Table 4-36. Maximum Combustion Efficiency for PRF50

\begin{tabular}{|c|l|l|l|}
\hline & $\begin{array}{l}\text { Combustion } \\
\text { efficiency }\end{array}$ & $\begin{array}{l}\text { Injection } \\
\text { timing }\end{array}$ & PRR \\
\hline & $(\%)$ & (deg ATDC) & (bar/deg) \\
\hline Baseline & 90.91 & -40 & 10.98 \\
\hline Increased Charge Pressure & 90.84 & -30 & 13.66 \\
\hline
\end{tabular}

For PRF50, maximum combustion efficiency values are closer however baseline operating condition gets lower PRR.

Considering combustion efficiency as the only parameter to judge, higher boost pressures are advantageous for light naphtha for the entire injection timing spectrum. For injection near TDC higher $\mathrm{O} 2$ and for early injections reduced ignition delay helps to increase combustion efficiency. However, for more reactive fuels (for example heavy naphtha and PRF50) higher boost levels are only beneficial for injection timing near TDC. For early injections in compression, reduced residence time prevents mixing of fuel and results into incomplete combustion. Although, higher combustion efficiency cannot guarantee stratified combustion. Optimum cases should have combustion efficiency $>/=90 \%$ with PRR $</=10 \mathrm{bar} / \mathrm{deg}$ along with NOx $</=5 \mathrm{~g} / \mathrm{Kg}-\mathrm{f}$. For the higher charge pressure operating condition studied here, only heavy naphtha successfully gives optimum cases for injection timings -45 and -50 deg ATDC. Therefore, in order to achieve stratified combustion at higher boost pressure as compared to baseline, maximum equivalence ratio approximately should be $</=1.78$ to avoid over rich regions and minimum value should be $>/=0.0018$ to maintain higher combustion efficiency.

\subsubsection{Injection Pressure Variation}

Table 4-37. Maximum combustion efficiency and injection timing for injection pressure sweep

\begin{tabular}{|c|c|c|c|c|c|c|}
\hline $\begin{array}{c}\text { Injection } \\
\text { Pressure }\end{array}$ & \multicolumn{2}{|c|}{ Light Naphtha } & \multicolumn{2}{c|}{ Heavy Naphtha } & \multicolumn{2}{c|}{ PRF50 } \\
\hline Bar & $\begin{array}{c}\text { Combustion } \\
\text { Efficiency }\end{array}$ & $\begin{array}{c}\text { Injection } \\
\text { Timing }\end{array}$ & $\begin{array}{c}\text { Combustion } \\
\text { Efficiency }\end{array}$ & $\begin{array}{c}\text { Injection } \\
\text { Timing }\end{array}$ & $\begin{array}{c}\text { Combustion } \\
\text { Efficiency }\end{array}$ & $\begin{array}{c}\text { Injection } \\
\text { Timing }\end{array}$ \\
\hline & $\%$ & & $\%$ & & $\%$ & \\
\hline 600 & 95.02448 & -30 & 95.34534 & -25 & 91.25103 & -25 \\
\hline 500 & 94.97976 & -30 & 94.42484 & -30 & 90.70328 & -25 \\
\hline 400 & 94.73375 & -30 & 95.03851 & -40 & 90.83742 & -25 \\
\hline 300 & 95.0133 & -35 & 96.18629 & -40 & 90.36792 & -30 \\
\hline 200 & 93.50374 & -40 & 96.97042 & -45 & 89.67485 & -35 \\
\hline
\end{tabular}

To study the effect of different injection pressure, a similar injection timing sweep is conducted for 600, 500, 300 and 200 Bar. Table 4-37 indicates maximum combustion efficiency, injection timing for which it is achieved for all fuels at different injection 
pressures. Maximum combustion efficiency values are dominated by more reactive heavy naphtha. However, no specific relation can be seen for the maximum combustion efficiency and higher injection pressure. Again, as discussed in previous sections, maximum combustion efficiency does not guaranty good combustion with PRR less than or equal to $10 \mathrm{bar} / \mathrm{deg}$ and NOx less than or equal to $5 \mathrm{~g} / \mathrm{Kg}$-f. Therefore let's discuss such cases for different injection pressure. Only heavy naphtha shows optimum combustion cases for different injection pressure. A range of pressure studied here does not give enough stratification. Table 4-38 below gives details of optimum cases for heavy naphtha.

Table 4-38. Optimum case condition for each fuel at injection pressure sweep

\begin{tabular}{|l|c|c|c|c|}
\hline & $\begin{array}{c}\text { Injection } \\
\text { Timing }\end{array}$ & $\begin{array}{c}\text { Combustion } \\
\text { Efficiency }\end{array}$ & PRR & NOx \\
\hline & Deg ATDC & $\%$ & Bar/deg & g/Kg-f \\
\hline \multicolumn{7}{|c|}{ Injection Pressure :600 Bar } \\
\hline \multicolumn{5}{|c|}{ NONE } \\
\hline \multicolumn{7}{|c|}{ Injection Pressure :500 Bar } \\
\hline Heavy Naphtha & -40 & 91.40 & 9 & 4.83 \\
\hline \multicolumn{7}{|c|}{ Injection Pressure :400 Bar } \\
\hline Heavy Naphtha & -45 & 92.97 & 8.32 & 4.25 \\
\hline \multicolumn{7}{|c|}{ Injection Pressure :300 Bar } \\
\hline Heavy Naphtha & -45 & 92.03 & 9.46 & 5.47 \\
\hline \multicolumn{7}{|c|}{ Injection Pressure :200 Bar } \\
\hline Heavy Naphtha & -50 & 91.04 & 8.77 & 4.57 \\
\hline
\end{tabular}

For injection pressure equal to 600 bar, no injection timing achieves stratified combustion. Higher the injection, higher mixing. For baseline cases, a stratified case has achieved at injection timings near TDC. However, with more availability of oxygen at elevated charge conditions, only rich region goes under combustion and it cannot be sustained in lean regions. For lower injection pressure, as we reduce injection pressure, injection timings for which good cases are obtained are advanced. Lower injection pressure reduces the mixture and more residence time is required to achieve the stratification. Value of combustion efficiency shows not much variation. 


\section{Conclusion}

Compression ignition engine combustion with direct injection of heavy naphtha, light naphtha and PRF50 fuels was investigated numerically. Parametric variation was employed to study the effects of fuel characteristics and engine operating conditions on charge mixture preparation, combustion characteristics, engine performance and emissions. Based on the results following conclusions were drawn.

1. For baseline operating conditions, all three fuels could be successfully burned achieving low temperature combustion to meet strict constraints of combustion efficiency, maximum pressure rise rates and engine-out emissions.

2. For light naphtha, with increasing mixture temperature at IVC, the operation range becomes wider than that of the baseline case since the combustion efficiencies are improved while meeting the MPRR constraint with advancing injection timings. Injection timings for optimal stratification are shifted to advanced timings. However, too early timings tend to increase MPRR again since combustion approaches more $\mathrm{HCCI}$, and thus the operation range is constrained by MPRR again. On the contrary, for heavy naphtha and PRF50 fuels, the operation range becomes narrower than those of the baseline cases since MPRR is increased too much with improved combustion efficiencies.

3. With increase of EGR ratio, the operation ranges become wider due to reduction of MPRR for heavy naphtha and PRF50 fuels in spite of reduction of combustion efficiencies. However, for light naphtha, the increase of operation range is minimal because the combustion efficiency becomes poor due to reduced reactivity with increase of EGR ratio while MPRR is significantly reduced.

4. With increase of boost pressure, the combustion efficiency of light naphtha combustion is significantly improved, but MPRR is also increased, resulting in a narrower operation range. For the heavy naphtha and PRF50 fuels, combustion efficiencies become poorer for advanced injection timings, while they are improved slightly for late injection timings. Their PRR becomes slightly lower for the advanced injection timings, and thus the operation ranges become a bit wider by extending to the later injection timings than the corresponding baseline cases.

5. The performance of PRF50 combustion is very similar to that of heavy naphtha under the operating conditions considered in the study. This indicates that PRF50 can be used as surrogate for heavy naphtha.

6. With increase of injection pressure, the injection timings for maximum combustion efficiencies tend to be retarded for all three fuels.

7. Between the naphtha fuels, the optimal injection timings tend to earlier in the heavy naphtha. 


\section{Reference List}

1. Stacy C. Davis; Susan E. Williams \& Robert G. Boundy (July 2016). "Transportation Energy Data Book: Edition 35" (PDF). Vehicle Technologies Office, Office of Energy Efficiency and Renewable Energy, U.S. Department of Energy. Retrieved 2017-08-24. See Tables 3.2 and 3.3 for 2010, 2012 and 2014 figures

2. https://www.statista.com/statistics/262747/worldwide-automobile-productionsince-2000/, accessed Nov.2019

3. https://www.eia.gov/energyexplained/?page=us_energy_transportation, accessed Nov. 2019

4. Koci, C., Ra, Y., Krieger, R., Andrie, M. et al., "Multiple-Event Fuel Injection Investigations in a Highly-Dilute Diesel Low Temperature Combustion Regime," SAE Int. J. Engines 2(1):837-857, 2009, https://doi.org/10.4271/200901-0925.

5. Koci, C., Ra, Y., Krieger, R., Andrie, M. et al., "Multiple-Event Fuel Injection Investigations in a Highly-Dilute Diesel Low Temperature Combustion Regime," SAE Int. J. Engines 2(1):837-857, 2009, https://doi.org/10.4271/200901-0925.

6. Dronniou, N., Lejeune, M., Balloul, I., and Higelin, P., "Combination of High EGR Rates and Multiple Injection Strategies to Reduce Pollutant Emissions," SAE Technical Paper 2005-01-3726, 2005, https://doi.org/10.4271/2005-01-3726.

7. Yun, H., Sellnau, M., Milovanovic, N., and Zuelch, S., "Development of Premixed Low-Temperature Diesel Combustion in a HSDI Diesel Engine," SAE Technical Paper 2008-01-0639, 2008, https://doi.org/10.4271/2008-01-0639

8. Onishi, S., Jo, S., Shoda, K., Jo, P. et al., "Active Thermo-Atmosphere Combustion (ATAC) - A New Combustion Process for Internal Combustion Engines," SAE Technical Paper 790501, 1979, https://doi.org/10.4271/790501.

9. Najt, P. and Foster, D., "Compression-Ignited Homogeneous Charge Combustion," SAE Technical Paper 830264, 1983, https://doi.org/10.4271/830264.

10. Krieger, R., Siewert, R., Pinson, J., Gallopoulos, N. et al., "Diesel Engines: One Option to Power Future Personal Transportation Vehicles," SAE Technical Paper 972683, 1997, https://doi.org/10.4271/972683

11. Risberg, P., Kalghatgi, G., Ångstrom, H., and Wåhlin, F., "Auto-ignition quality of Diesel-like fuels in HCCI engines," SAE Technical Paper 2005-01-2127, 2005, https://doi.org/10.4271/2005-01-2127.

12. Kimura, S., Aoki, O., Ogawa, H., Muranaka, S. et al., "New Combustion Concept for Ultra-Clean and High-Efficiency Small DI Diesel Engines," SAE Technical Paper 1999-01-3681, 1999, https://doi.org/10.4271/1999-01-3681.

13. Kimura, S., Aoki, O., Kitahara, Y., and Aiyoshizawa, E., "Ultra-Clean Combustion Technology Combining a Low-Temperature and Premixed Combustion Concept 
for Meeting Future Emission Standards," SAE Technical Paper 2001-01-0200, 2001, https://doi.org/10.4271/2001-01-0200

14. Iida, N., "Combustion Analysis of Methanol-Fueled Active Thermo-Atmosphere Combustion (ATAC) Engine Using a Spectroscopic Observation," SAE Technical Paper 940684, 1994, https://doi.org/10.4271/940684.

15. Aoyama, T., Hattori, Y., Mizuta, J., and Sato, Y., "An Experimental Study on Premixed-Charge Compression Ignition Gasoline Engine," SAE Technical Paper 960081, 1996, https://doi.org/10.4271/960081

16. Yoshizawa, K., Teraji, A., Aochi, E., Kubo, M. et al., "Numerical Analysis of Combustion in Gasoline Compression Ignition Engines," SAE Technical Paper 2002-01-2865, 2002, https://doi.org/10.4271/2002-01-2865.

17. Kimura, S., Matsui, Y. and Koike, M., "New Combustion Concept for Simultaneous Reduction of NOx and Particulate Emissions from Small DI Diesel Engines”, Paper No. F98T132, Proceedings of the 1998 FISTA World Automotive Congress, 1998.

18. Masahiro, F., Ohta, Y., Kono, M. and Hasegawa, M., "An Ultra-Lean Premixed Compression-Ignition Engine Concept and Its Characteristics", Proceedings of The Fourth International Symposium COMODIA, 1998

19. Willand, J., Nieberding, R., Vent G. and Enderle, C., "The Knocking Syndrome-Its Cure and Its Potential”, SAE Paper 982483, 1998.

20. Jacques, L., Dabadie, J., Angelberger, C., Duret, P., Willand, J., Juretzka, A., Schaflein, J., Ma, T., Downloaded from SAE International by Cummins Inc., Sunday, November 11, 201814 Lendresse, Y., Satre, A., Schulz, C., Kramer, H., Zhao, H. and Damiano, L., "Innovative Ultra-low NOx Controlled Auto-Ignition Combustion Process for Gasoline Engine: the 4-SPACE Project", SAE Paper 200001-1837, 2000.

21.Epping, K., Aceves, S., Bechtold, R., and Dec, J., "The Potential of HCCI Combustion for High Efficiency and Low Emissions," SAE Technical Paper 200201-1923, 2002, https://doi.org/10.4271/2002-01-1923

22. Thring, R., "Homogeneous-Charge Compression-Ignition (HCCI) Engines," SAE Technical Paper 892068, 1989, https://doi.org/10.4271/892068.

23. Ishibashi, Y. and Asai, M., "Improving the Exhaust Emissions of Two-Stroke Engines by Applying the Activated Radical Combustion," SAE Technical Paper 960742, 1996, https://doi.org/10.4271/960742

24. Christensen, M., Johansson, B., and Einewall, P., "Homogeneous Charge Compression Ignition (HCCI) Using Isooctane, Ethanol and Natural Gas - A Comparison with Spark Ignition Operation," SAE Technical Paper 972874, 1997, https://doi.org/10.4271/972874

25. (Bill) Gray, A. and Ryan, T., "Homogeneous Charge Compression Ignition (HCCI) of Diesel Fuel," SAE Technical Paper 971676, 1997, https://doi.org/10.4271/971676

26. Singh, A. and Agarwal, A., "An Experimental Investigation of Combustion, Emissions and Performance of a Diesel Fuelled HCCI Engine," SAE Technical Paper 2012-28-0005, 2012, https://doi.org/10.4271/2012-28-0005 
27. Hiraya, K., Hasegawa, K., Urushihara, T., Iiyama, A. et al., "A Study on Gasoline Fueled Compression Ignition Engine A Trial of Operation Region Expansion ," SAE Technical Paper 2002-01-0416, 2002, https://doi.org/10.4271/2002-01-0416

28. Kanda, T., Hakozaki, T., Uchimoto, T., Hatano, J. et al., "PCCI Operation with Early Injection of Conventional Diesel Fuel," SAE Technical Paper 2005-01-0378, 2005, https://doi.org/10.4271/2005-01-0378

29. Opat, R., Ra, Y., Gonzalez D., M., Krieger, R. et al., "Investigation of Mixing and Temperature Effects on HC/CO Emissions for Highly Dilute Low Temperature Combustion in a Light Duty Diesel Engine," SAE Technical Paper 2007-01-0193, 2007, https://doi.org/10.4271/2007-01-0193

30. Ra, Y., Loeper, P., Reitz, R., Andrie, M. et al., "Study of High Speed Gasoline Direct Injection Compression Ignition (GDICI) Engine Operation in the LTC Regime," SAE Int. J. Engines 4(1):1412-1430, 2011, https://doi.org/10.4271/201101-1182.

31. Kalghatgi, G., Risberg, P., and Ångström, H., "Advantages of Fuels with High Resistance to Auto-ignition in Late-injection, Low-temperature, Compression Ignition Combustion," SAE Technical Paper 2006-01-3385, 2006, https://doi.org/10.4271/2006-01-3385

32. Kalghatgi, G., Risberg, P., and Ångström, H., "Partially Pre-Mixed Auto-Ignition of Gasoline to Attain Low Smoke and Low NOx at High Load in a Compression Ignition Engine and Comparison with a Diesel Fuel," SAE Technical Paper 200701-0006, 2007, https://doi.org/10.4271/2007-01-0006

33. Hanson, R., Splitter, D., and Reitz, R., "Operating a Heavy-Duty Direct-Injection Compression-Ignition Engine with Gasoline for Low Emissions," SAE Technical Paper 2009-01-1442, 2009, https://doi.org/10.4271/2009-01-1442

34. Akihama, K., Kosaka, H., Hotta, Y., Nishikawa, K. et al., "An Investigation of High Load (Compression Ignition) Operation of the "Naphtha Engine" - a Combustion Strategy for Low Well-to-Wheel CO2 Emissions," SAE Int. J. Fuels Lubr. 1(1):920-932, 2009, https://doi.org/10.4271/2008-01-1599.

35. Shen, M., Tuner, M., Johansson, B., and Cannella, W., "Effects of EGR and Intake Pressure on PPC of Conventional Diesel, Gasoline and Ethanol in a Heavy Duty Diesel Engine," SAE Technical Paper 2013-01-2702, 2013, https://doi.org/10.4271/2013-01-2702

36. Manente, V., Johansson, B., Tunestal, P., and Cannella, W., "Effects of Different Type of Gasoline Fuels on Heavy Duty Partially Premixed Combustion," SAE Int. J. Engines 2(2):71-88, 2010, https://doi.org/10.4271/2009-01-2668

37. Koci, C., Ra, Y., Krieger, R., Andrie, M. et al., "Detailed Unburned Hydrocarbon Investigations in a Highly-Dilute Diesel Low Temperature Combustion Regime," SAE Int. J. Engines 2(1):858-879, 2009, https://doi.org/10.4271/2009$\underline{01-0928}$

38. Marriott, C. and Reitz, R., "Experimental Investigation of Direct Injection-Gasoline for Premixed Compression Ignited Combustion Phasing Control," SAE Technical Paper 2002-01-0418, 2002, https://doi.org/10.4271/2002-01-0418

39. Costa, M., Catapano, F., Marseglia, G., Sorge, U. et al., "Experimental and Numerical Investigation of the Effect of Split Injections on the Performance of a 
GDI Engine Under Lean Operation," SAE Technical Paper 2015-24-2413, 2015, https://doi.org/10.4271/2015-24-2413

40. Shibata, G., Shibaike, Y., Ushijima, H., and Ogawa, H., "Identification of Factors Influencing Premixed Diesel Engine Noise and Mechanism of Noise Reduction by EGR and Supercharging," SAE Technical Paper 2013-01-0313, 2013, https://doi.org/10.4271/2013-01-0313

41. Rose, K., Ariztegui, J., Cracknell, R., Dubois, T. et al., "Exploring a Gasoline Compression Ignition (GCI) Engine Concept," SAE Technical Paper 2013-010911, 2013, https://doi.org/10.4271/2013-01-0911

42. https://www.worldenergy.org/wpcontent/uploads/2012/09/wec_transport_scenarios_2050.pdf

43. Leermakers, C., Bakker, P., Somers, L., de Goey, L. et al., "Commercial Naphtha Blends for Partially Premixed Combustion," SAE Int. J. Fuels Lubr. 6(1):199-216, 2013, https://doi.org/10.4271/2013-01-1681

44. Chang, J., Kalghatgi, G., Amer, A., Adomeit, P. et al., "Vehicle Demonstration of Naphtha Fuel Achieving Both High Efficiency and Drivability with EURO6 Engine-Out NOx Emission," SAE Int. J. Engines 6(1):101-119, 2013, https://doi.org/10.4271/2013-01-0267

45. Viollet, Y., Chang, J., and Kalghatgi, G., "Compression Ratio and Derived Cetane Number Effects on Gasoline Compression Ignition Engine Running with Naphtha Fuels," SAE Int. J. Fuels Lubr. 7(2):412-426, 2014, https://doi.org/10.4271/2014$01-1301$

46. https://science.howstuffworks.com/environmental/energy/oil-refining5.htm

47. Amsden, A. A., O’Rourke, P. J. and Butler, T. D., "KIVA-II: A Computer Program for Chemically Reactive Flows with Sprays," Los Alamos National Laboratory, LA-11560-MS, 1989

48. R. J. Kee, F. M. Rupley, J. A. Miller, M. E. Coltrin, J. F. Grcar, E. Meeks, H. K. Moffat, A. E. Lutz, G. DixonLewis, M. D. Smooke, J. Warnatz, G. H. Evans, R. S. Larson, R. E. Mitchell, L. R. Petzold, W. C. Reynolds, M. Caracotsios, W. E. Stewart, P. Glarborg, C. Wang, and O. Adigun, CHEMKIN Collection, Release 3.6, Reaction Design, Inc., San Diego, CA (2000).

49. Beale, C., Rolf, R., "Modeling spray atomization with the KelvinHelmholtz/Rayleigh-Taylor hybrid model," Atomization and Sprays. 9. 623-650. 10.1615/AtomizSpr.v9.i6.40.1999.

50.Perini, F., Reitz, R., "Improved atomization, collision and sub-grid scale momentum coupling models for transient vaporizing engine sprays," International Journal of Multiphase Flow: 107-123, March. 2016.

51. Munnannur, A., Reitz, R.," Droplet Collision Modeling in Multi-Dimensional Spray Computations," International Multidimensional Engine Modeling User's Group Meeting at the SAE Congress, Detroit, April-2007.

52. Liu, A., Mather, D., and Reitz, R., "Modeling the Effects of Drop Drag and Breakup on Fuel Sprays," SAE Technical Paper 930072, 1993, https://doi.org/10.4271/930072

53. Ra, Y., and Reitz, R.D., "A vaporization model for discrete multi-component fuel sprays,” Int. J. Multiphase Flow 35, 101-117, 2009. 
54. O'Rourke, P. and Amsden, A., "A Spray/Wall Interaction Sub model for the KIVA3 Wall Film Model," SAE Technical Paper 2000-01-0271, 2000, https://doi.org/10.4271/2000-01-0271

55. Han, Z., and Reitz, R.D., "Turbulence Modeling of Internal Combustion Engines Using RNG k-e models," Comb. Sci. Tech., 106, 267-295, 1995.

56. Yakhot, V. and Orzag, S. A., (1986). Renormalization Group Analysis of Turbulence. I. Basic Theory. J. Sci. Comput., 1, 3.

57. Yakhot, V. and Smith, L. M., (1992). The Renormalization Group the epsilonexpansion and Derivation of Turbulence Models, J. Sci. Comput., 7, 35.

58.http://www.me.berkeley.edu/gri_mech/

59. S.C. Kong, Y. Sun, and R.D. Reitz, "Modeling Diesel Spray Flame Lift-Off, Sooting Tendency and NOx Emissions Using Detailed Chemistry with Phenomenological Soot Model,” ASME ICES20051009, 2005.

60. J. Nagle and R.F. Strickland-Constable, "Oxidation of Carbon between 1000-2000o C", Proc. of the Fifth Carbon Conf., pp. 154-164, 1962.

61. Hiroyasu, H. and Kadota, T., "Models for Combustion and Formation of Nitric Oxide and Soot in Direct Injection Diesel Engines," SAE Technical Paper 760129, 1976, https://doi.org/10.4271/760129.

62. Tamagna, D., Ra, Y., and Reitz, R., "Multidimensional Simulation of PCCI Combustion Using Gasoline and Dual-Fuel Direct Injection with Detailed Chemical Kinetics," SAE Technical Paper 2007-01-0190, 2007, https://doi.org/10.4271/2007-01-0190

63. ICEM CFD (14.0), Computer Software, ANSYS Inc, Southpointe, 275.

64. Ra, Y. and Reitz, R.D., "A Vaporization Model for Discrete Multi-Component Fuel Sprays,” Int. J. Multiph. Flow 35(2):101-117, 2009

65. Anand, K., Ra, Y., Reitz, R.D., and Bunting, B., "Surrogate Model Development for Fuels for Advanced Combustion Engines," Energy \& Fuels 25(4):1474-1484, 2011

66. Dec, J., Hwang, W., and Sjöberg, M., "An Investigation of Thermal Stratification in HCCI Engines Using Chemiluminescence Imaging," SAE Technical Paper 2006-01-1518, 2006, https://doi.org/10.4271/2006-01-1518

67. Ito, S., Ikeda, H., Jung, D., and Iida, N., "Potential of Stratification Charge for Reducing Pressure-Rise Rate in HCCI Engines Based on Multi-Zone Modeling and Experiments by using RCM," SAE Technical Paper 2013-32-9083, 2013, https://doi.org/10.4271/2013-32-9083

68. Splitter, D., Hanson, R., Kokjohn, S., Wissink, M. et al., "Injection Effects in Low Load RCCI Dual-Fuel Combustion," SAE Technical Paper 2011-24-0047, 2011, https://doi.org/10.4271/2011-24-0047

69. Jingeun, S., Munsoo, C., Sungwook, P., "Effect of injection strategy on air-fuel mixing process in a gasoline direct injection (GDI) optical engine," $16^{\text {th }}$ Annual Conference of ILASS, Asia, 2013.

70. Anders, H., Christensen, M., Johansson, B., Franke, A. et al., "A Study of the Homogeneous Charge Compression Ignition Combustion Process by Chemiluminescence Imaging," SAE Technical Paper 1999-01-3680, 1999, https://doi.org/10.4271/1999-01-3680 
71. Sjöberg, M., Dec, J., "AN Investigation of the Relationship Between Intake Temperature, BDC Temperature, and Combustion Phasing for Premixed and DI HCCI Engines," SAE Technical Paper 2004-01-1900, 2004, https://doi.org/10.4271/2004-01-1900

72. Hardy, W. and Reitz, R., "A Study of the Effects of High EGR, High Equivalence Ratio, and Mixing Time on Emissions Levels in a Heavy-Duty Diesel Engine for PCCI Combustion," SAE Technical Paper 2006-01-0026, 2006, https://doi.org/10.4271/2006-01-0026

73. Sjöberg, M. and Dec, J., "Smoothing HCCI Heat-Release Rates Using Partial Fuel Stratification with Two-Stage Ignition Fuels," SAE Technical Paper 2006-01-0629, 2006, https://doi.org/10.4271/2006-01-0629

74. Bessonette, P., Schleyer, C., Duffy, K., Hardy, W. et al., "Effects of Fuel Property Changes on Heavy-Duty HCCI Combustion," SAE Technical Paper 2007-01-0191, 2007, https://doi.org/10.4271/2007-01-0191

75. Hwang, W., Dec, J., and Sjöberg, M., "Fuel Stratification for Low-Load HCCI Combustion: Performance \& Fuel-PLIF Measurements," SAE Technical Paper 2007-01-4130, 2007, https://doi.org/10.4271/2007-01-4130

76. Dec, J. and Hwang, W., "Characterizing the Development of Thermal Stratification in an HCCI Engine Using Planar-Imaging Thermometry," SAE Int. J. Engines 2(1):421-438, 2009, https://doi.org/10.4271/2009-01-0650

77. Manente, V., Johansson, B., and Tunestal, P., "Partially Premixed Combustion at High Load using Gasoline and Ethanol, a Comparison with Diesel," SAE Technical Paper 2009-01-0944, 2009, https://doi.org/10.4271/2009-01-0944

78. Splitter, D., Kokjohn, S., Rein, K., Hanson, R. et al., "An Optical Investigation of Ignition Processes in Fuel Reactivity Controlled PCCI Combustion," SAE Int. J. Engines 3(1):142-162, 2010, https://doi.org/10.4271/2010-01-0345

79. Manente, V., Tunestal, P., Johansson, B., and Cannella, W., "Effects of Ethanol and Different Type of Gasoline Fuels on Partially Premixed Combustion from Low to High Load," SAE Technical Paper 2010-01-0871, 2010, https://doi.org/10.4271/2010-01-0871

80. Viollet, Y., Chang, J., and Kalghatgi, G., "Compression Ratio and Derived Cetane Number Effects on Gasoline Compression Ignition Engine Running with Naphtha Fuels," SAE Int. J. Fuels Lubr. 7(2):412-426, 2014, https://doi.org/10.4271/201401-1301.

81.Liu, K., "Large-Eddy Simulation of In-cylinder Flows In Motored Reciprocating Piston Internal Combustion Engines," Ph.D. thesis, Mechanical Engineering Department, The Pennsylvania State University, University Park, 2012

82. Heywood, J., "Internal Combustion Engine Fundamentals," (McGraw-Hill, 1988), ISBN: 0-07-028637-X.

83. Turns, S., "An Introduction to Combustion, Second Edition," (McGraw-Hill, 2000), ISBN: 0-07-116910-5.

84.Dec, J., Zion, P., "HCCI Combustion Fundamentals: In-Cylinder Diagnostics and Kinetic-Rate Computations," Diesel Engine Emissions Reduction workshopDEER 2000, Aug. 2000. 
85. Sinnamon, J. and Cole, D., "The Influence of Overall Equivalence Ratio and Degree of Stratification on the Fuel Consumption and Emissions of A Prechamber, Stratified-Charge Engine," SAE Technical Paper 790438, 1979, https://doi.org/10.4271/790438

86. Vigild, C., "The Internal Combustion Engine-Modeling, Estimation and Control Issue," Ph.D. thesis, Mechanical Engineering Department, Technical University of Denmark, Lyngby, 2001

87. Drallmeier, J., Wissink, M., Curran, S., and Wagner, R. "Ignition Delay in Low Temperature Combustion," SAE Technical Paper 2018-01-1125, 2018, doi:10.4271/2018-01-1125

88. Reddy, A. and Mallikarjuna, J., "Parametric Study on a Gasoline Direct Injection Engine - A CFD Analysis," SAE Technical Paper 2017-26-0039, 2017, https://doi.org/10.4271/2017-26-0039

89. Vedharaj, S., Vallinayagam, R., An, Y., Dawood, A. et al., "Fuel Effect on Combustion Stratification in Partially Premixed Combustion," SAE Technical Paper 2017-24-0089, 2017, https://doi.org/10.4271/2017-24-0089

90. Vallinayagam, R., Vedharaj, S., An, Y., Dawood, A. et al., "Combustion Stratification for Naphtha from CI Combustion to PPC," SAE Technical Paper 2017-01-0745, 2017, doi:10.4271/2017-01-0745

91.Liu, X., Tong, L., Wang, H., Zheng, Z. et al., "Experimental and Modelling Investigations of the Gasoline Compression Ignition Combustion in Diesel Engine," SAE Technical Paper 2017-01-0741, 2017, doi:10.4271/2017-01-0741

92. Yu, H. and Su, W., "Numerical Study on a High Efficiency Gasoline Reformed Molecule HCCI Combustion Using Exergy Analysis," SAE Technical Paper 201701-0735, 2017, doi:10.4271/2017-01-0735

93. Kolodziej, C., Sellnau, M., Cho, K., and Cleary, D., "Operation of a Gasoline Direct Injection Compression Ignition Engine on Naphtha and E10 Gasoline Fuels," SAE Int. J. Engines 9(2):2016, doi:10.4271/2016-01-0759

94. Das, P., Selokar, M., Subbarao, P., and Subrahmanyam, J., "Effect of Injection Timing, Premixed Equivalence Ratio and EGR on Combustion Characteristics of an HCCI-DI Combustion Engine Using In-Cylinder Dual Injection Strategy," SAE Technical Paper 2016-01-0752, 2016, doi:10.4271/2016-01-0752

95. Costa, M., Catapano, F., Marseglia, G., Sorge, U. et al., "Experimental and Numerical Investigation of the Effect of Split Injections on the Performance of a GDI Engine Under Lean Operation," SAE Technical Paper 2015-24-2413, 2015, doi:10.4271/201524-2413

96. Cracknell, R., Ariztegui, J., Dubois, T., Hamje, H. et al., "Modelling a Gasoline Compression Ignition (GCI) Engine Concept," SAE Technical Paper 2014-011305, 2014, doi:10.4271/2014-01-1305

97. Kokjohn, S., Reitz, R., Splitter, D., and Musculus, M., "Investigation of Fuel Reactivity Stratification for Controlling PCI Heat-Release Rates Using High-Speed Chemiluminescence Imaging and Fuel Tracer Fluorescence," SAE Int. J. Engines 5(2):248-269, 2012, https://doi.org/10.4271/2012-01-0375

98. Yang, Y., Dec, J., Dronniou, N., Sjöberg, M. et al., "Partial Fuel Stratification to Control HCCI Heat Release Rates: Fuel Composition and Other Factors Affecting 
Pre-Ignition Reactions of Two-Stage Ignition Fuels," SAE Int. J. Engines4(1):1903-1920, 2011, https://doi.org/10.4271/2011-01-1359

99. Herold, R., Krasselt, J., Foster, D., Ghandhi, J. et al., "Investigations into the Effects of Thermal and Compositional Stratification on HCCI Combustion - Part II: Optical Engine Results," SAE Int. J. Engines 2(1):1034-1053, 2009, https://doi.org/10.4271/2009-01-1106

100. Berntsson, A. and Denbratt, I., "HCCI Combustion Using Charge Stratification for Combustion Control," SAE Technical Paper 2007-01-0210, 2007, https://doi.org/10.4271/2007-01-0210 